\title{
The impact of reservoir properties on mixing of inert cushion and natural gas in storage reservoirs
}

\author{
Balaji S. Srinivasan \\ West Virginia University
}

Follow this and additional works at: https://researchrepository.wvu.edu/etd

\section{Recommended Citation}

Srinivasan, Balaji S., "The impact of reservoir properties on mixing of inert cushion and natural gas in storage reservoirs" (2006). Graduate Theses, Dissertations, and Problem Reports. 3238.

https://researchrepository.wvu.edu/etd/3238

This Thesis is protected by copyright and/or related rights. It has been brought to you by the The Research Repository @ WVU with permission from the rights-holder(s). You are free to use this Thesis in any way that is permitted by the copyright and related rights legislation that applies to your use. For other uses you must obtain permission from the rights-holder(s) directly, unless additional rights are indicated by a Creative Commons license in the record and/ or on the work itself. This Thesis has been accepted for inclusion in WVU Graduate Theses, Dissertations, and Problem Reports collection by an authorized administrator of The Research Repository @ WVU. For more information, please contact researchrepository@mail.wvu.edu. 


\title{
THE IMPACT OF RESERVOIR PROPERTIES ON MIXING OF INERT CUSHION AND NATURAL GAS IN STORAGE RESERVOIRS
}

\author{
Balaji S Srinivasan
}

Thesis Submitted to the College of Engineering and Mineral Resources at West Virginia University in Partial Fulfillment of the

Requirements for the Degree of

\author{
Master of Science \\ In \\ Petroleum \& Natural Gas Engineering
}

\section{Committee}

Kashy Aminian, Ph.D., Chair

Samuel Ameri, M.S

IIkin Bilgesu, Ph.D

Department of Petroleum \& Natural Gas Engineering

Morgantown, West Virginia 2006

Keywords: Natural Gas, Underground Storage, Inert Cushion Mixing, Pipeline Quality Gas 


\title{
ABSTRACT \\ THE IMPACT OF RESERVOIR PROPERTIES ON MIXING OF INERT CUSHION AND NATURAL GAS IN STORAGE RESERVOIRS
}

\begin{abstract}
Balaji S Srinivasan
Underground natural gas storage is a process which effectively balances a variable demand market with a nearly constant supply of energy provided by the pipeline system. Cushion gas in storage reservoirs provide the necessary pressure for the withdrawal of working gas and it makes up for the largest part of investments in underground storage reservoirs. Usually, a part of the cushion gas is replaced by an inert gas such as Nitrogen in order to reduce the investment costs. Due to this replacement there might be problems caused by the mixing of inert cushion and natural gas, which is a cause of concern as it affects the quality of the natural gas.

In this study, the inert gas mixing problem is investigated in storage reservoirs by using a reservoir simulator based on the equation of state. The degree of mixing between the two dissimilar gases was found by the amount of inert cushion that is produced along with the withdrawn gas. Reservoir parameters like Volume of inert cushion, porosity, permeability, reservoir pressure and reservoir temperature were varied to study their effect on mixing.

It has been found that reservoir parameters porosity, permeability and temperature do not impact the degree of mixing to a great extent. However, reservoir pressure has a slight impact on the mixing between these two dissimilar gases. It is evident from these simulations that the degree of mixing is purely a function of withdrawal rate and also the percentage of inert cushion in the storage reservoir to a great extent.
\end{abstract}




\section{ACKNOWLEDGEMENTS}

It is a pleasure to express my gratitude to my research advisor Dr.Kashy Aminian for providing me with an opportunity to work on this topic. I would like to thank him for his valuable guidance, encouragement and support throughout this work. I would like to extend my thanks to my other two committee members Dr.IIkin Bilgesu and Dr.Samuel Ameri, who also is the chair of Petroleum \& Natural Gas Engineering department for being a part of my research. I would also like to thank Dr.Shahab Mohaghegh and other faculty for their help during the course of my study.

There needs to be a special mention for Ms.Beverly Matheny who has helped with the administrative matters. Thanks to Amol Bhavsar, Sandip Raj Melkaveri and Sunil Lakshminarayanan for helping me during the course of my research.

Heartfelt thanks to my parents and my sister for their constant encouragement, support and love. I would like to thank my closest buddy Srilakshmi for all her support during the course of my study. Big thanks to my friends, Naveen, Latha, Renee, Krishna, Arvind, Sukanya, Senthil, Niveditha, Murali, Abishek and Karthik for their timely help and making my stay at WVU enjoyable. 


\section{TABLE OF CONTENTS}

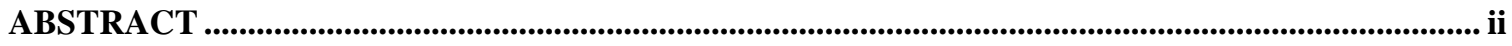

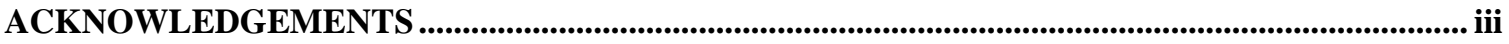

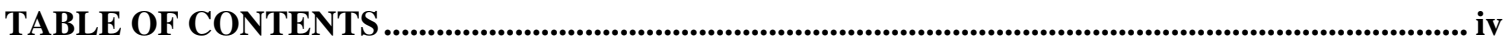

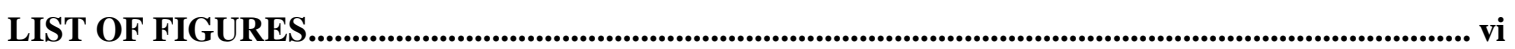

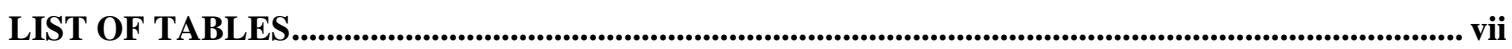

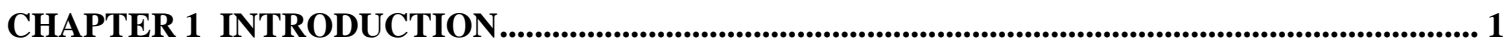

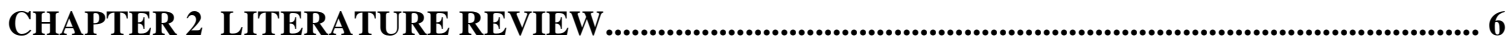

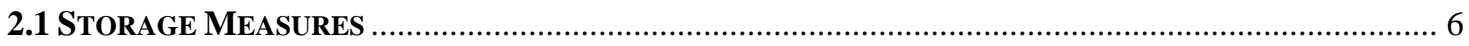

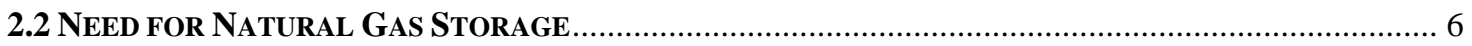

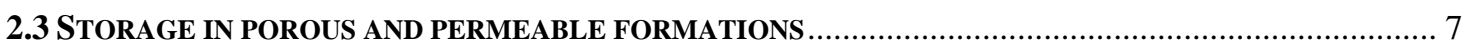

2.3.1 Optimization of the use of storage structures................................................................. 7

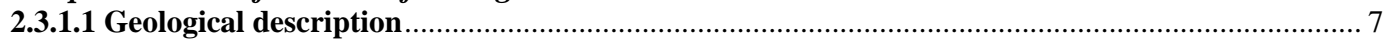

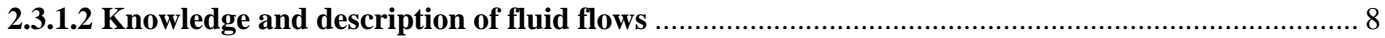

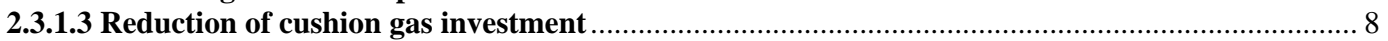

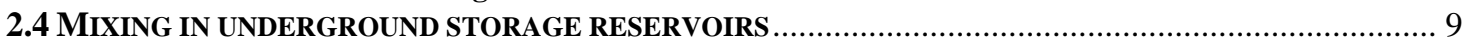

2.4.1 Factors Influencing mixing between inert cushion and natural gas ............................... 10

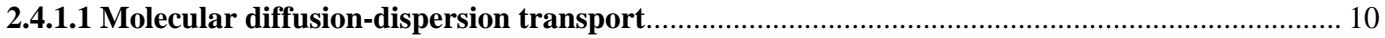

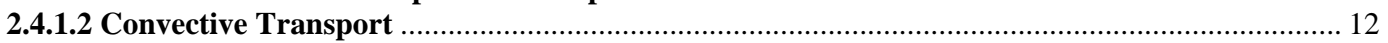

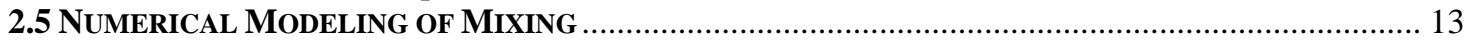

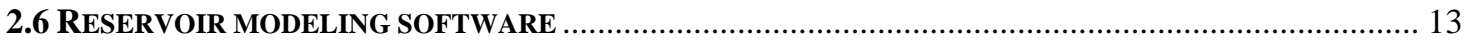

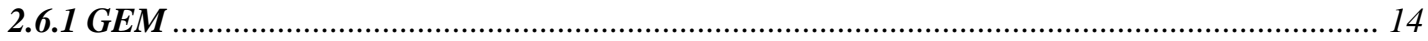

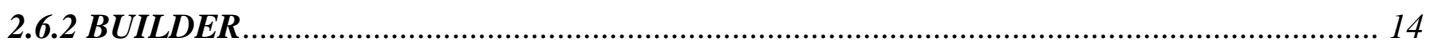

CHAPTER 3 METHODOLOGY

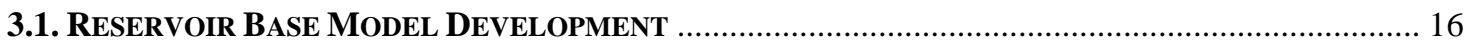

3.1.1 Vertical Distribution Case of Nitrogen in the Storage Reservoir ....................................... 16

3.1.2 Horizontal distribution Case of Nitrogen in the storage reservoir .................................... 23

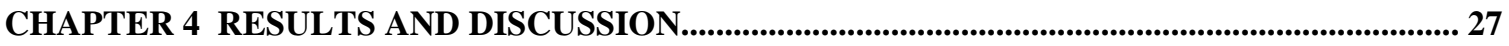

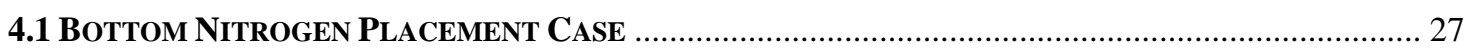

4.1.1 Effect on Mixing due to Variation in Percentage of Nitrogen Cushion in Reservoir ........... 27

4.1.2 Effect of Pressure on Mixing between Nitrogen and Methane .......................................... 28

4.1.3 Effect of Temperature on Mixing between Nitrogen and Methane .................................... 30

4.1.4 Effect of Permeability on Mixing between Nitrogen and Methane ...................................... 31

4.1.5 Effect of Porosity on Mixing between Nitrogen and Methane ........................................... 32

4.1.6 Effect on mixing with constant pressure withdrawal...................................................... 33

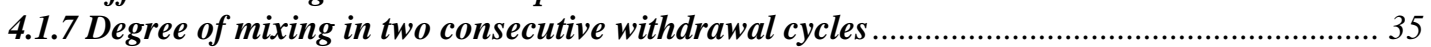

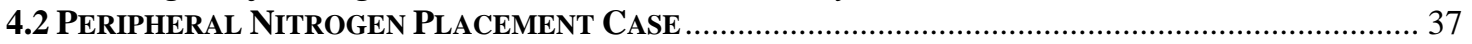

4.2.1 Variation in Percentage of Nitrogen as Base Gas in the reservoir.................................... 37

4.2.2 Effect of Pressure on Mixing between Nitrogen and Methane .......................................... 38

4.2.3 Effect of Temperature on Mixing between Nitrogen and Methane .................................. 39

4.2.4 Effect of Permeability on Mixing between Nitrogen and Methane ...................................... 41

4.2.5 Effect of Porosity on Mixing between Nitrogen and Methane ............................................ 42

4.2.6 Effect on mixing with constant pressure withdrawal...................................................... 45

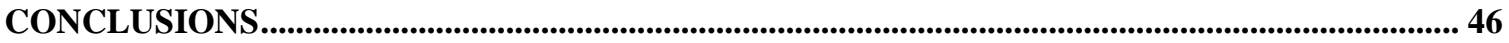

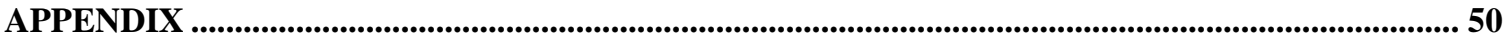

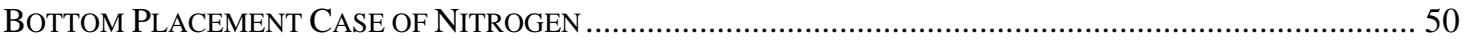

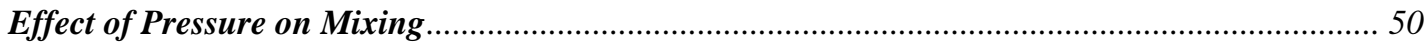

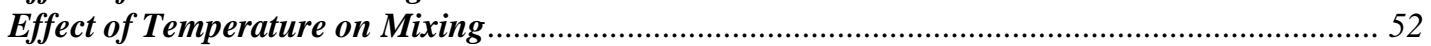


Effect of Permeability on Mixing

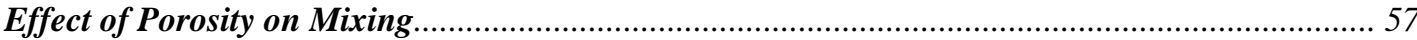

Effect on mixing due to variation in percentage of nitrogen cushion in reservoir.......................... 59

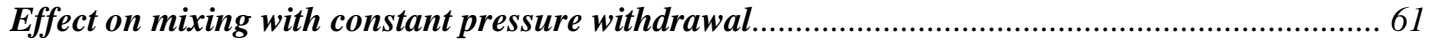

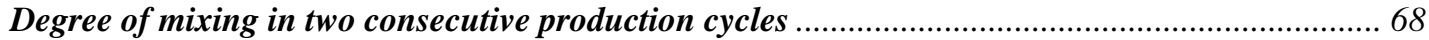

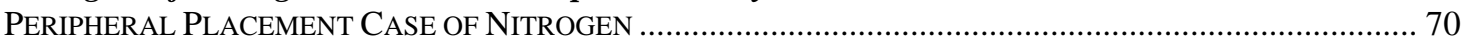

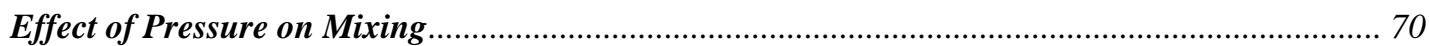

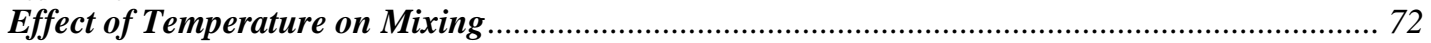

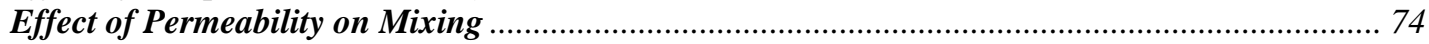

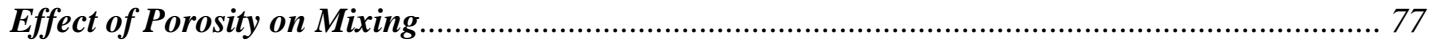

Effect on mixing due to variation in percentage of nitrogen cushion in reservoir.......................... 79

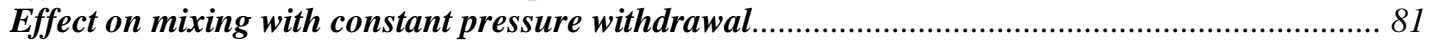




\section{LIST OF FIGURES}

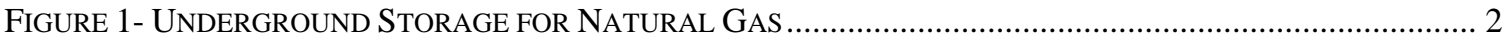

FigURE 2- COMPARISON OF COSTS FOR NATURAL GAS STORAGE .............................................................. 3

FiguRE 3- Distribution OF NATURAL GAS StORAGE FACILITIES IN UnitEd STATES ....................................... 4

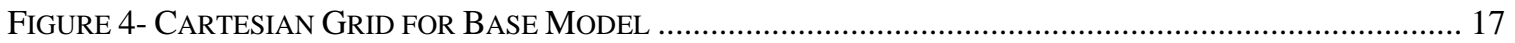

FIGURE 5- 3-D REPRESENTATION OF THE RESERVOIR GRID SYSTEM ....................................................... 17

FIGURE 6- CROSS-SECTIONAL VIEW OF THE RESERVOIR GRID SYSTEM......................................................... 18

FiguRE 7- REPRESENTATION OF THE RESERVOIR GRID SYSTEM WITH PERIPHERAL NitROgEN PlacEMENT

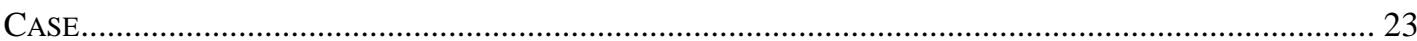

Figure 9- Bottom Nitrogen Placement Case - EfFect of Pressure on Mixing ................................... 29

Figure 10- Bottom Nitrogen Placement CASE - EFFeCt OF TemPerature ON Mixing........................ 30

Figure 11- Bottom Nitrogen Placement CASE - EfFect of Permeability on Mixing ........................ 32

Figure 12 - Bottom Nitrogen Placement Case - Vertical Placement Case of Nitrogen - Effect

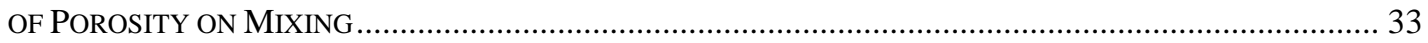

Figure 13 - Bottom Nitrogen Placement Case -Vertical Placement Case Of Nitrogen CONSTANT PRESSURE WITHDRAWAL WITH 100 MD PERMEABILITY ...................................................... 34

Figure 14- Bottom Nitrogen Placement Case - Vertical Placement Case of Nitrogen - Mixing WITH CONSTANT PRESSURE WITHDRAWAL WITH 200 MD PERMEABILITY ................................................ 34

Figure 16 - Bottom Placement Case of Nitrogen Comparison of Degree of Mixing in Two

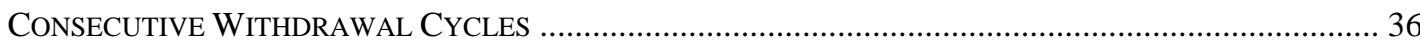

Figure 17 - Bottom Nitrogen Placement Case -Vertical Placement Case of Nitrogen - Degree

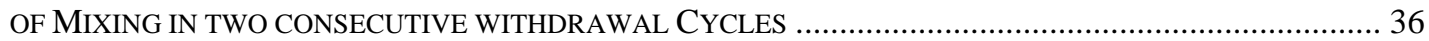

Figure 18- Peripheral Nitrogen Placement Case - Percentage of Nitrogen in Withdrawn gas

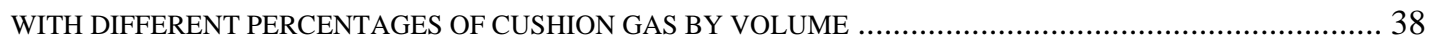

Figure 19- Peripheral Nitrogen Placement Case - EfFect of Pressure on Mixing .......................... 39

Figure 20- Peripheral Nitrogen Placement CASE - EfFect of TemPerature on Mixing .................. 40

Figure 21- Peripheral Nitrogen Placement Case - EfFect of Permeability on Mixing ................. 41

Figure 22 - Peripheral Nitrogen Placement CASE - EfFect of Porosity on Mixing ......................... 43

Figure 23- Bottom Nitrogen Placement Case - Vertical Placement Case of Nitrogen CONSTANT PRESSURE WITHDRAWAL WITH 100 MD PERMEABILITY ........................................................ 44

Figure 24- Bottom Nitrogen Placement Case - Vertical Placement Case of Nitrogen - Mixing WITH CONSTANT PRESSURE WITHDRAWAL WITH 200 MD PERMEABILITY ............................................ 44

Figure 25- Bottom Nitrogen Placement Case -Vertical Placement Case OF Nitrogen - Mixing WITH CONSTANT PRESSURE WithDRAWAL WITH 300 MD PERMEABILITY ............................................. 45 


\section{LIST OF TABLES}

TABle 1 - Bottom Nitrogen Placement CASE - Reservoir PARAmeters For BASE Model................. 19

TABle 2 -Bottom Nitrogen Placement CASE - Distribution of CoMPONENTS IN THE BASE Model.. 20

TABle 3 - Bottom Placement CASE of NitRogen - Distribution of CoMPONENTS AND PRODUCTion RATE

TABle 4 - BOTTOM Placement CASE OF NITROgEN - DistRIBUTION OF COMPONENTS AND WiTHDRAWAL RATE

TABle 5- BOtTOM PlaCEMENT CASE OF NitROGEN - DistRIBUtion OF COMPONENTS AND WitHDRAWAL RATE

TABLE 6- BOtTOM PlACEMENT CASE OF NitROGEN - DistRIBUTION OF COMPONENTS AND WITHDRAWAL RATE

TABle 7- BotTOM Placement CASE OF NITROGEN - Distribution OF COMPONENTS AND WithDRAWAL RATE With DifFERENT PERCENTAGES OF NitRogen CuShion By Volume In RESERVOIR................. 22

TABle 8 - Bottom Placement CASE of Nitrogen - Distribution of CoMPONENTS With CONSTANT PRESSURE WITHDRAWAL

TABle 9- Peripheral Nitrogen Placement CASe - Distribution of Components in Base Model ... 24

TABle 10- PeriPheral Nitrogen Placement CASE - Distribution of CoMPONENTS IN ReSERVOIR .... 24

Table 11- Peripheral Nitrogen Placement Case - Distribution of Components in Reservoir .... 25

Table 12- Peripheral Nitrogen Placement Case - Distribution of Components in Reservoir With DIFFERENT PERMEABILITY'S

Table 13 - Peripheral Nitrogen Placement CASe - Percentage of Nitrogen in WithdraWn Gas WITH DIFFERENT POROSITY'S

Table 14- Peripheral Nitrogen Placement Case - Percentage of Nitrogen in Withdrawn Gas WITH DIFFERENT PERCENTAGES OF CUSHION GAS BY VOLUME

Table 15- Peripheral Nitrogen Placement Case - Distribution of Components with Constant

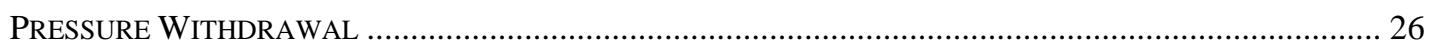

TABle 16 - Vertical Placement CASE OF NitROgen - MATERIAL BALANCE FOR CASES With DifFerent Percentages of Nitrogen Cushion by Volume in Reservoir .

TABle 17 - Bottom Nitrogen Placement CASE - Material Balance for CASES With Different

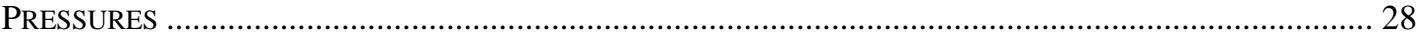

TABLE 18 - BotTOM NitRogen Placement CASE - MATERIAL BALANCE FOR CASES …................................ 30

TABle 19 - Bottom Nitrogen Placement CASE - Material BalanCE fOR CASES .................................. 31

TABle 20 - Bottom Nitrogen Placement CASE - MAterial Balance for CASES With Different POROSITY'S

TABle 21- Peripheral Nitrogen Placement CASE -Material Balance for CASES With DiffERent PERCENTAGES OF CUSHION GAS BY VOLUME

Table 22- Peripheral Nitrogen Placement CASe - Material Balance for Cases with Different PRESSURES

TAble 23 - Peripheral Nitrogen Placement CASe - Material Balance for Cases at Different TEMPERATURES

TABle 24- Horizontal Distribution CASE of Nitrogen - MATERIAl BAlANCE FOR CASES WiTH DIFFERENT PERMEABILITY'S

TABle 25 - Peripheral Nitrogen Placement CASE - MAterial BalanCe FOR CASES With DifFerent POROSITY'S 


\section{CHAPTER 1}

\section{INTRODUCTION}

Natural gas is an important component in the overall energy production and consumption picture for the United States. Since natural gas is considered more environmentally benign than other fossil fuels, its use has grown to approximately one quarter of the total energy consumption and the demand is expected to rise rapidly in the

coming decades. The use of underground formations to store natural gas ${ }^{(1,2)}$ for subsequent withdrawal has assumed major importance in recent years. It is a process which effectively balances a variable demand market with a nearly constant supply of energy provided by the pipeline system. Natural gas is injected during summer when supply exceeds demand and withdrawn during winter to meet peak space heating needs. One of the requirements for such operations is an initial quantity (cushion) of compressed gas in the storage to furnish the expulsive energy for the removal of the gas (working gas) desired to be withdrawn. Cushion gas is the volume of gas intended as permanent inventory in the storage reservoir to maintain adequate pressure and deliverability rates throughout the withdrawal season.

There are three principal types of underground storage sites used in the United States today namely, (1) Depleted reservoirs in oil and/or gas fields, (2) Aquifers, and (3) Salt cavern formations ${ }^{(3)}$. Apart from these, several reconditioned mines are also in use as gas storage facilities. Figure 1 shows the diagrammatic representation of the different types of storage facilities for Natural Gas storage. Each type has its own physical characteristics (porosity, permeability and retention capability) and economics ${ }^{(4)}$ (site preparation costs, deliverability rates, cycling capability), which govern its suitability to particular applications. Two of the most important characteristics of underground storage 
reservoirs are its capability to hold natural gas for future use, and the rate at which gas inventory can be withdrawn- its deliverability rate.

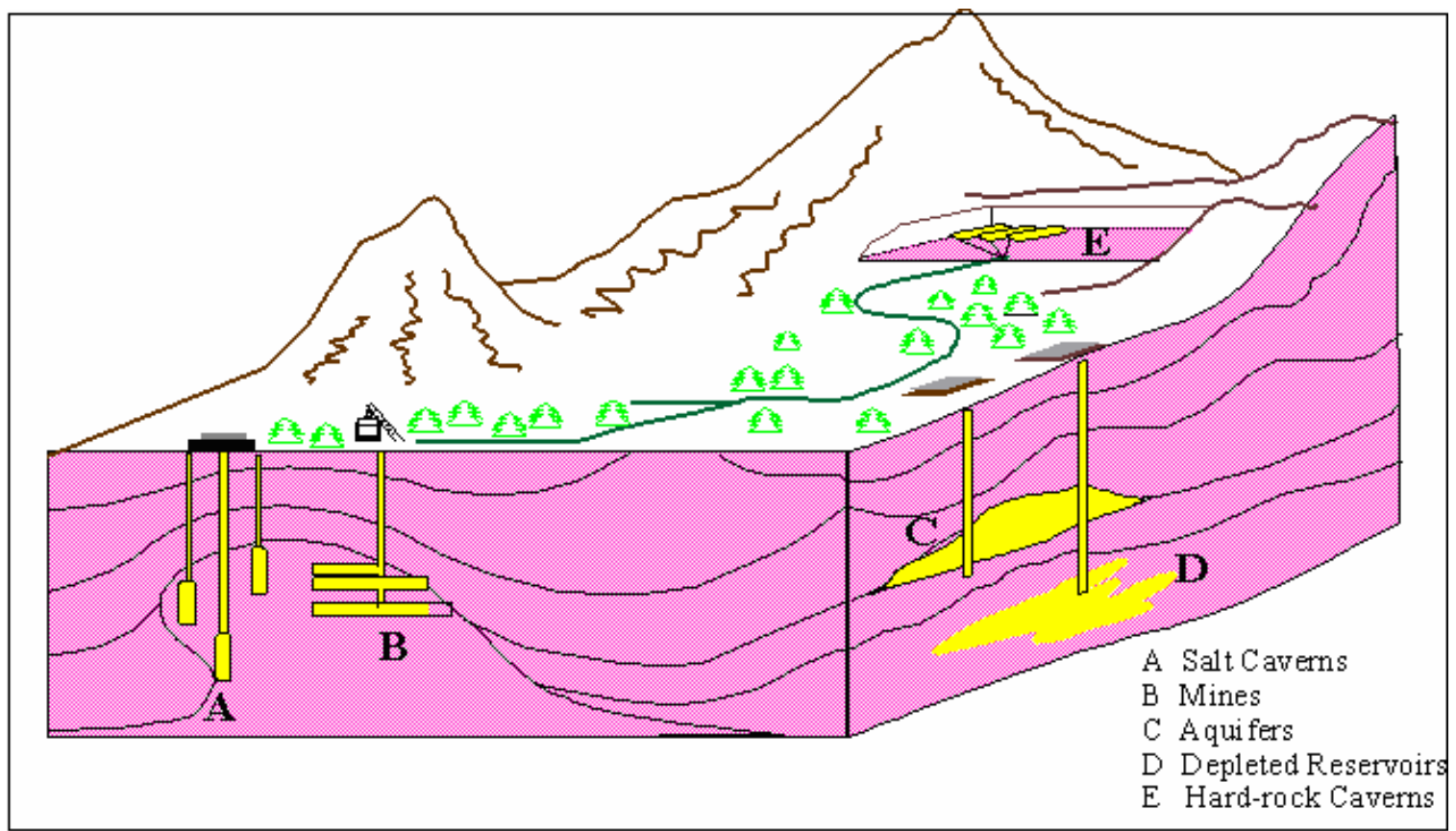

Figure 1- Underground Storage for Natural Gas

Most of the existing gas storages in the United States are in depleted natural gas or oil fields that are close to consumption centers. Conversion of a field from production to storage duty takes advantage of the existing wells, gathering systems and pipeline connections. Due to this reason and their wide availability, depleted oil and gas reservoirs are the most commonly used underground storage facility in the United States.

Aquifers are also used to gas storage, only if the water bearing sedimentary rock formation is overlaid with an impermeable cap rock. While the geology of aquifers is similar to depleted production fields, their use in gas storage usually requires more base (cushion) gas and greater monitoring of withdrawal and injection performance. Salt 
caverns provide very high withdrawal and injection rates when compared with their working gas capacity.

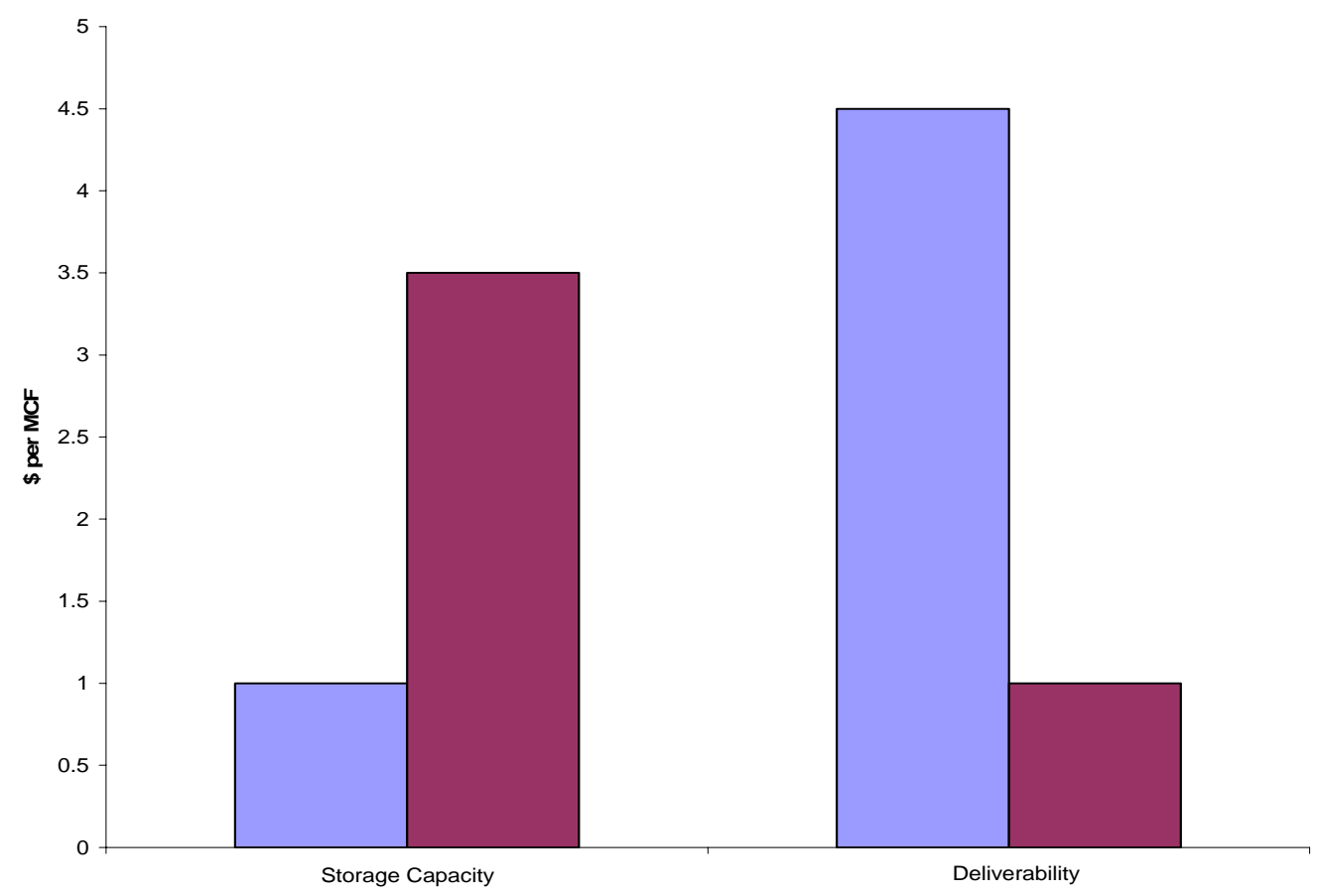

Depleted Fields 口Salt Caverns

Figure 2- Comparison of Costs for Natural Gas Storage

Figure 2 gives the comparison of storage and deliverability costs, mainly between the salt cavern facilities and depleted reservoirs per mcf of Gas in US Dollars. It can be seen that storage costs in salt caverns are more than twice as costly when compared to the depleted storage fields. Also, Construction of salt caverns to store natural gas is more costly than the depleted field conversions, when measured on the basis of dollars per thousand cubic feet of working gas capacity. One of the main reasons why depleted reservoirs are used more when compared to salt caverns and aquifer storage fields is due to the fact that, the geology is well known and these fields have previously trapped hydrocarbons. This minimizes the risk of reservoir leaks and moreover, the storage costs 
are also significantly lower in the case of depleted reservoirs. Figure 3 shows the regional breakdown of Natural gas storage facilities in the United States. Geographically, the east coast region is characterized by depleted reservoir and aquifer storage, the gulf coast has a mix of depleted reservoir and Salt Cavern storage and the west coast has primarily got depleted reservoir storage.

Typically, in an underground storage field, a large part of the total gas stored is used as cushion to provide a desired deliverability, particularly at the end of the withdrawal season. When a storage field is abandoned, a significant portion of the cushion gas is not economically recoverable and cushion gas is a major cost item for new storage fields. In new storage fields where cushion gas must be supplied at present prices, substantial reduction in cost can be achieved by the replacement of natural gas by the less expensive cushion gas ${ }^{(5)}$. The use of an inert gas to replace all or a part of existing storage field cushion gas requirements will result in saving of valuable natural gas which would be lost at abandonment, thereby making the replaced natural gas available to the consumer.

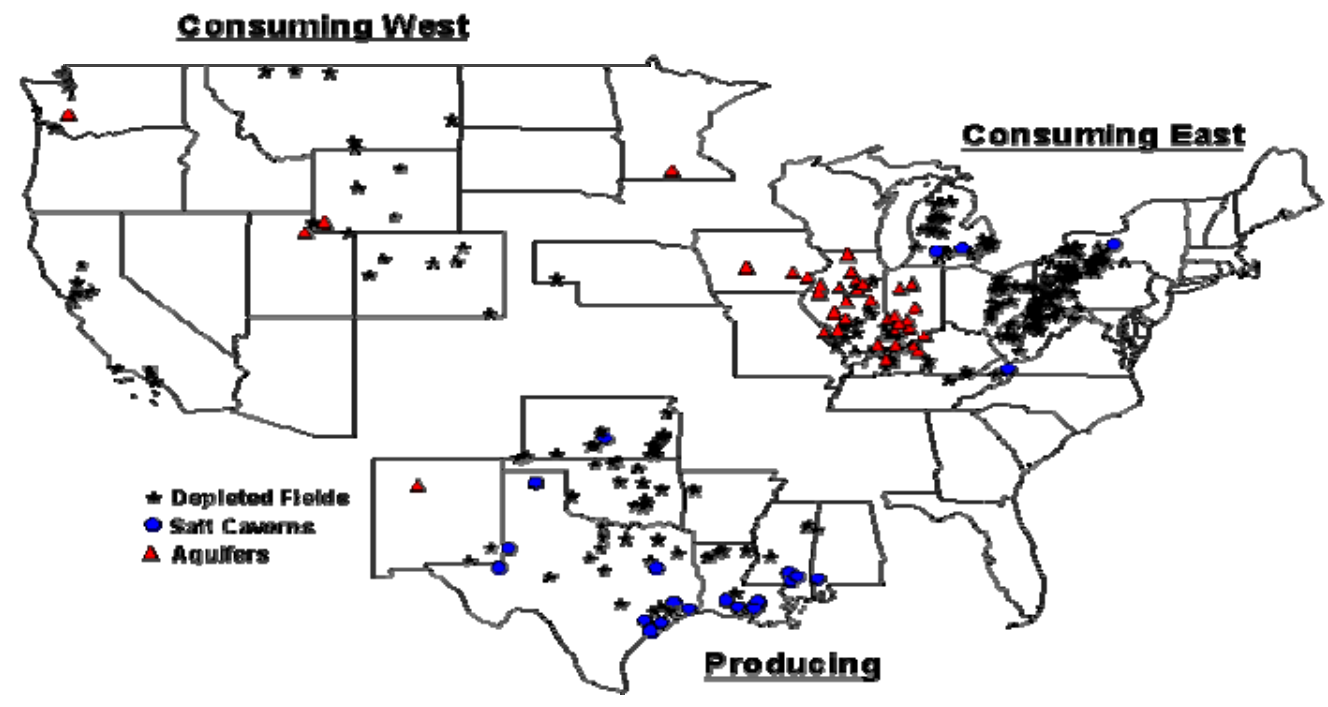

Figure 3- Distribution of Natural Gas Storage Facilities in United States 
The key technical issue due to the replacement of cushion gas by an inert gas is the mixing ${ }^{(6,7,8)}$ of inert cushion and the working gas (Natural Gas). Mixing of inert cushion and the working gas may reach such proportion that separation would be required to yield pipeline quality gas upon withdrawal. The cost for this separation would nullify the economic advantages gained by the usage of less expensive inert gas as cushion.

This study uses a three dimensional simulation model to ascertain the amount of mixing between the working gas and nitrogen (inert cushion) when a part of the cushion gas is replaced ${ }^{(9,10)}$ by the same. The purpose of this modeling is to provide a basis for the choice of the optimum mode and to enhance the understanding of the long term mixing and diffusion effects which would take place between nitrogen and natural gas during underground storage. This study also involves an analysis on the effects of various reservoir parameters on the mixing phenomena and helps in determining the optimum quantity of nitrogen (cushion) that can be used during natural storage operations. 


\section{CHAPTER 2}

\section{LITERATURE REVIEW}

\subsection{Storage Measures}

There are several storage measures that are used to describe physical capabilities of storage facilities and some of the terms which have been used in this study are defined as follows. Total capacity is the maximum volume of working gas that can be stored in an underground storage facility and is determined by the physical characteristics of the reservoir. Cushion gas refers to the volume of working gas intended as permanent inventory in a storage reservoir to maintain adequate pressure and deliverability throughout withdrawal, and it is also known as cushion gas. Working gas capacity is defined as total gas capacity minus base gas, and the volume of gas in the reservoir above the designed level of base gas which is available to the market. Turn-around refers to the capability to perform reverse injection and withdrawal operations at a storage facility. The deliverability of a facility is variable depending on such factors as the amount of gas in storage at any particular time, the pressure within the storage, compression capability available to the storage, and the configuration and capabilities of other facilities associated with the storage.

\subsection{Need for Natural Gas Storage}

There are basically two uses for natural gas in storage facilities: meeting base gas requirements and meeting peak load requirement. Base load storage capacity is used to meet seasonal demand increases and the facilities are capable of holding enough natural gas to satisfy long term seasonal demand requirements. Typically, the turn-over rate for natural gas in these facilities is a year; natural gas is generally injected during the summer 
(non-heating season), which usually runs from April through October, and withdrawn during the winter (heating season), usually from November to March. Depleted gas reservoirs ${ }^{(13)}$ are the most common type of base load storage facilities and they provide a prolonged and steady supply of natural gas in spite of their low deliverability rates.

Peak load storage facilities, on the other hand, are designed to have highdeliverability for short periods of time, meaning natural gas can be withdrawn from storage quickly should the need arise and peak load facilities are intended to meet sudden, short-term demand increases. These facilities cannot hold as much natural gas as base load facilities; however they can deliver smaller amounts of gas more quickly, and can also be replenished in a shorter amount of time than base load facilities. Base load facilities have long term injection and withdrawal seasons.

\subsection{Storage in Porous and Permeable Formations}

Storage in porous and permeable formations, in both hydrocarbon reservoirs and aquifers, accounts for $98 \%$ of the working capacity of all the storage facilities in the world. Technological progress in optimizing the knowledge and use of structures and the reduction of investments in cushion gas ${ }^{(5)}$, and in operating and monitoring of wells are therefore behind gains in productivity recorded in the field of underground storage of natural gas.

\subsubsection{Optimization of the Use of Storage Structures}

\subsubsection{Geological Description}

The search for structures capable of being used as storage facilities differs from, and, in a way more complex than, the search for hydrocarbon deposits. In fact, just because a well has indicated a good, suitably covered reservoir does not mean that the 
structure is appropriate for storage purposes. It is necessary to prove that the gas to be stored there will not escape and therefore ensure the cap rock's continuity and the closure. Certifying whether a structure can be used for storage purposes is a complex and costly operation, involving at the very least one seismic survey, drilling and many measures and tests. A structure's geological and geometrical characteristics play a commanding role in determining the principal performances of an underground storage facility and therefore, sound knowledge of the structural form and heterogeneity of the reservoir helps optimize development and operation. Considering these facts, the geology of depleted storage reservoirs are well known as it has been producing gas before being used for storage purposes. This makes it less risky to use depleted reservoirs for storage purposes.

\subsubsection{Knowledge and Description of Fluid Flows}

Advances in knowledge and models of fluid flows in underground storage facilities go hand in hand. Fluid flow simulations give a clearer picture of how gas is distributed in the facility at any moment and at any place. In this way, they allow the assessment of the working volume and peak withdrawal rate, the number and location of new wells required, the volume of gas cushion to be injected and also the mixing effects between cushion gas and natural gas if a dissimilar gas such as nitrogen is used as cushion.

\subsubsection{Reduction of Cushion Gas Investment}

When natural gas is stored in porous formations, cushion gas accounts for large investment ${ }^{(5)}$ representing about 30 to $40 \%$ of the development cost of the depleted reservoir storage facility. It is possible to significantly reduce this cost by replacing the natural gas with a dissimilar cushion gas which in most cases is an inert gas. The gain due to this replacement depends on the price of natural gas and also on the rate of assets tax. 
The degree of success of using inert gas as a cushion depends on the following technological aspects

- Hydrodynamic analysis and conditions of inert injection related to storage operations and development

- Geochemical studies

- Simulation studies for the optimization of inert Injection and storage operation

- Location of inert gas wells

- Gas mixing monitoring

Monitoring of gas mixing must be performed by a through measuring network and modeling tool that correctly handles gas mixing phenomena specifically to predict inert production according to different cycling scenarios.

\subsection{Mixing in Underground Storage Reservoirs}

Depleted storage reservoirs which are converted from producing reservoirs frequently encounter problems related to molecular transport and mixing phenomena. The need for understanding flow and displacement processes, affected by mixing and dispersion in the porous matrix is important for the design and operation of storage units. There are three specific occasions where mixing and dispersion takes on practical significance in storage:

- Total or partial conversion of working gas inventory from native to pipeline quality gas

- Use of the storage unit for selective storage of gases having different compositions

- $\quad$ Prospects of replacing part of the cushion gas by an inert substitute 


\subsubsection{Factors Influencing Mixing between Inert Cushion and Natural Gas}

Aside from economic reasons, the feasibility of using an inert gas cushion ${ }^{(11)}$ in a natural- gas storage, is dependent upon the rate of mixing of the cushion and working gases brought about by three mechanisms taking place in the gaseous system during storage: (1) Molecular diffusion-dispersion transport; (2) Mutual displacement efficiency of the cushion and the working gases (convective transport); (3) Effect of variable permeability, allowing one gas to move faster than another

\subsubsection{Molecular Diffusion-Dispersion Transport}

Diffusion-dispersion transport ${ }^{(12)}$ results from several causes. Molecular diffusion is a physical phenomena related to molecular agitation. "Brownian movement" creates a particle displacement in all directions. This results in a transport of particles from the higher concentration zones to the lower ones. Molecular diffusion is isotropic and occurs even without any fluid displacement. Its action is very limited in porous media and it acts only inside the fluid gas phase.

The theory of molecular diffusion ${ }^{(13)}$ was first developed on a quantitative basis by Fick. The equation of diffusion in homogeneous substances is based on the hypothesis that the rate of transfer of a diffusing substance through unit area of cross section is proportional to the concentration gradient measured at right angles to the cross section.

$$
F=-D \frac{d C}{d X}
$$

Where

F - Rate of transfer per unit area of section

D - Coefficient of diffusion, dependent upon substances considered

C - Concentration of diffusing substance

$\mathrm{X}$ - Distance measured at right angles to section 
Equation (1) is Fick's first law of diffusion from which his second law is derived, which is as follows:

$$
\frac{d C}{d t}=D \frac{d^{2} C}{d X^{2}}
$$

Where
$\mathrm{C}$ - Concentration of diffusing substance at time $\mathrm{t}$
D - Coefficient of diffusion, dependent upon substances considered

The magnitude of the diffusion depends on the formation factor of the reservoir, the porosity and the gas saturation. Due to the pore geometry and fluid saturation of underground formations, the diffusion coefficient as determined by classical methods has to be altered to an effective value. This value would be a function of the average porosity, gas saturation and pore geometry of the formation. For practical considerations, in a completely gas saturated formation, the effective diffusion coefficient can be expressed as

$$
D_{e}=\frac{D}{\tau}
$$

Where

$$
\begin{aligned}
& \mathrm{D}_{\mathrm{e}}=\text { Effective coefficient of diffusion } \\
& \mathrm{D}=\text { Standard coefficient of diffusion at temperature } \mathrm{T} \text { and pressure } \mathrm{P} \\
& \tau=\text { Tortuosity factor of reservoir formation }
\end{aligned}
$$

The value of tortuosity gives an indication of how the structure of the porous medium restricts the flow of liquids or gases through the material.

Kinematic dispersion is a mixing phenomena created by the different velocities of fluids in pores and the heterogeneities in the porous medium. At the pore's scale the velocity profile is not constant but parabolic for laminar conditions. This leads to a 
quicker transport in the middle of the pores, and then mixing and dispersion of the transported fluid on both sides of the mean convective front. At the reservoir's scale, layering effects, clay lenses, fractures and other kind of macro geological heterogeneity create various velocities and consequently are responsible for mixing.

\subsubsection{Convective Transport}

Convective transport results from the following phenomena

- Gravity

- Capillarity

- Viscosity

These three phenomena may contribute to mixing between two different gases. The difference of density between two gases may cause vertical movements that mix two gases. On the other hand, one could take advantage of a vertical movement caused by gravity to introduce an inert (heavy gas) at the bottom of a thick gas storage reservoir. The hysteresis of capillarity phenomena is responsible for a large part of the mixing problems with convective transport.

The viscosity effect on mixing ${ }^{(14,15,16)}$ is the most well known effect and it is defined by the mobility ratio of the two gases involved. It has been found by numerical simulations that an unfavorable viscosity ratio $(M>1)$ in enhanced oil recovery by gas sweeping, sometimes causes poor efficiency because of too much of mixing (by fingering). One has to take care of this problem when sweeping an inert gas (higher viscosity) by natural gas (lower viscosity). So, a high viscosity cheap gas like nitrogen is preferred for displacing natural gas during mixing. Both density and viscosity differences affect stability. If natural gas displaces a denser gas such as nitrogen in a downward direction, a stable displacement is likely to result, because buoyancy effects will work to 
damp out fingers as they are formed. On the other hand, if natural gas is displaced in a downward direction, buoyancy effects will tend to increase fingering ${ }^{(17)}$. Similarly, a less viscous fluid will tend to finger into a more viscous fluid during a displacement in any direction. For gases, a decrease in density corresponds to an increase in viscosity. For the example of natural gas displacing nitrogen in a downward direction in a homogeneous medium, one is ensured of stability, since both viscous effects and density effects will act to promote it.

\subsection{Numerical Modeling of Mixing}

The purpose of properly modeling mixing phenomena is to enable good decisions in the areas of inert gas substitution or inventory conversion. In the first case, the simulations permit determination of the optimum quantity to be injected, location of wells, and injection schedule, as well as estimates of time and space evaluation of compositions. In the case of inventory, results from simulations provide the basis for the

optimum mode and also enhance the understanding of long term mixing effects $(10,12)$ between the gases involved.

Proper simulation of the behavior of several different gases in a gas storage field involves two-phase flow model when a gas phase itself is composed of several miscible ingredients.

\subsection{Reservoir Modeling Software}

Reservoir simulation model is a cost effective engineering and management tool that helps you make the most of the exploration and production investments. Computer Modeling group (CMG) is one engineering program that is capable of simulating oil and gas reservoirs. CMG has various simulation packages within itself to meet the specific needs to model a particular type of reservoir. 


\subsubsection{GEM}

GEM $^{(18)}$ is general equation of state (EOS) based compositional reservoir simulator to model the flow of multi component fluid systems. GEM is a robust, fully compositional simulator used to model any type of reservoir where the importance of fluid composition and their interactions are essential to the understanding of the recovery process. GEM features a range of dual porosity and dual permeability techniques for modeling gas storage reservoirs including gas phase diffusion due to the mixing of a dissimilar cushion gas with natural gas. These techniques allow accurate modeling of the matrix-fracture transfer in fractures reservoir systems.

\subsubsection{BUILDER}

Builder ${ }^{(19)}$ is an application that is used in the preparation of reservoir simulation models. It provides a windows interface which organizes the data the way the engineer sees it, unconstrained by simulator keywords. Grid builder is to create simulation grids and rock property data for GEM.

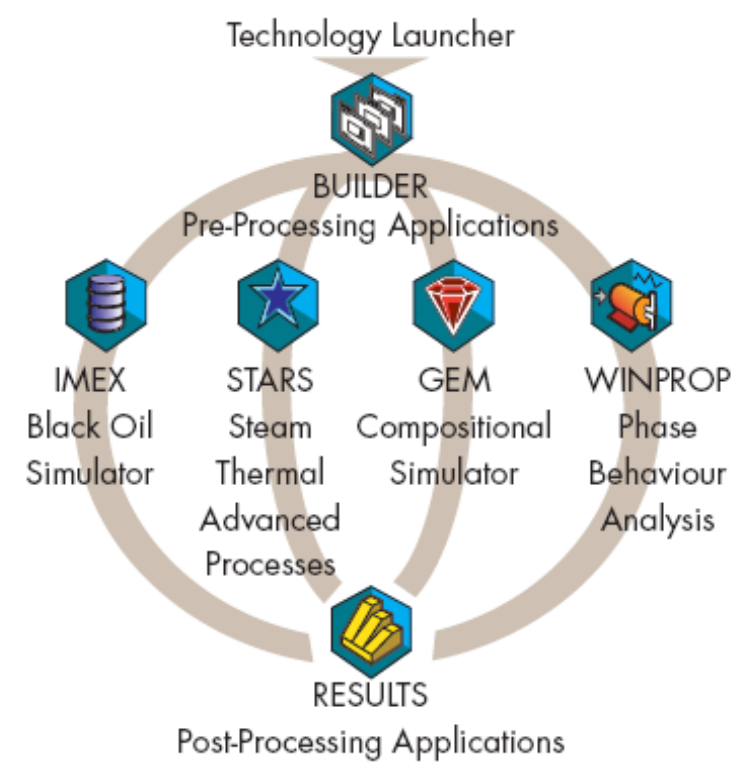

It allows you to easily create and edit grids- positioning them with respect to geological maps and then interpolating geological structure and rock properties. The grid 
generated can be displayed in a variety of 2-D and 3-D views that allows the quick checking of the grid correctness and conformance. 


\section{CHAPTER 3}

\section{METHODOLOGY}

The main objective of this research is to predict the mixing of inert cushion and natural gas in storage reservoirs when a part of the cushion gas is replaced by nitrogen (inert gas).

To study the effect of mixing, the following methodology was followed

1. Two base case models for a storage reservoir were developed with a given set of reservoir parameters and volume of Nitrogen. The reservoir simulation software used in this study was GEM, which has been developed by Computer Modeling Group (CMG). GEM is an advanced compositional simulator that utilizes equation of state to track various components.

2. The impact of reservoir properties on mixing between inert cushion and natural gas during the withdrawal cycle was determined by varying the reservoir parameters in the simulation runs.

3. The mole percentages of Nitrogen in withdrawn gas at the end of each day during withdrawal cycle were calculated.

4. A plot of percentage nitrogen in withdrawn gas as a function of time was prepared to observe the mixing trend.

\subsection{Development of the Base Models}

\subsubsection{Bottom Nitrogen Placement Case}

A three dimensional Cartesian grid system was used for the base model in which the well is located at the center of the storage reservoir as indicated in Figure 4 and Figure 5. The base case has a horizontal permeability of $100 \mathrm{md}$ and a vertical 
permeability of $10 \mathrm{md}$. In all the cases simulated in this study, a ratio of 10:1 is maintained between horizontal and vertical permeability.

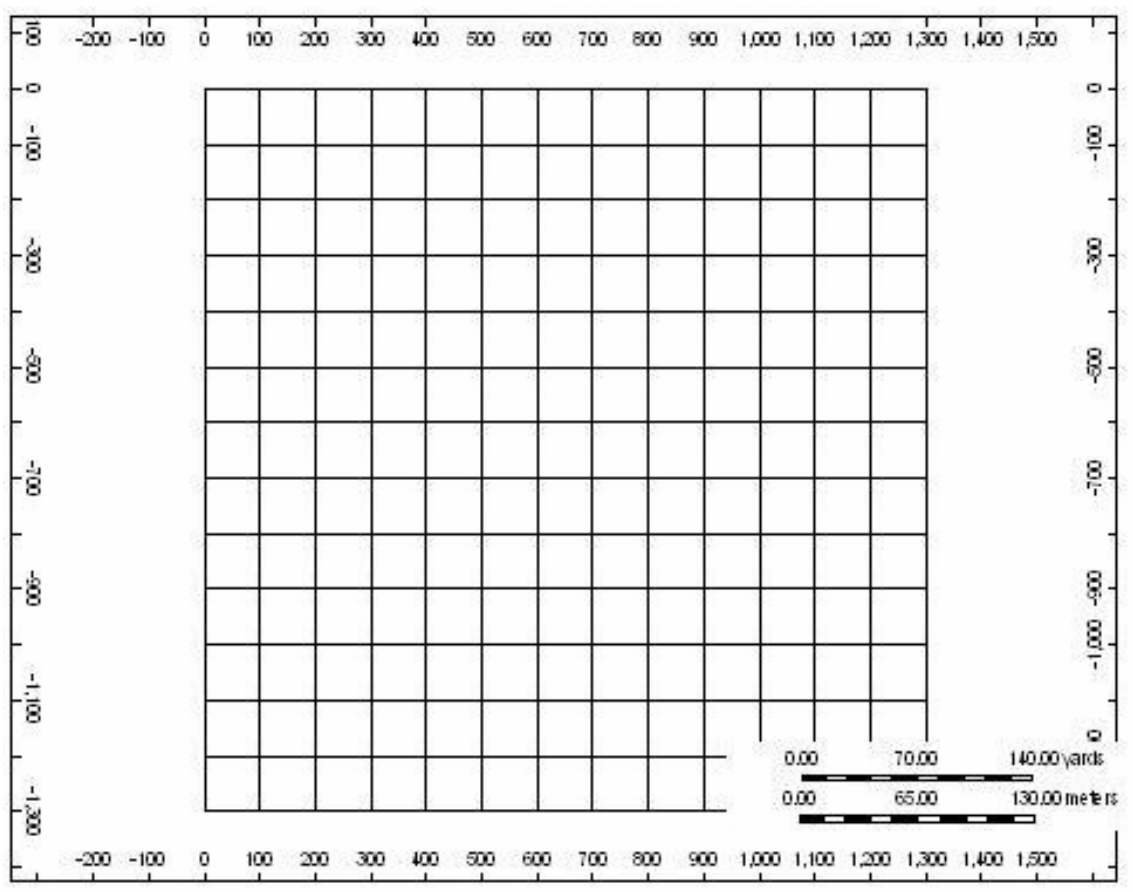

Figure 4- Cartesian Grid for Base Model

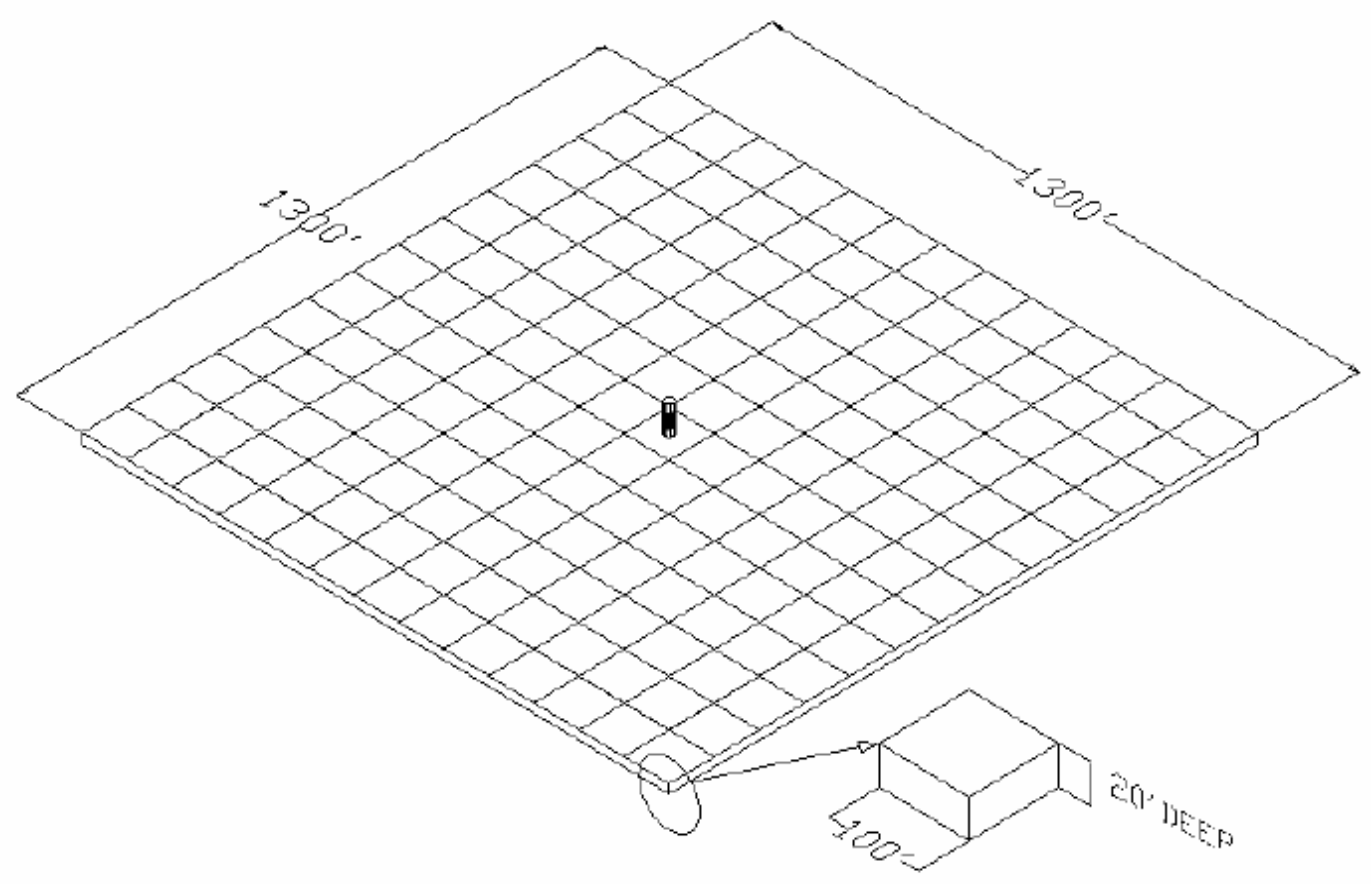

Figure 5- 3-D Representation of the Reservoir Grid System 
The Cartesian grid of the model consists of a square area with 13 blocks on each side, with a block width of $100 \mathrm{ft}$ for each block. The model is $20 \mathrm{ft}$ thick and has five different layers. The thickness of the first three layers from the top is $5 \mathrm{ft}$ each and the bottom two layers are of thickness $3 \mathrm{ft}$ and $2 \mathrm{ft}$ respectively. The first two layers are used for working gas which is about $50 \%$ of the total gas in the reservoir. The lower three layers are used as cushion gas in the reservoir. Figure 5 and Figure 6 gives a graphical representation of the model. The initial pressure in the reservoir is 1100 psia.

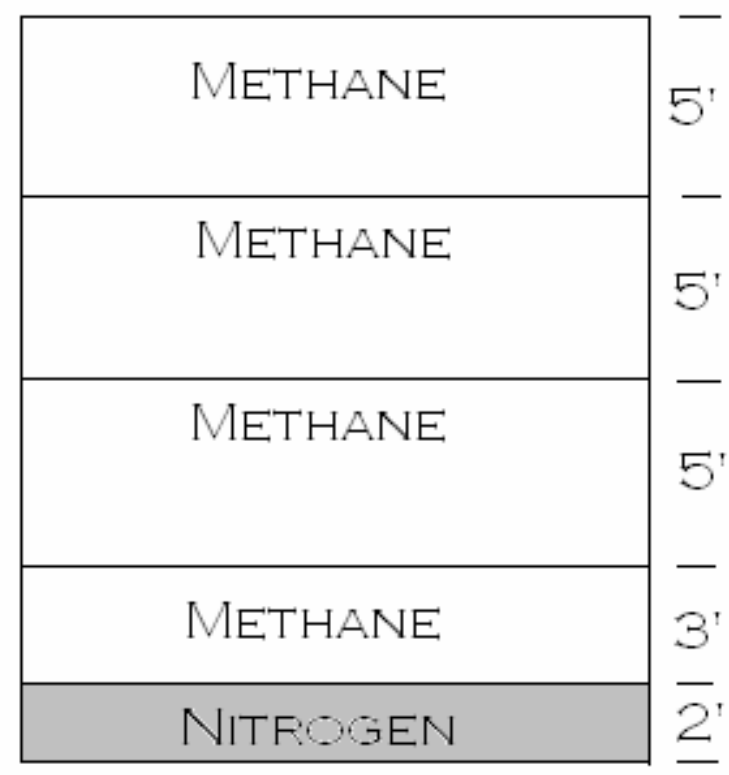

Figure 6- Cross-Sectional View of the Reservoir Grid System

The reservoir is assumed to contain of only methane (Natural Gas) and nitrogen. Water is considered to be non-movable. For the base case of this reservoir model, Nitrogen (cushion gas) is placed in the lower most layer of the grid and Methane is placed in the top four layers. That represents a Nitrogen content of about $10 \%$ by volume.

The grid system consists of a single production well that is located at the center of the reservoir. Two cases were considered, one with a constant rate and the other with a 
constant flowing pressure. The flow rate was estimated in such a way that, the working gas (50\% of the total gas) is produced during the withdrawal cycle (120 days). The well is perforated for $10 \mathrm{ft}$ from the top of the storage reservoir.

Table 1 - Bottom Nitrogen Placement Case - Reservoir Parameters for Base Model

\begin{tabular}{|c|c|c|}
\hline PARAMETER & $\begin{array}{c}\text { BASE MODEL } \\
\text { VALUE }\end{array}$ & RANGE \\
\hline Model Geometry & Cartesian & - \\
\hline Grid Size & $1300 \times 1300 \mathrm{ft}$ & - \\
\hline Reservoir Area & 40 Acres & - \\
\hline Reservoir Thickness & $20 \mathrm{ft}$ & - \\
\hline Number of layers & 5 & - \\
\hline Porosity & $20 \%$ & $10 \%, 15 \%, 25 \%$ \\
\hline Permeability & $100 \mathrm{md}$ & $\begin{array}{c}10,20,50,200,300,500 \& \\
1000 \mathrm{md}\end{array}$ \\
\hline Initial Pressure & 1100 Psia & $\begin{array}{l}\text { 1000, 1500, 2000, } \\
2500 \& 3000 \text { psia }\end{array}$ \\
\hline Temperature & $113^{\circ} \mathrm{F}$ & $90,100,125,150{ }^{\circ} \mathrm{F}$ \\
\hline $\begin{array}{l}\text { Percentage Nitrogen by } \\
\text { Volume } \\
\text { in Reservoir }\end{array}$ & $10 \%$ & $5 \%, 10 \%, 15 \%, 20 \%$ \\
\hline $\begin{array}{l}\text { Pressures for Constant } \\
\text { flowing Pressure Case }\end{array}$ & - & $\begin{array}{l}\text { 100, 150, 200, } 250 \\
\text { \& } 300 \text { psia }\end{array}$ \\
\hline
\end{tabular}


Table 2 -Bottom Nitrogen Placement Case - Distribution of Components in the Base Model

\begin{tabular}{|c|c|l|}
\hline Component & Volume & \multicolumn{1}{|c|}{ Distribution } \\
\hline $\begin{array}{c}\text { Working Gas } \\
\text { (Methane) }\end{array}$ & $50 \%$ & $\begin{array}{l}\text { Natural gas is distributed in the top } 4 \\
\text { layers with a total thickness of } 18 \text { ft and } \\
\text { nitrogen is present in the bottom most } \\
\text { layer with a thickness of } 2 \mathrm{ft} .\end{array}$ \\
\hline $\begin{array}{c}\text { Cushion Gas } \\
\text { (Nitrogen) }\end{array}$ & $10 \%$ & \\
\hline $\begin{array}{c}\text { Cushion Gas } \\
\text { (Methane) }\end{array}$ & $40 \%$ & \\
\hline
\end{tabular}

Table 1 and Table 2 give a summary of all the parameters that have been used in the base case model of this simulation.

Using the vertical distribution base case model, parameters like temperature, pressure, porosity, permeability, percentage of nitrogen cushion were varied and simulation runs were made. Due to the change in reservoir parameters like temperature, pressure and porosity, the total amount of gas that can be stored in the reservoir varies from case to case. In all of these cases, working gas equals $50 \%$ of the total gas in the reservoir and a withdrawal rate is chosen such that all of the working gas is withdrawn in a period of 120 days.

Table 3 through Table 8 shows the initial amount of gas in the reservoir before the start of withdrawal cycle and also the rate at which gas is withdrawn through out the cycle.

Table 3 - Bottom Placement Case of Nitrogen - Distribution of Components and Production Rate at Different Pressures

\begin{tabular}{|c|c|c|c|c|}
\hline Pressure & $\begin{array}{c}\text { Working } \\
\text { Gas }\end{array}$ & Methane & Nitrogen & $\begin{array}{c}\text { Withdrawa } \\
\text { I rate }\end{array}$ \\
\hline Psia & Scf & g-moles & g-moles & mmcfd \\
\hline 1000 & $2.96 \times 10^{8}$ & $5.40 \times 10^{8}$ & $5.31 \times 10^{7}$ & 2.00 \\
\hline 1500 & $4.50 \times 10^{8}$ & $8.22 \times 10^{8}$ & $7.76 \times 10^{7}$ & 3.15 \\
\hline 2000 & $5.95 \times 10^{8}$ & $1.09 \times 10^{9}$ & $1.00 \times 10^{8}$ & 4.13 \\
\hline 2500 & $7.20 \times 10^{8}$ & $1.32 \times 10^{9}$ & $1.21 \times 10^{8}$ & 5.02 \\
\hline 3000 & $8.35 \times 10^{8}$ & $1.53 \times 10^{9}$ & $1.40 \times 10^{8}$ & 5.80 \\
\hline
\end{tabular}


Table 4 - Bottom Placement Case of Nitrogen - Distribution of Components and Withdrawal Rate at Different Temperatures

\begin{tabular}{|c|c|c|c|c|}
\hline Temperature & $\begin{array}{c}\text { Working } \\
\text { Gas }\end{array}$ & Methane & Nitrogen & $\begin{array}{c}\text { Withdrawal } \\
\text { Rate }\end{array}$ \\
\hline${ }^{\mathbf{0}} \mathbf{F}$ & $\mathbf{S c f}$ & $\mathbf{g - m o l}$ & $\mathbf{g - m o l}$ & $\mathbf{m m c f d}$ \\
\hline 90 & $3.81 \times 10^{8}$ & $8.36 \times 10^{8}$ & $7.85 \times 10^{7}$ & 3.17 \\
\hline 100 & $3.69 \times 10^{8}$ & $8.11 \times 10^{8}$ & $7.68 \times 10^{7}$ & 3.08 \\
\hline 125 & $3.45 \times 10^{8}$ & $7.56 \times 10^{8}$ & $7.30 \times 10^{7}$ & 2.87 \\
\hline 150 & $3.24 \times 10^{8}$ & $7.09 \times 10^{8}$ & $6.96 \times 10^{7}$ & 2.70 \\
\hline
\end{tabular}

Table 5- Bottom Placement Case of Nitrogen - Distribution of Components and Withdrawal Rate for different Permeability's

\begin{tabular}{|c|c|c|c|c|}
\hline Permeability & $\begin{array}{l}\text { Working } \\
\text { Gas }\end{array}$ & Methane & Nitrogen & $\begin{array}{c}\text { Withdrawal } \\
\text { Rate }\end{array}$ \\
\hline md & Scf & g-mol & g-mol & mmcfd \\
\hline 10 & \multirow{8}{*}{$2.55 \times 10^{8}$} & \multirow{8}{*}{$5.57 \times 10^{8}$} & \multirow{8}{*}{$5.51 \times 10^{7}$} & \multirow{8}{*}{2.12} \\
\hline 20 & & & & \\
\hline 50 & & & & \\
\hline 100 & & & & \\
\hline 200 & & & & \\
\hline 300 & & & & \\
\hline 500 & & & & \\
\hline 1000 & & & & \\
\hline
\end{tabular}

Table 6- Bottom Placement Case of Nitrogen - Distribution of Components and Withdrawal Rate for different Porosities

\begin{tabular}{|c|c|c|c|c|}
\hline Porosity & $\begin{array}{c}\text { Working } \\
\text { Gas }\end{array}$ & Methane & Nitrogen & $\begin{array}{c}\text { Withdrawal } \\
\text { Rate }\end{array}$ \\
\hline$\%$ & Scf & g-mol & g-mol & mmcfd \\
\hline 10 & $1.90 \times 10^{8}$ & $2.21 \times 10^{8}$ & $2.20 \times 10^{7}$ & 1.04 \\
\hline 15 & $1.85 \times 10^{8}$ & $4.17 \times 10^{8}$ & $4.13 \times 10^{7}$ & 1.59 \\
\hline 20 & $1.73 \times 10^{8}$ & $5.56 \times 10^{8}$ & $5.51 \times 10^{7}$ & 2.12 \\
\hline 25 & $1.62 \times 10^{8}$ & $6.94 \times 10^{8}$ & $6.89 \times 10^{7}$ & 2.65 \\
\hline
\end{tabular}


Table 7- Bottom Placement Case of Nitrogen - Distribution of Components and Withdrawal Rate with different Percentages of Nitrogen Cushion by Volume in Reservoir

\begin{tabular}{|c|c|c|c|c|}
\hline $\begin{array}{c}\text { Nitrogen } \\
\text { Cushion }\end{array}$ & $\begin{array}{c}\text { Working } \\
\text { Gas }\end{array}$ & Methane & Nitrogen & Withdrawal Rate \\
\hline Volume \% & Scf & g-mol & g-mol & mmcfd \\
\hline 5 & $2.56 \times 10^{8}$ & $5.86 \times 10^{8}$ & $2.76 \times 10^{7}$ & \multirow{2}{*}{2.00} \\
\hline 10 & $2.55 \times 10^{8}$ & $5.55 \times 10^{8}$ & $5.51 \times 10^{7}$ & \multirow{2}{*}{2.00} \\
\hline 15 & $2.53 \times 10^{8}$ & $5.24 \times 10^{8}$ & $8.27 \times 10^{7}$ & \\
\hline 25 & $2.52 \times 10^{8}$ & $4.93 \times 10^{8}$ & $1.10 \times 10^{8}$ & \\
\hline
\end{tabular}

Table 8 - Bottom Placement Case of Nitrogen - Distribution of Components with Constant Pressure Withdrawal

\begin{tabular}{|c|c|c|c|c|}
\hline $\begin{array}{l}\text { Withdrawal } \\
\text { Pressure }\end{array}$ & Permeability & Working gas & Methane & Nitrogen \\
\hline Psia & \multirow{6}{*}{$\begin{array}{l}100 \mathrm{md} \text {, } \\
200 \mathrm{md}, \\
300 \mathrm{md} \& \\
400 \mathrm{md}\end{array}$} & Scf & g-mol & g-mol \\
\hline 100 & & \multirow{5}{*}{$2.55 \times 10^{8}$} & \multirow{5}{*}{$5.56 \times 10^{8}$} & \multirow{5}{*}{$4.61 \times 10^{7}$} \\
\hline 150 & & & & \\
\hline 200 & & & & \\
\hline 250 & & & & \\
\hline 300 & & & & \\
\hline
\end{tabular}




\subsubsection{Peripheral Nitrogen Placement Case in the Storage Reservoir}

The second base case model uses all the reservoir parameters as the first base case expect for the placement of nitrogen in the reservoir. This model consists of a single layer with a thickness $20 \mathrm{ft}$ and the Nitrogen is placed along the outer periphery of the grid system as shown in Figure 7.

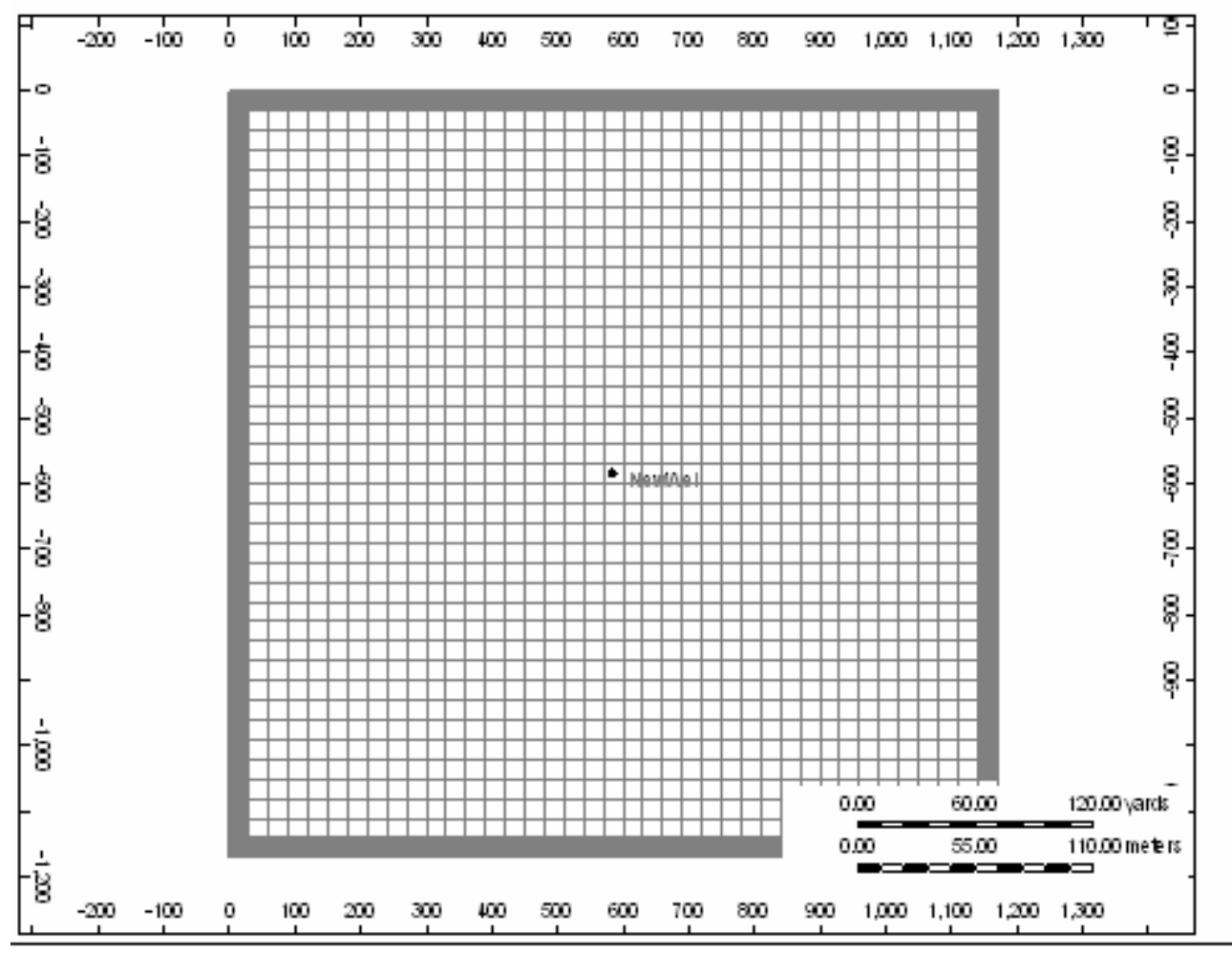

Figure 7- Representation of the Reservoir Grid System with Peripheral Nitrogen Placement Case

Various cases were simulated using this model by varying the percentage of Nitrogen (by volume). This is accomplished by the varying the number of blocks on the grid. This model represents an idealized single well natural gas storage system. 
Table 9- Peripheral Nitrogen Placement Case - Distribution of Components in Base Model

\begin{tabular}{|c|c|}
\hline Component & Value \\
\hline Working gas (Methane) & $50 \%$ \\
\hline Cushion Gas (Nitrogen) & $10 \%$ \\
\hline Cushion Gas (Methane) & $40 \%$ \\
\hline
\end{tabular}

Simulations were run by varying the parameters like porosity, permeability, pressure, temperature and the percentage of base gas by volume in the reservoir. The GEM compositional simulator gives an output of the cumulative gas moles of nitrogen and methane produced at the end of each day of 120 days production cycle. The produced moles of Nitrogen and Methane are got as an output from the simulator, and the percentage of nitrogen in the gas withdrawn is determined. Table 9 gives the total amount of gas in the reservoir for the base case model with horizontal distribution of Nitrogen.

Table 10 through Table 15 show the amount of initial amount of gas in the reservoir before the start of the withdrawal cycle and also the rate at which gas is being withdrawn during the cycle.

Table 10- Peripheral Nitrogen Placement Case - Distribution of Components in Reservoir at different Pressures

\begin{tabular}{|c|c|c|c|c|}
\hline Pressure & Working Gas & Methane & Nitrogen & Withdrawal rate \\
\hline Psia & Scf & g-moles & g-moles & mmcfd \\
\hline 1000 & $1.86 \times 10^{8}$ & $4.05 \times 10^{8}$ & $4.05 \times 10^{7}$ & 1.55 \\
\hline 1500 & $2.88 \times 10^{8}$ & $6.31 \times 10^{8}$ & $6.05 \times 10^{7}$ & 2.40 \\
\hline 2000 & $3.91 \times 10^{8}$ & $8.59 \times 10^{8}$ & $7.98 \times 10^{7}$ & 3.26 \\
\hline 2500 & $4.91 \times 10^{8}$ & $1.07 \times 10^{9}$ & $9.83 \times 10^{7}$ & 4.09 \\
\hline 3000 & $5.84 \times 10^{8}$ & $1.28 \times 10^{9}$ & $1.16 \times 10^{8}$ & 4.86 \\
\hline
\end{tabular}


Table 11- Peripheral Nitrogen Placement Case - Distribution of Components in Reservoir at different Temperatures

\begin{tabular}{|c|c|c|c|c|}
\hline Temperature & $\begin{array}{c}\text { Working } \\
\text { Gas }\end{array}$ & Methane & Nitrogen & Production Rate \\
\hline${ }^{\mathbf{0}} \mathbf{F}$ & $\mathbf{S c f}$ & $\mathbf{g}-\mathbf{m o l}$ & $\mathbf{g}-\mathbf{m o l}$ & $\mathbf{m m c f d}$ \\
\hline 90 & $2.47 \times 10^{8}$ & $4.51 \times 10^{8}$ & $4.25 \times 10^{7}$ & 1.64 \\
\hline 100 & $2.30 \times 10^{8}$ & $4.19 \times 10^{8}$ & $4.16 \times 10^{7}$ & 1.60 \\
\hline 125 & $2.16 \times 10^{8}$ & $3.93 \times 10^{8}$ & $3.96 \times 10^{7}$ & 1.50 \\
\hline 150 & $2.04 \times 10^{8}$ & $3.71 \times 10^{8}$ & $3.78 \times 10^{7}$ & 1.42 \\
\hline
\end{tabular}

Table 12- Peripheral Nitrogen Placement Case - Distribution of Components in Reservoir with Different Permeability's

\begin{tabular}{|c|c|c|c|c|}
\hline Permeability & $\begin{array}{c}\text { Working } \\
\text { Gas }\end{array}$ & Methane & Nitrogen & Withdrawal Rate \\
\hline md & Scf & g-mol & g-mol & mmcfd \\
\hline 10 & \multirow{7}{*}{$2.23 \times 10^{8}$} & \multirow{7}{*}{$4.05 \times 10^{8}$} & \multirow{7}{*}{$4.05 \times 10^{7}$} & \multirow{7}{*}{1.55} \\
\hline 20 & & & & \\
\hline 50 & & & & \\
\hline 100 & & & & \\
\hline 200 & & & & \\
\hline 300 & & & & \\
\hline 500 & & & & \\
\hline
\end{tabular}

Table 13 - Peripheral Nitrogen Placement Case - Percentage of Nitrogen in Withdrawn Gas with different Porosity's

\begin{tabular}{|c|c|c|c|c|}
\hline Porosity & Working Gas & Methane & Nitrogen & Withdrawal Rate \\
\hline$\%$ & Scf & g-mol & g-mol & mmcfd \\
\hline 10 & $1.01 \times 10^{8}$ & $2.02 \times 10^{8}$ & $2.02 \times 10^{7}$ & 0.76 \\
\hline 15 & $1.67 \times 10^{8}$ & $3.04 \times 10^{8}$ & $3.04 \times 10^{7}$ & 1.16 \\
\hline 20 & $2.23 \times 10^{8}$ & $4.05 \times 10^{8}$ & $4.05 \times 10^{7}$ & 1.55 \\
\hline 25 & $2.79 \times 10^{8}$ & $5.07 \times 10^{9}$ & $5.07 \times 10^{7}$ & 1.94 \\
\hline
\end{tabular}

Table 14- Peripheral Nitrogen Placement Case - Percentage of Nitrogen in Withdrawn Gas with different Percentages of Cushion Gas by Volume

\begin{tabular}{|c|c|c|c|c|}
\hline $\begin{array}{c}\text { Nitrogen } \\
\text { Cushion }\end{array}$ & Working Gas & Methane & Nitrogen & Withdrawal Rate \\
\hline \% & Scf & g-mol & g-mol & mmcfd \\
\hline 5 & $2.31 \times 10^{8}$ & $4.42 \times 10^{8}$ & $2.07 \times 10^{7}$ & \multirow{2}{*}{1.55} \\
\hline 10 & $2.43 \times 10^{8}$ & $4.42 \times 10^{8}$ & $4.38 \times 10^{7}$ & \\
\hline 15 & $2.56 \times 10^{8}$ & $4.42 \times 10^{8}$ & $6.96 \times 10^{7}$ & \\
\hline 25 & $2.70 \times 10^{8}$ & $4.42 \times 10^{8}$ & $9.87 \times 10^{7}$ & \\
\hline
\end{tabular}


Table 15- Peripheral Nitrogen Placement Case - Distribution of Components with Constant Pressure Withdrawal

\begin{tabular}{|c|c|c|c|c|}
\hline $\begin{array}{l}\text { Withdrawal } \\
\text { Pressure }\end{array}$ & Permeability & Working gas & Methane & Nitrogen \\
\hline Psia & \multirow{6}{*}{$\begin{array}{l}100 \mathrm{md}, 200 \mathrm{md} \\
300 \mathrm{md} \& 400 \mathrm{md}\end{array}$} & Scf & g-mol & g-mol \\
\hline 100 & & \multirow{5}{*}{$2.23 \times 10^{8}$} & \multirow{5}{*}{$4.05 \times 10^{8}$} & \multirow{5}{*}{$4.05 \times 10^{7}$} \\
\hline 150 & & & & \\
\hline 200 & & & & \\
\hline 250 & & & & \\
\hline 300 & & & & \\
\hline
\end{tabular}




\section{CHAPTER 4}

\section{RESULTS AND DISCUSSION}

\subsection{Bottom Nitrogen Placement Case}

\subsubsection{Effect on Mixing due to Variation in Percentage of Nitrogen Cushion in}

\section{Reservoir}

Table 16 gives the Nitrogen material balance before and after the withdrawal cycle with different percentages of Nitrogen in the cushion gas.

Table 16 - Bottom Placement Case of Nitrogen - Material Balance for Cases with different Percentages of Nitrogen Cushion by Volume in Reservoir

\begin{tabular}{|c|c|c|c|}
\hline $\begin{array}{c}\text { Nitrogen } \\
\text { Cushion }\end{array}$ & $\begin{array}{c}\text { Nitrogen in } \\
\text { Reservoir before } \\
\text { Start of Withdrawal } \\
\text { Cycle }\end{array}$ & $\begin{array}{c}\text { Nitrogen in } \\
\text { Reservoir after } \\
\text { Withdrawal } \\
\text { Cycle }\end{array}$ & $\begin{array}{c}\text { Nitrogen in } \\
\text { Withdrawn Gas }\end{array}$ \\
\hline$\%$ & g-mol & g-mol & g-mol \\
\hline 5 & $2.76 \times 10^{7}$ & $1.81 \times 10^{7}$ & $9.42 \times 10^{6}$ \\
\hline 10 & $5.51 \times 10^{7}$ & $3.59 \times 10^{7}$ & $1.92 \times 10^{7}$ \\
\hline 15 & $8.27 \times 10^{7}$ & $5.33 \times 10^{7}$ & $2.94 \times 10^{7}$ \\
\hline 20 & $1.10 \times 10^{8}$ & $7.03 \times 10^{7}$ & $3.99 \times 10^{7}$ \\
\hline
\end{tabular}

Figure 8 illustrates, as the percentage of Nitrogen cushion in the reservoir increases the degree of mixing between the inert cushion gas and Natural Gas also increases. For the case with $10 \%$ inert cushion, the percentage Nitrogen in withdrawn gas reaches $2.41 \%$ at the end of 120 days.

The percentage of Nitrogen produced drastically increases in the first 5 or 6 days and then stabilizes around the $10^{\text {th }}$ day of the withdrawal cycle when about $5 \%$ of the total working gas is produced. The Nitrogen in the withdrawn gas reaches a highest value of $7.90 \%$ and $11.95 \%$ with Nitrogen cushion percentages of $10 \%$ and $15 \%$ in the reservoir 


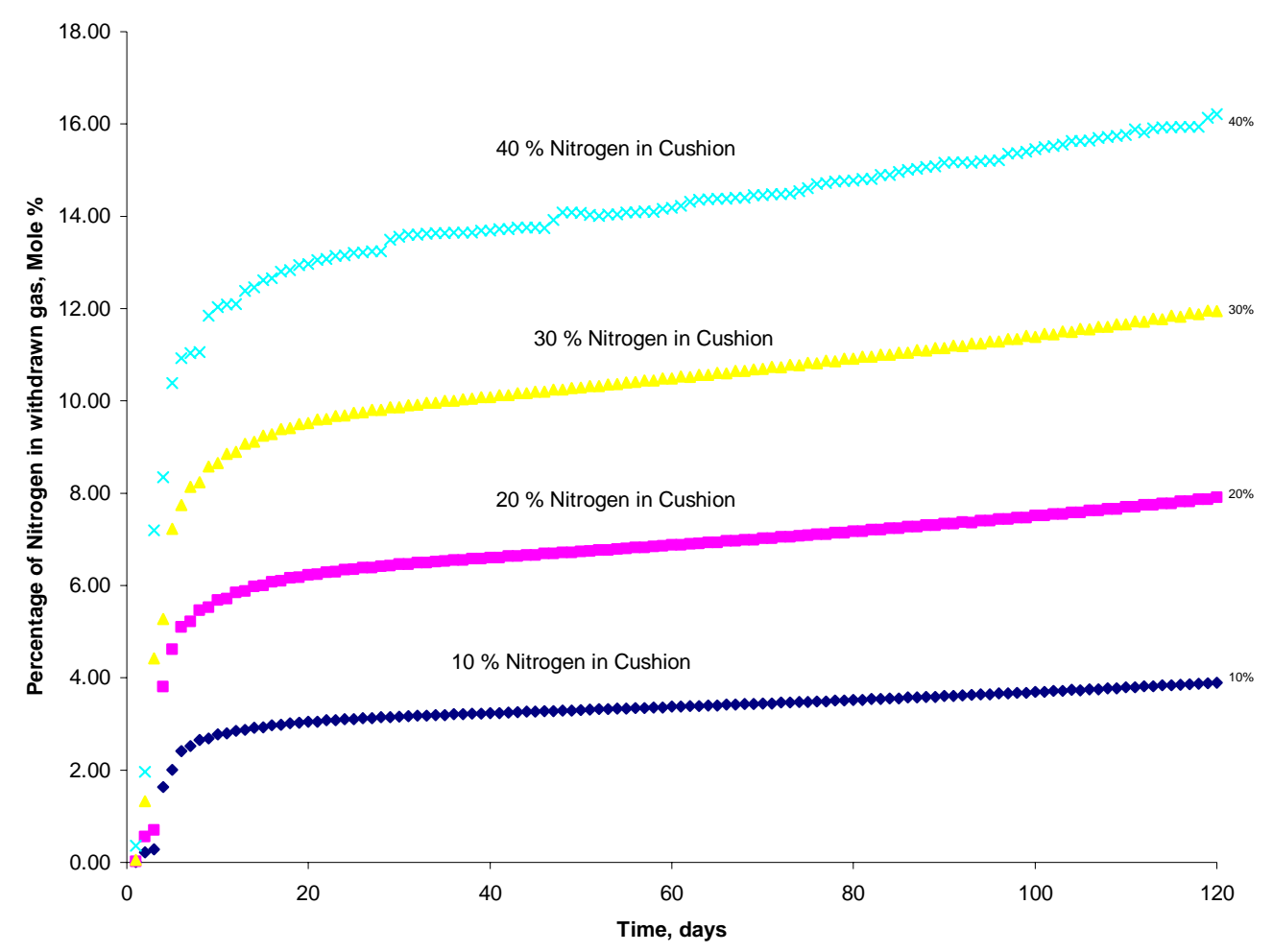

Figure 8- Bottom Nitrogen Placement Case - Mixing with different Percentages Nitrogen as Cushion

. Irrespective of how much Nitrogen is present in the reservoir as gas cushion, the Nitrogen production along with the withdrawn gas follows a similar trend at a given withdrawal rate.

\subsubsection{Effect of Pressure on Mixing between Nitrogen and Methane}

Table 17 shows the amount of Nitrogen that has been withdrawn during the withdrawal cycle.

Table 17 - Bottom Nitrogen Placement Case - Material Balance for Cases with Different Pressures

\begin{tabular}{|c|c|c|c|}
\hline Pressure & $\begin{array}{c}\text { Nitrogen in } \\
\text { Reservoir before } \\
\text { Start of Withdrawal } \\
\text { Cycle }\end{array}$ & $\begin{array}{c}\text { Nitrogen in } \\
\text { Reservoir after } \\
\text { Withdrawal Cycle }\end{array}$ & $\begin{array}{c}\text { Nitrogen in } \\
\text { Withdrawn Gas }\end{array}$ \\
\hline Psia & g-mol & g-mol & g-mol \\
\hline 1000 & $5.31 \times 10^{7}$ & $3.32 \times 10^{7}$ & $2.00 \times 10^{7}$ \\
\hline 1500 & $7.76 \times 10^{7}$ & $4.77 \times 10^{7}$ & $2.99 \times 10^{7}$ \\
\hline 2000 & $1.00 \times 10^{8}$ & $6.13 \times 10^{7}$ & $3.90 \times 10^{7}$ \\
\hline 2500 & $1.21 \times 10^{8}$ & $7.30 \times 10^{7}$ & $4.80 \times 10^{7}$ \\
\hline 3000 & $1.40 \times 10^{8}$ & $8.32 \times 10^{7}$ & $5.66 \times 10^{7}$ \\
\hline
\end{tabular}




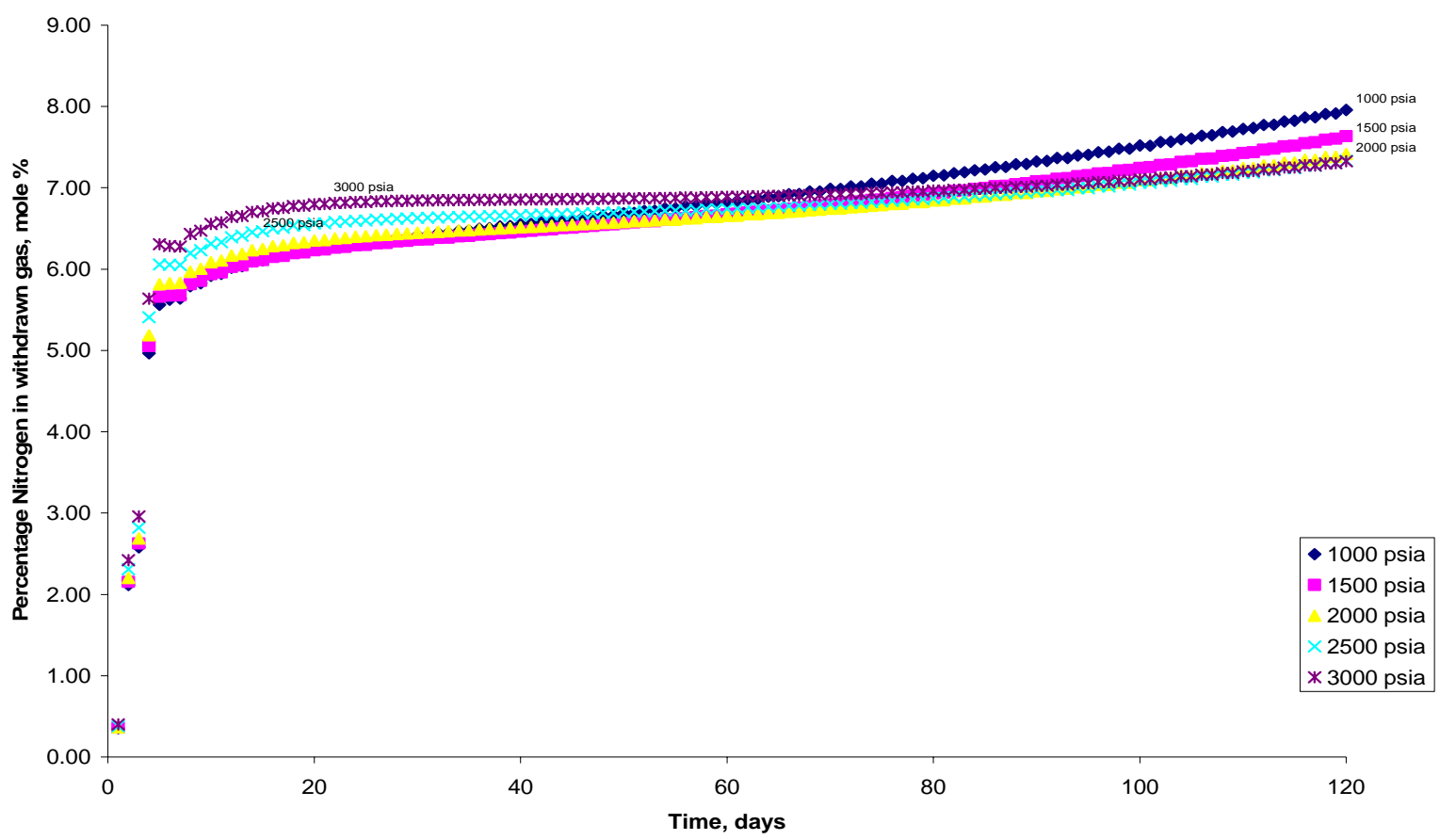

Figure 9- Bottom Nitrogen Placement Case - Effect of Pressure on Mixing

Figure 9 shows the comparison for the degree of mixing between Nitrogen and Methane simulated at different pressures using the base case model. Nitrogen starts to be produced in the withdrawn gas at the end of 2 days. At a pressure of 1000 psia, the mole \% of Nitrogen reaches a value of about $5.6 \%$ at the end of 5 days. The percentage of Nitrogen in the withdrawn gas then starts to rise slowly and reaches a peak value of $7.9 \%$ at the end of the withdrawal cycle. The Nitrogen mole \% follows a similar trend for all other pressures. At higher pressures, the maximum Nitrogen mole \% is slightly lower than at lower pressure values.

When about $50 \%$ of the total working gas is withdrawn the percentage of Nitrogen in the withdrawn gas seems to be nearly equal at all the pressures. After the half way mark through the production cycle, the cases with higher pressures produce lesser Nitrogen along with the withdrawn gas. 


\subsubsection{Effect of Temperature on Mixing between Nitrogen and Methane}

Table 18 gives the nitrogen material balance before and after the withdrawal cycle at different temperatures. The comparison for the Nitrogen mole percent in withdrawn gas at different temperatures is given by Figure 10. It is evident that there is an instantaneous production of Nitrogen during the early part of the withdrawal cycle, say for about a period of 3 days and then the Percentage of Nitrogen starts to stabilize.

Table 18 - Bottom Nitrogen Placement Case - Material Balance for Cases at Different Temperatures

\begin{tabular}{|c|c|c|c|}
\hline Temperature & $\begin{array}{c}\text { Nitrogen in } \\
\text { Reservoir before } \\
\text { Start of } \\
\text { Withdrawal Cycle }\end{array}$ & $\begin{array}{c}\text { Nitrogen in } \\
\text { Reservoir after } \\
\text { Withdrawal Cycle }\end{array}$ & $\begin{array}{c}\text { Nitrogen in } \\
\text { Withdrawn Gas }\end{array}$ \\
\hline${ }^{\mathbf{0}} \mathbf{F}$ & g-mol & g-mol & g-mol \\
\hline 90 & $7.85 \times 10^{7}$ & $4.86 \times 10^{7}$ & $2.99 \times 10^{7}$ \\
\hline 100 & $7.68 \times 10^{7}$ & $4.76 \times 10^{7}$ & $2.92 \times 10^{7}$ \\
\hline 125 & $7.30 \times 10^{7}$ & $4.53 \times 10^{7}$ & $2.78 \times 10^{7}$ \\
\hline 150 & $6.96 \times 10^{7}$ & $4.32 \times 10^{7}$ & $2.65 \times 10^{7}$ \\
\hline
\end{tabular}

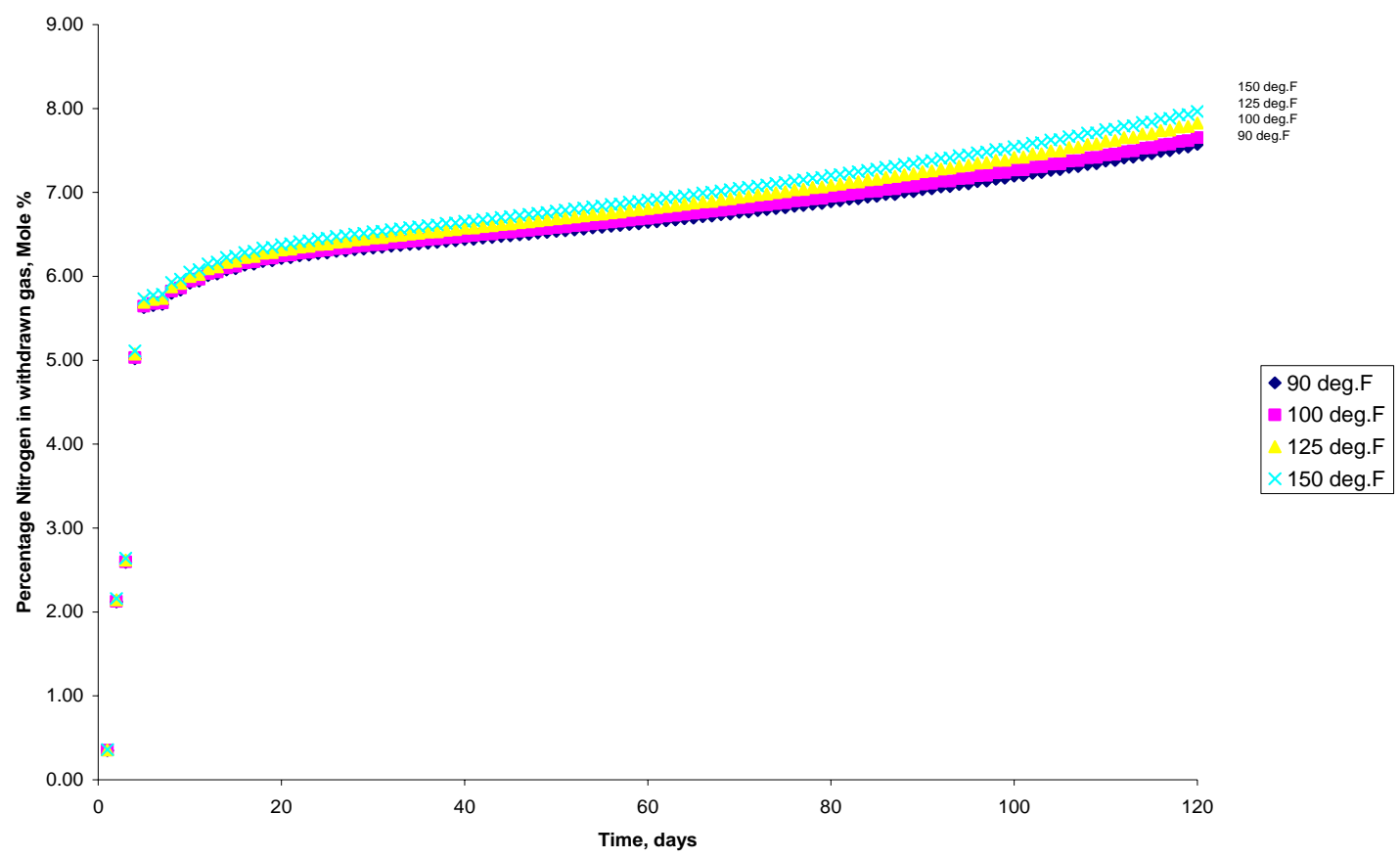

Figure 10- Bottom Nitrogen Placement Case - Effect of Temperature on Mixing 
The curves in Figure 10 for different temperatures are very close for all the temperature values and follow a similar pattern throughout the withdrawal cycle. Generally, the increase in temperature results in increased mixing but the impact is of minor nature.

\subsubsection{Effect of Permeability on Mixing between Nitrogen and Methane}

Nitrogen material balance before and after the withdrawal cycle is given in Table 19 at different permeability values used for the simulation runs. Figure 11 illustrates the peak value of Nitrogen content in the withdrawn gas is about $7.03 \%$ at the end of 120 days for a permeability of $10 \mathrm{md}$. There is a slight increase in mixing when the permeability is varied from $10 \mathrm{md}$ to $20 \mathrm{md}$, which reaches a maximum value of $7.56 \%$.

Table 19 - Bottom Nitrogen Placement Case - Material Balance for Cases with different Permeability's

\begin{tabular}{|c|c|c|c|}
\hline Permeability & $\begin{array}{c}\text { Nitrogen in } \\
\text { Reservoir before } \\
\text { Start of } \\
\text { Withdrawal Cycle }\end{array}$ & $\begin{array}{c}\text { Nitrogen in } \\
\text { Reservoir after } \\
\text { Withdrawal } \\
\text { Cycle }\end{array}$ & $\begin{array}{c}\text { Nitrogen in } \\
\text { Withdrawn Gas }\end{array}$ \\
\hline md & g-mol & g-mol & g-mol \\
\hline 10 & $5.51 \times 10^{7}$ & $4.39 \times 10^{7}$ & $1.12 \times 10^{7}$ \\
\hline 20 & $5.51 \times 10^{7}$ & $3.81 \times 10^{7}$ & $1.71 \times 10^{7}$ \\
\hline 50 & $5.51 \times 10^{7}$ & $3.52 \times 10^{7}$ & $2.00 \times 10^{7}$ \\
\hline 100 & $5.51 \times 10^{7}$ & $3.52 \times 10^{7}$ & $1.99 \times 10^{7}$ \\
\hline 200 & $5.51 \times 10^{7}$ & $3.52 \times 10^{7}$ & $1.99 \times 10^{7}$ \\
\hline 300 & $5.51 \times 10^{7}$ & $3.52 \times 10^{7}$ & $1.99 \times 10^{7}$ \\
\hline 500 & $5.51 \times 10^{7}$ & $3.52 \times 10^{7}$ & $1.99 \times 10^{7}$ \\
\hline 1000 & $5.51 \times 10^{7}$ & $3.52 \times 10^{7}$ & $1.99 \times 10^{7}$ \\
\hline
\end{tabular}




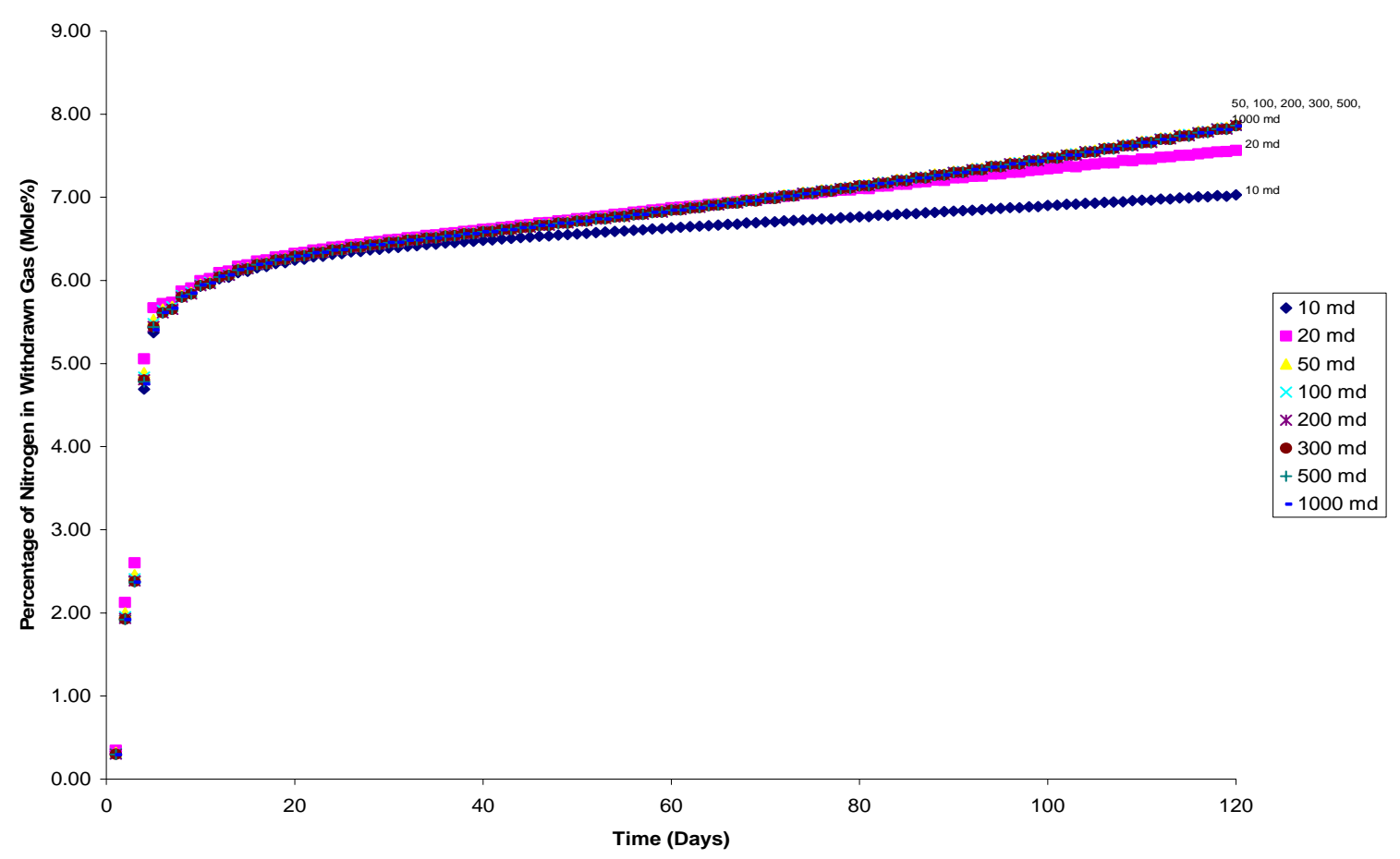

Figure 11- Bottom Nitrogen Placement Case - Effect of Permeability on Mixing

Case with permeability's of 50 md and higher follow an identical pattern of Nitrogen production during the course of the production cycle and they reach a maximum value of $7.88 \%$ of Nitrogen in the withdrawn gas.

\subsubsection{Effect of Porosity on Mixing between Nitrogen and Methane}

Table 20 - Bottom Nitrogen Placement Case - Material Balance for Cases with different Porosity's

\begin{tabular}{|c|c|c|c|}
\hline Porosity & $\begin{array}{c}\text { Nitrogen in } \\
\text { Reservoir before } \\
\text { Start of Withdrawal } \\
\text { Cycle }\end{array}$ & $\begin{array}{c}\text { Nitrogen in } \\
\text { Reservoir after } \\
\text { Withdrawal } \\
\text { Cycle }\end{array}$ & $\begin{array}{c}\text { Nitrogen in } \\
\text { Withdrawn } \\
\text { Gas }\end{array}$ \\
\hline$\%$ & g-mol & g-mol & g-mol \\
\hline 10 & $7.83 \times 10^{7}$ & $1.71 \times 10^{7}$ & $1.04 \times 10^{7}$ \\
\hline 15 & $4.13 \times 10^{7}$ & $2.53 \times 10^{7}$ & $1.60 \times 10^{7}$ \\
\hline 20 & $5.51 \times 10^{7}$ & $3.37 \times 10^{7}$ & $2.14 \times 10^{7}$ \\
\hline 25 & $6.89 \times 10^{7}$ & $4.21 \times 10^{7}$ & $2.68 \times 10^{7}$ \\
\hline
\end{tabular}

Table 20 gives an indication of the amount of Nitrogen that has been produced along with the natural gas during the withdrawal cycle. The effect of porosity on mixing between Nitrogen and Natural Gas is illustrated graphically in Figure 12. There doesn't seem to be much of variation between the different cases simulated throughout the 
withdrawal cycle. During the first 5 days of production the percentage quickly rises to 5.55\%. After that, Nitrogen production in the withdrawn gas increases with respect to time but at a much slower rate.

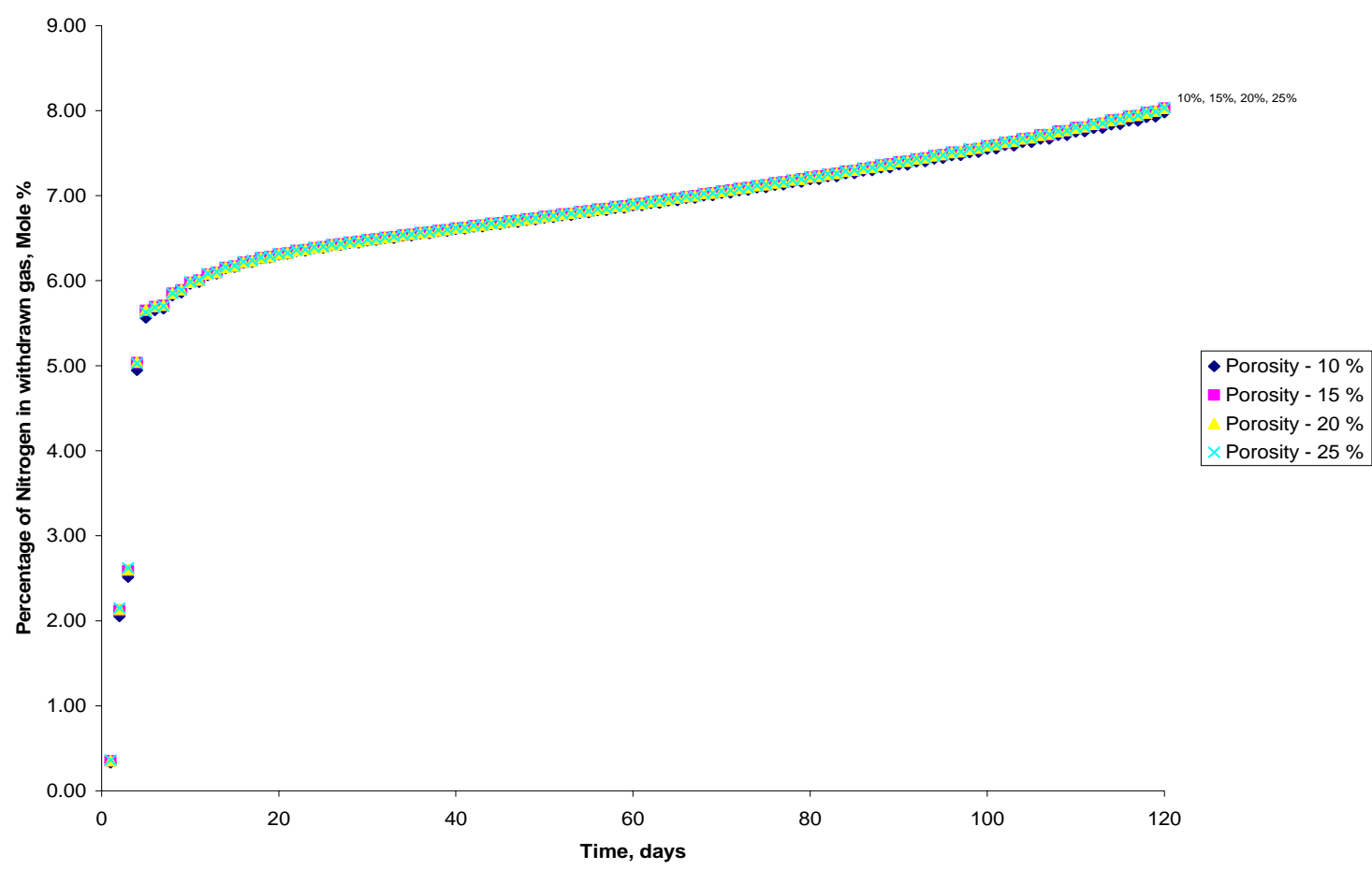

Figure 12 - Bottom Nitrogen Placement Case -Vertical Placement Case of Nitrogen - Effect of Porosity on Mixing

After around 20 days of production, when about $1.6 \%$ of the total working gas is withdrawn, Nitrogen production is linear with time until the end of the withdrawal cycle and reaches a value of $8 \%$ for all the cases.

\subsubsection{Constant Flowing Pressure Case}

Figure 13 through 16 gives the results of the simulation runs that were made with different constant flowing pressures during withdrawal with a combination of different permeability values. At a permeability of $100 \mathrm{md}$ and a withdrawal pressure of 300 psia, maximum of $8 \%$ mixing is reached but with $92 \%$ of the total working gas being withdrawn at the end of 120 day cycle. During the same period the case with 100 psia produces $107 \%$ of the working gas with a Nitrogen 
concentration of nearly $11 \%$. As the withdrawal pressure is increased, the total working gas produced in a given time period decreases.

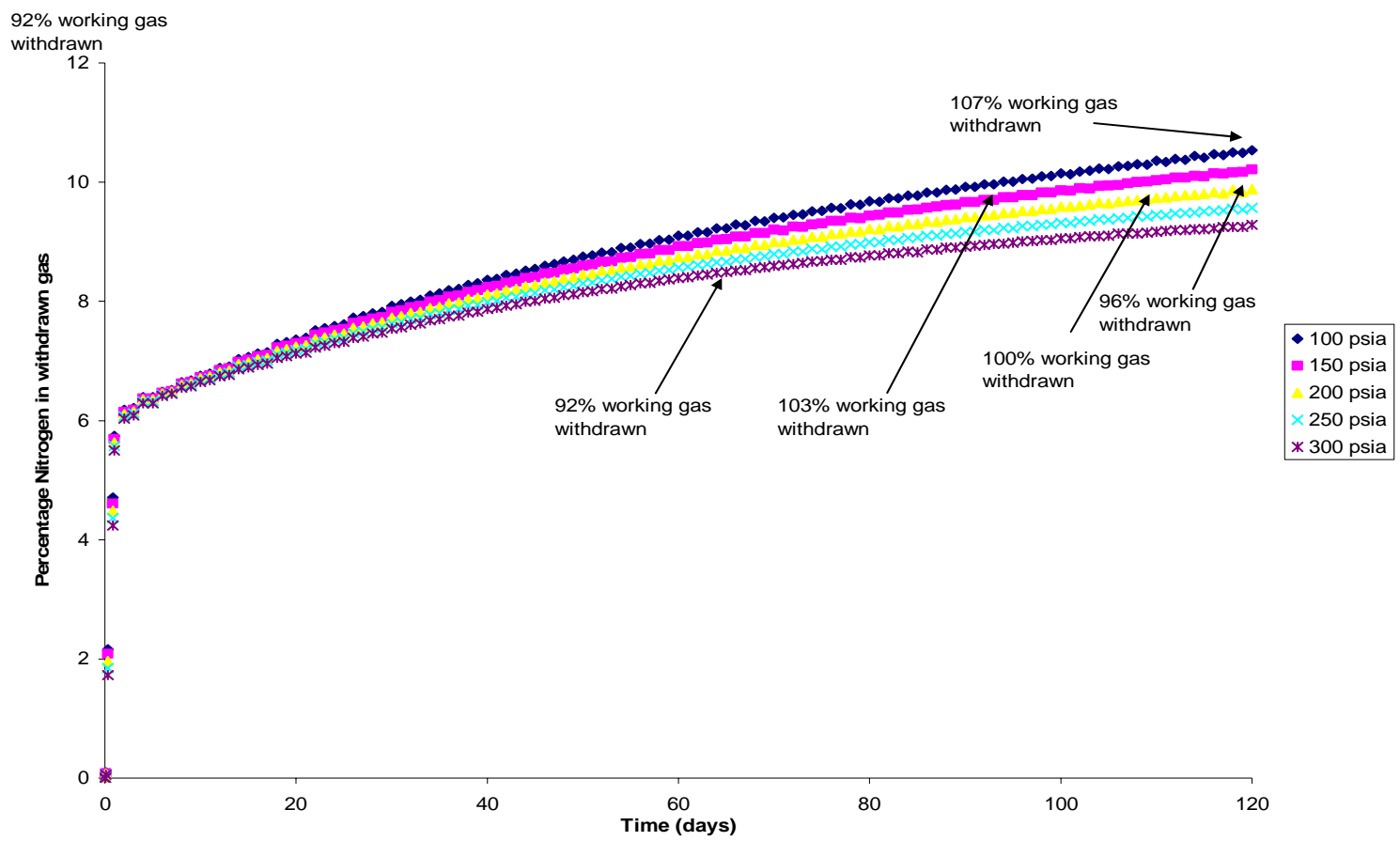

Figure 13 - Bottom Nitrogen Placement Case - Vertical Placement Case of Nitrogen - Constant Pressure withdrawal with 100 md Permeability

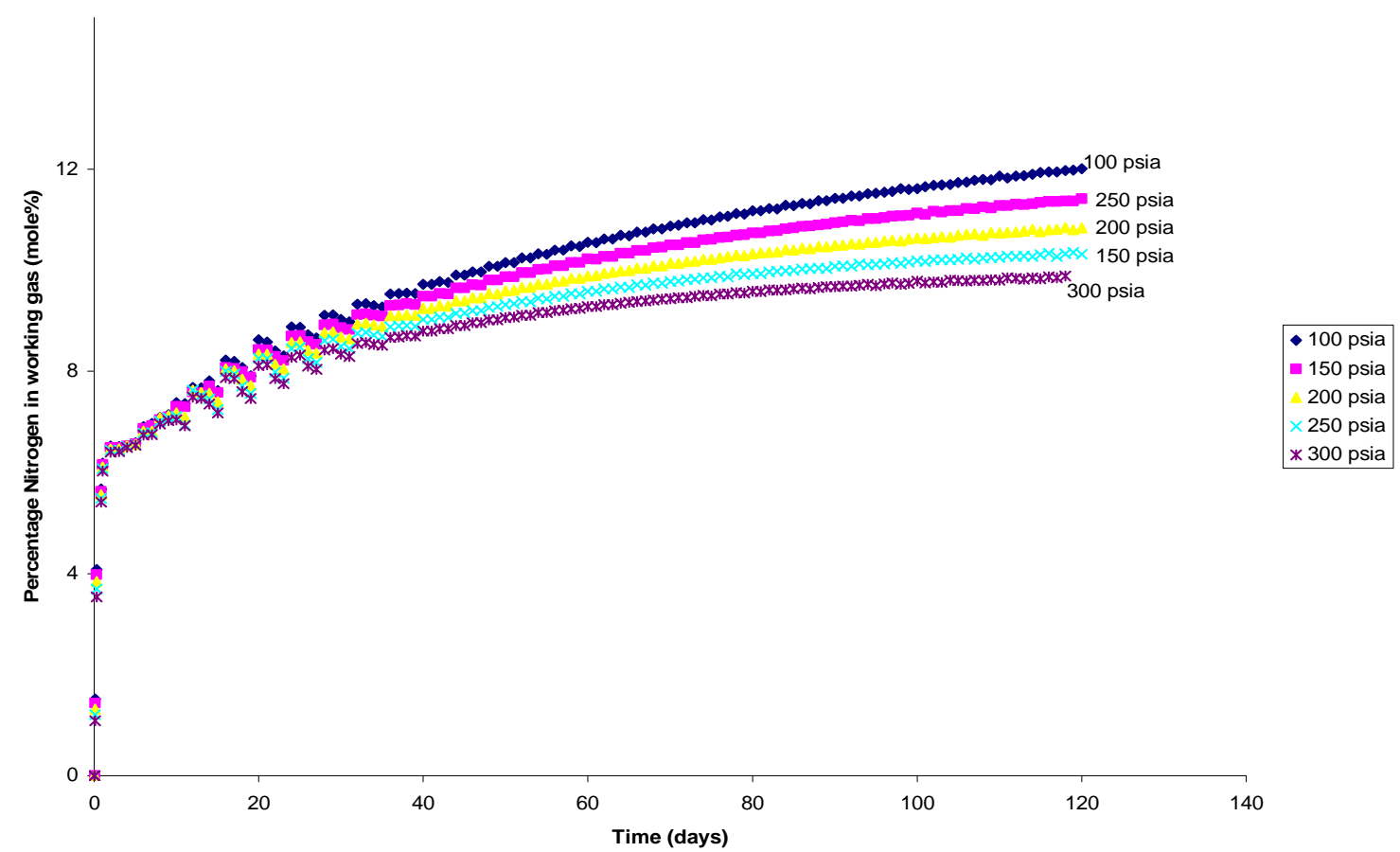

Figure 14- Bottom Nitrogen Placement Case -Vertical Placement Case of Nitrogen - Mixing with constant Pressure Withdrawal with 200 md Permeability 


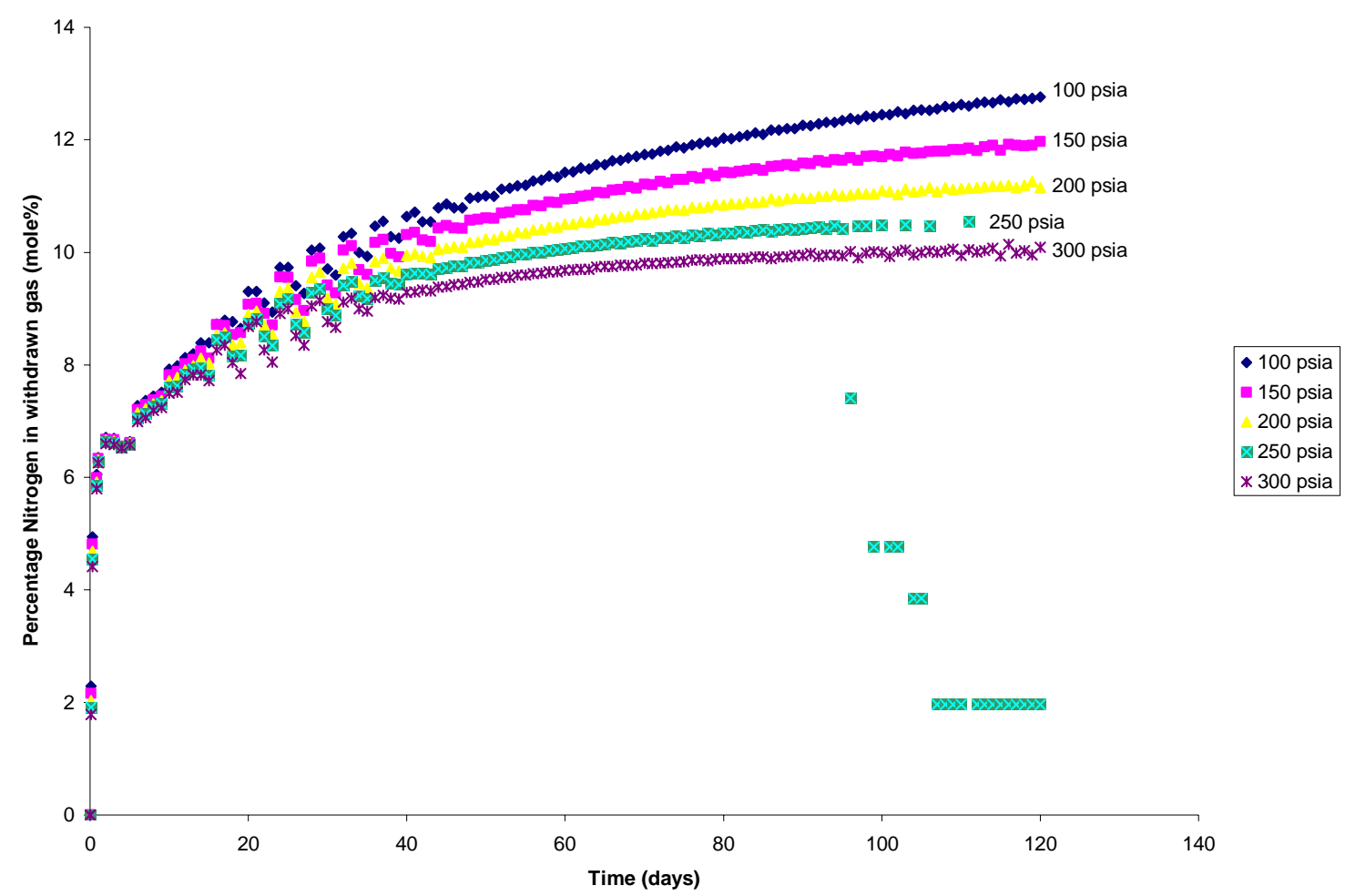

Figure 15 - Bottom Nitrogen Placement Case - Vertical Placement Case of Nitrogen - Mixing with Constant Pressure Withdrawal with 300 md Permeability

It can be noted from the above plots that faster the gas is withdrawn from the reservoir; there is more mixing taking place. In all of these cases, the percentage of Nitrogen reaches a maximum of around $13 \%$ when $121 \%$ of the working gas is produced for the case with $300 \mathrm{md}$ and $100 \mathrm{psi}$ flowing pressure.

\subsubsection{Degree of Mixing in Two Consecutive Cycles}

Figure 16 and Figure 17 illustrates that there is a slight deviation in the degree of mixing between Nitrogen and Natural Gas during the initial stages of two consecutive withdrawal cycles. In the first withdrawal cycle there is slightly higher mixing taking place on comparison with the second production cycle during the first 10 days of production. During this time, $7.87 \%$ of the total working gas is withdrawn from the reservoir at a constant rate of $2 \mathrm{mmcfd}$. 


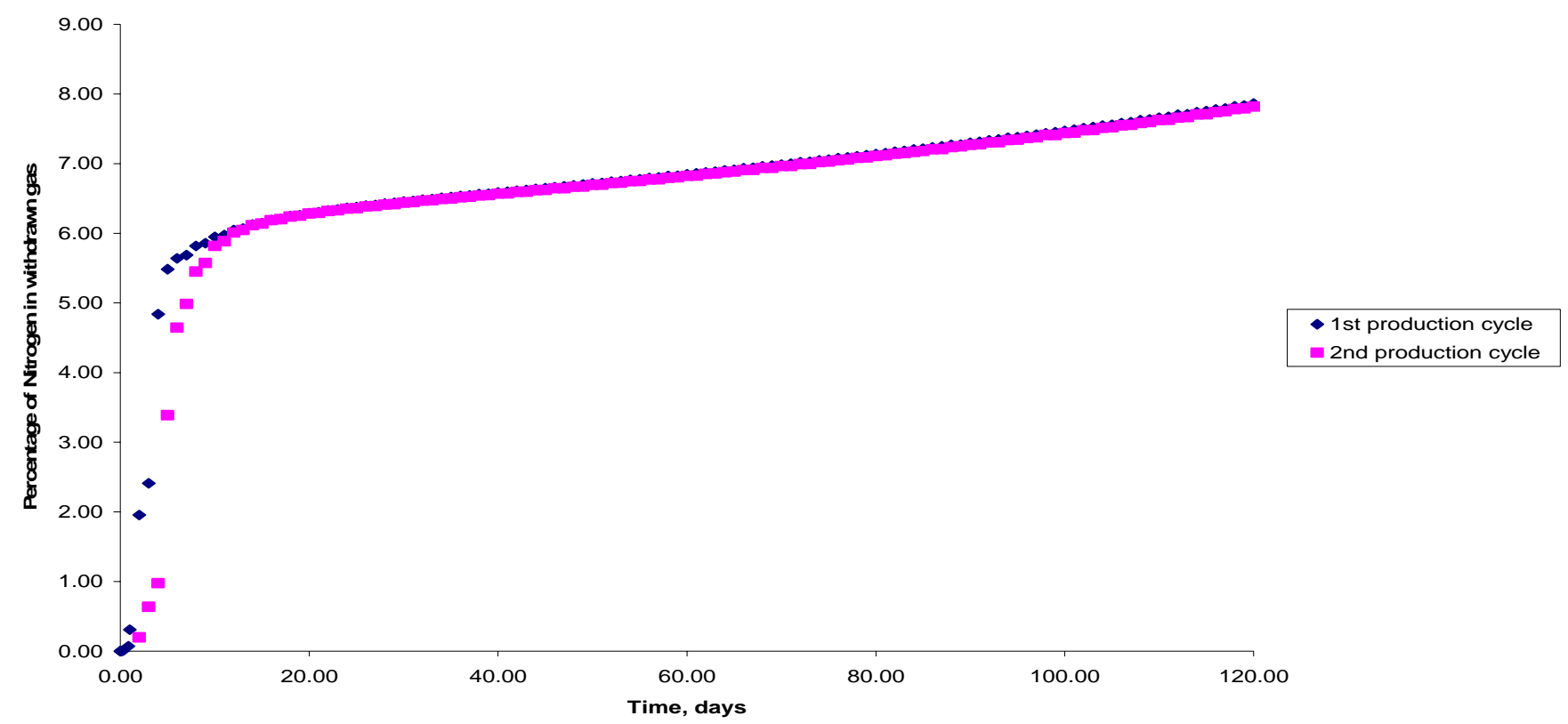

Figure 16 - Bottom Placement Case of Nitrogen Comparison of Degree of Mixing in Two Consecutive Withdrawal Cycles

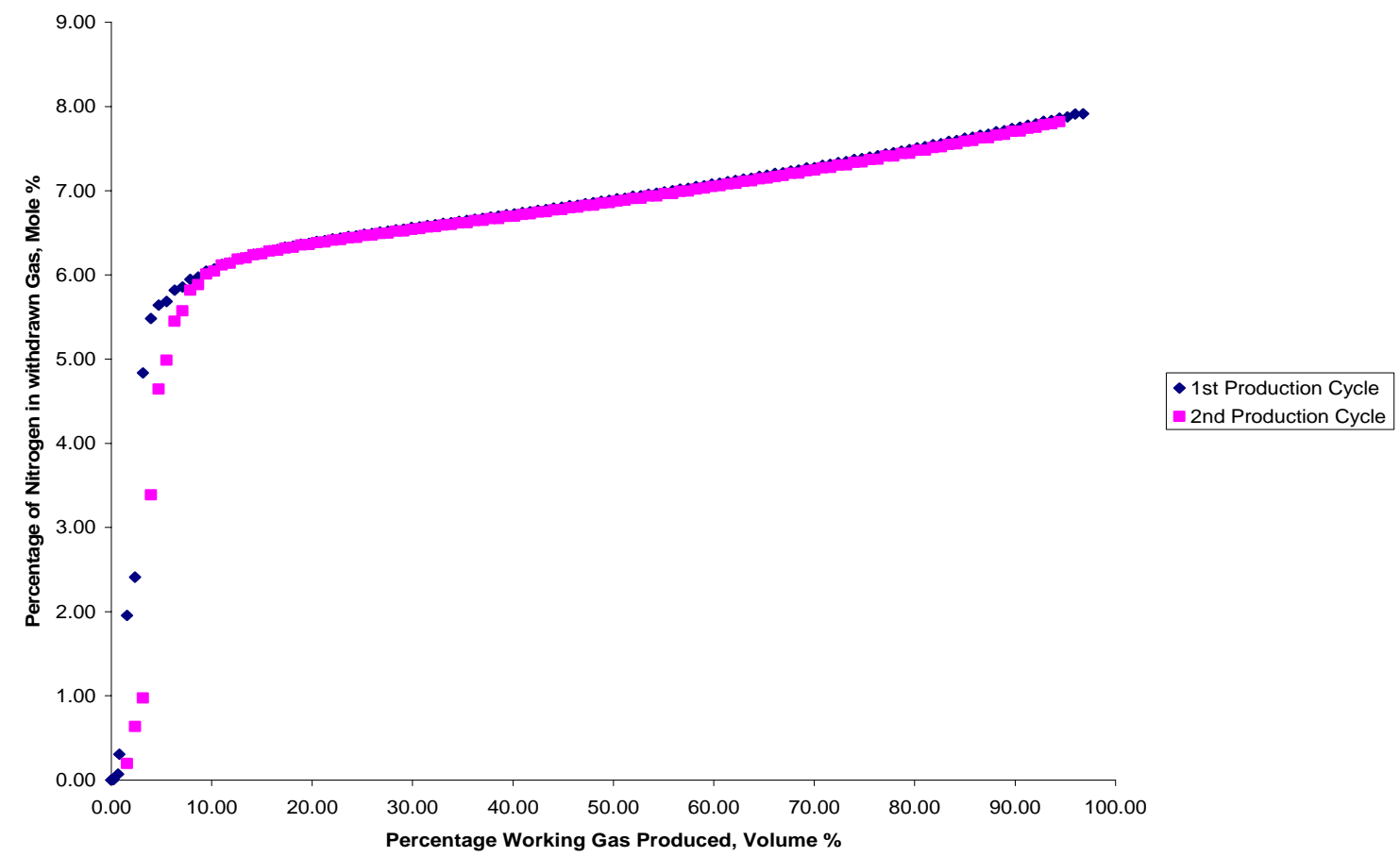

Figure 17 - Bottom Nitrogen Placement Case -Vertical Placement Case of Nitrogen - Degree of Mixing in two consecutive withdrawal Cycles

Percentage Working Gas Produced vs. Percentage of Nitrogen in withdrawn Gas 
There is a steady increase in the amount of Nitrogen produced in both of these cycles after this period and the curves for both the withdrawal cycles are close to each other. At the end of 120 days of withdrawal, the amount of Nitrogen production is $7.92 \%$ and $7.82 \%$ for the two consecutive cycles respectively.

\subsection{Peripheral Nitrogen Placement Case}

\subsubsection{Variation in Percentage of Nitrogen as Base Gas in the Reservoir}

Table 21 gives the Nitrogen material balance during the course of the withdrawal cycle.

Table 21- Peripheral Nitrogen Placement Case -Material Balance for Cases with different Percentages of Cushion Gas by Volume

\begin{tabular}{|c|c|c|c|}
\hline $\begin{array}{c}\text { Nitrogen } \\
\text { Cushion }\end{array}$ & $\begin{array}{c}\text { Nitrogen in } \\
\text { Reservoir before } \\
\text { Start of Withdrawal } \\
\text { Cycle }\end{array}$ & $\begin{array}{c}\text { Nitrogen in } \\
\text { Reservoir after } \\
\text { Withdrawal } \\
\text { Cycle }\end{array}$ & $\begin{array}{c}\text { Nitrogen in } \\
\text { Withdrawn Gas }\end{array}$ \\
\hline$\%$ & g-mol & g-mol & g-mol \\
\hline 5 & $2.26 \times 10^{7}$ & $2.26 \times 10^{7}$ & 3.31 \\
\hline 10 & $4.46 \times 10^{7}$ & $4.46 \times 10^{7}$ & 6243 \\
\hline 15 & $8.15 \times 10^{7}$ & $6.48 \times 10^{7}$ & $2.90 \times 10^{4}$ \\
\hline 20 & $8.92 \times 10^{7}$ & $8.86 \times 10^{7}$ & $5.01 \times 10^{5}$ \\
\hline
\end{tabular}

As expected, the simulation results indicate that the amount of mixing is directly proportional to the percentage of Nitrogen in the reservoir. Nitrogen production is least for the case with 10\% cushion gas as Nitrogen. In this Case there is negligible amount of Nitrogen produced up to a period of about 100 days. From Figure 18, a maximum of $0.12 \%$ Nitrogen is produced when $30 \%$ of Nitrogen cushion is present in the reservoir. For the case with $20 \%$ cushion, Nitrogen concentration reaches a value of $0.04 \%$.. 


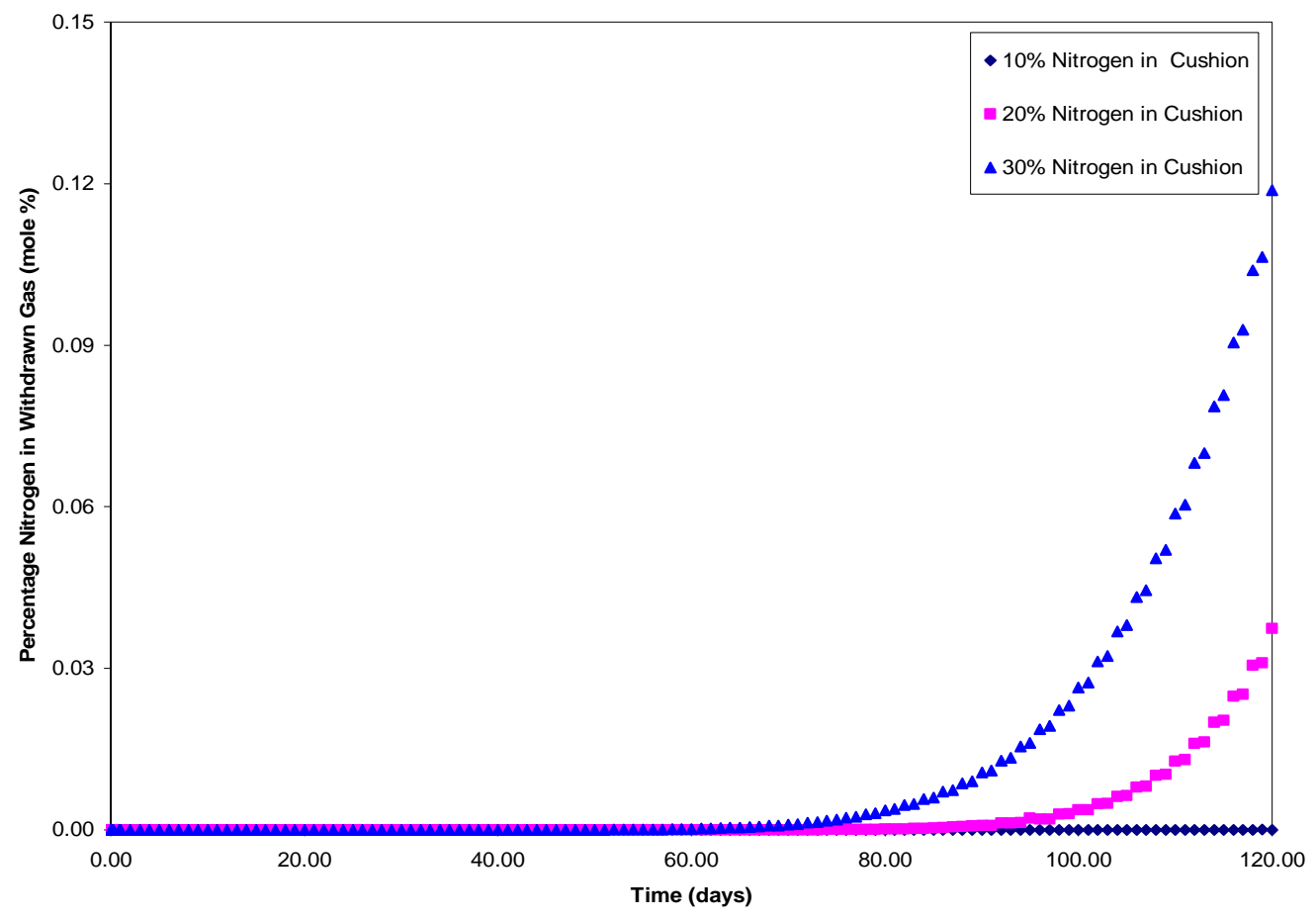

Figure 18- Peripheral Nitrogen Placement Case - Percentage of Nitrogen in withdrawn gas with different percentages of cushion gas by volume

This indicates that, as the percentage of Nitrogen cushion goes up there is an increased mixing taking place.

\subsubsection{Effect of Pressure on Mixing between Nitrogen and Methane}

At different reservoir pressures, moles of Nitrogen produced during the withdrawal cycle and the moles of Nitrogen remaining in the reservoir is given by Table 22.

Table 22- Peripheral Nitrogen Placement Case - Material Balance for Cases with Different Pressures

\begin{tabular}{|c|c|c|c|}
\hline Pressure & $\begin{array}{c}\text { Nitrogen in } \\
\text { Reservoir before } \\
\text { Start of } \\
\text { Withdrawal Cycle }\end{array}$ & $\begin{array}{c}\text { Nitrogen in } \\
\text { Reservoir after } \\
\text { Withdrawal } \\
\text { Cycle }\end{array}$ & $\begin{array}{c}\text { Nitrogen in } \\
\text { Withdrawn Gas }\end{array}$ \\
\hline Psia & g-mol & g-mol & g-mol \\
\hline 1000 & $4.05 \times 10^{7}$ & $4.05 \times 10^{7}$ & 21459 \\
\hline 1500 & $6.05 \times 10^{7}$ & $6.05 \times 10^{7}$ & 30143 \\
\hline 2000 & $7.98 \times 10^{7}$ & $7.98 \times 10^{7}$ & 39912 \\
\hline 2500 & $9.83 \times 10^{7}$ & $9.83 \times 10^{7}$ & 51111 \\
\hline 3000 & $1.15 \times 10^{8}$ & $1.15 \times 10^{8}$ & 63323 \\
\hline
\end{tabular}




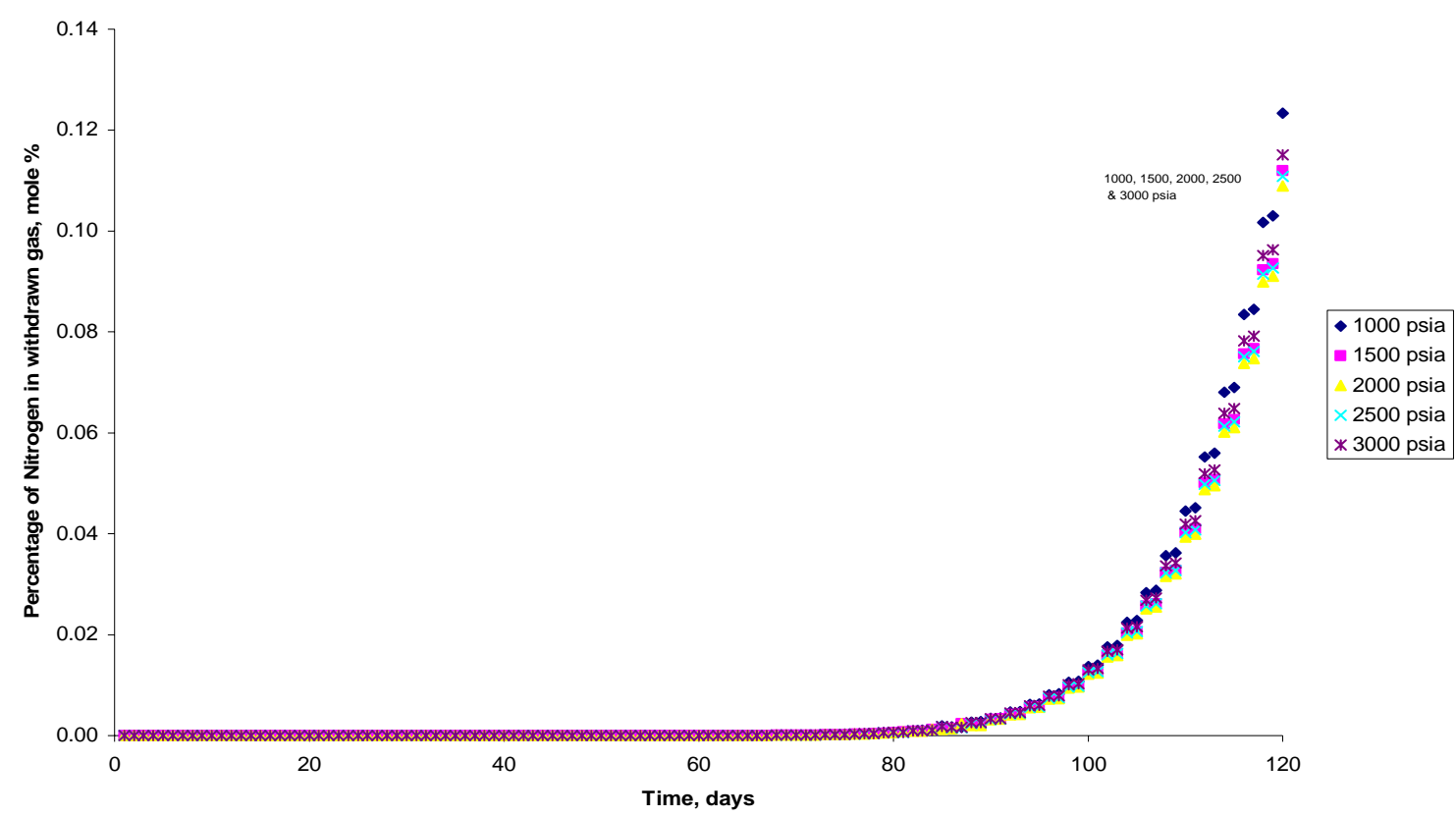

Figure 19- Peripheral Nitrogen Placement Case - Effect of Pressure on Mixing

In Figure 19, Nitrogen production along with the withdrawn gas for all of these cases is negligible until a period of about 82 days of the withdrawal cycle. After that the percentage of Nitrogen slowly starts increasing until the end of the withdrawal. Nitrogen content in the withdrawn gas tends to increase exponentially and reaches a maximum of $0.13 \%$ at all the reservoir pressures. The plot above illustrates that reservoir pressure really does not affect the mixing pattern between the two dissimilar gases.

\subsubsection{Effect of Temperature on Mixing between Nitrogen and Methane}

Table 23 and Figure 20, shows that there is almost no production of Nitrogen along with the withdrawn gas up to a period of about 80 days of withdrawal. Between the period of 80 and 100 days of production, Nitrogen concentration in the withdrawn gas increases linearly. 
Table 23 - Peripheral Nitrogen Placement Case - Material Balance for Cases at different Temperatures

\begin{tabular}{|c|c|c|c|}
\hline Temperature & $\begin{array}{c}\text { Nitrogen in Reservoir } \\
\text { before Start of } \\
\text { Withdrawal Cycle }\end{array}$ & $\begin{array}{c}\text { Nitrogen in } \\
\text { Reservoir after } \\
\text { Withdrawal } \\
\text { Cycle }\end{array}$ & $\begin{array}{c}\text { Nitrogen in } \\
\text { Withdrawn Gas }\end{array}$ \\
\hline${ }^{\mathbf{0}} \mathbf{F}$ & g-mol & g-mol & g-mol \\
\hline 90 & $4.25 \times 10^{7}$ & $4.25 \times 10^{7}$ & 22802 \\
\hline 100 & $4.16 \times 10^{7}$ & $4.16 \times 10^{7}$ & 22089 \\
\hline 125 & $3.96 \times 10^{7}$ & $3.96 \times 10^{7}$ & 21451 \\
\hline 150 & $3.78 \times 10^{7}$ & $3.78 \times 10^{7}$ & 20970 \\
\hline
\end{tabular}

The curve then tends to rise rapidly after this point and maximum of $0.13 \%$ of Nitrogen is produced in all cases. This can be accounted for the movement of Nitrogen closer to the well bore during the course of the withdrawal cycle. It can also be seen that all the curves match with each other from which it can be concluded that there is no effect of temperature on mixing.

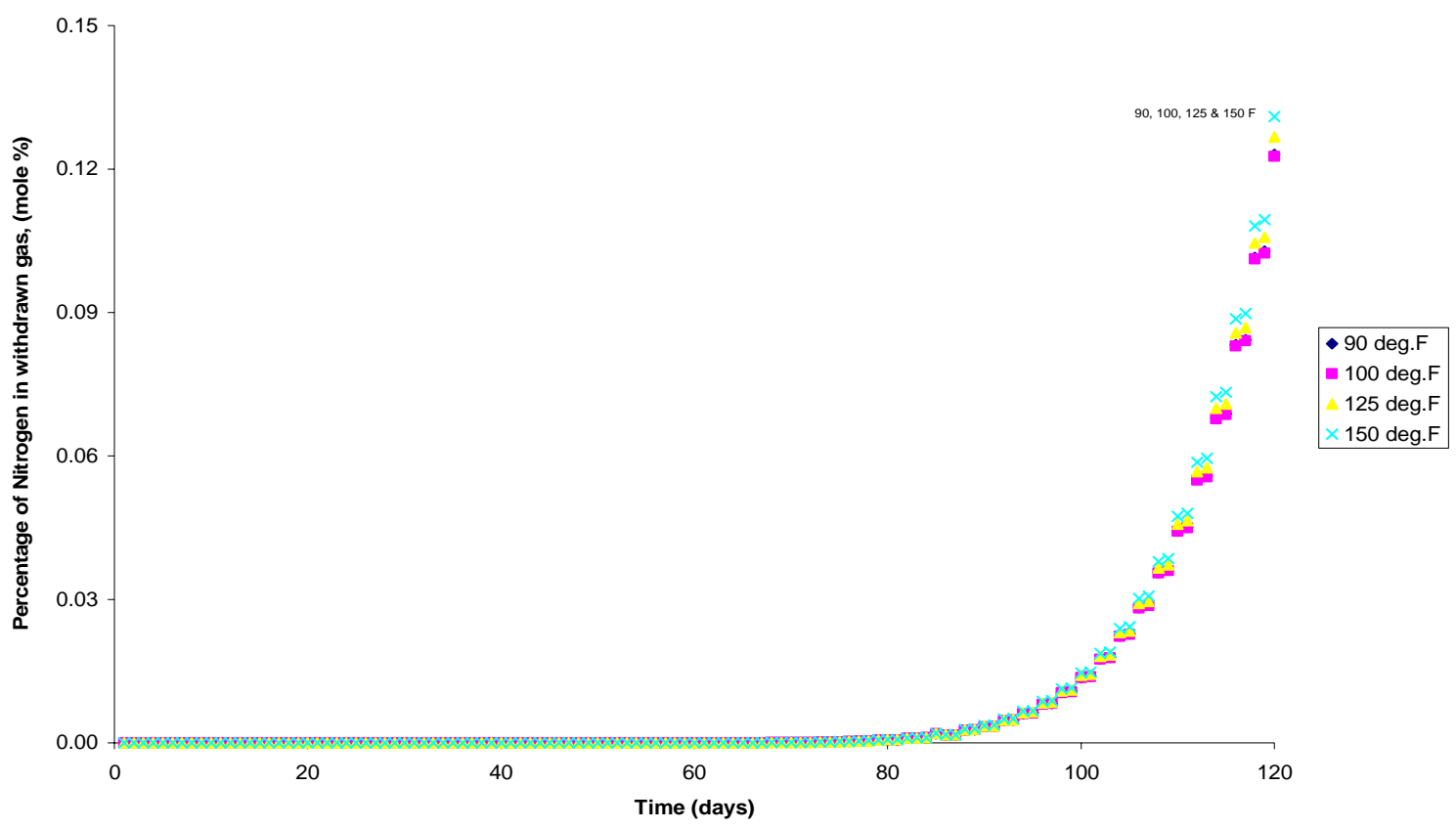

Figure 20- Peripheral Nitrogen Placement Case - Effect of Temperature on Mixing 


\subsubsection{Effect of Permeability on Mixing between Nitrogen and Methane}

Table 24 gives the material balance for Nitrogen before and after the withdrawal cycle which lasts for a period of 120 days.

Table 24- Peripheral Placement Case of Nitrogen - Material Balance for Cases with Different

Permeability's

\begin{tabular}{|c|c|c|c|}
\hline Permeability & $\begin{array}{c}\text { Nitrogen in } \\
\text { Reservoir before } \\
\text { Start of Withdrawal } \\
\text { Cycle }\end{array}$ & $\begin{array}{c}\text { Nitrogen in } \\
\text { Reservoir after } \\
\text { Withdrawal Cycle }\end{array}$ & $\begin{array}{c}\text { Nitrogen in } \\
\text { Withdrawn Gas }\end{array}$ \\
\hline md & g-mol & g-mol & g-mol \\
\hline 10 & $4.05 \times 10^{7}$ & $4.05 \times 10^{7}$ & 11868 \\
\hline 20 & $4.05 \times 10^{7}$ & $4.05 \times 10^{7}$ & 21297 \\
\hline 50 & $4.05 \times 10^{7}$ & $4.05 \times 10^{7}$ & 21681 \\
\hline 100 & $4.05 \times 10^{7}$ & $4.05 \times 10^{7}$ & 21792 \\
\hline 200 & $4.05 \times 10^{7}$ & $4.05 \times 10^{7}$ & 21873 \\
\hline 300 & $4.05 \times 10^{7}$ & $4.05 \times 10^{7}$ & 21893 \\
\hline 500 & $4.05 \times 10^{7}$ & $4.05 \times 10^{7}$ & 21916 \\
\hline 1000 & $4.05 \times 10^{7}$ & $4.05 \times 10^{7}$ & 21876 \\
\hline
\end{tabular}

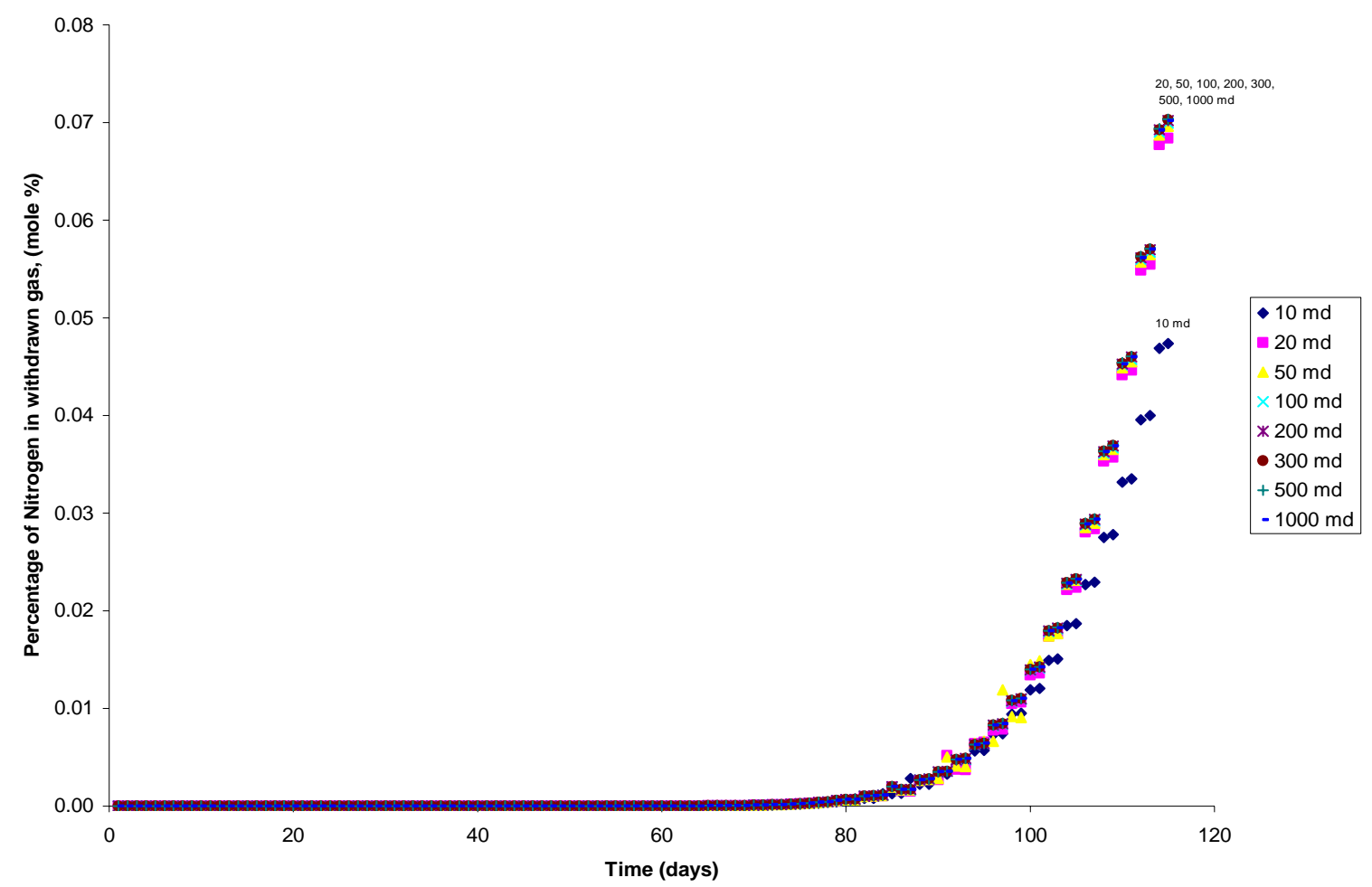

Figure 21- Peripheral Nitrogen Placement Case - Effect of Permeability on Mixing 
From Figure 21, it is notable that irrespective of the permeability of the reservoir, mixing follows a definite pattern. As in all the other cases we had seen before, Nitrogen production is not significant until around 80 days of withdrawal. In all the cases Nitrogen concentrations reach a peak value of $0.07 \%$ at the end with the exception of the case with $10 \mathrm{md}$. Nitrogen production with permeability of $10 \mathrm{md}$ is less than that of the other cases simulated.

\subsubsection{Effect of Porosity on Mixing between Nitrogen and Methane}

Table 25 shows the material balance for Nitrogen before and after the withdrawal cycle. This table gives an idea of how much Nitrogen is withdrawn and how much has to be injected for the injection cycle.

Table 25 - Peripheral Nitrogen Placement Case - Material Balance for Cases with different Porosity's

\begin{tabular}{|c|c|c|c|}
\hline Porosity & $\begin{array}{c}\text { Nitrogen in } \\
\text { Reservoir before } \\
\text { Start of Withdrawal } \\
\text { Cycle }\end{array}$ & $\begin{array}{c}\text { Nitrogen in } \\
\text { Reservoir after } \\
\text { Withdrawal } \\
\text { Cycle }\end{array}$ & $\begin{array}{c}\text { Nitrogen in } \\
\text { Withdrawn Gas }\end{array}$ \\
\hline$\%$ & g-mol & g-mol & g-mol \\
\hline 10 & $7.82 \times 10^{7}$ & $7.44 \times 10^{7}$ & $3.77 \times 10^{6}$ \\
\hline 15 & $2.06 \times 10^{8}$ & $2.00 \times 10^{8}$ & $5.64 \times 10^{6}$ \\
\hline 20 & $2.79 \times 10^{8}$ & $2.71 \times 10^{8}$ & $7.52 \times 10^{6}$ \\
\hline 25 & $3.18 \times 10^{8}$ & $3.09 \times 10^{8}$ & $9.39 \times 10^{6}$ \\
\hline
\end{tabular}

In Figure 22, cases with porosity values of $10 \%, 15 \%$ and $20 \%$ follow the same pattern and produce a maximum of about $0.07 \%$ Nitrogen. The case with porosity of $25 \%$ starts to deviate from the other curves and produces about $0.12 \%$ Nitrogen. 


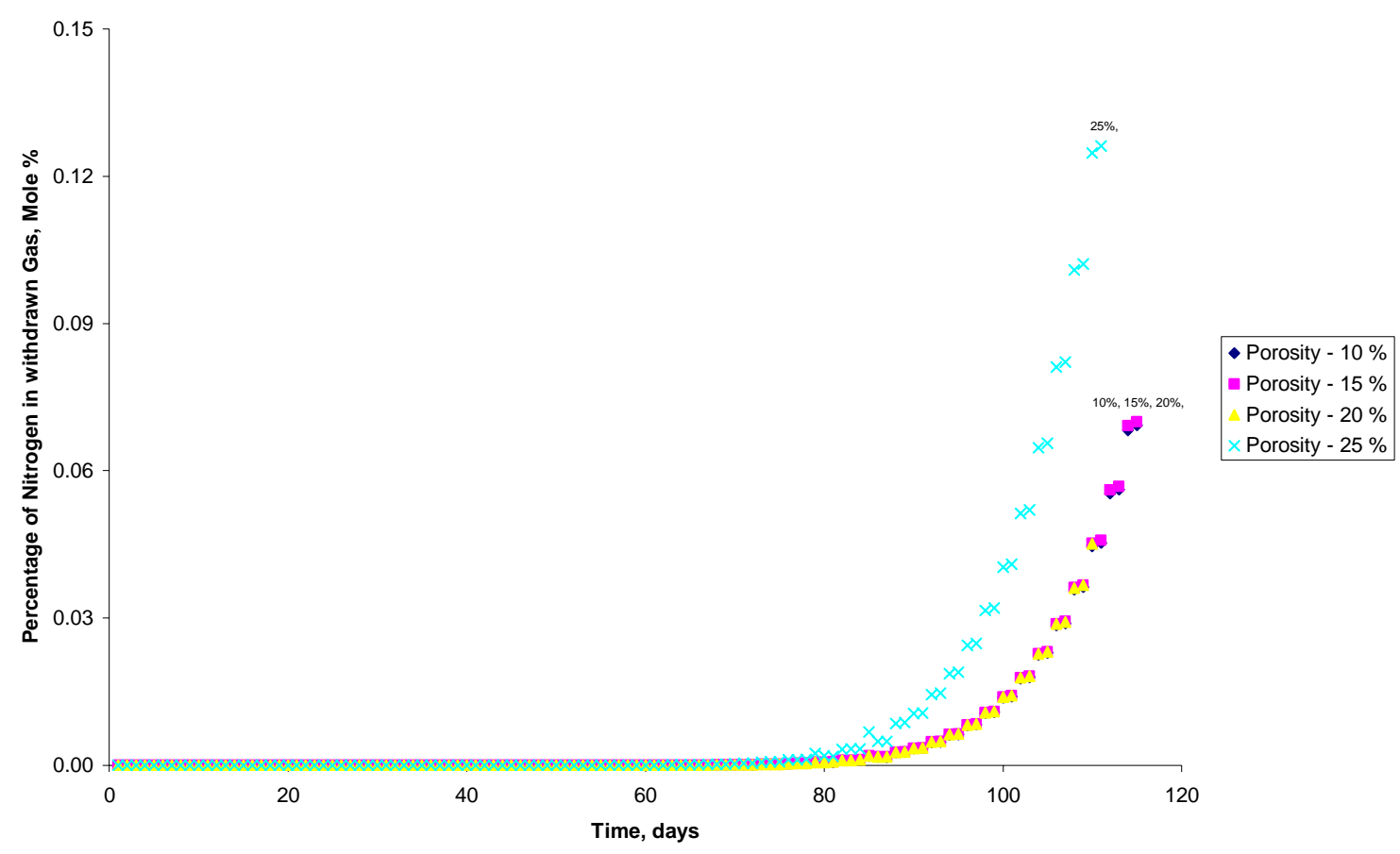

Figure 22 - Peripheral Nitrogen Placement Case - Effect of Porosity on Mixing

Considering the fact the difference in mixing at various reservoir temperatures is negligible, it can be concluded that temperature does not play a significant part on the mixing phenomena.

\subsubsection{Effect on Mixing with Constant Pressure Withdrawal}

Figure 23 through 25 gives the results of the simulation runs that were made with different constant flowing pressures during withdrawal with a combination of different permeability values. At a permeability of $100 \mathrm{md}$ and a withdrawal pressure of $300 \mathrm{psia}$, maximum of $5 \%$ mixing is reached but with $105 \%$ of the total working gas being withdrawn at the end of 120 day cycle. During the same period the case with 100 psia produces $129 \%$ of the working gas with a Nitrogen concentration of nearly $27 \%$. As the withdrawal pressure is increased, the total working gas produced in a given time period decreases. 


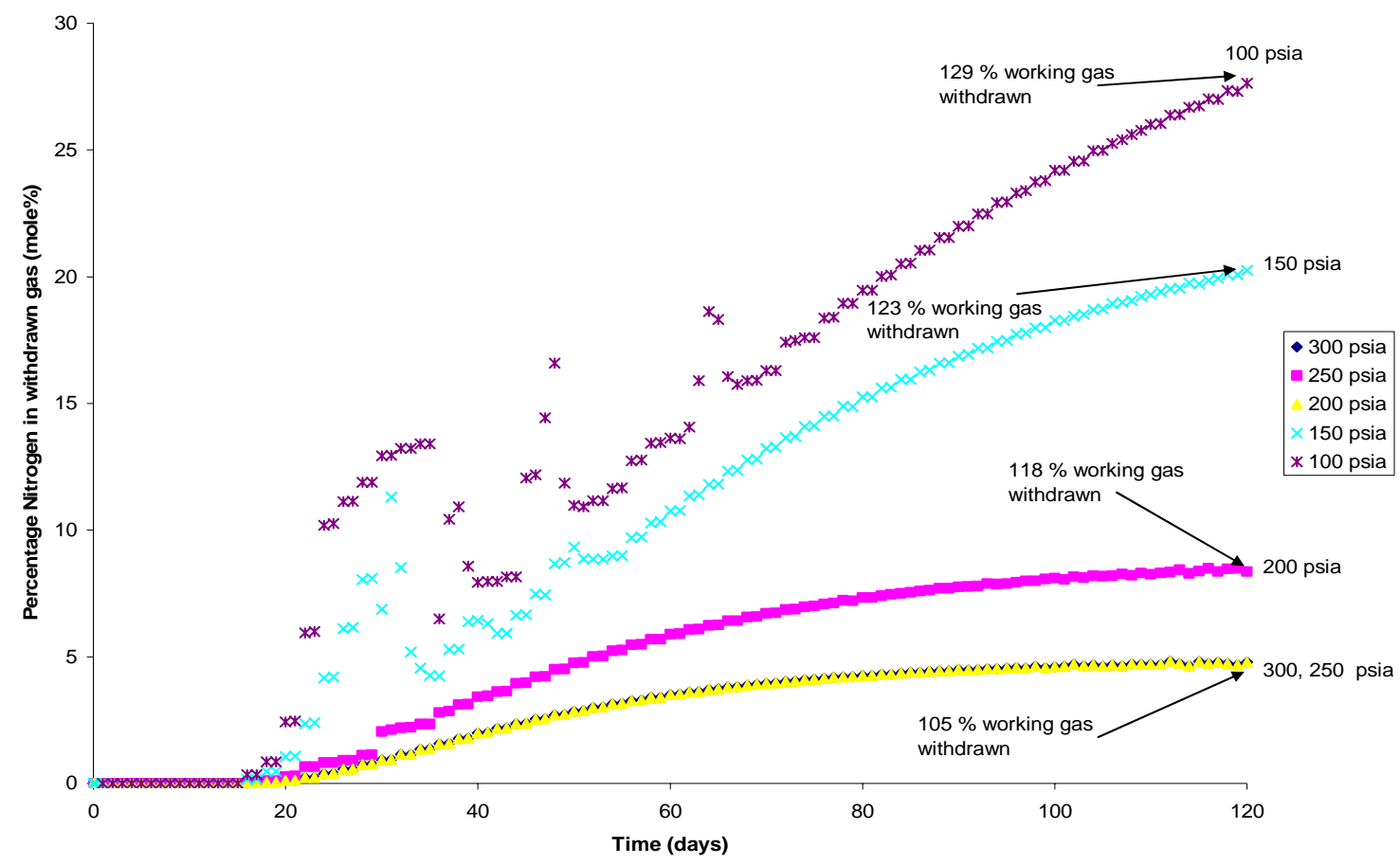

Figure 23- Bottom Nitrogen Placement Case -Vertical Placement Case of Nitrogen - Constant Pressure withdrawal with 100 md Permeability

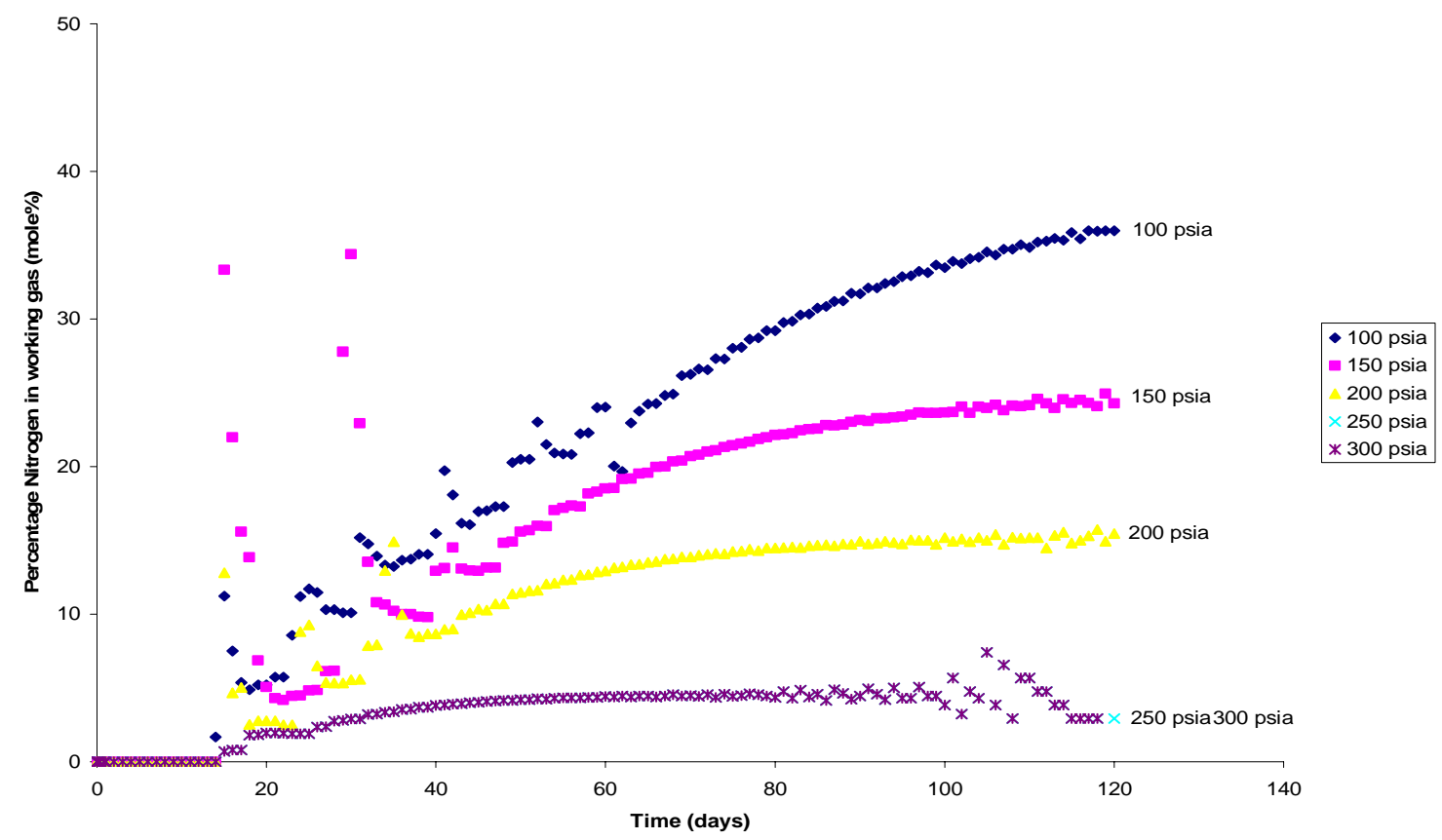

Figure 24- Bottom Nitrogen Placement Case -Vertical Placement Case of Nitrogen - Mixing with constant Pressure Withdrawal with 200 md Permeability 


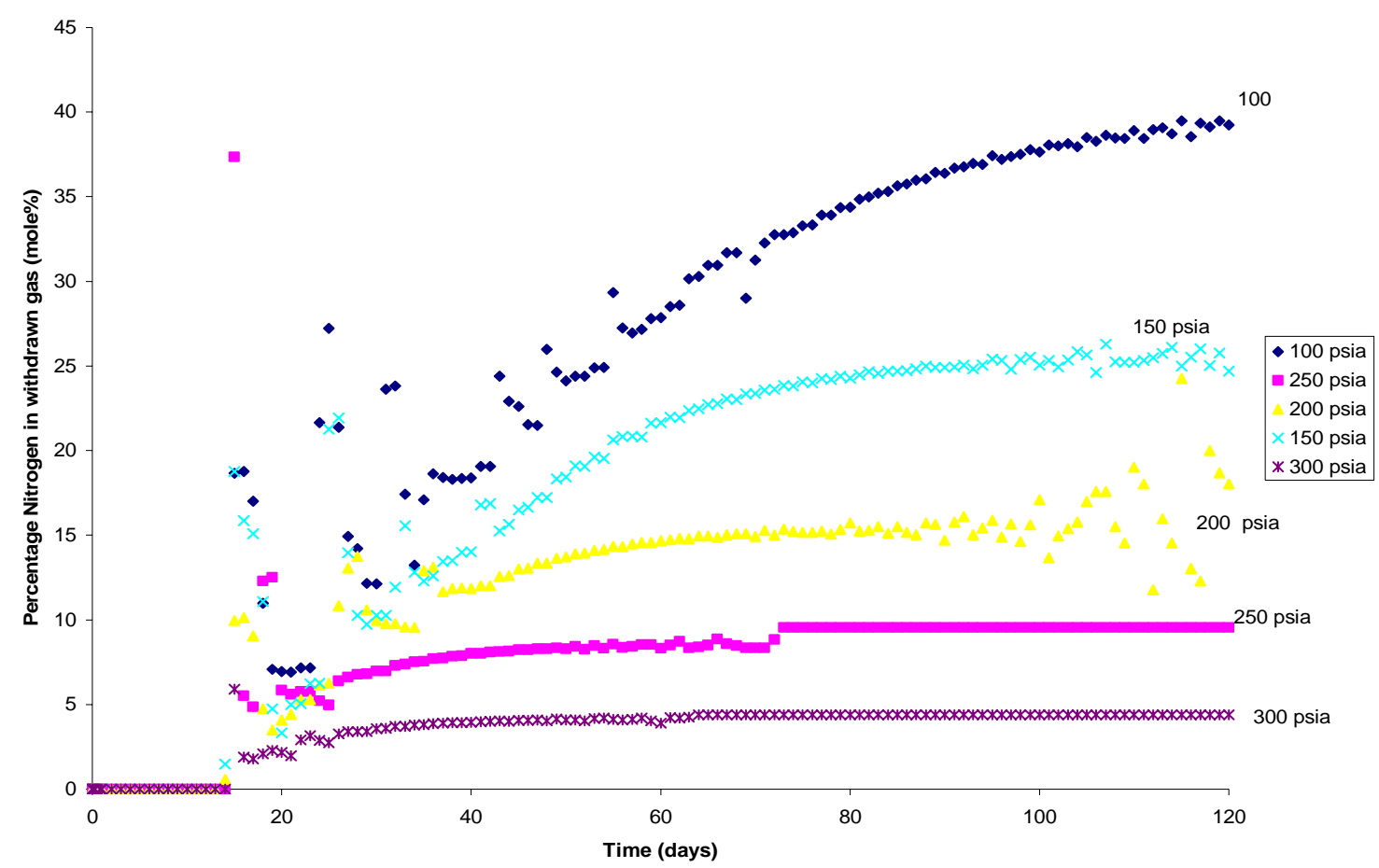

Figure 25- Bottom Nitrogen Placement Case -Vertical Placement Case of Nitrogen - Mixing with Constant Pressure Withdrawal with 300 md Permeability

It can be noted from the above plots that faster the gas is withdrawn from the reservoir; there is more mixing taking place. In all of these cases, the percentage of Nitrogen reaches a maximum of around $40 \%$ when $132 \%$ of the working gas is produced for the case with $300 \mathrm{md}$ and 100 psi flowing pressure. 


\section{CONCLUSIONS}

Analyzing the Results that were obtained from various simulation runs that were made for both the base case models, the following conclusions can be made.

1. Reservoir parameters temperature, permeability and porosity does not play a major part on the degree of mixing that takes place between Nitrogen and Natural Gas in storage reservoirs.

2. Though the effect of reservoir pressure has a slight impact on mixing between nitrogen and Natural Gas, it is not that significant considering the long term effects of mixing.

3. On comparison of the two models used, the one with Nitrogen placement along the periphery of the reservoir was found to have lesser degree of mixing throughout the withdrawal cycle.

4. The amount of mixing between the two dissimilar gases in a given period of time increases with increase in percentage of Nitrogen cushion in the reservoir.

5. It is evident from constant pressure withdrawal runs that mixing is a function of withdrawal rate. i.e. The faster the gas is produced, more is the degree of mixing.

6. The optimum amount of Nitrogen cushion that can be used in storage reservoirs is about $20 \%$ of the cushion gas above which mixing tends to increase and affects the quality of the Natural gas. 


\section{REFERENCES}

1) “Underground Storage of Natural Gas: Theory and Practice”; Tek, Rasin M.., Gulf Publishing Co., C1987

2) “Overview on Underground Storage of Natural Gas”; Katz, Donald L., Tek, Rasin M; U.of Michigan., Journal of Petroleum Technology, June1981, PP 943-951

3) "Storage of Natural Gas in Salt Caverns"; Medley, Alfred H; Fenix and Scisson Inc., SPE 5427, Regional Gas Industry Symposium of the Northern Plains Section of SPE, 1975

4) “Economics of Underground Gas Storage”; Schwalm, Harold E; Northern Illinois Gas Co., SPE 3288, Midwest Oil and Gas Industry Symposium, Chicago 1971

5) “The Use of Inert Base Gas in Underground Natural Gas Storage”; Misra, B.R., Foh, S.E., Inst. Of Gas Technology; Shikari, Y.A., Gas Research Inst; Berry, R.M., Texas Gas Transmission Corporation; Labaune, F., Sofregaz., SPE 17741, SPE Gas Technology Symposium, Dallas, TX 1988

6) “Long Term Study of Cushion Gas Replacement by Inert Gas”; De Moegen H., Giouse, H., Gaz De France., SPE 19754 MS, SPE Annual Technical Conference and Exhibition, San Antonio, TX 1989

7) “Mixing in Underground Storage Reservoirs”; Carriere, J.F., Fasanino, G., Gaz de France; Tek, M.R., U.of Michigan., SPE 14202, SPE Annual Technical Conference and Exhibition, Las Vegas, NV 1985

8) “Experiments on Mixing during Miscible Displacement in Porous Media"; Brigham, W.E., P.W. Reed, and J.N.Dew., SPE Journal, Vol.1, No.1, March 1961, PP. 1-8 
9) "Inert Gas Injection as Part of the Cushion of the Underground Storage of SaintClair-Sur-Epte, France”; Laille, J.P., Molinard, J.E., Wents, A., Gaz De France., SPE 17740, SPE Gas Technology Symposium, Dallas, TX 1988

10) “Underground Storage in Cerville-Velaine, France: A Case History in Conversion and Inert Gas Injection as Cushion Substitute”; Laille, J.P., Coulomb, C., Gaz De France; Tek, M.R., U.of Michigan., SPE 15588, SPE Annual Technical Conference and Exhibition, New Orleans, LA 1986

11) “Feasibility of Inert Gas Cushions in Gas Storages”; Walker C.J., Ray V.Huff., Report of Investigations, Bureau of Mines, U.S. Department of the Interior and American Gas Association, 1964

12) “Diffusion in Solids, Liquids \& Gases”; Jost, W., Academic Press Inc, Newyork., 1952, PP. 558

13) “Mass Transfer Operations”; Treybal, Robert E., McGraw Hill Education, 1980

14) “Natural Gas Production and Storage”; Katz, Donald E., McGraw Hill Company, 1991, PP. 681-687

15) “Factors Influencing the Efficiency of Miscible Displacement”; Trans AIME 1959; Blackwell, R.J., Rayne J.R., Terry W.M., Trans. AMIE, V. 217, 1959, PP. $1-8$

16) “A Study of Gas-Gas Displacements in Linear Unconsolidated Porous Media”; Penn State University; Harris, M., Bissey, L.T., Pennsylvania State University, Miner. Ind. Exp. Sta. Circ. 61, 1961, PP. 58-87

17) “Mixing in Underground Storage Reservoirs”; Carriere J.F, Fasanino G., Gaz de France, Tek M.R, U. of Michigan, SPE 14202, SPE Annual Technical Conference and Exhibition, Las Vegas, NV 1985

18) “CMG-GEM User’s Guide”; Computer Modeling Group 
19) “CMG-Model Builder 2005.10 User’s Guide”; Computer Modeling Group 


\section{APPENDIX}

\section{Bottom Placement Case of Nitrogen}

\section{Effect of Pressure on Mixing}

\begin{tabular}{|c|c|c|c|c|c|c|c|c|c|c|}
\hline \multicolumn{11}{|c|}{ Bottom Placement of Nitrogen } \\
\hline \multirow{2}{*}{$\begin{array}{l}\text { Time } \\
\text { (days) }\end{array}$} & \multicolumn{2}{|c|}{ Pressure - 1000 psia } & \multicolumn{2}{|c|}{ Pressure - 1500 psia } & \multicolumn{2}{|c|}{ Pressure - 2000 psia } & \multicolumn{2}{|c|}{ Pressure - 2500 psia } & \multicolumn{2}{|c|}{ Pressure - 3000 psia } \\
\hline & $\begin{array}{c}\% N_{2} \text { in } \\
\text { withdrawn } \\
\text { gas }\end{array}$ & $\begin{array}{c}\text { \% W.G } \\
\text { withdrawn } \\
\text { (by } \\
\text { volume) }\end{array}$ & $\begin{array}{c}\% N_{2} \text { in } \\
\text { withdrawn } \\
\text { gas }\end{array}$ & $\begin{array}{c}\text { \% W.G } \\
\text { withdrawn } \\
\text { (by } \\
\text { volume) }\end{array}$ & $\begin{array}{c}\% \mathrm{~N}_{2} \text { in } \\
\text { withdrawn } \\
\text { gas }\end{array}$ & $\begin{array}{c}\% \text { W.G } \\
\text { withdrawn } \\
\text { (by } \\
\text { volume) }\end{array}$ & $\begin{array}{c}\% N_{2} \text { in } \\
\text { withdrawn } \\
\text { gas }\end{array}$ & $\begin{array}{c}\text { \% W.G } \\
\text { withdrawn } \\
\text { (by } \\
\text { volume) }\end{array}$ & $\begin{array}{c}\% \mathrm{~N}_{2} \text { in } \\
\text { withdrawn } \\
\text { gas }\end{array}$ & $\begin{array}{c}\text { \% W.G } \\
\text { withdrawn } \\
\text { (by } \\
\text { volume) }\end{array}$ \\
\hline 1 & 0.35 & 0.84 & 0.36 & 0.84 & 0.36 & 0.84 & 0.38 & 0.84 & 0.40 & 0.84 \\
\hline 2 & 2.12 & 1.67 & 2.15 & 1.67 & 2.20 & 1.67 & 2.31 & 1.67 & 2.42 & 1.67 \\
\hline 3 & 2.58 & 2.51 & 2.62 & 2.51 & 2.69 & 2.51 & 2.82 & 2.51 & 2.96 & 2.51 \\
\hline 4 & 4.97 & 3.34 & 5.06 & 3.34 & 5.19 & 3.34 & 5.41 & 3.34 & 5.64 & 3.34 \\
\hline 5 & 5.56 & 4.18 & 5.66 & 4.18 & 5.81 & 4.18 & 6.06 & 4.18 & 6.31 & 4.18 \\
\hline 6 & 5.62 & 5.01 & 5.67 & 5.01 & 5.83 & 5.01 & 6.05 & 5.01 & 6.29 & 5.01 \\
\hline 7 & 5.64 & 5.85 & 5.68 & 5.85 & 5.83 & 5.85 & 6.05 & 5.85 & 6.28 & 5.85 \\
\hline 8 & 5.79 & 6.68 & 5.82 & 6.68 & 5.97 & 6.68 & 6.19 & 6.68 & 6.43 & 6.68 \\
\hline 9 & 5.83 & 7.52 & 5.85 & 7.52 & 6.01 & 7.52 & 6.23 & 7.52 & 6.47 & 7.52 \\
\hline 10 & 5.92 & 8.36 & 5.94 & 8.36 & 6.08 & 8.36 & 6.31 & 8.36 & 6.56 & 8.36 \\
\hline 11 & 5.94 & 9.19 & 5.96 & 9.19 & 6.11 & 9.19 & 6.33 & 9.19 & 6.58 & 9.19 \\
\hline 12 & 6.02 & 10.03 & 6.03 & 10.03 & 6.17 & 10.03 & 6.39 & 10.03 & 6.64 & 10.03 \\
\hline 13 & 6.04 & 10.86 & 6.04 & 10.86 & 6.19 & 10.86 & 6.41 & 10.86 & 6.66 & 10.86 \\
\hline 14 & 6.10 & 11.70 & 6.09 & 11.70 & 6.23 & 11.70 & 6.46 & 11.70 & 6.70 & 11.70 \\
\hline 15 & 6.11 & 12.53 & 6.11 & 12.53 & 6.25 & 12.53 & 6.47 & 12.53 & 6.71 & 12.53 \\
\hline 16 & 6.16 & 13.37 & 6.15 & 13.37 & 6.28 & 13.37 & 6.50 & 13.37 & 6.75 & 13.37 \\
\hline 17 & 6.17 & 14.20 & 6.16 & 14.20 & 6.29 & 14.20 & 6.51 & 14.20 & 6.75 & 14.20 \\
\hline 18 & 6.21 & 15.04 & 6.19 & 15.04 & 6.32 & 15.04 & 6.54 & 15.04 & 6.78 & 15.04 \\
\hline 19 & 6.22 & 15.88 & 6.21 & 15.88 & 6.33 & 15.88 & 6.54 & 15.88 & 6.78 & 15.88 \\
\hline 20 & 6.25 & 16.71 & 6.23 & 16.71 & 6.35 & 16.71 & 6.56 & 16.71 & 6.80 & 16.71 \\
\hline 21 & 6.26 & 17.55 & 6.24 & 17.55 & 6.36 & 17.55 & 6.57 & 17.55 & 6.80 & 17.55 \\
\hline 22 & 6.29 & 18.38 & 6.26 & 18.38 & 6.38 & 18.38 & 6.58 & 18.38 & 6.81 & 18.38 \\
\hline 23 & 6.30 & 19.22 & 6.27 & 19.22 & 6.38 & 19.22 & 6.58 & 19.22 & 6.82 & 19.22 \\
\hline 24 & 6.33 & 20.05 & 6.29 & 20.05 & 6.40 & 20.05 & 6.60 & 20.05 & 6.83 & 20.05 \\
\hline 25 & 6.33 & 20.89 & 6.30 & 20.89 & 6.40 & 20.89 & 6.60 & 20.89 & 6.83 & 20.89 \\
\hline 26 & 6.36 & 21.72 & 6.32 & 21.72 & 6.42 & 21.72 & 6.61 & 21.72 & 6.83 & 21.72 \\
\hline 27 & 6.36 & 22.56 & 6.32 & 22.56 & 6.42 & 22.56 & 6.61 & 22.56 & 6.83 & 22.56 \\
\hline 28 & 6.39 & 23.40 & 6.34 & 23.40 & 6.43 & 23.40 & 6.62 & 23.40 & 6.84 & 23.40 \\
\hline 29 & 6.39 & 24.23 & 6.35 & 24.23 & 6.44 & 24.23 & 6.62 & 24.23 & 6.84 & 24.23 \\
\hline 30 & 6.42 & 25.07 & 6.36 & 25.07 & 6.45 & 25.07 & 6.63 & 25.07 & 6.84 & 25.07 \\
\hline 31 & 6.42 & 25.90 & 6.37 & 25.90 & 6.45 & 25.90 & 6.63 & 25.90 & 6.85 & 25.90 \\
\hline 32 & 6.44 & 26.74 & 6.38 & 26.74 & 6.46 & 26.74 & 6.64 & 26.74 & 6.85 & 26.74 \\
\hline 33 & 6.45 & 27.57 & 6.39 & 27.57 & 6.47 & 27.57 & 6.64 & 27.57 & 6.85 & 27.57 \\
\hline 34 & 6.47 & 28.41 & 6.40 & 28.41 & 6.48 & 28.41 & 6.64 & 28.41 & 6.85 & 28.41 \\
\hline 35 & 6.48 & 29.24 & 6.41 & 29.24 & 6.48 & 29.24 & 6.65 & 29.24 & 6.85 & 29.24 \\
\hline 36 & 6.50 & 30.08 & 6.42 & 30.08 & 6.49 & 30.08 & 6.65 & 30.08 & 6.85 & 30.08 \\
\hline 37 & 6.50 & 30.92 & 6.43 & 30.92 & 6.49 & 30.92 & 6.65 & 30.91 & 6.85 & 30.91 \\
\hline 38 & 6.52 & 31.75 & 6.44 & 31.75 & 6.50 & 31.75 & 6.66 & 31.75 & 6.86 & 31.75 \\
\hline 39 & 6.53 & 32.59 & 6.45 & 32.59 & 6.51 & 32.59 & 6.66 & 32.59 & 6.85 & 32.59 \\
\hline 40 & 6.55 & 33.42 & 6.46 & 33.42 & 6.51 & 33.42 & 6.66 & 33.42 & 6.86 & 33.42 \\
\hline 41 & 6.56 & 34.26 & 6.47 & 34.26 & 6.52 & 34.26 & 6.67 & 34.26 & 6.86 & 34.26 \\
\hline 42 & 6.58 & 35.09 & 6.48 & 35.09 & 6.53 & 35.09 & 6.67 & 35.09 & 6.86 & 35.09 \\
\hline 43 & 6.58 & 35.93 & 6.49 & 35.93 & 6.53 & 35.93 & 6.67 & 35.93 & 6.86 & 35.93 \\
\hline 44 & 6.61 & 36.76 & 6.50 & 36.76 & 6.54 & 36.76 & 6.68 & 36.76 & 6.86 & 36.76 \\
\hline 45 & 6.61 & 37.60 & 6.51 & 37.60 & 6.55 & 37.60 & 6.68 & 37.60 & 6.86 & 37.60 \\
\hline 46 & 6.63 & 38.44 & 6.52 & 38.44 & 6.55 & 38.43 & 6.69 & 38.43 & 6.87 & 38.43 \\
\hline 47 & 6.64 & 39.27 & 6.53 & 39.27 & 6.56 & 39.27 & 6.69 & 39.27 & 6.86 & 39.27 \\
\hline 48 & 6.66 & 40.11 & 6.54 & 40.11 & 6.57 & 40.11 & 6.69 & 40.11 & 6.87 & 40.11 \\
\hline 49 & 6.66 & 40.94 & 6.55 & 40.94 & 6.57 & 40.94 & 6.69 & 40.94 & 6.87 & 40.94 \\
\hline 50 & 6.69 & 41.78 & 6.56 & 41.78 & 6.58 & 41.78 & 6.70 & 41.78 & 6.87 & 41.78 \\
\hline 51 & 6.69 & 42.61 & 6.57 & 42.61 & 6.59 & 42.61 & 6.70 & 42.61 & 6.87 & 42.61 \\
\hline 52 & 6.72 & 43.45 & 6.59 & 43.45 & 6.59 & 43.45 & 6.71 & 43.45 & 6.87 & 43.45 \\
\hline 53 & 6.72 & 44.28 & 6.59 & 44.28 & 6.60 & 44.28 & 6.71 & 44.28 & 6.87 & 44.28 \\
\hline 54 & 6.75 & 45.12 & 6.61 & 45.12 & 6.61 & 45.12 & 6.72 & 45.12 & 6.88 & 45.12 \\
\hline 55 & 6.75 & 45.95 & 6.61 & 45.95 & 6.61 & 45.95 & 6.72 & 45.95 & 6.88 & 45.95 \\
\hline 56 & 6.77 & 46.79 & 6.63 & 46.79 & 6.62 & 46.79 & 6.72 & 46.79 & 6.88 & 46.79 \\
\hline 57 & 6.78 & 47.63 & 6.64 & 47.63 & 6.63 & 47.63 & 6.72 & 47.63 & 6.88 & 47.63 \\
\hline 58 & 6.80 & 48.46 & 6.65 & 48.46 & 6.64 & 48.46 & 6.74 & 48.46 & 6.88 & 48.46 \\
\hline
\end{tabular}




\begin{tabular}{|c|c|c|c|c|c|c|c|c|c|c|}
\hline 59 & 6.81 & 49.30 & 6.66 & 49.30 & 6.64 & 49.30 & 6.75 & 49.30 & 6.88 & 49.30 \\
\hline 60 & 6.83 & 50.13 & 6.68 & 50.13 & 6.66 & 50.13 & 6.74 & 50.13 & 6.89 & 50.13 \\
\hline 61 & 6.84 & 50.97 & 6.68 & 50.97 & 6.66 & 50.97 & 6.75 & 50.97 & 6.89 & 50.97 \\
\hline 62 & 6.86 & 51.80 & 6.70 & 51.80 & 6.67 & 51.80 & 6.76 & 51.80 & 6.90 & 51.80 \\
\hline 63 & 6.86 & 52.64 & 6.71 & 52.64 & 6.67 & 52.64 & 6.76 & 52.64 & 6.89 & 52.64 \\
\hline 64 & 6.89 & 53.47 & 6.72 & 53.47 & 6.69 & 53.47 & 6.77 & 53.47 & 6.90 & 53.47 \\
\hline 65 & 6.90 & 54.31 & 6.73 & 54.31 & 6.69 & 54.31 & 6.77 & 54.31 & 6.90 & 54.31 \\
\hline 66 & 6.92 & 55.15 & 6.74 & 55.15 & 6.71 & 55.15 & 6.78 & 55.15 & 6.91 & 55.15 \\
\hline 67 & 6.92 & 55.98 & 6.75 & 55.98 & 6.71 & 55.98 & 6.78 & 55.98 & 6.91 & 55.98 \\
\hline 68 & 6.96 & 56.82 & 6.77 & 56.82 & 6.72 & 56.82 & 6.79 & 56.82 & 6.91 & 56.82 \\
\hline 69 & 6.96 & 57.65 & 6.78 & 57.65 & 6.73 & 57.65 & 6.79 & 57.65 & 6.91 & 57.65 \\
\hline 70 & 6.99 & 58.49 & 6.80 & 58.49 & 6.74 & 58.49 & 6.80 & 58.49 & 6.92 & 58.49 \\
\hline 71 & 6.99 & 59.32 & 6.81 & 59.32 & 6.75 & 59.32 & 6.81 & 59.32 & 6.92 & 59.32 \\
\hline 72 & 7.02 & 60.16 & 6.82 & 60.16 & 6.76 & 60.16 & 6.82 & 60.16 & 6.93 & 60.16 \\
\hline 73 & 7.02 & 60.99 & 6.83 & 60.99 & 6.77 & 60.99 & 6.82 & 60.99 & 6.93 & 60.99 \\
\hline 74 & 7.05 & 61.83 & 6.85 & 61.83 & 6.78 & 61.83 & 6.83 & 61.83 & 6.94 & 61.83 \\
\hline 75 & 7.05 & 62.67 & 6.86 & 62.67 & 6.79 & 62.67 & 6.83 & 62.67 & 6.94 & 62.66 \\
\hline 76 & 7.08 & 63.50 & 6.87 & 63.50 & 6.80 & 63.50 & 6.84 & 63.50 & 6.94 & 63.50 \\
\hline 77 & 7.09 & 64.34 & 6.88 & 64.34 & 6.81 & 64.34 & 6.85 & 64.34 & 6.95 & 64.34 \\
\hline 78 & 7.11 & 65.17 & 6.90 & 65.17 & 6.82 & 65.17 & 6.86 & 65.17 & 6.96 & 65.17 \\
\hline 79 & 7.12 & 66.01 & 6.91 & 66.01 & 6.83 & 66.01 & 6.86 & 66.01 & 6.96 & 66.01 \\
\hline 80 & 7.15 & 66.84 & 6.93 & 66.84 & 6.85 & 66.84 & 6.87 & 66.84 & 6.97 & 66.84 \\
\hline 81 & 7.15 & 67.68 & 6.94 & 67.68 & 6.85 & 67.68 & 6.88 & 67.68 & 6.97 & 67.68 \\
\hline 82 & 7.18 & 68.51 & 6.96 & 68.51 & 6.87 & 68.51 & 6.89 & 68.51 & 6.98 & 68.51 \\
\hline 83 & 7.19 & 69.35 & 6.97 & 69.35 & 6.87 & 69.35 & 6.89 & 69.35 & 6.98 & 69.35 \\
\hline 84 & 7.22 & 70.18 & 6.99 & 70.19 & 6.89 & 70.18 & 6.91 & 70.18 & 6.99 & 70.18 \\
\hline 85 & 7.22 & 71.02 & 7.00 & 71.02 & 6.89 & 71.02 & 6.91 & 71.02 & 6.99 & 71.02 \\
\hline 86 & 7.25 & 71.86 & 7.02 & 71.86 & 6.91 & 71.86 & 6.92 & 71.86 & 7.00 & 71.86 \\
\hline 87 & 7.26 & 72.69 & 7.03 & 72.69 & 6.92 & 72.69 & 6.93 & 72.69 & 7.00 & 72.69 \\
\hline 88 & 7.29 & 73.53 & 7.05 & 73.53 & 6.94 & 73.53 & 6.94 & 73.53 & 7.01 & 73.53 \\
\hline 89 & 7.29 & 74.36 & 7.06 & 74.36 & 6.94 & 74.36 & 6.94 & 74.36 & 7.01 & 74.36 \\
\hline 90 & 7.32 & 75.20 & 7.08 & 75.20 & 6.96 & 75.20 & 6.96 & 75.20 & 7.03 & 75.20 \\
\hline 91 & 7.33 & 76.03 & 7.09 & 76.03 & 6.96 & 76.03 & 6.96 & 76.03 & 7.03 & 76.03 \\
\hline 92 & 7.37 & 76.87 & 7.11 & 76.87 & 6.98 & 76.87 & 6.97 & 76.87 & 7.04 & 76.87 \\
\hline 93 & 7.37 & 77.70 & 7.12 & 77.70 & 6.99 & 77.70 & 6.98 & 77.70 & 7.04 & 77.70 \\
\hline 94 & 7.40 & 78.54 & 7.14 & 78.54 & 7.01 & 78.54 & 7.00 & 78.54 & 7.06 & 78.54 \\
\hline 95 & 7.41 & 79.38 & 7.16 & 79.38 & 7.01 & 79.38 & 7.00 & 79.38 & 7.06 & 79.38 \\
\hline 96 & 7.44 & 80.21 & 7.18 & 80.21 & 7.04 & 80.21 & 7.02 & 80.21 & 7.07 & 80.21 \\
\hline 97 & 7.44 & 81.05 & 7.18 & 81.05 & 7.04 & 81.05 & 7.02 & 81.05 & 7.07 & 81.05 \\
\hline 98 & 7.48 & 81.88 & 7.21 & 81.88 & 7.06 & 81.88 & 7.04 & 81.88 & 7.09 & 81.88 \\
\hline 99 & 7.48 & 82.72 & 7.22 & 82.72 & 7.06 & 82.72 & 7.04 & 82.72 & 7.09 & 82.72 \\
\hline 100 & 7.52 & 83.55 & 7.24 & 83.55 & 7.09 & 83.55 & 7.06 & 83.55 & 7.10 & 83.55 \\
\hline 101 & 7.52 & 84.39 & 7.25 & 84.39 & 7.09 & 84.39 & 7.06 & 84.39 & 7.11 & 84.39 \\
\hline 102 & 7.56 & 85.22 & 7.28 & 85.22 & 7.12 & 85.22 & 7.09 & 85.22 & 7.12 & 85.22 \\
\hline 103 & 7.57 & 86.06 & 7.29 & 86.06 & 7.12 & 86.06 & 7.09 & 86.06 & 7.12 & 86.06 \\
\hline 104 & 7.60 & 86.89 & 7.32 & 86.90 & 7.15 & 86.90 & 7.11 & 86.89 & 7.14 & 86.89 \\
\hline 105 & 7.61 & 87.73 & 7.33 & 87.73 & 7.15 & 87.73 & 7.11 & 87.73 & 7.14 & 87.73 \\
\hline 106 & 7.64 & 88.57 & 7.35 & 88.57 & 7.18 & 88.57 & 7.14 & 88.57 & 7.16 & 88.57 \\
\hline 107 & 7.65 & 89.40 & 7.36 & 89.40 & 7.18 & 89.40 & 7.14 & 89.40 & 7.16 & 89.40 \\
\hline 108 & 7.69 & 90.24 & 7.39 & 90.24 & 7.21 & 90.24 & 7.16 & 90.24 & 7.18 & 90.24 \\
\hline 109 & 7.69 & 91.07 & 7.40 & 91.07 & 7.21 & 91.07 & 7.16 & 91.07 & 7.18 & 91.07 \\
\hline 110 & 7.73 & 91.91 & 7.43 & 91.91 & 7.25 & 91.91 & 7.19 & 91.91 & 7.20 & 91.91 \\
\hline 111 & 7.74 & 92.74 & 7.44 & 92.74 & 7.24 & 92.74 & 7.19 & 92.74 & 7.21 & 92.74 \\
\hline 112 & 7.77 & 93.58 & 7.47 & 93.58 & 7.28 & 93.58 & 7.21 & 93.58 & 7.23 & 93.58 \\
\hline 113 & 7.78 & 94.41 & 7.48 & 94.41 & 7.28 & 94.41 & 7.22 & 94.41 & 7.23 & 94.41 \\
\hline 114 & 7.82 & 95.25 & 7.51 & 95.25 & 7.31 & 95.25 & 7.24 & 95.25 & 7.25 & 95.25 \\
\hline 115 & 7.82 & 96.08 & 7.52 & 96.09 & 7.31 & 96.09 & 7.24 & 96.09 & 7.25 & 96.09 \\
\hline 116 & 7.86 & 96.92 & 7.55 & 96.92 & 7.35 & 96.92 & 7.27 & 96.92 & 7.28 & 96.92 \\
\hline 117 & 7.87 & 97.76 & 7.56 & 97.76 & 7.35 & 97.76 & 7.27 & 97.76 & 7.27 & 97.76 \\
\hline 118 & 7.91 & 98.59 & 7.59 & 98.59 & 7.38 & 98.59 & 7.30 & 98.59 & 7.30 & 98.59 \\
\hline 119 & 7.92 & 99.43 & 7.60 & 99.43 & 7.38 & 99.43 & 7.30 & 99.43 & 7.30 & 99.43 \\
\hline 120 & 7.96 & 100.26 & 7.64 & 100.26 & 7.42 & 100.26 & 7.33 & 100.26 & 7.33 & 100.26 \\
\hline
\end{tabular}




\section{Effect of Temperature on Mixing}

\begin{tabular}{|c|c|c|c|c|c|c|c|c|}
\hline \multicolumn{9}{|c|}{ Bottom Placement of Nitrogen } \\
\hline \multirow{2}{*}{$\begin{array}{l}\text { Time } \\
\text { (days) }\end{array}$} & \multicolumn{2}{|c|}{ Temperature $-90^{\circ} \mathrm{F}$} & \multicolumn{2}{|c|}{ Temperature $-100^{\circ} \mathrm{F}$} & \multicolumn{2}{|c|}{ Temperature $-125^{\circ} \mathrm{F}$} & \multicolumn{2}{|c|}{ Temperature $-150^{\circ} \mathrm{F}$} \\
\hline & $\begin{array}{c}\% N_{2} \text { in } \\
\text { withdrawn gas }\end{array}$ & $\begin{array}{c}\% \text { W.G } \\
\text { withdrawn } \\
\text { (by volume) }\end{array}$ & $\begin{array}{c}\% N_{2} \text { in } \\
\text { withdrawn gas }\end{array}$ & $\begin{array}{c}\% \text { W.G } \\
\text { withdrawn } \\
\text { (by volume) }\end{array}$ & $\begin{array}{c}\% N_{2} \text { in } \\
\text { withdrawn gas }\end{array}$ & $\begin{array}{c}\% \text { W.G } \\
\text { withdrawn } \\
\text { (by volume) }\end{array}$ & $\begin{array}{c}\% N_{2} \text { in } \\
\text { withdrawn gas }\end{array}$ & $\begin{array}{c}\% \text { W.G } \\
\text { withdrawn } \\
\text { (by volume) }\end{array}$ \\
\hline 1 & 0.35 & 0.84 & 0.35 & 0.84 & 0.36 & 0.84 & 0.36 & 0.84 \\
\hline 2 & 2.12 & 1.67 & 2.13 & 1.67 & 2.14 & 1.67 & 2.16 & 1.67 \\
\hline 3 & 2.59 & 2.51 & 2.60 & 2.51 & 2.62 & 2.51 & 2.64 & 2.51 \\
\hline 4 & 5.02 & 3.34 & 5.03 & 3.34 & 5.07 & 3.34 & 5.11 & 3.34 \\
\hline 5 & 5.63 & 4.18 & 5.64 & 4.17 & 5.69 & 4.18 & 5.73 & 4.18 \\
\hline 6 & 5.65 & 5.01 & 5.67 & 5.01 & 5.73 & 5.01 & 5.77 & 5.01 \\
\hline 7 & 5.66 & 5.85 & 5.69 & 5.84 & 5.74 & 5.85 & 5.79 & 5.85 \\
\hline 8 & 5.80 & 6.68 & 5.82 & 6.68 & 5.88 & 6.68 & 5.93 & 6.68 \\
\hline 9 & 5.84 & 7.52 & 5.86 & 7.51 & 5.92 & 7.52 & 5.97 & 7.52 \\
\hline 10 & 5.92 & 8.36 & 5.94 & 8.35 & 6.00 & 8.35 & 6.05 & 8.35 \\
\hline 11 & 5.94 & 9.19 & 5.97 & 9.18 & 6.03 & 9.19 & 6.08 & 9.19 \\
\hline 12 & 6.01 & 10.03 & 6.03 & 10.02 & 6.09 & 10.02 & 6.15 & 10.02 \\
\hline 13 & 6.03 & 10.86 & 6.05 & 10.85 & 6.11 & 10.86 & 6.17 & 10.86 \\
\hline 14 & 6.08 & 11.70 & 6.10 & 11.69 & 6.17 & 11.70 & 6.22 & 11.70 \\
\hline 15 & 6.09 & 12.53 & 6.12 & 12.52 & 6.18 & 12.53 & 6.24 & 12.53 \\
\hline 16 & 6.13 & 13.37 & 6.16 & 13.36 & 6.23 & 13.37 & 6.29 & 13.37 \\
\hline 17 & 6.14 & 14.20 & 6.17 & 14.19 & 6.24 & 14.20 & 6.30 & 14.20 \\
\hline 18 & 6.18 & 15.04 & 6.21 & 15.03 & 6.27 & 15.04 & 6.34 & 15.04 \\
\hline 19 & 6.19 & 15.88 & 6.22 & 15.86 & 6.29 & 15.87 & 6.35 & 15.87 \\
\hline 20 & 6.21 & 16.71 & 6.24 & 16.70 & 6.31 & 16.71 & 6.38 & 16.71 \\
\hline 21 & 6.22 & 17.55 & 6.25 & 17.53 & 6.32 & 17.54 & 6.39 & 17.54 \\
\hline 22 & 6.24 & 18.38 & 6.28 & 18.37 & 6.35 & 18.38 & 6.42 & 18.38 \\
\hline 23 & 6.25 & 19.22 & 6.28 & 19.20 & 6.36 & 19.21 & 6.42 & 19.21 \\
\hline 24 & 6.27 & 20.05 & 6.30 & 20.04 & 6.38 & 20.05 & 6.45 & 20.05 \\
\hline 25 & 6.28 & 20.89 & 6.31 & 20.87 & 6.39 & 20.89 & 6.46 & 20.88 \\
\hline 26 & 6.30 & 21.72 & 6.33 & 21.71 & 6.41 & 21.72 & 6.48 & 21.72 \\
\hline 27 & 6.30 & 22.56 & 6.34 & 22.54 & 6.42 & 22.56 & 6.49 & 22.56 \\
\hline 28 & 6.32 & 23.40 & 6.35 & 23.38 & 6.43 & 23.39 & 6.51 & 23.39 \\
\hline 29 & 6.33 & 24.23 & 6.36 & 24.21 & 6.44 & 24.23 & 6.51 & 24.23 \\
\hline 30 & 6.34 & 25.07 & 6.37 & 25.05 & 6.46 & 25.06 & 6.53 & 25.06 \\
\hline 31 & 6.35 & 25.90 & 6.38 & 25.88 & 6.47 & 25.90 & 6.54 & 25.90 \\
\hline 32 & 6.36 & 26.74 & 6.40 & 26.72 & 6.48 & 26.73 & 6.56 & 26.73 \\
\hline 33 & 6.37 & 27.57 & 6.40 & 27.55 & 6.49 & 27.57 & 6.57 & 27.57 \\
\hline 34 & 6.38 & 28.41 & 6.42 & 28.39 & 6.51 & 28.40 & 6.58 & 28.40 \\
\hline 35 & 6.39 & 29.24 & 6.42 & 29.22 & 6.51 & 29.24 & 6.59 & 29.24 \\
\hline 36 & 6.40 & 30.08 & 6.44 & 30.06 & 6.53 & 30.07 & 6.61 & 30.07 \\
\hline 37 & 6.41 & 30.92 & 6.45 & 30.89 & 6.53 & 30.91 & 6.61 & 30.91 \\
\hline 38 & 6.42 & 31.75 & 6.46 & 31.73 & 6.55 & 31.75 & 6.63 & 31.75 \\
\hline 39 & 6.42 & 32.59 & 6.47 & 32.56 & 6.56 & 32.58 & 6.64 & 32.58 \\
\hline 40 & 6.44 & 33.42 & 6.48 & 33.40 & 6.57 & 33.42 & 6.66 & 33.42 \\
\hline 41 & 6.44 & 34.26 & 6.48 & 34.23 & 6.58 & 34.25 & 6.66 & 34.25 \\
\hline 42 & 6.46 & 35.09 & 6.50 & 35.07 & 6.60 & 35.09 & 6.68 & 35.09 \\
\hline 43 & 6.46 & 35.93 & 6.51 & 35.90 & 6.60 & 35.92 & 6.69 & 35.92 \\
\hline 44 & 6.48 & 36.76 & 6.52 & 36.74 & 6.62 & 36.76 & 6.70 & 36.76 \\
\hline 45 & 6.48 & 37.60 & 6.53 & 37.57 & 6.63 & 37.59 & 6.71 & 37.59 \\
\hline 46 & 6.50 & 38.43 & 6.54 & 38.41 & 6.64 & 38.43 & 6.73 & 38.43 \\
\hline 47 & 6.50 & 39.27 & 6.55 & 39.24 & 6.65 & 39.26 & 6.74 & 39.26 \\
\hline 48 & 6.52 & 40.11 & 6.56 & 40.08 & 6.66 & 40.10 & 6.75 & 40.10 \\
\hline 49 & 6.52 & 40.94 & 6.57 & 40.91 & 6.67 & 40.93 & 6.76 & 40.93 \\
\hline 50 & 6.53 & 41.78 & 6.58 & 41.75 & 6.69 & 41.77 & 6.78 & 41.77 \\
\hline 51 & 6.54 & 42.61 & 6.59 & 42.58 & 6.70 & 42.61 & 6.79 & 42.61 \\
\hline 52 & 6.56 & 43.45 & 6.60 & 43.42 & 6.71 & 43.44 & 6.81 & 43.44 \\
\hline 53 & 6.56 & 44.28 & 6.61 & 44.25 & 6.72 & 44.28 & 6.81 & 44.28 \\
\hline 54 & 6.58 & 45.12 & 6.63 & 45.09 & 6.74 & 45.11 & 6.83 & 45.11 \\
\hline 55 & 6.58 & 45.95 & 6.63 & 45.92 & 6.74 & 45.95 & 6.84 & 45.95 \\
\hline 56 & 6.60 & 46.79 & 6.65 & 46.76 & 6.76 & 46.78 & 6.86 & 46.78 \\
\hline 57 & 6.61 & 47.63 & 6.66 & 47.59 & 6.77 & 47.62 & 6.86 & 47.62 \\
\hline 58 & 6.62 & 48.46 & 6.67 & 48.43 & 6.79 & 48.45 & 6.88 & 48.45 \\
\hline 59 & 6.63 & 49.30 & 6.68 & 49.26 & 6.79 & 49.29 & 6.89 & 49.29 \\
\hline 60 & 6.64 & 50.13 & 6.69 & 50.10 & 6.81 & 50.12 & 6.91 & 50.12 \\
\hline 61 & 6.65 & 50.97 & 6.70 & 50.93 & 6.82 & 50.96 & 6.92 & 50.96 \\
\hline 62 & 6.66 & 51.80 & 6.72 & 51.77 & 6.83 & 51.79 & 6.94 & 51.79 \\
\hline 63 & 6.67 & 52.64 & 6.73 & 52.60 & 6.85 & 52.63 & 6.95 & 52.63 \\
\hline 64 & 6.69 & 53.47 & 6.74 & 53.44 & 6.86 & 53.47 & 6.96 & 53.46 \\
\hline 65 & 6.69 & 54.31 & 6.75 & 54.27 & 6.87 & 54.30 & 6.97 & 54.30 \\
\hline 66 & 6.71 & 55.15 & 6.76 & 55.11 & 6.89 & 55.14 & 6.99 & 55.14 \\
\hline 67 & 6.72 & 55.98 & 6.78 & 55.94 & 6.90 & 55.97 & 7.00 & 55.97 \\
\hline 68 & 6.74 & 56.82 & 6.79 & 56.78 & 6.92 & 56.81 & 7.02 & 56.81 \\
\hline 69 & 6.74 & 57.65 & 6.80 & 57.61 & 6.93 & 57.64 & 7.03 & 57.64 \\
\hline
\end{tabular}




\begin{tabular}{|c|c|c|c|c|c|c|c|c|}
\hline 70 & 6.76 & 58.49 & 6.82 & 58.45 & 6.94 & 58.48 & 7.05 & 58.48 \\
\hline 71 & 6.77 & 59.32 & 6.82 & 59.28 & 6.95 & 59.31 & 7.06 & 59.31 \\
\hline 72 & 6.78 & 60.16 & 6.84 & 60.12 & 6.97 & 60.15 & 7.08 & 60.15 \\
\hline 73 & 6.79 & 60.99 & 6.85 & 60.95 & 6.98 & 60.98 & 7.09 & 60.98 \\
\hline 74 & 6.81 & 61.83 & 6.87 & 61.79 & 7.00 & 61.82 & 7.11 & 61.82 \\
\hline 75 & 6.82 & 62.66 & 6.88 & 62.62 & 7.01 & 62.65 & 7.12 & 62.65 \\
\hline 76 & 6.84 & 63.50 & 6.90 & 63.46 & 7.03 & 63.49 & 7.14 & 63.49 \\
\hline 77 & 6.84 & 64.34 & 6.90 & 64.29 & 7.04 & 64.33 & 7.15 & 64.32 \\
\hline 78 & 6.86 & 65.17 & 6.92 & 65.13 & 7.06 & 65.16 & 7.17 & 65.16 \\
\hline 79 & 6.87 & 66.01 & 6.93 & 65.96 & 7.07 & 66.00 & 7.18 & 66.00 \\
\hline 80 & 6.89 & 66.84 & 6.95 & 66.80 & 7.09 & 66.83 & 7.20 & 66.83 \\
\hline 81 & 6.90 & 67.68 & 6.96 & 67.63 & 7.10 & 67.67 & 7.21 & 67.67 \\
\hline 82 & 6.92 & 68.51 & 6.98 & 68.47 & 7.12 & 68.50 & 7.23 & 68.50 \\
\hline 83 & 6.93 & 69.35 & 6.99 & 69.30 & 7.13 & 69.34 & 7.25 & 69.34 \\
\hline 84 & 6.94 & 70.18 & 7.01 & 70.14 & 7.15 & 70.17 & 7.26 & 70.17 \\
\hline 85 & 6.95 & 71.02 & 7.02 & 70.97 & 7.16 & 71.01 & 7.28 & 71.01 \\
\hline 86 & 6.97 & 71.86 & 7.04 & 71.81 & 7.18 & 71.84 & 7.30 & 71.84 \\
\hline 87 & 6.98 & 72.69 & 7.04 & 72.64 & 7.19 & 72.68 & 7.31 & 72.68 \\
\hline 88 & 7.00 & 73.53 & 7.07 & 73.48 & 7.21 & 73.51 & 7.33 & 73.51 \\
\hline 89 & 7.01 & 74.36 & 7.07 & 74.31 & 7.22 & 74.35 & 7.35 & 74.35 \\
\hline 90 & 7.03 & 75.20 & 7.10 & 75.15 & 7.25 & 75.19 & 7.37 & 75.18 \\
\hline 91 & 7.04 & 76.03 & 7.11 & 75.98 & 7.26 & 76.02 & 7.38 & 76.02 \\
\hline 92 & 7.06 & 76.87 & 7.13 & 76.82 & 7.28 & 76.86 & 7.40 & 76.85 \\
\hline 93 & 7.07 & 77.70 & 7.14 & 77.65 & 7.29 & 77.69 & 7.41 & 77.69 \\
\hline 94 & 7.10 & 78.54 & 7.16 & 78.49 & 7.31 & 78.53 & 7.44 & 78.53 \\
\hline 95 & 7.10 & 79.38 & 7.17 & 79.32 & 7.33 & 79.36 & 7.45 & 79.36 \\
\hline 96 & 7.13 & 80.21 & 7.20 & 80.16 & 7.35 & 80.20 & 7.47 & 80.20 \\
\hline 97 & 7.14 & 81.05 & 7.20 & 80.99 & 7.36 & 81.03 & 7.48 & 81.03 \\
\hline 98 & 7.16 & 81.88 & 7.23 & 81.83 & 7.38 & 81.87 & 7.51 & 81.87 \\
\hline 99 & 7.17 & 82.72 & 7.24 & 82.66 & 7.39 & 82.70 & 7.51 & 82.70 \\
\hline 100 & 7.19 & 83.55 & 7.27 & 83.50 & 7.42 & 83.54 & 7.55 & 83.54 \\
\hline 101 & 7.20 & 84.39 & 7.27 & 84.33 & 7.42 & 84.37 & 7.55 & 84.37 \\
\hline 102 & 7.23 & 85.22 & 7.30 & 85.17 & 7.46 & 85.21 & 7.59 & 85.21 \\
\hline 103 & 7.24 & 86.06 & 7.31 & 86.00 & 7.46 & 86.04 & 7.59 & 86.04 \\
\hline 104 & 7.26 & 86.89 & 7.34 & 86.84 & 7.50 & 86.88 & 7.63 & 86.88 \\
\hline 105 & 7.27 & 87.73 & 7.34 & 87.67 & 7.50 & 87.72 & 7.63 & 87.71 \\
\hline 106 & 7.30 & 88.57 & 7.37 & 88.51 & 7.54 & 88.55 & 7.67 & 88.55 \\
\hline 107 & 7.31 & 89.40 & 7.38 & 89.34 & 7.54 & 89.39 & 7.67 & 89.39 \\
\hline 108 & 7.33 & 90.24 & 7.41 & 90.18 & 7.57 & 90.22 & 7.71 & 90.22 \\
\hline 109 & 7.34 & 91.07 & 7.42 & 91.01 & 7.58 & 91.06 & 7.71 & 91.06 \\
\hline 110 & 7.38 & 91.91 & 7.45 & 91.85 & 7.61 & 91.89 & 7.75 & 91.89 \\
\hline 111 & 7.38 & 92.74 & 7.46 & 92.68 & 7.62 & 92.73 & 7.76 & 92.73 \\
\hline 112 & 7.41 & 93.58 & 7.49 & 93.52 & 7.65 & 93.56 & 7.79 & 93.56 \\
\hline 113 & 7.42 & 94.41 & 7.49 & 94.35 & 7.66 & 94.40 & 7.80 & 94.40 \\
\hline 114 & 7.45 & 95.25 & 7.53 & 95.18 & 7.70 & 95.23 & 7.83 & 95.23 \\
\hline 115 & 7.46 & 96.08 & 7.53 & 96.02 & 7.70 & 96.07 & 7.84 & 96.07 \\
\hline 116 & 7.49 & 96.92 & 7.57 & 96.85 & 7.74 & 96.90 & 7.88 & 96.90 \\
\hline 117 & 7.50 & 97.76 & 7.58 & 97.69 & 7.74 & 97.74 & 7.88 & 97.74 \\
\hline 118 & 7.53 & 98.59 & 7.61 & 98.52 & 7.78 & 98.58 & 7.92 & 98.57 \\
\hline 119 & 7.54 & 99.43 & 7.62 & 99.36 & 7.79 & 99.41 & 7.93 & 99.41 \\
\hline 120 & 7.57 & 100.26 & 7.65 & 100.19 & 7.83 & 100.25 & 7.97 & 100.24 \\
\hline
\end{tabular}




\section{Effect of Permeability on Mixing}

Permeability values - 10 md, 20 md, 50 md, 100 md

\begin{tabular}{|c|c|c|c|c|c|c|c|c|}
\hline \multicolumn{9}{|c|}{ Bottom Placement of Nitrogen } \\
\hline \multirow{2}{*}{$\begin{array}{l}\text { Time } \\
\text { (days) }\end{array}$} & \multicolumn{2}{|c|}{ Permeability - $10 \mathrm{md}$} & \multicolumn{2}{|c|}{ Permeability - 20 md } & \multicolumn{2}{|c|}{ Permeability - $50 \mathrm{md}$} & \multicolumn{2}{|c|}{ Permeability - 100 md } \\
\hline & $\begin{array}{c}\% \mathrm{~N}_{2} \text { in } \\
\text { withdrawn } \\
\text { gas }\end{array}$ & $\begin{array}{c}\% \text { W.G } \\
\text { withdrawn } \\
\text { (volume) }\end{array}$ & $\begin{array}{c}\% \mathrm{~N}_{2} \text { in } \\
\text { withdrawn } \\
\text { gas }\end{array}$ & $\begin{array}{c}\% \text { W.G } \\
\text { withdrawn } \\
\text { (volume) }\end{array}$ & $\begin{array}{c}\% \mathrm{~N}_{2} \text { in } \\
\text { withdrawn } \\
\text { gas }\end{array}$ & $\begin{array}{c}\% \text { W.G } \\
\text { withdrawn } \\
\text { (volume) }\end{array}$ & $\begin{array}{c}\% \mathrm{~N}_{2} \text { in } \\
\text { withdrawn } \\
\text { gas }\end{array}$ & $\begin{array}{c}\text { \% W.G } \\
\text { withdrawn } \\
\text { (volume) }\end{array}$ \\
\hline 1 & 0.33 & 0.74 & 0.35 & 0.79 & 0.32 & 0.79 & 0.31 & 0.79 \\
\hline 2 & 1.96 & 1.42 & 2.13 & 1.57 & 2.00 & 1.57 & 1.96 & 1.57 \\
\hline 3 & 2.44 & 2.10 & 2.60 & 2.36 & 2.46 & 2.36 & 2.41 & 2.36 \\
\hline 4 & 4.69 & 2.75 & 5.06 & 3.15 & 4.89 & 3.15 & 4.84 & 3.15 \\
\hline 5 & 5.37 & 3.39 & 5.67 & 3.93 & 5.53 & 3.93 & 5.48 & 3.93 \\
\hline 6 & 5.62 & 4.03 & 5.72 & 4.72 & 5.65 & 4.72 & 5.64 & 4.72 \\
\hline 7 & 5.70 & 4.66 & 5.74 & 5.51 & 5.69 & 5.51 & 5.69 & 5.51 \\
\hline 8 & 5.81 & 5.29 & 5.87 & 6.29 & 5.82 & 6.29 & 5.82 & 6.29 \\
\hline 9 & 5.85 & 5.92 & 5.91 & 7.08 & 5.85 & 7.08 & 5.86 & 7.08 \\
\hline 10 & 5.93 & 6.53 & 6.00 & 7.87 & 5.95 & 7.87 & 5.95 & 7.87 \\
\hline 11 & 5.95 & 7.15 & 6.02 & 8.65 & 5.98 & 8.66 & 5.98 & 8.66 \\
\hline 12 & 6.02 & 7.76 & 6.09 & 9.44 & 6.05 & 9.44 & 6.05 & 9.44 \\
\hline 13 & 6.04 & 8.37 & 6.11 & 10.23 & 6.07 & 10.23 & 6.07 & 10.23 \\
\hline 14 & 6.09 & 8.97 & 6.17 & 11.02 & 6.14 & 11.02 & 6.13 & 11.02 \\
\hline 15 & 6.11 & 9.57 & 6.19 & 11.80 & 6.15 & 11.80 & 6.14 & 11.80 \\
\hline 16 & 6.15 & 10.17 & 6.23 & 12.59 & 6.20 & 12.59 & 6.19 & 12.59 \\
\hline 17 & 6.17 & 10.76 & 6.25 & 13.38 & 6.21 & 13.38 & 6.21 & 13.38 \\
\hline 18 & 6.20 & 11.35 & 6.28 & 14.16 & 6.26 & 14.16 & 6.24 & 14.16 \\
\hline 19 & 6.22 & 11.94 & 6.30 & 14.95 & 6.27 & 14.95 & 6.26 & 14.95 \\
\hline 20 & 6.24 & 12.52 & 6.33 & 15.74 & 6.30 & 15.74 & 6.29 & 15.74 \\
\hline 21 & 6.26 & 13.10 & 6.34 & 16.52 & 6.31 & 16.52 & 6.30 & 16.52 \\
\hline 22 & 6.28 & 13.68 & 6.37 & 17.31 & 6.34 & 17.31 & 6.33 & 17.31 \\
\hline 23 & 6.29 & 14.25 & 6.38 & 18.10 & 6.35 & 18.10 & 6.34 & 18.10 \\
\hline 24 & 6.31 & 14.82 & 6.40 & 18.88 & 6.38 & 18.88 & 6.37 & 18.88 \\
\hline 25 & 6.32 & 15.38 & 6.41 & 19.67 & 6.38 & 19.67 & 6.38 & 19.67 \\
\hline 26 & 6.34 & 15.94 & 6.43 & 20.46 & 6.41 & 20.46 & 6.40 & 20.46 \\
\hline 27 & 6.35 & 16.50 & 6.44 & 21.24 & 6.41 & 21.24 & 6.41 & 21.24 \\
\hline 28 & 6.37 & 17.06 & 6.46 & 22.03 & 6.44 & 22.03 & 6.43 & 22.03 \\
\hline 29 & 6.37 & 17.61 & 6.47 & 22.82 & 6.44 & 22.82 & 6.44 & 22.82 \\
\hline 30 & 6.39 & 18.16 & 6.49 & 23.60 & 6.47 & 23.60 & 6.46 & 23.60 \\
\hline 31 & 6.40 & 18.71 & 6.49 & 24.39 & 6.47 & 24.39 & 6.46 & 24.39 \\
\hline 32 & 6.41 & 19.25 & 6.51 & 25.18 & 6.49 & 25.18 & 6.48 & 25.18 \\
\hline 33 & 6.42 & 19.79 & 6.52 & 25.96 & 6.50 & 25.97 & 6.49 & 25.97 \\
\hline 34 & 6.43 & 20.33 & 6.54 & 26.75 & 6.52 & 26.75 & 6.51 & 26.75 \\
\hline 35 & 6.44 & 20.86 & 6.55 & 27.54 & 6.52 & 27.54 & 6.52 & 27.54 \\
\hline 36 & 6.45 & 21.39 & 6.56 & 28.33 & 6.54 & 28.33 & 6.54 & 28.33 \\
\hline 37 & 6.45 & 21.92 & 6.57 & 29.11 & 6.55 & 29.11 & 6.54 & 29.11 \\
\hline 38 & 6.47 & 22.44 & 6.59 & 29.90 & 6.57 & 29.90 & 6.56 & 29.90 \\
\hline 39 & 6.47 & 22.96 & 6.60 & 30.69 & 6.58 & 30.69 & 6.57 & 30.69 \\
\hline 40 & 6.48 & 23.48 & 6.61 & 31.47 & 6.60 & 31.47 & 6.59 & 31.47 \\
\hline 41 & 6.49 & 24.00 & 6.62 & 32.26 & 6.60 & 32.26 & 6.60 & 32.26 \\
\hline 42 & 6.50 & 24.51 & 6.64 & 33.05 & 6.62 & 33.05 & 6.61 & 33.05 \\
\hline 43 & 6.50 & 25.02 & 6.65 & 33.83 & 6.63 & 33.83 & 6.62 & 33.83 \\
\hline 44 & 6.51 & 25.53 & 6.66 & 34.62 & 6.65 & 34.62 & 6.64 & 34.62 \\
\hline 45 & 6.52 & 26.03 & 6.67 & 35.41 & 6.65 & 35.41 & 6.65 & 35.41 \\
\hline 46 & 6.53 & 26.53 & 6.69 & 36.19 & 6.67 & 36.19 & 6.66 & 36.19 \\
\hline 47 & 6.54 & 27.03 & 6.70 & 36.98 & 6.68 & 36.98 & 6.67 & 36.98 \\
\hline 48 & 6.55 & 27.53 & 6.72 & 37.77 & 6.70 & 37.77 & 6.69 & 37.77 \\
\hline 49 & 6.55 & 28.02 & 6.72 & 38.55 & 6.70 & 38.55 & 6.70 & 38.55 \\
\hline 50 & 6.56 & 28.51 & 6.74 & 39.34 & 6.72 & 39.34 & 6.72 & 39.34 \\
\hline 51 & 6.57 & 29.00 & 6.75 & 40.13 & 6.73 & 40.13 & 6.72 & 40.13 \\
\hline 52 & 6.57 & 29.48 & 6.77 & 40.91 & 6.75 & 40.91 & 6.74 & 40.92 \\
\hline 53 & 6.58 & 29.97 & 6.78 & 41.70 & 6.76 & 41.70 & 6.75 & 41.70 \\
\hline 54 & 6.59 & 30.45 & 6.79 & 42.49 & 6.78 & 42.49 & 6.77 & 42.49 \\
\hline 55 & 6.59 & 30.92 & 6.80 & 43.27 & 6.78 & 43.28 & 6.78 & 43.28 \\
\hline 56 & 6.60 & 31.40 & 6.82 & 44.06 & 6.80 & 44.06 & 6.79 & 44.06 \\
\hline 57 & 6.61 & 31.87 & 6.83 & 44.85 & 6.81 & 44.85 & 6.80 & 44.85 \\
\hline 58 & 6.62 & 32.34 & 6.85 & 45.64 & 6.83 & 45.64 & 6.82 & 45.64 \\
\hline 59 & 6.62 & 32.81 & 6.86 & 46.42 & 6.84 & 46.42 & 6.83 & 46.42 \\
\hline 60 & 6.63 & 33.27 & 6.88 & 47.21 & 6.86 & 47.21 & 6.85 & 47.21 \\
\hline 61 & 6.64 & 33.73 & 6.88 & 47.98 & 6.86 & 48.00 & 6.86 & 48.00 \\
\hline 62 & 6.65 & 34.19 & 6.89 & 48.75 & 6.88 & 48.78 & 6.87 & 48.78 \\
\hline 63 & 6.65 & 34.65 & 6.90 & 49.51 & 6.89 & 49.57 & 6.89 & 49.57 \\
\hline 64 & 6.66 & 35.10 & 6.91 & 50.27 & 6.91 & 50.36 & 6.90 & 50.36 \\
\hline 65 & 6.67 & 35.56 & 6.92 & 51.01 & 6.92 & 51.14 & 6.91 & 51.14 \\
\hline 66 & 6.68 & 36.01 & 6.94 & 51.75 & 6.94 & 51.93 & 6.93 & 51.93 \\
\hline 67 & 6.68 & 36.45 & 6.95 & 52.48 & 6.95 & 52.72 & 6.94 & 52.72 \\
\hline 68 & 6.69 & 36.90 & 6.96 & 53.21 & 6.97 & 53.50 & 6.96 & 53.50 \\
\hline 69 & 6.69 & 37.34 & 6.97 & 53.92 & 6.97 & 54.29 & 6.97 & 54.29 \\
\hline
\end{tabular}




\begin{tabular}{|c|c|c|c|c|c|c|c|c|}
\hline 70 & 6.70 & 37.78 & 6.99 & 54.63 & 7.00 & 55.08 & 6.99 & 55.08 \\
\hline 71 & 6.70 & 38.22 & 7.00 & 55.34 & 7.00 & 55.86 & 7.00 & 55.86 \\
\hline 72 & 6.72 & 38.66 & 7.01 & 56.03 & 7.03 & 56.65 & 7.02 & 56.65 \\
\hline 73 & 6.72 & 39.09 & 7.02 & 56.73 & 7.03 & 57.44 & 7.03 & 57.44 \\
\hline 74 & 6.73 & 39.52 & 7.04 & 57.41 & 7.06 & 58.22 & 7.05 & 58.22 \\
\hline 75 & 6.73 & 39.95 & 7.04 & 58.09 & 7.06 & 59.01 & 7.06 & 59.01 \\
\hline 76 & 6.74 & 40.38 & 7.06 & 58.76 & 7.09 & 59.80 & 7.08 & 59.80 \\
\hline 77 & 6.74 & 40.80 & 7.07 & 59.42 & 7.10 & 60.58 & 7.09 & 60.59 \\
\hline 78 & 6.76 & 41.22 & 7.08 & 60.08 & 7.11 & 61.37 & 7.11 & 61.37 \\
\hline 79 & 6.76 & 41.64 & 7.09 & 60.73 & 7.13 & 62.16 & 7.12 & 62.16 \\
\hline 80 & 6.77 & 42.06 & 7.11 & 61.38 & 7.15 & 62.95 & 7.14 & 62.95 \\
\hline 81 & 6.77 & 42.48 & 7.10 & 62.02 & 7.16 & 63.73 & 7.15 & 63.73 \\
\hline 82 & 6.78 & 42.89 & 7.13 & 62.66 & 7.18 & 64.52 & 7.17 & 64.52 \\
\hline 83 & 6.78 & 43.30 & 7.14 & 63.28 & 7.18 & 65.31 & 7.18 & 65.31 \\
\hline 84 & 6.80 & 43.71 & 7.16 & 63.91 & 7.22 & 66.09 & 7.20 & 66.09 \\
\hline 85 & 6.80 & 44.12 & 7.15 & 64.53 & 7.22 & 66.88 & 7.21 & 66.88 \\
\hline 86 & 6.80 & 44.52 & 7.18 & 65.14 & 7.25 & 67.67 & 7.23 & 67.67 \\
\hline 87 & 6.81 & 44.93 & 7.19 & 65.74 & 7.25 & 68.45 & 7.25 & 68.45 \\
\hline 88 & 6.82 & 45.33 & 7.20 & 66.35 & 7.28 & 69.24 & 7.27 & 69.24 \\
\hline 89 & 6.83 & 45.73 & 7.20 & 66.94 & 7.28 & 70.03 & 7.27 & 70.03 \\
\hline 90 & 6.83 & 46.13 & 7.23 & 67.53 & 7.31 & 70.81 & 7.30 & 70.81 \\
\hline 91 & 6.84 & 46.52 & 7.23 & 68.12 & 7.31 & 71.60 & 7.31 & 71.60 \\
\hline 92 & 6.84 & 46.91 & 7.25 & 68.70 & 7.35 & 72.39 & 7.33 & 72.39 \\
\hline 93 & 6.85 & 47.31 & 7.25 & 69.27 & 7.35 & 73.17 & 7.35 & 73.17 \\
\hline 94 & 6.86 & 47.69 & 7.28 & 69.84 & 7.38 & 73.96 & 7.37 & 73.96 \\
\hline 95 & 6.87 & 48.08 & 7.28 & 70.41 & 7.38 & 74.75 & 7.38 & 74.75 \\
\hline 96 & 6.87 & 48.47 & 7.30 & 70.97 & 7.42 & 75.53 & 7.40 & 75.53 \\
\hline 97 & 6.88 & 48.85 & 7.30 & 71.52 & 7.42 & 76.32 & 7.42 & 76.32 \\
\hline 98 & 6.89 & 49.23 & 7.32 & 72.07 & 7.45 & 77.11 & 7.44 & 77.11 \\
\hline 99 & 6.89 & 49.61 & 7.33 & 72.62 & 7.46 & 77.89 & 7.45 & 77.89 \\
\hline 100 & 6.90 & 49.99 & 7.34 & 73.16 & 7.49 & 78.68 & 7.47 & 78.68 \\
\hline 101 & 6.90 & 50.37 & 7.35 & 73.70 & 7.49 & 79.47 & 7.49 & 79.47 \\
\hline 102 & 6.92 & 50.74 & 7.37 & 74.23 & 7.52 & 80.25 & 7.51 & 80.26 \\
\hline 103 & 6.92 & 51.11 & 7.37 & 74.76 & 7.53 & 81.04 & 7.52 & 81.04 \\
\hline 104 & 6.93 & 51.48 & 7.39 & 75.28 & 7.56 & 81.83 & 7.55 & 81.83 \\
\hline 105 & 6.93 & 51.85 & 7.40 & 75.80 & 7.57 & 82.62 & 7.56 & 82.62 \\
\hline 106 & 6.94 & 52.22 & 7.41 & 76.31 & 7.60 & 83.40 & 7.58 & 83.40 \\
\hline 107 & 6.94 & 52.58 & 7.41 & 76.82 & 7.60 & 84.19 & 7.60 & 84.19 \\
\hline 108 & 6.95 & 52.95 & 7.44 & 77.33 & 7.63 & 84.98 & 7.62 & 84.98 \\
\hline 109 & 6.96 & 53.31 & 7.44 & 77.83 & 7.64 & 85.76 & 7.63 & 85.76 \\
\hline 110 & 6.97 & 53.67 & 7.46 & 78.33 & 7.68 & 86.55 & 7.66 & 86.55 \\
\hline 111 & 6.97 & 54.03 & 7.46 & 78.82 & 7.68 & 87.34 & 7.67 & 87.34 \\
\hline 112 & 6.98 & 54.38 & 7.48 & 79.31 & 7.71 & 88.12 & 7.70 & 88.12 \\
\hline 113 & 6.98 & 54.74 & 7.49 & 79.80 & 7.72 & 88.91 & 7.71 & 88.91 \\
\hline 114 & 6.99 & 55.09 & 7.50 & 80.28 & 7.76 & 89.70 & 7.74 & 89.70 \\
\hline 115 & 6.99 & 55.44 & 7.50 & 80.75 & 7.76 & 90.48 & 7.76 & 90.48 \\
\hline 116 & 7.01 & 55.79 & 7.52 & 81.23 & 7.79 & 91.27 & 7.78 & 91.27 \\
\hline 117 & 7.01 & 56.14 & 7.53 & 81.70 & 7.80 & 92.06 & 7.79 & 92.06 \\
\hline 118 & 7.02 & 56.48 & 7.55 & 82.16 & 7.83 & 92.84 & 7.82 & 92.84 \\
\hline 119 & 7.01 & 56.83 & 7.55 & 82.63 & 7.84 & 93.63 & 7.83 & 93.63 \\
\hline 120 & 7.03 & 57.17 & 7.56 & 83.09 & 7.88 & 94.42 & 7.86 & 94.42 \\
\hline
\end{tabular}

Permeability values - 200 md, 300 md, 500 md, 1000 md

\begin{tabular}{|c|c|c|c|c|c|c|c|c|}
\hline \multicolumn{9}{|c|}{ Bottom Placement of Nitrogen } \\
\hline \multirow{2}{*}{$\begin{array}{l}\text { Time } \\
\text { (days) }\end{array}$} & \multicolumn{2}{|c|}{ Permeability - 200 md } & \multicolumn{2}{|c|}{ Permeability - $\mathbf{3 0 0} \mathrm{md}$} & \multicolumn{2}{|c|}{ Permeability - $500 \mathrm{md}$} & \multicolumn{2}{|c|}{ Permeability - 1000 md } \\
\hline & $\begin{array}{c}\% \mathrm{~N}_{2} \text { in } \\
\text { withdrawn } \\
\text { gas }\end{array}$ & $\begin{array}{c}\% \text { W.G } \\
\text { withdrawn } \\
\text { (volume) }\end{array}$ & $\begin{array}{c}\% N_{2} \text { in } \\
\text { withdrawn } \\
\text { gas }\end{array}$ & $\begin{array}{c}\% \text { W.G } \\
\text { withdrawn } \\
\text { (volume) }\end{array}$ & $\begin{array}{c}\% \mathrm{~N}_{2} \text { in } \\
\text { withdrawn } \\
\text { gas }\end{array}$ & $\begin{array}{c}\% \text { W.G } \\
\text { withdrawn } \\
\text { (volume) }\end{array}$ & $\begin{array}{c}\% \mathrm{~N}_{2} \text { in } \\
\text { withdrawn } \\
\text { gas }\end{array}$ & $\begin{array}{c}\% \text { W.G } \\
\text { withdrawn } \\
\text { (volume) }\end{array}$ \\
\hline 1 & 0.30 & 0.79 & 0.30 & 0.79 & 0.30 & 0.79 & 0.29 & 0.79 \\
\hline 2 & 1.93 & 1.57 & 1.93 & 1.57 & 1.92 & 1.57 & 1.92 & 1.57 \\
\hline 3 & 2.39 & 2.36 & 2.38 & 2.36 & 2.37 & 2.36 & 2.37 & 2.36 \\
\hline 4 & 4.81 & 3.15 & 4.80 & 3.15 & 4.78 & 3.15 & 4.75 & 3.15 \\
\hline 5 & 5.45 & 3.93 & 5.44 & 3.93 & 5.44 & 3.93 & 5.40 & 3.93 \\
\hline 6 & 5.61 & 4.72 & 5.61 & 4.72 & 5.61 & 4.72 & 5.61 & 4.72 \\
\hline 7 & 5.65 & 5.51 & 5.65 & 5.51 & 5.65 & 5.51 & 5.67 & 5.51 \\
\hline 8 & 5.80 & 6.29 & 5.80 & 6.29 & 5.80 & 6.29 & 5.81 & 6.30 \\
\hline 9 & 5.84 & 7.08 & 5.84 & 7.08 & 5.84 & 7.08 & 5.85 & 7.08 \\
\hline 10 & 5.94 & 7.87 & 5.94 & 7.87 & 5.94 & 7.87 & 5.95 & 7.87 \\
\hline 11 & 5.96 & 8.66 & 5.96 & 8.66 & 5.96 & 8.66 & 5.97 & 8.66 \\
\hline 12 & 6.04 & 9.44 & 6.04 & 9.44 & 6.04 & 9.44 & 6.05 & 9.44 \\
\hline 13 & 6.06 & 10.23 & 6.06 & 10.23 & 6.06 & 10.23 & 6.07 & 10.23 \\
\hline 14 & 6.12 & 11.02 & 6.12 & 11.02 & 6.12 & 11.02 & 6.13 & 11.02 \\
\hline 15 & 6.14 & 11.80 & 6.14 & 11.80 & 6.14 & 11.80 & 6.14 & 11.80 \\
\hline 16 & 6.19 & 12.59 & 6.19 & 12.59 & 6.19 & 12.59 & 6.19 & 12.59 \\
\hline
\end{tabular}




\begin{tabular}{|c|c|c|c|c|c|c|c|c|}
\hline 17 & 6.20 & 13.38 & 6.20 & 13.38 & 6.20 & 13.38 & 6.21 & 13.38 \\
\hline 18 & 6.24 & 14.16 & 6.24 & 14.16 & 6.24 & 14.16 & 6.25 & 14.16 \\
\hline 19 & 6.25 & 14.95 & 6.25 & 14.95 & 6.25 & 14.95 & 6.26 & 14.95 \\
\hline 20 & 6.29 & 15.74 & 6.29 & 15.74 & 6.29 & 15.74 & 6.29 & 15.74 \\
\hline 21 & 6.30 & 16.52 & 6.30 & 16.52 & 6.30 & 16.52 & 6.30 & 16.52 \\
\hline 22 & 6.33 & 17.31 & 6.33 & 17.31 & 6.33 & 17.31 & 6.33 & 17.31 \\
\hline 23 & 6.34 & 18.10 & 6.33 & 18.10 & 6.33 & 18.10 & 6.34 & 18.10 \\
\hline 24 & 6.37 & 18.88 & 6.36 & 18.88 & 6.36 & 18.88 & 6.37 & 18.88 \\
\hline 25 & 6.37 & 19.67 & 6.37 & 19.67 & 6.37 & 19.67 & 6.37 & 19.67 \\
\hline 26 & 6.40 & 20.46 & 6.40 & 20.46 & 6.40 & 20.46 & 6.40 & 20.46 \\
\hline 27 & 6.40 & 21.24 & 6.40 & 21.24 & 6.40 & 21.24 & 6.40 & 21.25 \\
\hline 28 & 6.43 & 22.03 & 6.43 & 22.03 & 6.43 & 22.03 & 6.43 & 22.03 \\
\hline 29 & 6.43 & 22.82 & 6.43 & 22.82 & 6.43 & 22.82 & 6.43 & 22.82 \\
\hline 30 & 6.46 & 23.61 & 6.45 & 23.61 & 6.45 & 23.61 & 6.45 & 23.61 \\
\hline 31 & 6.46 & 24.39 & 6.46 & 24.39 & 6.46 & 24.39 & 6.46 & 24.39 \\
\hline 32 & 6.48 & 25.18 & 6.48 & 25.18 & 6.48 & 25.18 & 6.48 & 25.18 \\
\hline 33 & 6.49 & 25.97 & 6.48 & 25.97 & 6.48 & 25.97 & 6.49 & 25.97 \\
\hline 34 & 6.51 & 26.75 & 6.51 & 26.75 & 6.51 & 26.75 & 6.51 & 26.75 \\
\hline 35 & 6.51 & 27.54 & 6.51 & 27.54 & 6.51 & 27.54 & 6.51 & 27.54 \\
\hline 36 & 6.53 & 28.33 & 6.53 & 28.33 & 6.53 & 28.33 & 6.53 & 28.33 \\
\hline 37 & 6.54 & 29.11 & 6.54 & 29.11 & 6.54 & 29.11 & 6.54 & 29.11 \\
\hline 38 & 6.56 & 29.90 & 6.56 & 29.90 & 6.56 & 29.90 & 6.56 & 29.90 \\
\hline 39 & 6.56 & 30.69 & 6.56 & 30.69 & 6.56 & 30.69 & 6.56 & 30.69 \\
\hline 40 & 6.59 & 31.47 & 6.58 & 31.47 & 6.58 & 31.47 & 6.58 & 31.47 \\
\hline 41 & 6.59 & 32.26 & 6.59 & 32.26 & 6.59 & 32.26 & 6.59 & 32.26 \\
\hline 42 & 6.61 & 33.05 & 6.61 & 33.05 & 6.61 & 33.05 & 6.61 & 33.05 \\
\hline 43 & 6.61 & 33.83 & 6.61 & 33.83 & 6.61 & 33.83 & 6.61 & 33.83 \\
\hline 44 & 6.64 & 34.62 & 6.63 & 34.62 & 6.63 & 34.62 & 6.63 & 34.62 \\
\hline 45 & 6.64 & 35.41 & 6.64 & 35.41 & 6.64 & 35.41 & 6.64 & 35.41 \\
\hline 46 & 6.66 & 36.19 & 6.66 & 36.19 & 6.66 & 36.19 & 6.66 & 36.19 \\
\hline 47 & 6.66 & 36.98 & 6.66 & 36.98 & 6.66 & 36.98 & 6.66 & 36.98 \\
\hline 48 & 6.69 & 37.77 & 6.69 & 37.77 & 6.68 & 37.77 & 6.69 & 37.77 \\
\hline 49 & 6.69 & 38.55 & 6.69 & 38.55 & 6.69 & 38.55 & 6.69 & 38.56 \\
\hline 50 & 6.71 & 39.34 & 6.71 & 39.34 & 6.71 & 39.34 & 6.71 & 39.34 \\
\hline 51 & 6.72 & 40.13 & 6.71 & 40.13 & 6.71 & 40.13 & 6.72 & 40.13 \\
\hline 52 & 6.74 & 40.92 & 6.74 & 40.92 & 6.74 & 40.92 & 6.74 & 40.92 \\
\hline 53 & 6.74 & 41.70 & 6.74 & 41.70 & 6.74 & 41.70 & 6.74 & 41.70 \\
\hline 54 & 6.77 & 42.49 & 6.76 & 42.49 & 6.76 & 42.49 & 6.76 & 42.49 \\
\hline 55 & 6.77 & 43.28 & 6.77 & 43.28 & 6.77 & 43.28 & 6.77 & 43.28 \\
\hline 56 & 6.79 & 44.06 & 6.79 & 44.06 & 6.79 & 44.06 & 6.79 & 44.06 \\
\hline 57 & 6.80 & 44.85 & 6.79 & 44.85 & 6.79 & 44.85 & 6.79 & 44.85 \\
\hline 58 & 6.82 & 45.64 & 6.82 & 45.64 & 6.82 & 45.64 & 6.82 & 45.64 \\
\hline 59 & 6.82 & 46.42 & 6.82 & 46.42 & 6.82 & 46.42 & 6.82 & 46.42 \\
\hline 60 & 6.85 & 47.21 & 6.84 & 47.21 & 6.84 & 47.21 & 6.84 & 47.21 \\
\hline 61 & 6.85 & 48.00 & 6.85 & 48.00 & 6.85 & 48.00 & 6.85 & 48.00 \\
\hline 62 & 6.87 & 48.78 & 6.87 & 48.78 & 6.87 & 48.78 & 6.87 & 48.78 \\
\hline 63 & 6.88 & 49.57 & 6.88 & 49.57 & 6.88 & 49.57 & 6.87 & 49.57 \\
\hline 64 & 6.90 & 50.36 & 6.90 & 50.36 & 6.90 & 50.36 & 6.90 & 50.36 \\
\hline 65 & 6.91 & 51.14 & 6.90 & 51.14 & 6.90 & 51.14 & 6.90 & 51.14 \\
\hline 66 & 6.93 & 51.93 & 6.93 & 51.93 & 6.93 & 51.93 & 6.93 & 51.93 \\
\hline 67 & 6.93 & 52.72 & 6.93 & 52.72 & 6.93 & 52.72 & 6.93 & 52.72 \\
\hline 68 & 6.96 & 53.50 & 6.96 & 53.50 & 6.95 & 53.50 & 6.95 & 53.51 \\
\hline 69 & 6.96 & 54.29 & 6.96 & 54.29 & 6.96 & 54.29 & 6.96 & 54.29 \\
\hline 70 & 6.99 & 55.08 & 6.99 & 55.08 & 6.98 & 55.08 & 6.98 & 55.08 \\
\hline 71 & 6.99 & 55.86 & 6.99 & 55.86 & 6.99 & 55.86 & 6.99 & 55.87 \\
\hline 72 & 7.02 & 56.65 & 7.02 & 56.65 & 7.01 & 56.65 & 7.01 & 56.65 \\
\hline 73 & 7.02 & 57.44 & 7.02 & 57.44 & 7.02 & 57.44 & 7.02 & 57.44 \\
\hline 74 & 7.05 & 58.22 & 7.05 & 58.22 & 7.05 & 58.23 & 7.04 & 58.23 \\
\hline 75 & 7.05 & 59.01 & 7.05 & 59.01 & 7.05 & 59.01 & 7.05 & 59.01 \\
\hline 76 & 7.07 & 59.80 & 7.08 & 59.80 & 7.07 & 59.80 & 7.08 & 59.80 \\
\hline 77 & 7.08 & 60.59 & 7.07 & 60.59 & 7.08 & 60.59 & 7.08 & 60.59 \\
\hline 78 & 7.10 & 61.37 & 7.10 & 61.37 & 7.10 & 61.37 & 7.11 & 61.37 \\
\hline 79 & 7.11 & 62.16 & 7.11 & 62.16 & 7.10 & 62.16 & 7.11 & 62.16 \\
\hline 80 & 7.14 & 62.95 & 7.14 & 62.95 & 7.14 & 62.95 & 7.13 & 62.95 \\
\hline 81 & 7.14 & 63.73 & 7.14 & 63.73 & 7.14 & 63.73 & 7.14 & 63.73 \\
\hline 82 & 7.17 & 64.52 & 7.16 & 64.52 & 7.17 & 64.52 & 7.16 & 64.52 \\
\hline 83 & 7.17 & 65.31 & 7.17 & 65.31 & 7.17 & 65.31 & 7.17 & 65.31 \\
\hline 84 & 7.20 & 66.09 & 7.20 & 66.09 & 7.19 & 66.09 & 7.20 & 66.09 \\
\hline 85 & 7.20 & 66.88 & 7.20 & 66.88 & 7.20 & 66.88 & 7.20 & 66.88 \\
\hline 86 & 7.24 & 67.67 & 7.24 & 67.67 & 7.23 & 67.67 & 7.23 & 67.67 \\
\hline 87 & 7.24 & 68.45 & 7.23 & 68.45 & 7.24 & 68.45 & 7.24 & 68.45 \\
\hline 88 & 7.27 & 69.24 & 7.26 & 69.24 & 7.26 & 69.24 & 7.26 & 69.24 \\
\hline 89 & 7.27 & 70.03 & 7.27 & 70.03 & 7.27 & 70.03 & 7.27 & 70.03 \\
\hline 90 & 7.30 & 70.81 & 7.30 & 70.81 & 7.30 & 70.81 & 7.29 & 70.82 \\
\hline 91 & 7.30 & 71.60 & 7.30 & 71.60 & 7.30 & 71.60 & 7.30 & 71.60 \\
\hline 92 & 7.33 & 72.39 & 7.33 & 72.39 & 7.33 & 72.39 & 7.33 & 72.39 \\
\hline 93 & 7.33 & 73.17 & 7.33 & 73.17 & 7.33 & 73.17 & 7.33 & 73.18 \\
\hline 94 & 7.37 & 73.96 & 7.37 & 73.96 & 7.36 & 73.96 & 7.36 & 73.96 \\
\hline 95 & 7.37 & 74.75 & 7.36 & 74.75 & 7.37 & 74.75 & 7.36 & 74.75 \\
\hline 96 & 7.40 & 75.53 & 7.40 & 75.53 & 7.40 & 75.53 & 7.40 & 75.54 \\
\hline 97 & 7.40 & 76.32 & 7.40 & 76.32 & 7.41 & 76.32 & 7.40 & 76.32 \\
\hline 98 & 7.44 & 77.11 & 7.44 & 77.11 & 7.43 & 77.11 & 7.43 & 77.11 \\
\hline
\end{tabular}




\begin{tabular}{|c|c|c|c|c|c|c|c|c|}
\hline 99 & 7.44 & 77.89 & 7.44 & 77.89 & 7.43 & 77.90 & 7.43 & 77.90 \\
\hline 100 & 7.47 & 78.68 & 7.47 & 78.68 & 7.47 & 78.68 & 7.47 & 78.68 \\
\hline 101 & 7.47 & 79.47 & 7.47 & 79.47 & 7.47 & 79.47 & 7.47 & 79.47 \\
\hline 102 & 7.51 & 80.26 & 7.50 & 80.26 & 7.50 & 80.26 & 7.51 & 80.26 \\
\hline 103 & 7.51 & 81.04 & 7.51 & 81.04 & 7.51 & 81.04 & 7.50 & 81.04 \\
\hline 104 & 7.55 & 81.83 & 7.54 & 81.83 & 7.54 & 81.83 & 7.54 & 81.83 \\
\hline 105 & 7.55 & 82.62 & 7.55 & 82.62 & 7.55 & 82.62 & 7.55 & 82.62 \\
\hline 106 & 7.58 & 83.40 & 7.58 & 83.40 & 7.58 & 83.40 & 7.58 & 83.40 \\
\hline 107 & 7.59 & 84.19 & 7.58 & 84.19 & 7.58 & 84.19 & 7.58 & 84.19 \\
\hline 108 & 7.62 & 84.98 & 7.62 & 84.98 & 7.62 & 84.98 & 7.62 & 84.98 \\
\hline 109 & 7.62 & 85.76 & 7.62 & 85.76 & 7.62 & 85.76 & 7.62 & 85.76 \\
\hline 110 & 7.66 & 86.55 & 7.65 & 86.55 & 7.66 & 86.55 & 7.66 & 86.55 \\
\hline 111 & 7.66 & 87.34 & 7.66 & 87.34 & 7.66 & 87.34 & 7.65 & 87.34 \\
\hline 112 & 7.70 & 88.12 & 7.70 & 88.12 & 7.70 & 88.12 & 7.69 & 88.12 \\
\hline 113 & 7.70 & 88.91 & 7.69 & 88.91 & 7.69 & 88.91 & 7.69 & 88.91 \\
\hline 114 & 7.74 & 89.70 & 7.73 & 89.70 & 7.74 & 89.70 & 7.74 & 89.70 \\
\hline 115 & 7.74 & 90.48 & 7.74 & 90.48 & 7.73 & 90.48 & 7.73 & 90.49 \\
\hline 116 & 7.78 & 91.27 & 7.77 & 91.27 & 7.78 & 91.27 & 7.77 & 91.27 \\
\hline 117 & 7.79 & 92.06 & 7.78 & 92.06 & 7.78 & 92.06 & 7.77 & 92.06 \\
\hline 118 & 7.82 & 92.84 & 7.82 & 92.84 & 7.82 & 92.84 & 7.82 & 92.85 \\
\hline 119 & 7.82 & 93.63 & 7.82 & 93.63 & 7.82 & 93.63 & 7.81 & 93.63 \\
\hline 120 & 7.87 & 94.42 & 7.86 & 94.42 & 7.86 & 94.42 & 7.86 & 94.42 \\
\hline
\end{tabular}

\section{Effect of Porosity on Mixing}

\begin{tabular}{|c|c|c|c|c|c|c|c|c|}
\hline \multicolumn{9}{|c|}{ Bottom Placement of Nitrogen } \\
\hline Time & Porosity - 10\% & & Porosity - 15\% & & Porosity - 20\% & & Porosity - 25\% & \\
\hline (days) & $\begin{array}{c}\% \mathrm{~N}_{2} \text { in } \\
\text { withdrawn gas }\end{array}$ & $\begin{array}{c}\text { \% W.G } \\
\text { withdrawn } \\
\text { (by volume) }\end{array}$ & $\begin{array}{c}\% \mathrm{~N}_{2} \text { in } \\
\text { withdrawn gas }\end{array}$ & $\begin{array}{c}\text { \% W.G } \\
\text { withdrawn } \\
\text { (by volume) }\end{array}$ & $\begin{array}{c}\% \mathrm{~N}_{2} \text { in } \\
\text { withdrawn gas }\end{array}$ & $\begin{array}{c}\text { \% W.G } \\
\text { withdrawn } \\
\text { (by volume) }\end{array}$ & $\begin{array}{c}\% \mathrm{~N}_{2} \text { in } \\
\text { withdrawn gas }\end{array}$ & $\begin{array}{c}\% \text { W.G } \\
\text { withdrawn } \\
\text { (by volume) }\end{array}$ \\
\hline 1 & 0.33 & 0.84 & 0.35 & 0.84 & 0.36 & 0.84 & 0.36 & 0.84 \\
\hline 2 & 2.05 & 1.67 & 2.12 & 1.67 & 2.14 & 1.67 & 2.15 & 1.67 \\
\hline 3 & 2.51 & 2.51 & 2.59 & 2.51 & 2.61 & 2.51 & 2.62 & 2.51 \\
\hline 4 & 4.95 & 3.34 & 5.03 & 3.34 & 5.05 & 3.34 & 5.03 & 3.34 \\
\hline 5 & 5.56 & 4.18 & 5.65 & 4.18 & 5.66 & 4.18 & 5.63 & 4.18 \\
\hline 6 & 5.65 & 5.01 & 5.69 & 5.01 & 5.70 & 5.01 & 5.69 & 5.01 \\
\hline 7 & 5.67 & 5.85 & 5.71 & 5.85 & 5.71 & 5.85 & 5.70 & 5.85 \\
\hline 8 & 5.82 & 6.68 & 5.85 & 6.68 & 5.85 & 6.68 & 5.85 & 6.68 \\
\hline 9 & 5.86 & 7.52 & 5.89 & 7.52 & 5.89 & 7.52 & 5.89 & 7.52 \\
\hline 10 & 5.96 & 8.36 & 5.98 & 8.36 & 5.98 & 8.36 & 5.99 & 8.36 \\
\hline 11 & 5.98 & 9.19 & 6.00 & 9.19 & 6.01 & 9.19 & 6.01 & 9.19 \\
\hline 12 & 6.06 & 10.03 & 6.08 & 10.03 & 6.08 & 10.03 & 6.08 & 10.03 \\
\hline 13 & 6.08 & 10.86 & 6.10 & 10.86 & 6.10 & 10.86 & 6.10 & 10.86 \\
\hline 14 & 6.14 & 11.70 & 6.15 & 11.70 & 6.16 & 11.70 & 6.16 & 11.70 \\
\hline 15 & 6.16 & 12.53 & 6.17 & 12.53 & 6.17 & 12.53 & 6.18 & 12.53 \\
\hline 16 & 6.21 & 13.37 & 6.22 & 13.37 & 6.22 & 13.37 & 6.23 & 13.37 \\
\hline 17 & 6.22 & 14.20 & 6.23 & 14.20 & 6.23 & 14.20 & 6.24 & 14.20 \\
\hline 18 & 6.26 & 15.04 & 6.27 & 15.04 & 6.27 & 15.04 & 6.28 & 15.04 \\
\hline 19 & 6.27 & 15.88 & 6.28 & 15.88 & 6.28 & 15.88 & 6.29 & 15.88 \\
\hline 20 & 6.31 & 16.71 & 6.31 & 16.71 & 6.32 & 16.71 & 6.32 & 16.71 \\
\hline 21 & 6.31 & 17.55 & 6.32 & 17.55 & 6.33 & 17.55 & 6.33 & 17.55 \\
\hline 22 & 6.35 & 18.38 & 6.35 & 18.38 & 6.35 & 18.38 & 6.36 & 18.38 \\
\hline 23 & 6.35 & 19.22 & 6.36 & 19.22 & 6.36 & 19.22 & 6.37 & 19.22 \\
\hline 24 & 6.38 & 20.05 & 6.39 & 20.05 & 6.39 & 20.05 & 6.40 & 20.05 \\
\hline 25 & 6.39 & 20.89 & 6.40 & 20.89 & 6.40 & 20.89 & 6.40 & 20.89 \\
\hline 26 & 6.41 & 21.72 & 6.42 & 21.72 & 6.42 & 21.72 & 6.43 & 21.72 \\
\hline 27 & 6.42 & 22.56 & 6.43 & 22.56 & 6.43 & 22.56 & 6.43 & 22.56 \\
\hline 28 & 6.44 & 23.40 & 6.45 & 23.40 & 6.45 & 23.40 & 6.46 & 23.40 \\
\hline 29 & 6.45 & 24.23 & 6.46 & 24.23 & 6.46 & 24.23 & 6.46 & 24.23 \\
\hline 30 & 6.47 & 25.07 & 6.48 & 25.07 & 6.48 & 25.07 & 6.49 & 25.07 \\
\hline 31 & 6.48 & 25.90 & 6.49 & 25.90 & 6.49 & 25.90 & 6.49 & 25.90 \\
\hline 32 & 6.50 & 26.74 & 6.51 & 26.74 & 6.51 & 26.74 & 6.51 & 26.74 \\
\hline 33 & 6.50 & 27.57 & 6.52 & 27.57 & 6.52 & 27.57 & 6.52 & 27.57 \\
\hline 34 & 6.53 & 28.41 & 6.54 & 28.41 & 6.54 & 28.41 & 6.54 & 28.41 \\
\hline 35 & 6.53 & 29.24 & 6.54 & 29.24 & 6.55 & 29.24 & 6.55 & 29.24 \\
\hline 36 & 6.55 & 30.08 & 6.56 & 30.08 & 6.56 & 30.08 & 6.57 & 30.08 \\
\hline 37 & 6.56 & 30.92 & 6.57 & 30.92 & 6.57 & 30.92 & 6.57 & 30.92 \\
\hline 38 & 6.58 & 31.75 & 6.59 & 31.75 & 6.59 & 31.75 & 6.59 & 31.75 \\
\hline 39 & 6.58 & 32.59 & 6.60 & 32.59 & 6.60 & 32.59 & 6.60 & 32.59 \\
\hline 40 & 6.61 & 33.42 & 6.62 & 33.42 & 6.62 & 33.42 & 6.62 & 33.42 \\
\hline 41 & 6.61 & 34.26 & 6.63 & 34.26 & 6.63 & 34.26 & 6.63 & 34.26 \\
\hline 42 & 6.63 & 35.09 & 6.64 & 35.09 & 6.64 & 35.09 & 6.65 & 35.09 \\
\hline
\end{tabular}




\begin{tabular}{|c|c|c|c|c|c|c|c|c|}
\hline 43 & 6.64 & 35.93 & 6.65 & 35.93 & 6.65 & 35.93 & 6.66 & 35.93 \\
\hline 44 & 6.66 & 36.76 & 6.67 & 36.76 & 6.67 & 36.76 & 6.67 & 36.76 \\
\hline 45 & 6.66 & 37.60 & 6.68 & 37.60 & 6.68 & 37.60 & 6.68 & 37.60 \\
\hline 46 & 6.69 & 38.43 & 6.70 & 38.44 & 6.70 & 38.44 & 6.70 & 38.43 \\
\hline 47 & 6.69 & 39.27 & 6.71 & 39.27 & 6.71 & 39.27 & 6.71 & 39.27 \\
\hline 48 & 6.71 & 40.11 & 6.73 & 40.11 & 6.73 & 40.11 & 6.73 & 40.11 \\
\hline 49 & 6.72 & 40.94 & 6.74 & 40.94 & 6.74 & 40.94 & 6.74 & 40.94 \\
\hline 50 & 6.74 & 41.78 & 6.75 & 41.78 & 6.75 & 41.78 & 6.76 & 41.78 \\
\hline 51 & 6.74 & 42.61 & 6.76 & 42.61 & 6.77 & 42.61 & 6.76 & 42.61 \\
\hline 52 & 6.77 & 43.45 & 6.78 & 43.45 & 6.78 & 43.45 & 6.79 & 43.45 \\
\hline 53 & 6.77 & 44.28 & 6.79 & 44.28 & 6.79 & 44.28 & 6.79 & 44.28 \\
\hline 54 & 6.80 & 45.12 & 6.81 & 45.12 & 6.81 & 45.12 & 6.82 & 45.12 \\
\hline 55 & 6.80 & 45.95 & 6.82 & 45.95 & 6.82 & 45.95 & 6.82 & 45.95 \\
\hline 56 & 6.82 & 46.79 & 6.84 & 46.79 & 6.84 & 46.79 & 6.84 & 46.79 \\
\hline 57 & 6.83 & 47.63 & 6.85 & 47.63 & 6.85 & 47.63 & 6.85 & 47.63 \\
\hline 58 & 6.85 & 48.46 & 6.87 & 48.46 & 6.87 & 48.46 & 6.88 & 48.46 \\
\hline 59 & 6.86 & 49.30 & 6.88 & 49.30 & 6.88 & 49.30 & 6.88 & 49.30 \\
\hline 60 & 6.88 & 50.13 & 6.90 & 50.13 & 6.90 & 50.13 & 6.90 & 50.13 \\
\hline 61 & 6.88 & 50.97 & 6.91 & 50.97 & 6.91 & 50.97 & 6.91 & 50.97 \\
\hline 62 & 6.91 & 51.80 & 6.93 & 51.80 & 6.93 & 51.80 & 6.93 & 51.80 \\
\hline 63 & 6.91 & 52.64 & 6.94 & 52.64 & 6.94 & 52.64 & 6.94 & 52.64 \\
\hline 64 & 6.94 & 53.47 & 6.96 & 53.47 & 6.96 & 53.47 & 6.96 & 53.47 \\
\hline 65 & 6.94 & 54.31 & 6.97 & 54.31 & 6.97 & 54.31 & 6.97 & 54.31 \\
\hline 66 & 6.97 & 55.15 & 6.99 & 55.15 & 6.99 & 55.15 & 6.99 & 55.15 \\
\hline 67 & 6.97 & 55.98 & 7.00 & 55.98 & 7.00 & 55.98 & 7.00 & 55.98 \\
\hline 68 & 7.00 & 56.82 & 7.02 & 56.82 & 7.03 & 56.82 & 7.03 & 56.82 \\
\hline 69 & 7.00 & 57.65 & 7.03 & 57.65 & 7.03 & 57.65 & 7.03 & 57.65 \\
\hline 70 & 7.03 & 58.49 & 7.05 & 58.49 & 7.05 & 58.49 & 7.06 & 58.49 \\
\hline 71 & 7.03 & 59.32 & 7.06 & 59.32 & 7.06 & 59.32 & 7.06 & 59.32 \\
\hline 72 & 7.06 & 60.16 & 7.08 & 60.16 & 7.09 & 60.16 & 7.09 & 60.16 \\
\hline 73 & 7.07 & 60.99 & 7.09 & 60.99 & 7.09 & 60.99 & 7.09 & 60.99 \\
\hline 74 & 7.09 & 61.83 & 7.11 & 61.83 & 7.12 & 61.83 & 7.12 & 61.83 \\
\hline 75 & 7.10 & 62.67 & 7.13 & 62.67 & 7.13 & 62.67 & 7.13 & 62.66 \\
\hline 76 & 7.13 & 63.50 & 7.15 & 63.50 & 7.15 & 63.50 & 7.16 & 63.50 \\
\hline 77 & 7.13 & 64.34 & 7.16 & 64.34 & 7.16 & 64.34 & 7.16 & 64.34 \\
\hline 78 & 7.16 & 65.17 & 7.18 & 65.17 & 7.19 & 65.17 & 7.19 & 65.17 \\
\hline 79 & 7.16 & 66.01 & 7.20 & 66.01 & 7.19 & 66.01 & 7.20 & 66.01 \\
\hline 80 & 7.19 & 66.84 & 7.21 & 66.84 & 7.22 & 66.84 & 7.22 & 66.84 \\
\hline 81 & 7.19 & 67.68 & 7.23 & 67.68 & 7.23 & 67.68 & 7.23 & 67.68 \\
\hline 82 & 7.23 & 68.51 & 7.25 & 68.51 & 7.25 & 68.51 & 7.26 & 68.51 \\
\hline 83 & 7.23 & 69.35 & 7.26 & 69.35 & 7.26 & 69.35 & 7.26 & 69.35 \\
\hline 84 & 7.26 & 70.18 & 7.29 & 70.18 & 7.29 & 70.18 & 7.29 & 70.18 \\
\hline 85 & 7.26 & 71.02 & 7.29 & 71.02 & 7.30 & 71.02 & 7.30 & 71.02 \\
\hline 86 & 7.29 & 71.86 & 7.32 & 71.86 & 7.32 & 71.86 & 7.33 & 71.86 \\
\hline 87 & 7.30 & 72.69 & 7.33 & 72.69 & 7.33 & 72.69 & 7.33 & 72.69 \\
\hline 88 & 7.33 & 73.53 & 7.36 & 73.53 & 7.36 & 73.53 & 7.36 & 73.53 \\
\hline 89 & 7.33 & 74.36 & 7.37 & 74.36 & 7.37 & 74.36 & 7.37 & 74.36 \\
\hline 90 & 7.37 & 75.20 & 7.39 & 75.20 & 7.40 & 75.20 & 7.40 & 75.20 \\
\hline 91 & 7.36 & 76.03 & 7.40 & 76.03 & 7.41 & 76.03 & 7.41 & 76.03 \\
\hline 92 & 7.40 & 76.87 & 7.43 & 76.87 & 7.43 & 76.87 & 7.44 & 76.87 \\
\hline 93 & 7.40 & 77.70 & 7.44 & 77.70 & 7.44 & 77.70 & 7.44 & 77.70 \\
\hline 94 & 7.43 & 78.54 & 7.47 & 78.54 & 7.47 & 78.54 & 7.48 & 78.54 \\
\hline 95 & 7.44 & 79.38 & 7.48 & 79.38 & 7.48 & 79.38 & 7.48 & 79.38 \\
\hline 96 & 7.47 & 80.21 & 7.51 & 80.21 & 7.51 & 80.21 & 7.52 & 80.21 \\
\hline 97 & 7.48 & 81.05 & 7.51 & 81.05 & 7.52 & 81.05 & 7.52 & 81.05 \\
\hline 98 & 7.51 & 81.88 & 7.54 & 81.88 & 7.55 & 81.88 & 7.56 & 81.88 \\
\hline 99 & 7.51 & 82.72 & 7.55 & 82.72 & 7.56 & 82.72 & 7.56 & 82.72 \\
\hline 100 & 7.55 & 83.55 & 7.58 & 83.55 & 7.59 & 83.55 & 7.59 & 83.55 \\
\hline 101 & 7.55 & 84.39 & 7.59 & 84.39 & 7.60 & 84.39 & 7.60 & 84.39 \\
\hline 102 & 7.59 & 85.22 & 7.62 & 85.22 & 7.63 & 85.22 & 7.64 & 85.22 \\
\hline 103 & 7.59 & 86.06 & 7.64 & 86.06 & 7.64 & 86.06 & 7.64 & 86.06 \\
\hline 104 & 7.63 & 86.89 & 7.67 & 86.89 & 7.67 & 86.89 & 7.67 & 86.89 \\
\hline 105 & 7.63 & 87.73 & 7.68 & 87.73 & 7.68 & 87.73 & 7.68 & 87.73 \\
\hline 106 & 7.67 & 88.57 & 7.71 & 88.57 & 7.71 & 88.57 & 7.72 & 88.57 \\
\hline 107 & 7.67 & 89.40 & 7.71 & 89.40 & 7.73 & 89.40 & 7.72 & 89.40 \\
\hline 108 & 7.71 & 90.24 & 7.76 & 90.24 & 7.75 & 90.24 & 7.76 & 90.24 \\
\hline 109 & 7.71 & 91.07 & 7.76 & 91.07 & 7.77 & 91.07 & 7.76 & 91.07 \\
\hline 110 & 7.75 & 91.91 & 7.80 & 91.91 & 7.79 & 91.91 & 7.80 & 91.91 \\
\hline 111 & 7.76 & 92.74 & 7.80 & 92.74 & 7.81 & 92.74 & 7.81 & 92.74 \\
\hline 112 & 7.79 & 93.58 & 7.84 & 93.58 & 7.84 & 93.58 & 7.85 & 93.58 \\
\hline 113 & 7.80 & 94.41 & 7.85 & 94.41 & 7.86 & 94.41 & 7.85 & 94.41 \\
\hline 114 & 7.83 & 95.25 & 7.89 & 95.25 & 7.88 & 95.25 & 7.89 & 95.25 \\
\hline 115 & 7.84 & 96.08 & 7.89 & 96.08 & 7.90 & 96.08 & 7.90 & 96.08 \\
\hline 116 & 7.88 & 96.92 & 7.93 & 96.92 & 7.93 & 96.92 & 7.94 & 96.92 \\
\hline 117 & 7.88 & 97.76 & 7.94 & 97.76 & 7.95 & 97.76 & 7.94 & 97.76 \\
\hline 118 & 7.92 & 98.59 & 7.98 & 98.59 & 7.97 & 98.59 & 7.99 & 98.59 \\
\hline 119 & 7.93 & 99.43 & 7.99 & 99.43 & 8.00 & 99.43 & 7.99 & 99.43 \\
\hline 120 & 7.98 & 100.26 & 8.03 & 100.26 & 8.03 & 100.26 & 8.04 & 100.26 \\
\hline
\end{tabular}




\section{Effect on Mixing due to Variation in Percentage of Nitrogen Cushion in Reservoir}

\begin{tabular}{|c|c|c|c|c|c|c|c|c|}
\hline \multicolumn{9}{|c|}{ Bottom Placement of Nitrogen } \\
\hline \multirow{2}{*}{$\begin{array}{l}\text { Time } \\
\text { (days) }\end{array}$} & \multicolumn{2}{|c|}{ Base Gas - $5 \%$ Nitrogen } & \multicolumn{2}{|c|}{ Base Gas - $10 \%$ Nitrogen } & \multicolumn{2}{|c|}{ Base Gas - $15 \%$ Nitrogen } & \multicolumn{2}{|c|}{ Base Gas - $20 \%$ Nitrogen } \\
\hline & $\begin{array}{c}\% \mathrm{~N}_{2} \text { in } \\
\text { withdrawn } \\
\text { gas }\end{array}$ & $\begin{array}{c}\% \text { W.G } \\
\text { withdrawn } \\
\text { (volume) }\end{array}$ & $\begin{array}{c}\% \mathrm{~N}_{2} \text { in } \\
\text { withdrawn } \\
\text { gas }\end{array}$ & $\begin{array}{c}\text { \% W.G } \\
\text { withdrawn } \\
\text { (volume) }\end{array}$ & $\begin{array}{c}\% \mathrm{~N}_{2} \text { in } \\
\text { withdrawn } \\
\text { gas }\end{array}$ & $\begin{array}{c}\% \text { W.G } \\
\text { withdrawn } \\
\text { (volume) }\end{array}$ & $\begin{array}{c}\% \mathrm{~N}_{2} \text { in } \\
\text { withdrawn } \\
\text { gas }\end{array}$ & $\begin{array}{c}\% \text { W.G } \\
\text { withdrawn } \\
\text { (volume) }\end{array}$ \\
\hline 1 & 0.01 & 0.79 & 0.03 & 0.79 & 0.06 & 0.79 & 0.36 & 0.79 \\
\hline 2 & 0.22 & 1.57 & 0.56 & 1.57 & 1.33 & 1.57 & 1.96 & 1.57 \\
\hline 3 & 0.28 & 2.36 & 0.70 & 2.36 & 4.42 & 2.36 & 7.20 & 2.36 \\
\hline 4 & 1.64 & 3.15 & 3.80 & 3.15 & 5.28 & 3.15 & 8.35 & 3.15 \\
\hline 5 & 2.00 & 3.93 & 4.61 & 3.93 & 7.23 & 3.93 & 10.38 & 3.93 \\
\hline 6 & 2.41 & 4.72 & 5.10 & 4.72 & 7.75 & 4.72 & 10.92 & 4.72 \\
\hline 7 & 2.52 & 5.51 & 5.22 & 5.51 & 8.14 & 5.51 & 11.04 & 5.51 \\
\hline 8 & 2.65 & 6.30 & 5.46 & 6.29 & 8.24 & 6.29 & 11.06 & 6.29 \\
\hline 9 & 2.69 & 7.08 & 5.52 & 7.08 & 8.57 & 7.08 & 11.85 & 7.08 \\
\hline 10 & 2.77 & 7.87 & 5.68 & 7.87 & 8.65 & 7.87 & 12.04 & 7.87 \\
\hline 11 & 2.79 & 8.66 & 5.72 & 8.66 & 8.85 & 8.65 & 12.09 & 8.65 \\
\hline 12 & 2.86 & 9.44 & 5.85 & 9.44 & 8.90 & 9.44 & 12.09 & 9.44 \\
\hline 13 & 2.87 & 10.23 & 5.88 & 10.23 & 9.07 & 10.23 & 12.39 & 10.23 \\
\hline 14 & 2.92 & 11.02 & 5.98 & 11.02 & 9.11 & 11.02 & 12.46 & 11.01 \\
\hline 15 & 2.93 & 11.80 & 6.00 & 11.80 & 9.25 & 11.80 & 12.62 & 11.80 \\
\hline 16 & 2.97 & 12.59 & 6.08 & 12.59 & 9.28 & 12.59 & 12.65 & 12.59 \\
\hline 17 & 2.98 & 13.38 & 6.10 & 13.38 & 9.39 & 13.38 & 12.80 & 13.37 \\
\hline 18 & 3.01 & 14.16 & 6.16 & 14.16 & 9.41 & 14.16 & 12.83 & 14.16 \\
\hline 19 & 3.02 & 14.95 & 6.18 & 14.95 & 9.50 & 14.95 & 12.94 & 14.95 \\
\hline 20 & 3.05 & 15.74 & 6.23 & 15.74 & 9.52 & 15.74 & 12.97 & 15.73 \\
\hline 21 & 3.05 & 16.52 & 6.24 & 16.52 & 9.60 & 16.52 & 13.06 & 16.52 \\
\hline 22 & 3.08 & 17.31 & 6.29 & 17.31 & 9.61 & 17.31 & 13.07 & 17.31 \\
\hline 23 & 3.08 & 18.10 & 6.30 & 18.10 & 9.68 & 18.10 & 13.14 & 18.09 \\
\hline 24 & 3.10 & 18.89 & 6.34 & 18.88 & 9.69 & 18.88 & 13.16 & 18.88 \\
\hline 25 & 3.11 & 19.67 & 6.35 & 19.67 & 9.75 & 19.67 & 13.21 & 19.67 \\
\hline 26 & 3.13 & 20.46 & 6.38 & 20.46 & 9.75 & 20.46 & 13.21 & 20.45 \\
\hline 27 & 3.13 & 21.25 & 6.39 & 21.24 & 9.81 & 21.24 & 13.24 & 21.24 \\
\hline 28 & 3.14 & 22.03 & 6.42 & 22.03 & 9.81 & 22.03 & 13.24 & 22.03 \\
\hline 29 & 3.15 & 22.82 & 6.43 & 22.82 & 9.86 & 22.82 & 13.50 & 22.81 \\
\hline 30 & 3.16 & 23.61 & 6.46 & 23.61 & 9.86 & 23.60 & 13.56 & 23.60 \\
\hline 31 & 3.16 & 24.39 & 6.46 & 24.39 & 9.91 & 24.39 & 13.60 & 24.39 \\
\hline 32 & 3.18 & 25.18 & 6.49 & 25.18 & 9.91 & 25.18 & 13.61 & 25.17 \\
\hline 33 & 3.18 & 25.97 & 6.49 & 25.97 & 9.96 & 25.96 & 13.62 & 25.96 \\
\hline 34 & 3.19 & 26.75 & 6.52 & 26.75 & 9.96 & 26.75 & 13.63 & 26.75 \\
\hline 35 & 3.20 & 27.54 & 6.52 & 27.54 & 10.00 & 27.54 & 13.64 & 27.54 \\
\hline 36 & 3.21 & 28.33 & 6.55 & 28.33 & 10.00 & 28.32 & 13.64 & 28.32 \\
\hline 37 & 3.21 & 29.12 & 6.55 & 29.11 & 10.04 & 29.11 & 13.64 & 29.11 \\
\hline 38 & 3.22 & 29.90 & 6.58 & 29.90 & 10.04 & 29.90 & 13.64 & 29.90 \\
\hline 39 & 3.22 & 30.69 & 6.58 & 30.69 & 10.08 & 30.68 & 13.69 & 30.68 \\
\hline 40 & 3.24 & 31.48 & 6.60 & 31.47 & 10.08 & 31.47 & 13.69 & 31.47 \\
\hline 41 & 3.24 & 32.26 & 6.61 & 32.26 & 10.12 & 32.26 & 13.73 & 32.26 \\
\hline 42 & 3.25 & 33.05 & 6.63 & 33.05 & 10.12 & 33.04 & 13.73 & 33.04 \\
\hline 43 & 3.25 & 33.84 & 6.63 & 33.83 & 10.16 & 33.83 & 13.75 & 33.83 \\
\hline 44 & 3.27 & 34.62 & 6.66 & 34.62 & 10.16 & 34.62 & 13.75 & 34.62 \\
\hline 45 & 3.27 & 35.41 & 6.66 & 35.41 & 10.20 & 35.40 & 13.75 & 35.40 \\
\hline 46 & 3.28 & 36.20 & 6.69 & 36.19 & 10.21 & 36.19 & 13.75 & 36.19 \\
\hline 47 & 3.28 & 36.98 & 6.69 & 36.98 & 10.24 & 36.98 & 13.92 & 36.98 \\
\hline 48 & 3.29 & 37.77 & 6.71 & 37.77 & 10.24 & 37.76 & 14.09 & 37.76 \\
\hline 49 & 3.29 & 38.56 & 6.72 & 38.55 & 10.28 & 38.55 & 14.09 & 38.55 \\
\hline 50 & 3.31 & 39.34 & 6.74 & 39.34 & 10.29 & 39.34 & 14.07 & 39.34 \\
\hline 51 & 3.31 & 40.13 & 6.74 & 40.13 & 10.32 & 40.13 & 14.03 & 40.12 \\
\hline 52 & 3.32 & 40.92 & 6.77 & 40.92 & 10.32 & 40.91 & 14.01 & 40.91 \\
\hline 53 & 3.32 & 41.71 & 6.77 & 41.70 & 10.36 & 41.70 & 14.04 & 41.70 \\
\hline 54 & 3.33 & 42.49 & 6.79 & 42.49 & 10.37 & 42.49 & 14.04 & 42.48 \\
\hline 55 & 3.33 & 43.28 & 6.80 & 43.28 & 10.40 & 43.27 & 14.08 & 43.27 \\
\hline 56 & 3.35 & 44.07 & 6.82 & 44.06 & 10.40 & 44.06 & 14.08 & 44.06 \\
\hline 57 & 3.35 & 44.85 & 6.82 & 44.85 & 10.44 & 44.85 & 14.11 & 44.84 \\
\hline 58 & 3.36 & 45.64 & 6.85 & 45.64 & 10.44 & 45.63 & 14.10 & 45.63 \\
\hline 59 & 3.36 & 46.43 & 6.85 & 46.42 & 10.48 & 46.42 & 14.16 & 46.42 \\
\hline 60 & 3.37 & 47.21 & 6.88 & 47.21 & 10.48 & 47.21 & 14.18 & 47.20 \\
\hline 61 & 3.37 & 48.00 & 6.88 & 48.00 & 10.53 & 47.99 & 14.23 & 47.99 \\
\hline 62 & 3.39 & 48.79 & 6.90 & 48.78 & 10.52 & 48.78 & 14.32 & 48.78 \\
\hline 63 & 3.39 & 49.57 & 6.91 & 49.57 & 10.56 & 49.57 & 14.36 & 49.56 \\
\hline 64 & 3.40 & 50.36 & 6.93 & 50.36 & 10.57 & 50.35 & 14.37 & 50.35 \\
\hline
\end{tabular}




\begin{tabular}{|c|c|c|c|c|c|c|c|c|}
\hline 65 & 3.40 & 51.15 & 6.93 & 51.14 & 10.61 & 51.14 & 14.38 & 51.14 \\
\hline 66 & 3.42 & 51.93 & 6.96 & 51.93 & 10.60 & 51.93 & 14.38 & 51.92 \\
\hline 67 & 3.42 & 52.72 & 6.96 & 52.72 & 10.65 & 52.71 & 14.40 & 52.71 \\
\hline 68 & 3.43 & 53.51 & 6.99 & 53.50 & 10.65 & 53.50 & 14.41 & 53.50 \\
\hline 69 & 3.43 & 54.30 & 6.99 & 54.29 & 10.69 & 54.29 & 14.46 & 54.28 \\
\hline 70 & 3.45 & 55.08 & 7.02 & 55.08 & 10.69 & 55.07 & 14.46 & 55.07 \\
\hline 71 & 3.45 & 55.87 & 7.02 & 55.86 & 10.73 & 55.86 & 14.48 & 55.86 \\
\hline 72 & 3.46 & 56.66 & 7.05 & 56.65 & 10.73 & 56.65 & 14.48 & 56.64 \\
\hline 73 & 3.46 & 57.44 & 7.05 & 57.44 & 10.78 & 57.43 & 14.49 & 57.43 \\
\hline 74 & 3.48 & 58.23 & 7.08 & 58.22 & 10.78 & 58.22 & 14.54 & 58.22 \\
\hline 75 & 3.48 & 59.02 & 7.08 & 59.01 & 10.83 & 59.01 & 14.61 & 59.00 \\
\hline 76 & 3.49 & 59.80 & 7.11 & 59.80 & 10.82 & 59.79 & 14.70 & 59.79 \\
\hline 77 & 3.49 & 60.59 & 7.11 & 60.59 & 10.87 & 60.58 & 14.72 & 60.58 \\
\hline 78 & 3.51 & 61.38 & 7.14 & 61.37 & 10.86 & 61.37 & 14.75 & 61.36 \\
\hline 79 & 3.51 & 62.16 & 7.14 & 62.16 & 10.91 & 62.15 & 14.76 & 62.15 \\
\hline 80 & 3.52 & 62.95 & 7.17 & 62.95 & 10.91 & 62.94 & 14.78 & 62.94 \\
\hline 81 & 3.52 & 63.74 & 7.17 & 63.73 & 10.95 & 63.73 & 14.81 & 63.72 \\
\hline 82 & 3.54 & 64.52 & 7.20 & 64.52 & 10.95 & 64.51 & 14.81 & 64.51 \\
\hline 83 & 3.54 & 65.31 & 7.21 & 65.31 & 11.00 & 65.30 & 14.90 & 65.30 \\
\hline 84 & 3.56 & 66.10 & 7.24 & 66.09 & 11.00 & 66.09 & 14.90 & 66.08 \\
\hline 85 & 3.56 & 66.89 & 7.24 & 66.88 & 11.05 & 66.87 & 14.96 & 66.87 \\
\hline 86 & 3.57 & 67.67 & 7.27 & 67.67 & 11.05 & 67.66 & 15.00 & 67.66 \\
\hline 87 & 3.57 & 68.46 & 7.27 & 68.45 & 11.10 & 68.45 & 15.03 & 68.44 \\
\hline 88 & 3.59 & 69.25 & 7.30 & 69.24 & 11.09 & 69.23 & 15.07 & 69.23 \\
\hline 89 & 3.59 & 70.03 & 7.30 & 70.03 & 11.14 & 70.02 & 15.09 & 70.02 \\
\hline 90 & 3.61 & 70.82 & 7.33 & 70.81 & 11.14 & 70.81 & 15.16 & 70.80 \\
\hline 91 & 3.61 & 71.61 & 7.33 & 71.60 & 11.20 & 71.59 & 15.17 & 71.59 \\
\hline 92 & 3.62 & 72.39 & 7.37 & 72.39 & 11.19 & 72.38 & 15.17 & 72.38 \\
\hline 93 & 3.63 & 73.18 & 7.36 & 73.17 & 11.24 & 73.17 & 15.15 & 73.16 \\
\hline 94 & 3.64 & 73.97 & 7.41 & 73.96 & 11.24 & 73.95 & 15.19 & 73.95 \\
\hline 95 & 3.64 & 74.75 & 7.40 & 74.75 & 11.29 & 74.74 & 15.20 & 74.74 \\
\hline 96 & 3.66 & 75.54 & 7.44 & 75.53 & 11.29 & 75.53 & 15.22 & 75.52 \\
\hline 97 & 3.66 & 76.33 & 7.44 & 76.32 & 11.34 & 76.31 & 15.36 & 76.31 \\
\hline 98 & 3.68 & 77.11 & 7.47 & 77.11 & 11.34 & 77.10 & 15.37 & 77.09 \\
\hline 99 & 3.68 & 77.90 & 7.47 & 77.89 & 11.40 & 77.89 & 15.40 & 77.88 \\
\hline 100 & 3.70 & 78.69 & 7.51 & 78.68 & 11.39 & 78.67 & 15.46 & 78.67 \\
\hline 101 & 3.70 & 79.47 & 7.51 & 79.47 & 11.45 & 79.46 & 15.50 & 79.46 \\
\hline 102 & 3.72 & 80.26 & 7.55 & 80.26 & 11.44 & 80.25 & 15.52 & 80.24 \\
\hline 103 & 3.71 & 81.05 & 7.55 & 81.04 & 11.50 & 81.03 & 15.55 & 81.03 \\
\hline 104 & 3.74 & 81.84 & 7.58 & 81.83 & 11.50 & 81.82 & 15.63 & 81.81 \\
\hline 105 & 3.73 & 82.62 & 7.58 & 82.62 & 11.56 & 82.61 & 15.63 & 82.60 \\
\hline 106 & 3.75 & 83.41 & 7.62 & 83.40 & 11.55 & 83.39 & 15.65 & 83.39 \\
\hline 107 & 3.75 & 84.20 & 7.62 & 84.19 & 11.61 & 84.18 & 15.69 & 84.17 \\
\hline 108 & 3.77 & 84.98 & 7.66 & 84.98 & 11.61 & 84.97 & 15.72 & 84.96 \\
\hline 109 & 3.77 & 85.77 & 7.66 & 85.76 & 11.66 & 85.76 & 15.74 & 85.75 \\
\hline 110 & 3.79 & 86.56 & 7.70 & 86.55 & 11.66 & 86.54 & 15.77 & 86.53 \\
\hline 111 & 3.79 & 87.34 & 7.70 & 87.34 & 11.72 & 87.33 & 15.88 & 87.32 \\
\hline 112 & 3.81 & 88.13 & 7.74 & 88.12 & 11.71 & 88.12 & 15.82 & 88.11 \\
\hline 113 & 3.81 & 88.92 & 7.74 & 88.91 & 11.79 & 88.90 & 15.90 & 88.89 \\
\hline 114 & 3.83 & 89.70 & 7.78 & 89.70 & 11.77 & 89.69 & 15.92 & 89.68 \\
\hline 115 & 3.84 & 90.49 & 7.78 & 90.48 & 11.84 & 90.48 & 15.92 & 90.47 \\
\hline 116 & 3.86 & 91.28 & 7.82 & 91.27 & 11.83 & 91.26 & 15.93 & 91.25 \\
\hline 117 & 3.86 & 92.06 & 7.82 & 92.06 & 11.90 & 92.05 & 15.94 & 92.04 \\
\hline 118 & 3.88 & 92.85 & 7.86 & 92.84 & 11.88 & 92.84 & 15.93 & 92.83 \\
\hline 119 & 3.88 & 93.64 & 7.87 & 93.63 & 11.96 & 93.62 & 16.13 & 93.61 \\
\hline 120 & 3.90 & 94.43 & 7.90 & 94.42 & 11.95 & 94.41 & 16.21 & 94.40 \\
\hline
\end{tabular}




\section{Effect on Mixing with Constant Pressure Withdrawal}

\section{Permeability - 100 md}

\begin{tabular}{|c|c|c|c|c|c|c|c|c|c|c|}
\hline \multicolumn{11}{|c|}{ Bottom Placement of Nitrogen } \\
\hline \multirow{2}{*}{$\begin{array}{l}\text { TIME } \\
\text { (days) }\end{array}$} & \multicolumn{2}{|c|}{$\begin{array}{l}\text { Withdrawal Pressure } \\
100 \text { psia }\end{array}$} & \multicolumn{2}{|c|}{$\begin{array}{c}\text { Withdrawal Pressure } \\
150 \text { psia }\end{array}$} & \multicolumn{2}{|c|}{$\begin{array}{c}\text { Withdrawal Pressure } \\
200 \text { psia }\end{array}$} & \multicolumn{2}{|c|}{$\begin{array}{c}\text { Withdrawal Pressure } \\
250 \text { psia }\end{array}$} & \multicolumn{2}{|c|}{$\begin{array}{c}\text { Withdrawal Pressure } \\
\mathbf{3 0 0} \text { psia }\end{array}$} \\
\hline & $\begin{array}{c}\% \mathrm{~N}_{2} \text { in } \\
\text { withdrawn } \\
\text { gas }\end{array}$ & $\begin{array}{c}\% \text { W.G } \\
\text { withdrawn } \\
\text { (volume) }\end{array}$ & $\begin{array}{c}\% \mathrm{~N}_{2} \text { in } \\
\text { withdrawn } \\
\text { gas }\end{array}$ & $\begin{array}{c}\% \text { W.G } \\
\text { withdrawn } \\
\text { (volume) }\end{array}$ & $\begin{array}{c}\% \mathrm{~N}_{2} \text { in } \\
\text { withdrawn } \\
\text { gas }\end{array}$ & $\begin{array}{c}\% \text { W.G } \\
\text { withdrawn } \\
\text { (volume) }\end{array}$ & $\begin{array}{l}\% \mathrm{~N}_{2} \text { in } \\
\text { withdrawn } \\
\text { gas }\end{array}$ & $\begin{array}{c}\% \text { W.G } \\
\text { withdrawn } \\
\text { (volume) }\end{array}$ & $\begin{array}{c}\% \mathrm{~N}_{2} \text { in } \\
\text { withdrawn } \\
\text { gas }\end{array}$ & $\begin{array}{c}\% \text { W.G } \\
\text { withdrawn } \\
\text { (volume) }\end{array}$ \\
\hline 0.01 & 0.00 & 0.03 & 0.00 & 0.02 & 0.00 & 0.02 & 0.00 & 0.01 & 0.00 & 0.01 \\
\hline 0.04 & 0.00 & 0.09 & 0.00 & 0.08 & 0.00 & 0.06 & 0.00 & 0.05 & 0.00 & 0.03 \\
\hline 0.10 & 0.00 & 0.25 & 0.00 & 0.21 & 0.00 & 0.17 & 0.00 & 0.13 & 0.00 & 0.08 \\
\hline 0.29 & 0.06 & 0.72 & 0.04 & 0.61 & 0.02 & 0.49 & 0.01 & 0.37 & 0.00 & 0.25 \\
\hline 0.85 & 1.85 & 2.11 & 1.57 & 1.77 & 0.84 & 1.44 & 0.53 & 1.09 & 0.05 & 0.73 \\
\hline 1.00 & 2.08 & 2.49 & 1.77 & 2.09 & 0.96 & 1.69 & 0.62 & 1.28 & 0.24 & 0.86 \\
\hline 2.00 & 3.15 & 4.90 & 2.95 & 4.12 & 2.74 & 3.34 & 2.24 & 2.53 & 1.58 & 1.71 \\
\hline 3.00 & 3.28 & 7.28 & 3.11 & 6.13 & 3.03 & 4.96 & 2.57 & 3.77 & 1.92 & 2.55 \\
\hline 4.00 & 3.68 & 9.62 & 3.64 & 8.12 & 3.60 & 6.57 & 3.43 & 5.00 & 2.92 & 3.38 \\
\hline 5.00 & 3.73 & 11.94 & 3.71 & 10.08 & 3.69 & 8.17 & 3.60 & 6.21 & 3.18 & 4.21 \\
\hline 6.00 & 3.71 & 14.24 & 3.67 & 12.03 & 3.59 & 9.75 & 3.55 & 7.42 & 3.39 & 5.03 \\
\hline 7.00 & 3.71 & 16.51 & 3.67 & 13.95 & 3.58 & 11.33 & 3.54 & 8.63 & 3.45 & 5.85 \\
\hline 8.00 & 3.80 & 18.75 & 3.76 & 15.86 & 3.73 & 12.89 & 3.64 & 9.82 & 3.52 & 6.66 \\
\hline 9.00 & 3.81 & 20.97 & 3.78 & 17.75 & 3.76 & 14.44 & 3.67 & 11.01 & 3.54 & 7.48 \\
\hline 10.00 & 3.81 & 23.16 & 3.79 & 19.63 & 3.75 & 15.97 & 3.70 & 12.19 & 3.59 & 8.28 \\
\hline 11.00 & 3.82 & 25.33 & 3.80 & 21.48 & 3.75 & 17.50 & 3.71 & 13.37 & 3.60 & 9.09 \\
\hline 12.00 & 3.85 & 27.47 & 3.82 & 23.32 & 3.79 & 19.01 & 3.74 & 14.54 & 3.64 & 9.89 \\
\hline 13.00 & 3.86 & 29.59 & 3.83 & 25.14 & 3.80 & 20.52 & 3.75 & 15.70 & 3.65 & 10.69 \\
\hline 14.00 & 3.87 & 31.68 & 3.85 & 26.94 & 3.81 & 22.01 & 3.77 & 16.86 & 3.69 & 11.49 \\
\hline 15.00 & 3.88 & 33.75 & 3.85 & 28.73 & 3.82 & 23.49 & 3.77 & 18.01 & 3.69 & 12.28 \\
\hline 16.00 & 3.90 & 35.79 & 3.87 & 30.50 & 3.84 & 24.95 & 3.79 & 19.15 & 3.72 & 13.07 \\
\hline 17.00 & 3.91 & 37.81 & 3.87 & 32.25 & 3.84 & 26.41 & 3.80 & 20.28 & 3.72 & 13.86 \\
\hline 18.00 & 3.92 & 39.81 & 3.89 & 33.99 & 3.85 & 27.86 & 3.81 & 21.41 & 3.74 & 14.64 \\
\hline 19.00 & 3.93 & 41.79 & 3.89 & 35.70 & 3.86 & 29.29 & 3.81 & 22.54 & 3.75 & 15.42 \\
\hline 20.00 & 3.94 & 43.74 & 3.91 & 37.40 & 3.87 & 30.72 & 3.83 & 23.65 & 3.76 & 16.20 \\
\hline 21.00 & 3.95 & 45.66 & 3.91 & 39.09 & 3.88 & 32.13 & 3.83 & 24.76 & 3.77 & 16.98 \\
\hline 22.00 & 3.97 & 47.57 & 3.93 & 40.76 & 3.89 & 33.53 & 3.84 & 25.87 & 3.78 & 17.75 \\
\hline 23.00 & 3.97 & 49.45 & 3.93 & 42.41 & 3.89 & 34.92 & 3.85 & 26.96 & 3.78 & 18.52 \\
\hline 24.00 & 3.99 & 51.31 & 3.95 & 44.05 & 3.90 & 36.30 & 3.85 & 28.06 & 3.79 & 19.28 \\
\hline 25.00 & 4.00 & 53.15 & 3.95 & 45.67 & 3.91 & 37.67 & 3.86 & 29.14 & 3.80 & 20.05 \\
\hline 26.00 & 4.01 & 54.97 & 3.97 & 47.27 & 3.92 & 39.03 & 3.87 & 30.22 & 3.81 & 20.81 \\
\hline 27.00 & 4.02 & 56.76 & 3.97 & 48.86 & 3.92 & 40.38 & 3.87 & 31.29 & 3.81 & 21.57 \\
\hline 28.00 & 4.04 & 58.53 & 3.98 & 50.43 & 3.93 & 41.72 & 3.88 & 32.36 & 3.82 & 22.32 \\
\hline 29.00 & 4.04 & 60.29 & 3.99 & 51.99 & 3.94 & 43.04 & 3.88 & 33.42 & 3.82 & 23.07 \\
\hline 30.00 & 4.06 & 62.02 & 4.00 & 53.53 & 3.95 & 44.36 & 3.89 & 34.47 & 3.83 & 23.82 \\
\hline 31.00 & 4.07 & 63.73 & 4.01 & 55.05 & 3.95 & 45.67 & 3.90 & 35.52 & 3.83 & 24.57 \\
\hline 32.00 & 4.08 & 65.41 & 4.02 & 56.56 & 3.96 & 46.96 & 3.90 & 36.56 & 3.84 & 25.31 \\
\hline 33.00 & 4.09 & 67.08 & 4.03 & 58.06 & 3.97 & 48.25 & 3.91 & 37.60 & 3.84 & 26.05 \\
\hline 34.00 & 4.11 & 68.73 & 4.04 & 59.54 & 3.98 & 49.52 & 3.92 & 38.63 & 3.85 & 26.79 \\
\hline 35.00 & 4.12 & 70.36 & 4.05 & 61.01 & 3.99 & 50.79 & 3.92 & 39.65 & 3.85 & 27.53 \\
\hline 36.00 & 4.13 & 71.97 & 4.06 & 62.46 & 4.00 & 52.05 & 3.93 & 40.67 & 3.86 & 28.26 \\
\hline 37.00 & 4.14 & 73.55 & 4.07 & 63.89 & 4.00 & 53.29 & 3.93 & 41.68 & 3.86 & 28.99 \\
\hline 38.00 & 4.15 & 75.12 & 4.08 & 65.31 & 4.01 & 54.53 & 3.94 & 42.69 & 3.87 & 29.71 \\
\hline 39.00 & 4.16 & 76.67 & 4.09 & 66.72 & 4.02 & 55.75 & 3.94 & 43.69 & 3.87 & 30.44 \\
\hline 40.00 & 4.18 & 78.20 & 4.10 & 68.11 & 4.03 & 56.97 & 3.95 & 44.68 & 3.87 & 31.16 \\
\hline 41.00 & 4.19 & 79.71 & 4.11 & 69.49 & 4.03 & 58.17 & 3.96 & 45.67 & 3.88 & 31.88 \\
\hline 42.00 & 4.20 & 81.21 & 4.12 & 70.86 & 4.04 & 59.37 & 3.96 & 46.65 & 3.88 & 32.59 \\
\hline 43.00 & 4.21 & 82.68 & 4.13 & 72.21 & 4.05 & 60.56 & 3.97 & 47.63 & 3.88 & 33.30 \\
\hline 44.00 & 4.23 & 84.14 & 4.14 & 73.54 & 4.06 & 61.74 & 3.97 & 48.60 & 3.89 & 34.01 \\
\hline 45.00 & 4.24 & 85.57 & 4.15 & 74.87 & 4.07 & 62.90 & 3.98 & 49.56 & 3.89 & 34.72 \\
\hline 46.00 & 4.25 & 86.99 & 4.16 & 76.18 & 4.07 & 64.06 & 3.99 & 50.52 & 3.90 & 35.42 \\
\hline 47.00 & 4.26 & 88.40 & 4.17 & 77.47 & 4.08 & 65.21 & 3.99 & 51.47 & 3.90 & 36.13 \\
\hline 48.00 & 4.28 & 89.78 & 4.19 & 78.76 & 4.09 & 66.35 & 4.00 & 52.42 & 3.91 & 36.83 \\
\hline 49.00 & 4.29 & 91.15 & 4.19 & 80.03 & 4.10 & 67.48 & 4.00 & 53.36 & 3.91 & 37.52 \\
\hline 50.00 & 4.30 & 92.50 & 4.20 & 81.28 & 4.11 & 68.60 & 4.01 & 54.30 & 3.92 & 38.22 \\
\hline 51.00 & 4.31 & 93.83 & 4.21 & 82.52 & 4.11 & 69.71 & 4.02 & 55.23 & 3.92 & 38.91 \\
\hline 52.00 & 4.33 & 95.15 & 4.23 & 83.76 & 4.12 & 70.81 & 4.02 & 56.15 & 3.92 & 39.59 \\
\hline 53.00 & 4.34 & 96.45 & 4.23 & 84.97 & 4.13 & 71.91 & 4.03 & 57.07 & 3.92 & 40.28 \\
\hline 54.00 & 4.35 & 97.73 & 4.25 & 86.18 & 4.14 & 72.99 & 4.03 & 57.99 & 3.93 & 40.96 \\
\hline 55.00 & 4.36 & 99.00 & 4.26 & 87.37 & 4.15 & 74.07 & 4.04 & 58.90 & 3.93 & 41.64 \\
\hline 56.00 & 4.38 & 100.25 & 4.27 & 88.55 & 4.16 & 75.14 & 4.05 & 59.80 & 3.94 & 42.32 \\
\hline 57.00 & 4.39 & 101.48 & 4.28 & 89.72 & 4.16 & 76.19 & 4.05 & 60.70 & 3.94 & 42.99 \\
\hline
\end{tabular}




\begin{tabular}{|c|c|c|c|c|c|c|c|c|c|c|}
\hline 58.00 & 4.40 & 102.70 & 4.29 & 90.87 & 4.17 & 77.24 & 4.06 & 61.59 & 3.95 & 43.67 \\
\hline 59.00 & 4.41 & 103.91 & 4.30 & 92.02 & 4.18 & 78.28 & 4.06 & 62.47 & 3.95 & 44.33 \\
\hline 60.00 & 4.43 & 105.09 & 4.31 & 93.15 & 4.19 & 79.32 & 4.07 & 63.35 & 3.96 & 45.00 \\
\hline 61.00 & 4.44 & 106.27 & 4.32 & 94.27 & 4.20 & 80.34 & 4.08 & 64.23 & 3.96 & 45.67 \\
\hline 62.00 & 4.45 & 107.43 & 4.33 & 95.37 & 4.21 & 81.36 & 4.08 & 65.10 & 3.96 & 46.33 \\
\hline 63.00 & 4.47 & 108.57 & 4.34 & 96.47 & 4.21 & 82.36 & 4.09 & 65.97 & 3.96 & 46.99 \\
\hline 64.00 & 4.48 & 109.70 & 4.35 & 97.55 & 4.22 & 83.36 & 4.10 & 66.83 & 3.97 & 47.64 \\
\hline 65.00 & 4.49 & 110.81 & 4.36 & 98.63 & 4.23 & 84.35 & 4.10 & 67.68 & 3.97 & 48.30 \\
\hline 66.00 & 4.50 & 111.91 & 4.37 & 99.69 & 4.24 & 85.33 & 4.11 & 68.53 & 3.98 & 48.95 \\
\hline 67.00 & 4.52 & 113.00 & 4.38 & 100.74 & 4.25 & 86.31 & 4.11 & 69.37 & 3.98 & 49.60 \\
\hline 68.00 & 4.53 & 114.07 & 4.39 & 101.78 & 4.26 & 87.27 & 4.12 & 70.21 & 3.99 & 50.24 \\
\hline 69.00 & 4.54 & 115.13 & 4.40 & 102.81 & 4.26 & 88.23 & 4.13 & 71.05 & 3.99 & 50.88 \\
\hline 70.00 & 4.56 & 116.18 & 4.42 & 103.82 & 4.27 & 89.18 & 4.13 & 71.88 & 4.00 & 51.52 \\
\hline 71.00 & 4.57 & 117.21 & 4.42 & 104.83 & 4.28 & 90.12 & 4.14 & 72.70 & 3.99 & 52.16 \\
\hline 72.00 & 4.58 & 118.23 & 4.44 & 105.82 & 4.29 & 91.05 & 4.14 & 73.52 & 4.00 & 52.80 \\
\hline 73.00 & 4.59 & 119.23 & 4.45 & 106.81 & 4.30 & 91.98 & 4.15 & 74.33 & 4.00 & 53.43 \\
\hline 74.00 & 4.61 & 120.22 & 4.46 & 107.78 & 4.31 & 92.90 & 4.16 & 75.14 & 4.01 & 54.06 \\
\hline 75.00 & 4.62 & 121.20 & 4.47 & 108.75 & 4.32 & 93.81 & 4.16 & 75.94 & 4.01 & 54.69 \\
\hline 76.00 & 4.63 & 122.17 & 4.48 & 109.70 & 4.33 & 94.71 & 4.17 & 76.74 & 4.02 & 55.32 \\
\hline 77.00 & 4.64 & 123.12 & 4.49 & 110.65 & 4.33 & 95.60 & 4.18 & 77.53 & 4.02 & 55.94 \\
\hline 78.00 & 4.66 & 124.06 & 4.50 & 111.58 & 4.34 & 96.49 & 4.18 & 78.32 & 4.03 & 56.56 \\
\hline 79.00 & 4.67 & 124.99 & 4.51 & 112.50 & 4.35 & 97.37 & 4.19 & 79.11 & 4.03 & 57.18 \\
\hline 80.00 & 4.68 & 125.91 & 4.53 & 113.42 & 4.36 & 98.24 & 4.20 & 79.88 & 4.04 & 57.79 \\
\hline 81.00 & 4.68 & 126.82 & 4.53 & 114.32 & 4.36 & 99.11 & 4.20 & 80.66 & 4.04 & 58.41 \\
\hline 82.00 & 4.71 & 127.71 & 4.55 & 115.21 & 4.38 & 99.96 & 4.21 & 81.43 & 4.04 & 59.02 \\
\hline 83.00 & 4.72 & 128.59 & 4.56 & 116.10 & 4.38 & 100.81 & 4.21 & 82.19 & 4.05 & 59.62 \\
\hline 84.00 & 4.74 & 129.46 & 4.56 & 116.97 & 4.40 & 101.66 & 4.22 & 82.95 & 4.05 & 60.23 \\
\hline 85.00 & 4.74 & 130.32 & 4.58 & 117.84 & 4.40 & 102.49 & 4.23 & 83.71 & 4.05 & 60.83 \\
\hline 86.00 & 4.77 & 131.17 & 4.59 & 118.69 & 4.41 & 103.32 & 4.23 & 84.46 & 4.06 & 61.43 \\
\hline 87.00 & 4.77 & 132.01 & 4.60 & 119.54 & 4.42 & 104.14 & 4.24 & 85.20 & 4.06 & 62.03 \\
\hline 88.00 & 4.79 & 132.83 & 4.61 & 120.38 & 4.43 & 104.96 & 4.25 & 85.94 & 4.07 & 62.63 \\
\hline 89.00 & 4.79 & 133.65 & 4.62 & 121.21 & 4.44 & 105.77 & 4.25 & 86.68 & 4.07 & 63.22 \\
\hline 90.00 & 4.82 & 134.46 & 4.63 & 122.03 & 4.44 & 106.57 & 4.26 & 87.41 & 4.08 & 63.81 \\
\hline 91.00 & 4.82 & 135.25 & 4.64 & 122.84 & 4.45 & 107.36 & 4.26 & 88.14 & 4.08 & 64.40 \\
\hline 92.00 & 4.84 & 136.03 & 4.66 & 123.64 & 4.46 & 108.15 & 4.28 & 88.86 & 4.09 & 64.99 \\
\hline 93.00 & 4.85 & 136.81 & 4.67 & 124.43 & 4.47 & 108.93 & 4.28 & 89.58 & 4.09 & 65.57 \\
\hline 94.00 & 4.87 & 137.57 & 4.67 & 125.22 & 4.48 & 109.70 & 4.29 & 90.29 & 4.09 & 66.15 \\
\hline 95.00 & 4.87 & 138.32 & 4.69 & 126.00 & 4.49 & 110.47 & 4.29 & 91.00 & 4.09 & 66.73 \\
\hline 96.00 & 4.90 & 139.07 & 4.69 & 126.76 & 4.50 & 111.23 & 4.30 & 91.70 & 4.10 & 67.31 \\
\hline 97.00 & 4.90 & 139.80 & 4.71 & 127.52 & 4.50 & 111.98 & 4.31 & 92.40 & 4.10 & 67.88 \\
\hline 98.00 & 4.92 & 140.53 & 4.72 & 128.27 & 4.52 & 112.73 & 4.31 & 93.10 & 4.11 & 68.46 \\
\hline 99.00 & 4.93 & 141.23 & 4.72 & 129.02 & 4.52 & 113.47 & 4.32 & 93.79 & 4.11 & 69.03 \\
\hline 100.00 & 4.94 & 141.92 & 4.74 & 129.75 & 4.53 & 114.20 & 4.33 & 94.47 & 4.12 & 69.59 \\
\hline 101.00 & 4.94 & 142.59 & 4.75 & 130.48 & 4.54 & 114.93 & 4.33 & 95.16 & 4.12 & 70.16 \\
\hline 102.00 & 4.97 & 143.25 & 4.77 & 131.20 & 4.55 & 115.65 & 4.33 & 95.83 & 4.13 & 70.72 \\
\hline 103.00 & 4.97 & 143.89 & 4.77 & 131.91 & 4.56 & 116.37 & 4.35 & 96.51 & 4.13 & 71.28 \\
\hline 104.00 & 4.99 & 144.52 & 4.79 & 132.61 & 4.57 & 117.08 & 4.35 & 97.18 & 4.13 & 71.84 \\
\hline 105.00 & 4.99 & 145.14 & 4.79 & 133.31 & 4.58 & 117.78 & 4.35 & 97.84 & 4.14 & 72.39 \\
\hline 106.00 & 5.02 & 145.74 & 4.81 & 134.00 & 4.59 & 118.48 & 4.36 & 98.50 & 4.14 & 72.95 \\
\hline 107.00 & 5.01 & 146.33 & 4.81 & 134.68 & 4.60 & 119.17 & 4.37 & 99.16 & 4.15 & 73.50 \\
\hline 108.00 & 5.04 & 146.90 & 4.83 & 135.35 & 4.61 & 119.86 & 4.38 & 99.81 & 4.15 & 74.05 \\
\hline 109.00 & 5.04 & 147.47 & 4.84 & 136.02 & 4.61 & 120.54 & 4.38 & 100.46 & 4.15 & 74.60 \\
\hline 110.00 & 5.06 & 148.02 & 4.85 & 136.68 & 4.62 & 121.21 & 4.39 & 101.10 & 4.16 & 75.14 \\
\hline 111.00 & 5.06 & 148.56 & 4.86 & 137.33 & 4.63 & 121.88 & 4.39 & 101.74 & 4.16 & 75.68 \\
\hline 112.00 & 5.08 & 149.09 & 4.88 & 137.97 & 4.64 & 122.54 & 4.40 & 102.38 & 4.17 & 76.22 \\
\hline 113.00 & 5.08 & 149.61 & 4.88 & 138.61 & 4.65 & 123.20 & 4.41 & 103.01 & 4.17 & 76.76 \\
\hline 114.00 & 5.10 & 150.12 & 4.90 & 139.24 & 4.66 & 123.85 & 4.41 & 103.64 & 4.18 & 77.30 \\
\hline 115.00 & 5.11 & 150.62 & 4.90 & 139.86 & 4.67 & 124.49 & 4.42 & 104.26 & 4.18 & 77.83 \\
\hline 116.00 & 5.12 & 151.11 & 4.93 & 140.48 & 4.67 & 125.13 & 4.43 & 104.88 & 4.19 & 78.36 \\
\hline 117.00 & 5.12 & 151.59 & 4.92 & 141.09 & 4.69 & 125.76 & 4.44 & 105.50 & 4.19 & 78.89 \\
\hline 118.00 & 5.15 & 152.06 & 4.95 & 141.69 & 4.69 & 126.39 & 4.44 & 106.11 & 4.20 & 79.41 \\
\hline 119.00 & 5.14 & 152.53 & 4.94 & 142.29 & 4.70 & 127.01 & 4.45 & 106.72 & 4.19 & 79.94 \\
\hline 120.00 & 5.17 & 152.98 & 4.97 & 142.88 & 4.71 & 127.63 & 4.46 & 107.32 & 4.21 & 80.46 \\
\hline
\end{tabular}


Permeability - 200 md

\begin{tabular}{|c|c|c|c|c|c|c|c|c|c|c|}
\hline \multicolumn{11}{|c|}{ Bottom Placement of Nitrogen } \\
\hline \multirow{3}{*}{$\begin{array}{l}\text { TIME } \\
\text { (days) }\end{array}$} & \multirow{2}{*}{\multicolumn{2}{|c|}{$\begin{array}{c}\text { Withdrawal Pressure } \\
100 \text { psia } \\
\end{array}$}} & \multirow{2}{*}{\multicolumn{2}{|c|}{$\begin{array}{c}\text { Withdrawal Pressure } \\
150 \text { psia } \\
\end{array}$}} & \multirow{2}{*}{\multicolumn{2}{|c|}{$\begin{array}{c}\text { Withdrawal Pressure } \\
200 \text { psia } \\
\end{array}$}} & \multirow{2}{*}{\multicolumn{2}{|c|}{$\begin{array}{c}\text { Withdrawal Pressure } \\
250 \text { psia } \\
\end{array}$}} & \multirow{2}{*}{\multicolumn{2}{|c|}{$\begin{array}{c}\text { Withdrawal Pressure } \\
300 \text { psia } \\
\end{array}$}} \\
\hline & & & & & & & & & & \\
\hline & $\begin{array}{c}\% \mathrm{~N}_{2} \text { in } \\
\text { withdrawn } \\
\text { gas }\end{array}$ & $\begin{array}{l}\text { \% W.G } \\
\text { withdrawn } \\
\text { (volume) }\end{array}$ & $\begin{array}{c}\% \mathrm{~N}_{2} \text { in } \\
\text { withdrawn } \\
\text { gas }\end{array}$ & $\begin{array}{c}\text { \% W.G } \\
\text { withdrawn } \\
\text { (volume) }\end{array}$ & $\begin{array}{c}\% \mathrm{~N}_{2} \text { in } \\
\text { withdrawn } \\
\text { gas }\end{array}$ & $\begin{array}{l}\text { \% W.G } \\
\text { withdrawn } \\
\text { (volume) }\end{array}$ & $\begin{array}{c}\% \mathrm{~N}_{2} \text { in } \\
\text { withdrawn } \\
\text { gas }\end{array}$ & $\begin{array}{c}\text { \% W.G } \\
\text { withdrawn } \\
\text { (volume) }\end{array}$ & $\begin{array}{c}\% \mathrm{~N}_{2} \text { in } \\
\text { withdrawn } \\
\text { gas }\end{array}$ & $\begin{array}{c}\% \text { W.G } \\
\text { withdrawn } \\
\text { (volume) }\end{array}$ \\
\hline 0.01 & 0.00 & 0.11 & 0.00 & 0.10 & 0.00 & 0.10 & 0.00 & 0.09 & 0.00 & 0.09 \\
\hline 0.04 & 0.00 & 0.36 & 0.00 & 0.34 & 0.00 & 0.32 & 0.00 & 0.31 & 0.00 & 0.29 \\
\hline 0.1 & 1.52 & 0.92 & 1.43 & 0.90 & 1.32 & 0.86 & 1.20 & 0.82 & 1.09 & 0.77 \\
\hline 0.29 & 4.08 & 1.91 & 3.98 & 1.85 & 3.84 & 1.77 & 3.69 & 1.70 & 3.54 & 1.62 \\
\hline 0.85 & 5.67 & 4.72 & 5.62 & 4.55 & 5.56 & 4.36 & 5.49 & 4.19 & 5.41 & 4.02 \\
\hline 1 & 6.18 & 8.42 & 6.15 & 8.05 & 6.11 & 7.68 & 6.07 & 7.31 & 6.03 & 6.92 \\
\hline 2 & 6.52 & 15.57 & 6.49 & 14.91 & 6.47 & 14.24 & 6.44 & 13.56 & 6.41 & 12.87 \\
\hline 3 & 6.51 & 22.06 & 6.49 & 21.14 & 6.47 & 20.21 & 6.44 & 19.25 & 6.41 & 18.28 \\
\hline 4 & 6.53 & 27.89 & 6.52 & 26.76 & 6.52 & 25.60 & 6.51 & 24.41 & 6.50 & 23.20 \\
\hline 5 & 6.58 & 33.21 & 6.57 & 31.88 & 6.56 & 30.52 & 6.55 & 29.13 & 6.54 & 27.70 \\
\hline 6 & 6.90 & 38.02 & 6.87 & 36.52 & 6.82 & 34.99 & 6.78 & 33.42 & 6.74 & 31.80 \\
\hline 7 & 6.97 & 42.43 & 6.93 & 40.79 & 6.81 & 39.11 & 6.78 & 37.37 & 6.75 & 35.58 \\
\hline 8 & 7.09 & 46.46 & 7.04 & 44.69 & 7.08 & 42.87 & 7.02 & 40.99 & 6.96 & 39.05 \\
\hline 9 & 7.14 & 50.17 & 7.10 & 48.29 & 7.13 & 46.34 & 7.08 & 44.34 & 7.02 & 42.26 \\
\hline 10 & 7.38 & 53.58 & 7.31 & 51.60 & 7.18 & 49.55 & 7.10 & 47.42 & 7.04 & 45.23 \\
\hline 11 & 7.37 & 56.75 & 7.30 & 54.67 & 7.09 & 52.52 & 6.94 & 50.30 & 6.92 & 47.99 \\
\hline 12 & 7.69 & 59.67 & 7.59 & 57.51 & 7.62 & 55.27 & 7.63 & 52.95 & 7.49 & 50.55 \\
\hline 13 & 7.67 & 62.38 & 7.59 & 60.16 & 7.59 & 57.84 & 7.53 & 55.43 & 7.46 & 52.93 \\
\hline 14 & 7.81 & 64.91 & 7.71 & 62.62 & 7.56 & 60.23 & 7.45 & 57.74 & 7.35 & 55.16 \\
\hline 15 & 7.62 & 67.27 & 7.59 & 64.92 & 7.39 & 62.46 & 7.24 & 59.91 & 7.18 & 57.24 \\
\hline 16 & 8.22 & 69.47 & 8.07 & 67.06 & 8.05 & 64.55 & 8.01 & 61.92 & 7.87 & 59.19 \\
\hline 17 & 8.20 & 71.54 & 8.06 & 69.08 & 8.02 & 66.51 & 7.95 & 63.82 & 7.86 & 61.02 \\
\hline 18 & 8.07 & 73.47 & 7.99 & 70.97 & 7.85 & 68.35 & 7.71 & 65.60 & 7.60 & 62.74 \\
\hline 19 & 7.91 & 75.30 & 7.89 & 72.75 & 7.72 & 70.08 & 7.56 & 67.28 & 7.46 & 64.36 \\
\hline 20 & 8.63 & 77.01 & 8.43 & 74.42 & 8.34 & 71.71 & 8.26 & 68.86 & 8.11 & 65.88 \\
\hline 21 & 8.58 & 78.62 & 8.42 & 76.00 & 8.34 & 73.24 & 8.25 & 70.35 & 8.13 & 67.31 \\
\hline 22 & 8.41 & 80.15 & 8.30 & 77.49 & 8.14 & 74.70 & 7.99 & 71.76 & 7.86 & 68.67 \\
\hline 23 & 8.31 & 81.60 & 8.22 & 78.91 & 8.05 & 76.08 & 7.87 & 73.10 & 7.75 & 69.96 \\
\hline 24 & 8.88 & 82.96 & 8.70 & 80.24 & 8.57 & 77.38 & 8.45 & 74.36 & 8.28 & 71.18 \\
\hline 25 & 8.87 & 84.26 & 8.70 & 81.51 & 8.59 & 78.61 & 8.47 & 75.55 & 8.32 & 72.33 \\
\hline 26 & 8.73 & 85.49 & 8.59 & 82.72 & 8.42 & 79.78 & 8.25 & 76.69 & 8.11 & 73.43 \\
\hline 27 & 8.66 & 86.66 & 8.53 & 83.86 & 8.36 & 80.90 & 8.17 & 77.77 & 8.04 & 74.47 \\
\hline 28 & 9.11 & 87.77 & 8.92 & 84.95 & 8.76 & 81.96 & 8.61 & 78.80 & 8.42 & 75.46 \\
\hline 29 & 9.12 & 88.83 & 8.94 & 85.99 & 8.78 & 82.97 & 8.64 & 79.78 & 8.45 & 76.41 \\
\hline 30 & 9.03 & 89.84 & 8.86 & 86.98 & 8.68 & 83.94 & 8.50 & 80.72 & 8.34 & 77.31 \\
\hline 31 & 8.99 & 90.81 & 8.83 & 87.93 & 8.64 & 84.86 & 8.45 & 81.61 & 8.30 & 78.17 \\
\hline 32 & 9.33 & 91.73 & 9.12 & 88.83 & 8.93 & 85.74 & 8.75 & 82.46 & 8.55 & 78.98 \\
\hline 33 & 9.34 & 92.61 & 9.13 & 89.69 & 8.95 & 86.58 & 8.77 & 83.27 & 8.57 & 79.76 \\
\hline 34 & 9.30 & 93.45 & 9.11 & 90.52 & 8.91 & 87.38 & 8.72 & 84.05 & 8.54 & 80.51 \\
\hline 35 & 9.27 & 94.26 & 9.09 & 91.31 & 8.89 & 88.15 & 8.69 & 84.79 & 8.52 & 81.23 \\
\hline 36 & 9.53 & 95.04 & 9.31 & 92.07 & 9.10 & 88.89 & 8.89 & 85.51 & 8.67 & 81.91 \\
\hline 37 & 9.54 & 95.78 & 9.31 & 92.80 & 9.10 & 89.60 & 8.90 & 86.19 & 8.68 & 82.57 \\
\hline 38 & 9.55 & 96.50 & 9.34 & 93.50 & 9.12 & 90.28 & 8.91 & 86.85 & 8.70 & 83.20 \\
\hline 39 & 9.54 & 97.18 & 9.32 & 94.17 & 9.11 & 90.93 & 8.89 & 87.48 & 8.70 & 83.80 \\
\hline
\end{tabular}




\begin{tabular}{|c|c|c|c|c|c|c|c|c|c|c|}
\hline 40 & 9.72 & 97.84 & 9.48 & 94.81 & 9.25 & 91.56 & 9.02 & 88.08 & 8.79 & 84.38 \\
\hline 41 & 9.72 & 98.48 & 9.48 & 95.43 & 9.25 & 92.16 & 9.02 & 88.66 & 8.80 & 84.93 \\
\hline 42 & 9.77 & 99.09 & 9.54 & 96.03 & 9.30 & 92.74 & 9.07 & 89.22 & 8.85 & 85.47 \\
\hline 43 & 9.76 & 99.68 & 9.53 & 96.61 & 9.29 & 93.30 & 9.06 & 89.76 & 8.84 & 85.98 \\
\hline 44 & 9.90 & 100.25 & 9.65 & 97.16 & 9.39 & 93.84 & 9.15 & 90.28 & 8.91 & 86.47 \\
\hline 45 & 9.91 & 100.80 & 9.65 & 97.70 & 9.40 & 94.36 & 9.15 & 90.77 & 8.91 & 86.95 \\
\hline 46 & 9.97 & 101.33 & 9.71 & 98.22 & 9.46 & 94.86 & 9.21 & 91.25 & 8.97 & 87.40 \\
\hline 47 & 9.97 & 101.84 & 9.71 & 98.72 & 9.45 & 95.34 & 9.21 & 91.72 & 8.96 & 87.84 \\
\hline 48 & 10.08 & 102.33 & 9.81 & 99.20 & 9.54 & 95.81 & 9.27 & 92.16 & 9.01 & 88.27 \\
\hline 49 & 10.07 & 102.81 & 9.80 & 99.67 & 9.53 & 96.26 & 9.28 & 92.60 & 9.02 & 88.68 \\
\hline 50 & 10.15 & 103.27 & 9.87 & 100.12 & 9.60 & 96.69 & 9.32 & 93.01 & 9.07 & 89.07 \\
\hline 51 & 10.16 & 103.72 & 9.87 & 100.55 & 9.60 & 97.11 & 9.33 & 93.41 & 9.07 & 89.45 \\
\hline 52 & 10.24 & 104.15 & 9.95 & 100.97 & 9.66 & 97.52 & 9.38 & 93.80 & 9.11 & 89.82 \\
\hline 53 & 10.24 & 104.57 & 9.95 & 101.38 & 9.67 & 97.91 & 9.38 & 94.18 & 9.11 & 90.17 \\
\hline 54 & 10.32 & 104.98 & 10.02 & 101.78 & 9.72 & 98.30 & 9.44 & 94.54 & 9.16 & 90.51 \\
\hline 55 & 10.32 & 105.37 & 10.02 & 102.16 & 9.72 & 98.66 & 9.43 & 94.89 & 9.16 & 90.84 \\
\hline 56 & 10.40 & 105.76 & 10.09 & 102.53 & 9.78 & 99.02 & 9.49 & 95.23 & 9.20 & 91.16 \\
\hline 57 & 10.40 & 106.13 & 10.09 & 102.89 & 9.78 & 99.37 & 9.49 & 95.56 & 9.21 & 91.47 \\
\hline 58 & 10.48 & 106.49 & 10.15 & 103.24 & 9.84 & 99.70 & 9.54 & 95.88 & 9.24 & 91.77 \\
\hline 59 & 10.47 & 106.84 & 10.15 & 103.58 & 9.84 & 100.03 & 9.53 & 96.19 & 9.25 & 92.06 \\
\hline 60 & 10.55 & 107.18 & 10.22 & 103.91 & 9.89 & 100.35 & 9.58 & 96.49 & 9.28 & 92.34 \\
\hline 61 & 10.54 & 107.51 & 10.22 & 104.23 & 9.89 & 100.65 & 9.58 & 96.78 & 9.28 & 92.61 \\
\hline 62 & 10.62 & 107.83 & 10.28 & 104.55 & 9.94 & 100.95 & 9.63 & 97.06 & 9.32 & 92.87 \\
\hline 63 & 10.62 & 108.14 & 10.28 & 104.85 & 9.96 & 101.24 & 9.63 & 97.33 & 9.32 & 93.13 \\
\hline 64 & 10.69 & 108.45 & 10.34 & 105.14 & 9.99 & 101.52 & 9.67 & 97.59 & 9.35 & 93.37 \\
\hline 65 & 10.69 & 108.74 & 10.34 & 105.43 & 9.99 & 101.79 & 9.66 & 97.85 & 9.36 & 93.61 \\
\hline 66 & 10.75 & 109.03 & 10.39 & 105.71 & 10.04 & 102.06 & 9.71 & 98.10 & 9.38 & 93.84 \\
\hline 67 & 10.76 & 109.31 & 10.39 & 105.98 & 10.05 & 102.32 & 9.71 & 98.34 & 9.39 & 94.06 \\
\hline 68 & 10.82 & 109.59 & 10.44 & 106.24 & 10.09 & 102.57 & 9.75 & 98.58 & 9.41 & 94.28 \\
\hline 69 & 10.82 & 109.85 & 10.46 & 106.50 & 10.08 & 102.81 & 9.74 & 98.81 & 9.43 & 94.49 \\
\hline 70 & 10.88 & 110.11 & 10.50 & 106.75 & 10.14 & 103.05 & 9.78 & 99.03 & 9.44 & 94.70 \\
\hline 71 & 10.89 & 110.37 & 10.50 & 106.99 & 10.13 & 103.28 & 9.79 & 99.24 & 9.46 & 94.89 \\
\hline 72 & 10.94 & 110.61 & 10.55 & 107.23 & 10.17 & 103.50 & 9.81 & 99.45 & 9.46 & 95.09 \\
\hline 73 & 10.94 & 110.86 & 10.55 & 107.46 & 10.18 & 103.72 & 9.82 & 99.66 & 9.48 & 95.27 \\
\hline 74 & 11.01 & 111.09 & 10.60 & 107.69 & 10.22 & 103.94 & 9.85 & 99.85 & 9.51 & 95.45 \\
\hline 75 & 11.00 & 111.32 & 10.61 & 107.91 & 10.22 & 104.14 & 9.85 & 100.05 & 9.50 & 95.63 \\
\hline 76 & 11.05 & 111.54 & 10.65 & 108.12 & 10.25 & 104.35 & 9.88 & 100.23 & 9.53 & 95.80 \\
\hline 77 & 11.06 & 111.76 & 10.66 & 108.33 & 10.27 & 104.54 & 9.87 & 100.42 & 9.53 & 95.97 \\
\hline 78 & 11.12 & 111.98 & 10.69 & 108.54 & 10.30 & 104.74 & 9.93 & 100.59 & 9.56 & 96.13 \\
\hline 79 & 11.11 & 112.19 & 10.70 & 108.74 & 10.29 & 104.92 & 9.92 & 100.77 & 9.55 & 96.28 \\
\hline 80 & 11.18 & 112.39 & 10.74 & 108.93 & 10.33 & 105.11 & 9.94 & 100.94 & 9.59 & 96.44 \\
\hline 81 & 11.17 & 112.59 & 10.74 & 109.12 & 10.35 & 105.28 & 9.94 & 101.10 & 9.57 & 96.58 \\
\hline 82 & 11.22 & 112.79 & 10.78 & 109.31 & 10.36 & 105.46 & 9.97 & 101.26 & 9.62 & 96.73 \\
\hline 83 & 11.21 & 112.98 & 10.78 & 109.49 & 10.36 & 105.63 & 9.98 & 101.42 & 9.60 & 96.87 \\
\hline 84 & 11.28 & 113.16 & 10.82 & 109.67 & 10.41 & 105.79 & 9.99 & 101.57 & 9.61 & 97.00 \\
\hline 85 & 11.28 & 113.35 & 10.84 & 109.84 & 10.40 & 105.96 & 10.00 & 101.71 & 9.63 & 97.14 \\
\hline 86 & 11.33 & 113.52 & 10.87 & 110.01 & 10.43 & 106.11 & 10.02 & 101.86 & 9.64 & 97.26 \\
\hline 87 & 11.31 & 113.70 & 10.87 & 110.18 & 10.42 & 106.27 & 10.04 & 102.00 & 9.63 & 97.39 \\
\hline 88 & 11.38 & 113.87 & 10.90 & 110.34 & 10.47 & 106.42 & 10.04 & 102.14 & 9.66 & 97.51 \\
\hline 89 & 11.38 & 114.04 & 10.91 & 110.50 & 10.46 & 106.57 & 10.04 & 102.27 & 9.67 & 97.63 \\
\hline 90 & 11.42 & 114.20 & 10.94 & 110.65 & 10.49 & 106.71 & 10.08 & 102.40 & 9.67 & 97.75 \\
\hline
\end{tabular}




\begin{tabular}{|c|c|c|c|c|c|c|c|c|c|c|}
\hline 91 & 11.42 & 114.36 & 10.95 & 110.81 & 10.50 & 106.85 & 10.09 & 102.53 & 9.69 & 97.86 \\
\hline 92 & 11.47 & 114.52 & 10.98 & 110.96 & 10.53 & 106.99 & 10.08 & 102.65 & 9.69 & 97.97 \\
\hline 93 & 11.47 & 114.68 & 10.98 & 111.10 & 10.52 & 107.12 & 10.12 & 102.77 & 9.70 & 98.07 \\
\hline 94 & 11.52 & 114.83 & 11.02 & 111.24 & 10.55 & 107.25 & 10.11 & 102.89 & 9.72 & 98.18 \\
\hline 95 & 11.52 & 114.97 & 11.02 & 111.38 & 10.55 & 107.38 & 10.12 & 103.00 & 9.70 & 98.28 \\
\hline 96 & 11.54 & 115.12 & 11.04 & 111.52 & 10.59 & 107.51 & 10.12 & 103.12 & 9.73 & 98.38 \\
\hline 97 & 11.56 & 115.26 & 11.07 & 111.65 & 10.59 & 107.63 & 10.15 & 103.23 & 9.75 & 98.47 \\
\hline 98 & 11.61 & 115.40 & 11.08 & 111.79 & 10.58 & 107.75 & 10.14 & 103.33 & 9.72 & 98.57 \\
\hline 99 & 11.60 & 115.54 & 11.09 & 111.91 & 10.62 & 107.87 & 10.16 & 103.44 & 9.74 & 98.66 \\
\hline 100 & 11.62 & 115.67 & 11.13 & 112.04 & 10.64 & 107.98 & 10.19 & 103.54 & 9.78 & 98.74 \\
\hline 101 & 11.65 & 115.81 & 11.10 & 112.16 & 10.63 & 108.09 & 10.17 & 103.64 & 9.75 & 98.83 \\
\hline 102 & 11.68 & 115.94 & 11.16 & 112.28 & 10.65 & 108.20 & 10.20 & 103.74 & 9.77 & 98.92 \\
\hline 103 & 11.69 & 116.06 & 11.15 & 112.40 & 10.66 & 108.31 & 10.21 & 103.83 & 9.76 & 99.00 \\
\hline 104 & 11.70 & 116.19 & 11.18 & 112.52 & 10.66 & 108.42 & 10.21 & 103.92 & 9.81 & 99.08 \\
\hline 105 & 11.74 & 116.31 & 11.18 & 112.63 & 10.69 & 108.52 & 10.22 & 104.01 & 9.80 & 99.15 \\
\hline 106 & 11.75 & 116.43 & 11.22 & 112.74 & 10.71 & 108.62 & 10.24 & 104.10 & 9.79 & 99.23 \\
\hline 107 & 11.78 & 116.55 & 11.21 & 112.85 & 10.72 & 108.72 & 10.22 & 104.19 & 9.81 & 99.30 \\
\hline 108 & 11.80 & 116.66 & 11.25 & 112.96 & 10.69 & 108.82 & 10.25 & 104.27 & 9.80 & 99.38 \\
\hline 109 & 11.79 & 116.78 & 11.23 & 113.07 & 10.75 & 108.91 & 10.25 & 104.36 & 9.82 & 99.45 \\
\hline 110 & 11.86 & 116.89 & 11.27 & 113.17 & 10.74 & 109.00 & 10.25 & 104.44 & 9.80 & 99.52 \\
\hline 111 & 11.83 & 117.00 & 11.28 & 113.27 & 10.75 & 109.09 & 10.28 & 104.52 & 9.85 & 99.58 \\
\hline 112 & 11.86 & 117.11 & 11.30 & 113.37 & 10.76 & 109.18 & 10.27 & 104.59 & 9.84 & 99.65 \\
\hline 113 & 11.87 & 117.22 & 11.29 & 113.47 & 10.77 & 109.27 & 10.28 & 104.67 & 9.83 & 99.71 \\
\hline 114 & 11.90 & 117.32 & 11.32 & 113.57 & 10.81 & 109.36 & 10.28 & 104.74 & 9.85 & 99.77 \\
\hline 115 & 11.93 & 117.42 & 11.34 & 113.66 & 10.77 & 109.44 & 10.30 & 104.82 & 9.83 & 99.83 \\
\hline 116 & 11.94 & 117.52 & 11.36 & 113.75 & 10.80 & 109.52 & 10.33 & 104.89 & 9.85 & 99.89 \\
\hline 117 & 11.94 & 117.62 & 11.36 & 113.84 & 10.81 & 109.60 & 10.27 & 104.96 & 9.87 & 99.95 \\
\hline 118 & 11.97 & 117.72 & 11.37 & 113.93 & 10.85 & 109.68 & 10.33 & 105.02 & 9.85 & 100.01 \\
\hline 119 & 11.98 & 117.82 & 11.37 & 114.02 & 10.80 & 109.76 & 10.36 & 105.09 & 9.87 & 100.06 \\
\hline 120 & 12.01 & 117.91 & 11.41 & 114.11 & 10.84 & 109.83 & 10.32 & 105.15 & 9.89 & 100.11 \\
\hline
\end{tabular}

\section{Permeability - 300 md}

\begin{tabular}{|c|c|c|c|c|c|c|c|c|c|c|}
\hline \multicolumn{11}{|c|}{ Bottom Placement of Nitrogen } \\
\hline \multirow{3}{*}{$\begin{array}{l}\text { TIME } \\
\text { (days) }\end{array}$} & \multirow{2}{*}{\multicolumn{2}{|c|}{$\begin{array}{c}\text { Withdrawal Pressure } \\
100 \text { psia } \\
\end{array}$}} & \multirow{2}{*}{\multicolumn{2}{|c|}{$\begin{array}{c}\text { Withdrawal Pressure } \\
150 \text { psia }\end{array}$}} & \multirow{2}{*}{\multicolumn{2}{|c|}{$\begin{array}{c}\text { Withdrawal Pressure } \\
200 \text { psia }\end{array}$}} & \multirow{2}{*}{\multicolumn{2}{|c|}{$\begin{array}{c}\text { Withdrawal Pressure } \\
250 \text { psia }\end{array}$}} & \multirow{2}{*}{\multicolumn{2}{|c|}{$\begin{array}{c}\text { Withdrawal Pressure } \\
300 \text { psia }\end{array}$}} \\
\hline & & & & & & & & & & \\
\hline & $\begin{array}{c}\% \mathrm{~N}_{2} \text { in } \\
\text { withdrawn } \\
\text { gas }\end{array}$ & $\begin{array}{c}\text { \% W.G } \\
\text { withdrawn } \\
\text { (volume) }\end{array}$ & $\begin{array}{c}\% \mathrm{~N}_{2} \text { in } \\
\text { withdrawn } \\
\text { gas }\end{array}$ & $\begin{array}{c}\text { \% W.G } \\
\text { withdrawn } \\
\text { (volume) }\end{array}$ & $\begin{array}{c}\% \mathrm{~N}_{2} \text { in } \\
\text { withdrawn } \\
\text { gas }\end{array}$ & $\begin{array}{l}\text { \% W.G } \\
\text { withdrawn } \\
\text { (volume) }\end{array}$ & $\begin{array}{c}\% \mathrm{~N}_{2} \text { in } \\
\text { withdrawn } \\
\text { gas }\end{array}$ & $\begin{array}{c}\text { \% W.G } \\
\text { withdrawn } \\
\text { (volume) }\end{array}$ & $\begin{array}{c}\% \mathrm{~N}_{2} \text { in } \\
\text { withdrawn } \\
\text { gas }\end{array}$ & $\begin{array}{c}\text { \% W.G } \\
\text { withdrawn } \\
\text { (volume) }\end{array}$ \\
\hline 0.01 & 0.00 & 0.16 & 0.00 & 0.15 & 0.00 & 0.14 & 0.00 & 0.13 & 0.00 & 0.13 \\
\hline 0.04 & 0.00 & 0.53 & 0.00 & 0.50 & 0.00 & 0.48 & 0.00 & 0.45 & 0.00 & 0.43 \\
\hline 0.1 & 2.28 & 1.16 & 2.16 & 1.12 & 2.03 & 1.09 & 1.91 & 1.06 & 1.79 & 1.03 \\
\hline 0.29 & 4.94 & 2.86 & 4.82 & 2.68 & 4.69 & 2.52 & 4.55 & 2.38 & 4.42 & 2.25 \\
\hline 0.85 & 6.05 & 7.59 & 6.00 & 7.01 & 5.92 & 6.50 & 5.86 & 6.06 & 5.80 & 5.67 \\
\hline 1 & 6.35 & 12.13 & 6.34 & 11.60 & 6.31 & 11.07 & 6.28 & 10.53 & 6.25 & 9.99 \\
\hline 2 & 6.71 & 21.83 & 6.68 & 20.92 & 6.66 & 20.00 & 6.63 & 19.06 & 6.59 & 18.10 \\
\hline 3 & 6.69 & 30.28 & 6.66 & 29.05 & 6.64 & 27.80 & 6.61 & 26.52 & 6.58 & 25.22 \\
\hline 4 & 6.56 & 37.59 & 6.55 & 36.11 & 6.54 & 34.59 & 6.53 & 33.04 & 6.52 & 31.44 \\
\hline 5 & 6.63 & 44.02 & 6.62 & 42.33 & 6.61 & 40.59 & 6.59 & 38.79 & 6.58 & 36.95 \\
\hline 6 & 7.28 & 49.65 & 7.21 & 47.78 & 7.14 & 45.85 & 7.05 & 43.87 & 6.99 & 41.82 \\
\hline 7 & 7.37 & 54.66 & 7.29 & 52.64 & 7.22 & 50.56 & 7.13 & 48.41 & 7.06 & 46.18 \\
\hline
\end{tabular}




\begin{tabular}{|c|c|c|c|c|c|c|c|c|c|c|}
\hline 8 & 7.44 & 59.11 & 7.38 & 56.97 & 7.31 & 54.75 & 7.26 & 52.45 & 7.19 & 50.07 \\
\hline 9 & 7.52 & 63.12 & 7.44 & 60.87 & 7.37 & 58.53 & 7.32 & 56.11 & 7.24 & 53.59 \\
\hline 10 & 7.92 & 66.71 & 7.82 & 64.37 & 7.72 & 61.93 & 7.60 & 59.40 & 7.49 & 56.77 \\
\hline 11 & 7.98 & 69.98 & 7.88 & 67.56 & 7.77 & 65.03 & 7.62 & 62.40 & 7.52 & 59.65 \\
\hline 12 & 8.13 & 72.94 & 8.02 & 70.45 & 7.91 & 67.84 & 7.84 & 65.12 & 7.73 & 62.28 \\
\hline 13 & 8.19 & 75.64 & 8.09 & 73.09 & 7.98 & 70.41 & 7.92 & 67.61 & 7.82 & 64.68 \\
\hline 14 & 8.40 & 78.11 & 8.25 & 75.51 & 8.12 & 72.76 & 7.95 & 69.89 & 7.82 & 66.88 \\
\hline 15 & 8.39 & 80.39 & 8.12 & 77.73 & 8.03 & 74.93 & 7.81 & 71.99 & 7.71 & 68.91 \\
\hline 16 & 8.72 & 82.48 & 8.72 & 79.78 & 8.53 & 76.92 & 8.44 & 73.92 & 8.26 & 70.77 \\
\hline 17 & 8.79 & 84.41 & 8.69 & 81.67 & 8.57 & 78.76 & 8.49 & 75.71 & 8.35 & 72.49 \\
\hline 18 & 8.77 & 86.20 & 8.53 & 83.42 & 8.36 & 80.47 & 8.16 & 77.36 & 8.04 & 74.09 \\
\hline 19 & 8.65 & 87.87 & 8.57 & 85.05 & 8.39 & 82.06 & 8.17 & 78.91 & 7.84 & 75.57 \\
\hline 20 & 9.31 & 89.42 & 9.07 & 86.57 & 8.89 & 83.53 & 8.74 & 80.33 & 8.68 & 76.95 \\
\hline 21 & 9.30 & 90.86 & 9.09 & 87.98 & 8.95 & 84.91 & 8.82 & 81.67 & 8.77 & 78.23 \\
\hline 22 & 9.10 & 92.21 & 8.91 & 89.31 & 8.71 & 86.20 & 8.50 & 82.91 & 8.26 & 79.43 \\
\hline 23 & 8.94 & 93.48 & 8.71 & 90.55 & 8.54 & 87.41 & 8.34 & 84.08 & 8.05 & 80.56 \\
\hline 24 & 9.73 & 94.67 & 9.56 & 91.71 & 9.31 & 88.53 & 9.09 & 85.17 & 8.91 & 81.60 \\
\hline 25 & 9.73 & 95.78 & 9.55 & 92.80 & 9.37 & 89.60 & 9.18 & 86.20 & 8.99 & 82.59 \\
\hline 26 & 9.41 & 96.84 & 9.16 & 93.83 & 8.94 & 90.60 & 8.72 & 87.16 & 8.52 & 83.51 \\
\hline 27 & 9.27 & 97.83 & 8.97 & 94.80 & 8.78 & 91.54 & 8.58 & 88.08 & 8.35 & 84.38 \\
\hline 28 & 10.04 & 98.77 & 9.85 & 95.72 & 9.55 & 92.43 & 9.28 & 88.93 & 9.05 & 85.20 \\
\hline 29 & 10.08 & 99.65 & 9.89 & 96.58 & 9.65 & 93.27 & 9.35 & 89.74 & 9.14 & 85.97 \\
\hline 30 & 9.70 & 100.49 & 9.42 & 97.41 & 9.19 & 94.07 & 8.99 & 90.50 & 8.76 & 86.70 \\
\hline 31 & 9.60 & 101.29 & 9.28 & 98.19 & 9.07 & 94.82 & 8.88 & 91.23 & 8.67 & 87.39 \\
\hline 32 & 10.28 & 102.05 & 10.04 & 98.92 & 9.71 & 95.53 & 9.41 & 91.91 & 9.12 & 88.04 \\
\hline 33 & 10.34 & 102.77 & 10.12 & 99.62 & 9.81 & 96.21 & 9.48 & 92.56 & 9.18 & 88.65 \\
\hline 34 & 9.99 & 103.45 & 9.69 & 100.29 & 9.45 & 96.86 & 9.23 & 93.18 & 9.00 & 89.24 \\
\hline 35 & 9.93 & 104.11 & 9.61 & 100.93 & 9.36 & 97.47 & 9.17 & 93.77 & 8.95 & 89.79 \\
\hline 36 & 10.47 & 104.73 & 10.17 & 101.53 & 9.84 & 98.05 & 9.50 & 94.32 & 9.20 & 90.32 \\
\hline 37 & 10.55 & 105.32 & 10.23 & 102.11 & 9.89 & 98.61 & 9.56 & 94.85 & 9.23 & 90.82 \\
\hline 38 & 10.28 & 105.89 & 9.98 & 102.67 & 9.71 & 99.14 & 9.44 & 95.36 & 9.19 & 91.29 \\
\hline 39 & 10.25 & 106.44 & 9.92 & 103.19 & 9.67 & 99.65 & 9.43 & 95.84 & 9.17 & 91.74 \\
\hline 40 & 10.63 & 106.96 & 10.31 & 103.70 & 9.94 & 100.13 & 9.60 & 96.30 & 9.29 & 92.17 \\
\hline 41 & 10.71 & 107.45 & 10.36 & 104.18 & 9.97 & 100.60 & 9.63 & 96.73 & 9.30 & 92.58 \\
\hline 42 & 10.54 & 107.93 & 10.22 & 104.64 & 9.92 & 101.04 & 9.62 & 97.15 & 9.33 & 92.97 \\
\hline 43 & 10.54 & 108.39 & 10.20 & 105.09 & 9.91 & 101.46 & 9.62 & 97.55 & 9.32 & 93.34 \\
\hline 44 & 10.79 & 108.83 & 10.43 & 105.52 & 10.05 & 101.87 & 9.70 & 97.93 & 9.38 & 93.70 \\
\hline 45 & 10.86 & 109.26 & 10.47 & 105.92 & 10.07 & 102.26 & 9.72 & 98.30 & 9.39 & 94.03 \\
\hline 46 & 10.79 & 109.66 & 10.43 & 106.32 & 10.09 & 102.63 & 9.75 & 98.65 & 9.43 & 94.36 \\
\hline 47 & 10.79 & 110.06 & 10.42 & 106.70 & 10.09 & 102.99 & 9.75 & 98.98 & 9.43 & 94.67 \\
\hline 48 & 10.96 & 110.43 & 10.57 & 107.06 & 10.17 & 103.33 & 9.81 & 99.30 & 9.47 & 94.96 \\
\hline 49 & 10.98 & 110.80 & 10.59 & 107.41 & 10.19 & 103.66 & 9.82 & 99.61 & 9.47 & 95.24 \\
\hline 50 & 11.00 & 111.15 & 10.61 & 107.75 & 10.23 & 103.98 & 9.86 & 99.91 & 9.52 & 95.51 \\
\hline 51 & 11.00 & 111.49 & 10.60 & 108.07 & 10.23 & 104.29 & 9.87 & 100.19 & 9.52 & 95.77 \\
\hline 52 & 11.12 & 111.81 & 10.69 & 108.38 & 10.29 & 104.58 & 9.91 & 100.46 & 9.55 & 96.02 \\
\hline 53 & 11.14 & 112.13 & 10.71 & 108.69 & 10.30 & 104.87 & 9.92 & 100.73 & 9.55 & 96.26 \\
\hline 54 & 11.18 & 112.43 & 10.76 & 108.98 & 10.35 & 105.14 & 9.96 & 100.98 & 9.59 & 96.48 \\
\hline 55 & 11.19 & 112.73 & 10.76 & 109.26 & 10.34 & 105.40 & 9.96 & 101.22 & 9.60 & 96.70 \\
\hline 56 & 11.27 & 113.01 & 10.83 & 109.53 & 10.40 & 105.66 & 9.99 & 101.45 & 9.62 & 96.91 \\
\hline 57 & 11.28 & 113.29 & 10.83 & 109.79 & 10.41 & 105.90 & 10.00 & 101.68 & 9.63 & 97.11 \\
\hline 58 & 11.35 & 113.56 & 10.89 & 110.05 & 10.45 & 106.14 & 10.04 & 101.89 & 9.65 & 97.31 \\
\hline
\end{tabular}




\begin{tabular}{|c|c|c|c|c|c|c|c|c|c|c|}
\hline 59 & 11.34 & 113.82 & 10.88 & 110.29 & 10.45 & 106.37 & 10.04 & 102.10 & 9.65 & 97.49 \\
\hline 60 & 11.42 & 114.07 & 10.95 & 110.53 & 10.50 & 106.59 & 10.06 & 102.30 & 9.68 & 97.67 \\
\hline 61 & 11.43 & 114.31 & 10.95 & 110.76 & 10.50 & 106.80 & 10.08 & 102.49 & 9.69 & 97.84 \\
\hline 62 & 11.50 & 114.55 & 10.99 & 110.98 & 10.54 & 107.00 & 10.11 & 102.67 & 9.70 & 98.00 \\
\hline 63 & 11.49 & 114.78 & 11.01 & 111.20 & 10.54 & 107.20 & 10.12 & 102.85 & 9.70 & 98.16 \\
\hline 64 & 11.56 & 115.00 & 11.06 & 111.41 & 10.59 & 107.39 & 10.13 & 103.03 & 9.74 & 98.31 \\
\hline 65 & 11.56 & 115.21 & 11.05 & 111.61 & 10.58 & 107.58 & 10.15 & 103.19 & 9.75 & 98.46 \\
\hline 66 & 11.62 & 115.42 & 11.10 & 111.80 & 10.61 & 107.76 & 10.17 & 103.35 & 9.75 & 98.60 \\
\hline 67 & 11.64 & 115.63 & 11.11 & 112.00 & 10.64 & 107.93 & 10.17 & 103.51 & 9.77 & 98.73 \\
\hline 68 & 11.68 & 115.82 & 11.17 & 112.18 & 10.64 & 108.10 & 10.20 & 103.66 & 9.77 & 98.86 \\
\hline 69 & 11.70 & 116.02 & 11.14 & 112.36 & 10.68 & 108.26 & 10.21 & 103.80 & 9.78 & 98.98 \\
\hline 70 & 11.74 & 116.20 & 11.21 & 112.53 & 10.68 & 108.42 & 10.23 & 103.94 & 9.81 & 99.10 \\
\hline 71 & 11.74 & 116.38 & 11.20 & 112.70 & 10.70 & 108.58 & 10.21 & 104.07 & 9.80 & 99.22 \\
\hline 72 & 11.80 & 116.56 & 11.26 & 112.87 & 10.73 & 108.72 & 10.25 & 104.20 & 9.81 & 99.33 \\
\hline 73 & 11.81 & 116.73 & 11.23 & 113.03 & 10.75 & 108.87 & 10.26 & 104.33 & 9.82 & 99.44 \\
\hline 74 & 11.87 & 116.90 & 11.30 & 113.18 & 10.76 & 109.01 & 10.28 & 104.45 & 9.82 & 99.54 \\
\hline 75 & 11.86 & 117.06 & 11.29 & 113.33 & 10.75 & 109.14 & 10.25 & 104.57 & 9.83 & 99.64 \\
\hline 76 & 11.91 & 117.22 & 11.34 & 113.48 & 10.80 & 109.27 & 10.31 & 104.68 & 9.86 & 99.73 \\
\hline 77 & 11.93 & 117.38 & 11.32 & 113.62 & 10.79 & 109.40 & 10.30 & 104.79 & 9.87 & 99.83 \\
\hline 78 & 11.96 & 117.53 & 11.40 & 113.76 & 10.81 & 109.52 & 10.34 & 104.90 & 9.85 & 99.91 \\
\hline 79 & 11.96 & 117.68 & 11.35 & 113.90 & 10.85 & 109.64 & 10.30 & 105.00 & 9.88 & 100.00 \\
\hline 80 & 12.03 & 117.82 & 11.42 & 114.03 & 10.85 & 109.76 & 10.34 & 105.10 & 9.88 & 100.08 \\
\hline 81 & 12.02 & 117.96 & 11.41 & 114.16 & 10.86 & 109.87 & 10.34 & 105.19 & 9.88 & 100.16 \\
\hline 82 & 12.05 & 118.10 & 11.44 & 114.28 & 10.86 & 109.98 & 10.36 & 105.29 & 9.89 & 100.24 \\
\hline 83 & 12.08 & 118.23 & 11.46 & 114.40 & 10.90 & 110.09 & 10.36 & 105.38 & 9.89 & 100.31 \\
\hline 84 & 12.12 & 118.36 & 11.49 & 114.52 & 10.88 & 110.19 & 10.38 & 105.46 & 9.92 & 100.38 \\
\hline 85 & 12.10 & 118.49 & 11.46 & 114.63 & 10.90 & 110.29 & 10.40 & 105.55 & 9.92 & 100.45 \\
\hline 86 & 12.17 & 118.61 & 11.52 & 114.75 & 10.95 & 110.39 & 10.36 & 105.63 & 9.89 & 100.52 \\
\hline 87 & 12.18 & 118.74 & 11.53 & 114.86 & 10.92 & 110.48 & 10.41 & 105.71 & 9.92 & 100.58 \\
\hline 88 & 12.20 & 118.85 & 11.55 & 114.96 & 10.95 & 110.57 & 10.42 & 105.79 & 9.92 & 100.64 \\
\hline 89 & 12.20 & 118.97 & 11.54 & 115.07 & 10.96 & 110.66 & 10.41 & 105.86 & 9.95 & 100.70 \\
\hline 90 & 12.26 & 119.08 & 11.58 & 115.17 & 10.96 & 110.75 & 10.42 & 105.93 & 9.94 & 100.76 \\
\hline 91 & 12.25 & 119.19 & 11.58 & 115.27 & 10.96 & 110.84 & 10.44 & 106.00 & 9.98 & 100.82 \\
\hline 92 & 12.28 & 119.30 & 11.63 & 115.36 & 11.00 & 110.92 & 10.45 & 106.07 & 9.93 & 100.87 \\
\hline 93 & 12.31 & 119.41 & 11.60 & 115.46 & 11.00 & 111.00 & 10.43 & 106.14 & 9.96 & 100.92 \\
\hline 94 & 12.31 & 119.51 & 11.64 & 115.55 & 11.03 & 111.08 & 10.47 & 106.20 & 9.95 & 100.97 \\
\hline 95 & 12.34 & 119.61 & 11.63 & 115.64 & 11.00 & 111.15 & 10.42 & 106.26 & 9.94 & 101.02 \\
\hline 96 & 12.38 & 119.71 & 11.67 & 115.73 & 11.02 & 111.23 & 7.41 & 106.32 & 10.01 & 101.07 \\
\hline 97 & 12.36 & 119.81 & 11.63 & 115.81 & 11.05 & 111.30 & 10.47 & 106.38 & 9.91 & 101.11 \\
\hline 98 & 12.42 & 119.91 & 11.70 & 115.90 & 11.04 & 111.37 & 10.47 & 106.43 & 9.98 & 101.15 \\
\hline 99 & 12.42 & 120.00 & 11.72 & 115.98 & 11.04 & 111.43 & 4.76 & 106.49 & 10.02 & 101.20 \\
\hline 100 & 12.44 & 120.09 & 11.70 & 116.06 & 11.10 & 111.50 & 10.48 & 106.54 & 10.00 & 101.24 \\
\hline 101 & 12.44 & 120.18 & 11.74 & 116.14 & 11.08 & 111.57 & 4.76 & 106.59 & 9.93 & 101.28 \\
\hline 102 & 12.50 & 120.27 & 11.71 & 116.21 & 11.03 & 111.63 & 4.76 & 106.64 & 10.01 & 101.31 \\
\hline 103 & 12.46 & 120.35 & 11.78 & 116.29 & 11.13 & 111.69 & 10.49 & 106.69 & 10.04 & 101.35 \\
\hline 104 & 12.52 & 120.44 & 11.76 & 116.36 & 11.07 & 111.75 & 3.85 & 106.74 & 9.96 & 101.39 \\
\hline 105 & 12.53 & 120.52 & 11.76 & 116.43 & 11.09 & 111.81 & 3.85 & 106.78 & 9.99 & 101.42 \\
\hline 106 & 12.52 & 120.60 & 11.79 & 116.50 & 11.15 & 111.86 & 10.48 & 106.83 & 10.02 & 101.45 \\
\hline 107 & 12.55 & 120.68 & 11.79 & 116.57 & 11.08 & 111.92 & 1.96 & 106.87 & 9.99 & 101.48 \\
\hline 108 & 12.59 & 120.76 & 11.79 & 116.63 & 11.15 & 111.97 & 1.96 & 106.91 & 10.02 & 101.51 \\
\hline 109 & 12.58 & 120.83 & 11.83 & 116.70 & 11.11 & 112.02 & 1.96 & 106.95 & 10.05 & 101.54 \\
\hline
\end{tabular}




\begin{tabular}{|l|l|l|l|l|l|l|l|l|l|l|}
110 & 12.62 & 120.91 & 11.83 & 116.76 & 11.13 & 112.08 & 1.96 & 106.99 & 9.95 & 101.57 \\
\hline 111 & 12.60 & 120.98 & 11.85 & 116.82 & 11.14 & 112.13 & 10.55 & 107.03 & 10.05 & 101.60 \\
\hline 112 & 12.65 & 121.05 & 11.81 & 116.88 & 11.15 & 112.17 & 1.96 & 107.06 & 10.01 & 101.63 \\
\hline 113 & 12.67 & 121.12 & 11.88 & 116.94 & 11.16 & 112.22 & 1.96 & 107.10 & 10.03 & 101.65 \\
\hline 114 & 12.66 & 121.19 & 11.90 & 117.00 & 11.18 & 112.27 & 1.96 & 107.13 & 10.07 & 101.68 \\
\hline 115 & 12.71 & 121.26 & 11.81 & 117.06 & 11.18 & 112.31 & 1.96 & 107.17 & 9.94 & 101.70 \\
\hline 116 & 12.68 & 121.32 & 11.92 & 117.11 & 11.19 & 112.36 & 1.96 & 107.20 & 10.14 & 101.73 \\
\hline 117 & 12.73 & 121.39 & 11.90 & 117.17 & 11.15 & 112.40 & 1.96 & 107.23 & 9.99 & 101.75 \\
\hline 118 & 12.72 & 121.45 & 11.89 & 117.22 & 11.19 & 112.44 & 1.96 & 107.26 & 10.03 & 101.77 \\
\hline 119 & 12.73 & 121.51 & 11.90 & 117.27 & 11.26 & 112.48 & 1.96 & 107.29 & 9.96 & 101.79 \\
\hline 120 & 12.76 & 121.58 & 11.97 & 117.32 & 11.15 & 112.52 & 1.96 & 107.32 & 10.09 & 101.81 \\
\hline
\end{tabular}

\section{Degree of Mixing in Two Consecutive Production Cycles}

\begin{tabular}{|c|c|c|c|c|}
\hline \multirow{2}{*}{$\begin{array}{l}\text { Time } \\
\text { (days) }\end{array}$} & \multicolumn{2}{|c|}{$1^{\text {st }}$ Production Cycle } & \multicolumn{2}{|c|}{$2^{\text {nd }}$ Production Cycle } \\
\hline & $\% \mathrm{~N}_{2}$ in withdrawn gas & \% W.G withdrawn (volume) & $\% \mathrm{~N}_{2}$ in withdrawn gas & $\%$ W.G withdrawn (volume) \\
\hline 2 & 1.96 & 1.57 & 0.20 & 1.57 \\
\hline 3 & 2.41 & 2.36 & 0.64 & 2.36 \\
\hline 4 & 4.84 & 3.15 & 0.97 & 3.15 \\
\hline 5 & 5.48 & 3.93 & 3.39 & 3.93 \\
\hline 6 & 5.64 & 4.72 & 4.64 & 4.72 \\
\hline 7 & 5.69 & 5.51 & 4.99 & 5.51 \\
\hline 8 & 5.82 & 6.29 & 5.45 & 6.30 \\
\hline 9 & 5.86 & 7.08 & 5.57 & 7.08 \\
\hline 10 & 5.95 & 7.87 & 5.82 & 7.87 \\
\hline 11 & 5.98 & 8.66 & 5.88 & 8.66 \\
\hline 12 & 6.05 & 9.44 & 6.01 & 9.44 \\
\hline 13 & 6.07 & 10.23 & 6.04 & 10.23 \\
\hline 14 & 6.13 & 11.02 & 6.12 & 11.02 \\
\hline 15 & 6.14 & 11.80 & 6.14 & 11.80 \\
\hline 16 & 6.19 & 12.59 & 6.19 & 12.59 \\
\hline 17 & 6.21 & 13.38 & 6.20 & 13.38 \\
\hline 18 & 6.24 & 14.16 & 6.24 & 14.16 \\
\hline 19 & 6.26 & 14.95 & 6.25 & 14.95 \\
\hline 20 & 6.29 & 15.74 & 6.28 & 15.74 \\
\hline 21 & 6.30 & 16.52 & 6.29 & 16.52 \\
\hline 22 & 6.33 & 17.31 & 6.32 & 17.31 \\
\hline 23 & 6.34 & 18.10 & 6.33 & 18.10 \\
\hline 24 & 6.37 & 18.88 & 6.35 & 18.88 \\
\hline 25 & 6.38 & 19.67 & 6.36 & 19.67 \\
\hline 26 & 6.40 & 20.46 & 6.38 & 20.46 \\
\hline 27 & 6.41 & 21.24 & 6.39 & 21.24 \\
\hline 28 & 6.43 & 22.03 & 6.41 & 22.03 \\
\hline 29 & 6.44 & 22.82 & 6.42 & 22.82 \\
\hline 30 & 6.46 & 23.60 & 6.44 & 23.61 \\
\hline 31 & 6.46 & 24.39 & 6.45 & 24.39 \\
\hline 32 & 6.48 & 25.18 & 6.47 & 25.18 \\
\hline 33 & 6.49 & 25.97 & 6.47 & 25.97 \\
\hline 34 & 6.51 & 26.75 & 6.49 & 26.75 \\
\hline 35 & 6.52 & 27.54 & 6.50 & 27.54 \\
\hline 36 & 6.54 & 28.33 & 6.52 & 28.33 \\
\hline 37 & 6.54 & 29.11 & 6.52 & 29.11 \\
\hline 38 & 6.56 & 29.90 & 6.54 & 29.90 \\
\hline 39 & 6.57 & 30.69 & 6.55 & 30.69 \\
\hline 40 & 6.59 & 31.47 & 6.57 & 31.47 \\
\hline 41 & 6.60 & 32.26 & 6.57 & 32.26 \\
\hline 42 & 6.61 & 33.05 & 6.59 & 33.05 \\
\hline 43 & 6.62 & 33.83 & 6.60 & 33.83 \\
\hline 44 & 6.64 & 34.62 & 6.62 & 34.62 \\
\hline 45 & 6.65 & 35.41 & 6.62 & 35.41 \\
\hline 46 & 6.66 & 36.19 & 6.65 & 36.19 \\
\hline 47 & 6.67 & 36.98 & 6.65 & 36.98 \\
\hline 48 & 6.69 & 37.77 & 6.67 & 37.77 \\
\hline 49 & 6.70 & 38.55 & 6.67 & 38.55 \\
\hline 50 & 6.72 & 39.34 & 6.69 & 39.34 \\
\hline
\end{tabular}




\begin{tabular}{|c|c|c|c|c|}
\hline 51 & 6.72 & 40.13 & 6.70 & 40.13 \\
\hline 52 & 6.74 & 40.92 & 6.72 & 40.92 \\
\hline 53 & 6.75 & 41.70 & 6.72 & 41.70 \\
\hline 54 & 6.77 & 42.49 & 6.75 & 42.49 \\
\hline 55 & 6.78 & 43.28 & 6.75 & 43.28 \\
\hline 56 & 6.79 & 44.06 & 6.77 & 44.06 \\
\hline 57 & 6.80 & 44.85 & 6.78 & 44.85 \\
\hline 58 & 6.82 & 45.64 & 6.80 & 45.64 \\
\hline 59 & 6.83 & 46.42 & 6.80 & 46.42 \\
\hline 60 & 6.85 & 47.21 & 6.83 & 47.21 \\
\hline 61 & 6.86 & 48.00 & 6.83 & 48.00 \\
\hline 62 & 6.87 & 48.78 & 6.85 & 48.78 \\
\hline 63 & 6.89 & 49.57 & 6.86 & 49.57 \\
\hline 64 & 6.90 & 50.36 & 6.88 & 50.36 \\
\hline 65 & 6.91 & 51.14 & 6.88 & 51.14 \\
\hline 66 & 6.93 & 51.93 & 6.91 & 51.93 \\
\hline 67 & 6.94 & 52.72 & 6.91 & 52.72 \\
\hline 68 & 6.96 & 53.50 & 6.94 & 53.50 \\
\hline 69 & 6.97 & 54.29 & 6.94 & 54.29 \\
\hline 70 & 6.99 & 55.08 & 6.97 & 55.08 \\
\hline 71 & 7.00 & 55.86 & 6.97 & 55.86 \\
\hline 72 & 7.02 & 56.65 & 6.99 & 56.65 \\
\hline 73 & 7.03 & 57.44 & 7.00 & 57.44 \\
\hline 74 & 7.05 & 58.22 & 7.02 & 58.23 \\
\hline 75 & 7.06 & 59.01 & 7.03 & 59.01 \\
\hline 76 & 7.08 & 59.80 & 7.05 & 59.80 \\
\hline 77 & 7.09 & 60.59 & 7.06 & 60.59 \\
\hline 78 & 7.11 & 61.37 & 7.08 & 61.37 \\
\hline 79 & 7.12 & 62.16 & 7.09 & 62.16 \\
\hline 80 & 7.14 & 62.95 & 7.11 & 62.95 \\
\hline 81 & 7.15 & 63.73 & 7.12 & 63.73 \\
\hline 82 & 7.17 & 64.52 & 7.14 & 64.52 \\
\hline 83 & 7.18 & 65.31 & 7.15 & 65.31 \\
\hline 84 & 7.20 & 66.09 & 7.17 & 66.09 \\
\hline 85 & 7.21 & 66.88 & 7.18 & 66.88 \\
\hline 86 & 7.23 & 67.67 & 7.21 & 67.67 \\
\hline 87 & 7.25 & 68.45 & 7.21 & 68.45 \\
\hline 88 & 7.27 & 69.24 & 7.24 & 69.24 \\
\hline 89 & 7.27 & 70.03 & 7.25 & 70.03 \\
\hline 90 & 7.30 & 70.81 & 7.27 & 70.81 \\
\hline 91 & 7.31 & 71.60 & 7.28 & 71.60 \\
\hline 92 & 7.33 & 72.39 & 7.30 & 72.39 \\
\hline 93 & 7.35 & 73.17 & 7.31 & 73.17 \\
\hline 94 & 7.37 & 73.96 & 7.34 & 73.96 \\
\hline 95 & 7.38 & 74.75 & 7.34 & 74.75 \\
\hline 96 & 7.40 & 75.53 & 7.37 & 75.53 \\
\hline 97 & 7.42 & 76.32 & 7.38 & 76.32 \\
\hline 98 & 7.44 & 77.11 & 7.41 & 77.11 \\
\hline 99 & 7.45 & 77.89 & 7.41 & 77.90 \\
\hline 100 & 7.47 & 78.68 & 7.44 & 78.68 \\
\hline 101 & 7.49 & 79.47 & 7.44 & 79.47 \\
\hline 102 & 7.51 & 80.26 & 7.48 & 80.26 \\
\hline 103 & 7.52 & 81.04 & 7.48 & 81.04 \\
\hline 104 & 7.55 & 81.83 & 7.51 & 81.83 \\
\hline 105 & 7.56 & 82.62 & 7.52 & 82.62 \\
\hline 106 & 7.58 & 83.40 & 7.55 & 83.40 \\
\hline 107 & 7.60 & 84.19 & 7.55 & 84.19 \\
\hline 108 & 7.62 & 84.98 & 7.58 & 84.98 \\
\hline 109 & 7.63 & 85.76 & 7.60 & 85.76 \\
\hline 110 & 7.66 & 86.55 & 7.63 & 86.55 \\
\hline 111 & 7.67 & 87.34 & 7.63 & 87.34 \\
\hline 112 & 7.70 & 88.12 & 7.66 & 88.12 \\
\hline 113 & 7.71 & 88.91 & 7.67 & 88.91 \\
\hline 114 & 7.74 & 89.70 & 7.71 & 89.70 \\
\hline 115 & 7.76 & 90.48 & 7.71 & 90.48 \\
\hline 116 & 7.78 & 91.27 & 7.74 & 91.27 \\
\hline 117 & 7.79 & 92.06 & 7.75 & 92.06 \\
\hline 118 & 7.82 & 92.84 & 7.78 & 92.84 \\
\hline 119 & 7.83 & 93.63 & 7.79 & 93.63 \\
\hline 120 & 7.86 & 94.42 & 7.82 & 94.42 \\
\hline
\end{tabular}




\section{Peripheral Placement Case of Nitrogen}

\section{Effect of Pressure on Mixing}

\begin{tabular}{|c|c|c|c|c|c|c|c|c|c|c|}
\hline \multicolumn{11}{|c|}{ Peripheral Placement of Nitrogen } \\
\hline \multirow{2}{*}{$\begin{array}{l}\text { Time } \\
\text { (days) }\end{array}$} & \multicolumn{2}{|c|}{ Pressure -1000 psia } & \multicolumn{2}{|c|}{ Pressure - 1500 psia } & \multicolumn{2}{|c|}{ Pressure - 2000 psia } & \multicolumn{2}{|c|}{ Pressure - 2500 psia } & \multicolumn{2}{|c|}{ Pressure -3000 psia } \\
\hline & $\begin{array}{c}\% N_{2} \text { in } \\
\text { withdrawn } \\
\text { gas }\end{array}$ & $\begin{array}{c}\% \text { W.G } \\
\text { withdrawn } \\
\text { (volume) }\end{array}$ & $\begin{array}{c}\% N_{2} \text { in } \\
\text { withdrawn } \\
\text { gas }\end{array}$ & $\begin{array}{c}\% \text { W.G } \\
\text { withdrawn } \\
\text { (volume) }\end{array}$ & $\begin{array}{c}\% N_{2} \text { in } \\
\text { withdrawn } \\
\text { gas }\end{array}$ & $\begin{array}{c}\% \text { W.G } \\
\text { withdrawn } \\
\text { (volume) }\end{array}$ & $\begin{array}{c}\% \mathrm{~N}_{2} \text { in } \\
\text { withdrawn } \\
\text { gas }\end{array}$ & $\begin{array}{c}\% \text { W.G } \\
\text { withdrawn } \\
\text { (volume) }\end{array}$ & $\begin{array}{c}\% \mathrm{~N}_{2} \text { in } \\
\text { withdrawn } \\
\text { gas }\end{array}$ & $\begin{array}{c}\text { \% W.G } \\
\text { withdrawn } \\
\text { (volume) }\end{array}$ \\
\hline 1 & 0.00 & 0.83 & 0.00 & 0.83 & 0.00 & 0.83 & 0.00 & 0.83 & 0.00 & 0.83 \\
\hline 2 & 0.00 & 1.67 & 0.00 & 1.67 & 0.00 & 1.67 & 0.00 & 1.67 & 0.00 & 1.67 \\
\hline 3 & 0.00 & 2.50 & 0.00 & 2.50 & 0.00 & 2.50 & 0.00 & 2.50 & 0.00 & 2.50 \\
\hline 4 & 0.00 & 3.34 & 0.00 & 3.33 & 0.00 & 3.34 & 0.00 & 3.34 & 0.00 & 3.34 \\
\hline 5 & 0.00 & 4.17 & 0.00 & 4.17 & 0.00 & 4.17 & 0.00 & 4.17 & 0.00 & 4.17 \\
\hline 6 & 0.00 & 5.01 & 0.00 & 5.00 & 0.00 & 5.01 & 0.00 & 5.01 & 0.00 & 5.01 \\
\hline 7 & 0.00 & 5.84 & 0.00 & 5.84 & 0.00 & 5.84 & 0.00 & 5.84 & 0.00 & 5.84 \\
\hline 8 & 0.00 & 6.68 & 0.00 & 6.67 & 0.00 & 6.67 & 0.00 & 6.68 & 0.00 & 6.68 \\
\hline 9 & 0.00 & 7.51 & 0.00 & 7.50 & 0.00 & 7.51 & 0.00 & 7.51 & 0.00 & 7.51 \\
\hline 10 & 0.00 & 8.35 & 0.00 & 8.34 & 0.00 & 8.34 & 0.00 & 8.35 & 0.00 & 8.35 \\
\hline 11 & 0.00 & 9.18 & 0.00 & 9.17 & 0.00 & 9.18 & 0.00 & 9.18 & 0.00 & 9.18 \\
\hline 12 & 0.00 & 10.02 & 0.00 & 10.00 & 0.00 & 10.01 & 0.00 & 10.02 & 0.00 & 10.01 \\
\hline 13 & 0.00 & 10.85 & 0.00 & 10.84 & 0.00 & 10.84 & 0.00 & 10.85 & 0.00 & 10.85 \\
\hline 14 & 0.00 & 11.68 & 0.00 & 11.67 & 0.00 & 11.68 & 0.00 & 11.69 & 0.00 & 11.68 \\
\hline 15 & 0.00 & 12.52 & 0.00 & 12.50 & 0.00 & 12.51 & 0.00 & 12.52 & 0.00 & 12.52 \\
\hline 16 & 0.00 & 13.35 & 0.00 & 13.34 & 0.00 & 13.35 & 0.00 & 13.36 & 0.00 & 13.35 \\
\hline 17 & 0.00 & 14.19 & 0.00 & 14.17 & 0.00 & 14.18 & 0.00 & 14.19 & 0.00 & 14.19 \\
\hline 18 & 0.00 & 15.02 & 0.00 & 15.01 & 0.00 & 15.02 & 0.00 & 15.02 & 0.00 & 15.02 \\
\hline 19 & 0.00 & 15.86 & 0.00 & 15.84 & 0.00 & 15.85 & 0.00 & 15.86 & 0.00 & 15.86 \\
\hline 20 & 0.00 & 16.69 & 0.00 & 16.67 & 0.00 & 16.68 & 0.00 & 16.69 & 0.00 & 16.69 \\
\hline 21 & 0.00 & 17.53 & 0.00 & 17.51 & 0.00 & 17.52 & 0.00 & 17.53 & 0.00 & 17.53 \\
\hline 22 & 0.00 & 18.36 & 0.00 & 18.34 & 0.00 & 18.35 & 0.00 & 18.36 & 0.00 & 18.36 \\
\hline 23 & 0.00 & 19.20 & 0.00 & 19.17 & 0.00 & 19.19 & 0.00 & 19.20 & 0.00 & 19.19 \\
\hline 24 & 0.00 & 20.03 & 0.00 & 20.01 & 0.00 & 20.02 & 0.00 & 20.03 & 0.00 & 20.03 \\
\hline 25 & 0.00 & 20.87 & 0.00 & 20.84 & 0.00 & 20.85 & 0.00 & 20.87 & 0.00 & 20.86 \\
\hline 26 & 0.00 & 21.70 & 0.00 & 21.67 & 0.00 & 21.69 & 0.00 & 21.70 & 0.00 & 21.70 \\
\hline 27 & 0.00 & 22.54 & 0.00 & 22.51 & 0.00 & 22.52 & 0.00 & 22.54 & 0.00 & 22.53 \\
\hline 28 & 0.00 & 23.37 & 0.00 & 23.34 & 0.00 & 23.36 & 0.00 & 23.37 & 0.00 & 23.37 \\
\hline 29 & 0.00 & 24.20 & 0.00 & 24.18 & 0.00 & 24.19 & 0.00 & 24.21 & 0.00 & 24.20 \\
\hline 30 & 0.00 & 25.04 & 0.00 & 25.01 & 0.00 & 25.03 & 0.00 & 25.04 & 0.00 & 25.04 \\
\hline 31 & 0.00 & 25.87 & 0.00 & 25.84 & 0.00 & 25.86 & 0.00 & 25.88 & 0.00 & 25.87 \\
\hline 32 & 0.00 & 26.71 & 0.00 & 26.68 & 0.00 & 26.69 & 0.00 & 26.71 & 0.00 & 26.70 \\
\hline 33 & 0.00 & 27.54 & 0.00 & 27.51 & 0.00 & 27.53 & 0.00 & 27.55 & 0.00 & 27.54 \\
\hline 34 & 0.00 & 28.38 & 0.00 & 28.34 & 0.00 & 28.36 & 0.00 & 28.38 & 0.00 & 28.37 \\
\hline 35 & 0.00 & 29.21 & 0.00 & 29.18 & 0.00 & 29.20 & 0.00 & 29.22 & 0.00 & 29.21 \\
\hline 36 & 0.00 & 30.05 & 0.00 & 30.01 & 0.00 & 30.03 & 0.00 & 30.05 & 0.00 & 30.04 \\
\hline 37 & 0.00 & 30.88 & 0.00 & 30.85 & 0.00 & 30.86 & 0.00 & 30.88 & 0.00 & 30.88 \\
\hline 38 & 0.00 & 31.72 & 0.00 & 31.68 & 0.00 & 31.70 & 0.00 & 31.72 & 0.00 & 31.71 \\
\hline 39 & 0.00 & 32.55 & 0.00 & 32.51 & 0.00 & 32.53 & 0.00 & 32.55 & 0.00 & 32.55 \\
\hline 40 & 0.00 & 33.39 & 0.00 & 33.35 & 0.00 & 33.37 & 0.00 & 33.39 & 0.00 & 33.38 \\
\hline 41 & 0.00 & 34.22 & 0.00 & 34.18 & 0.00 & 34.20 & 0.00 & 34.22 & 0.00 & 34.22 \\
\hline 42 & 0.00 & 35.05 & 0.00 & 35.01 & 0.00 & 35.04 & 0.00 & 35.06 & 0.00 & 35.05 \\
\hline 43 & 0.00 & 35.89 & 0.00 & 35.85 & 0.00 & 35.87 & 0.00 & 35.89 & 0.00 & 35.88 \\
\hline 44 & 0.00 & 36.72 & 0.00 & 36.68 & 0.00 & 36.70 & 0.00 & 36.73 & 0.00 & 36.72 \\
\hline 45 & 0.00 & 37.56 & 0.00 & 37.51 & 0.00 & 37.54 & 0.00 & 37.56 & 0.00 & 37.55 \\
\hline 46 & 0.00 & 38.39 & 0.00 & 38.35 & 0.00 & 38.37 & 0.00 & 38.40 & 0.00 & 38.39 \\
\hline 47 & 0.00 & 39.23 & 0.00 & 39.18 & 0.00 & 39.21 & 0.00 & 39.23 & 0.00 & 39.22 \\
\hline 48 & 0.00 & 40.06 & 0.00 & 40.02 & 0.00 & 40.04 & 0.00 & 40.07 & 0.00 & 40.06 \\
\hline 49 & 0.00 & 40.90 & 0.00 & 40.85 & 0.00 & 40.87 & 0.00 & 40.90 & 0.00 & 40.89 \\
\hline 50 & 0.00 & 41.73 & 0.00 & 41.68 & 0.00 & 41.71 & 0.00 & 41.74 & 0.00 & 41.73 \\
\hline 51 & 0.00 & 42.57 & 0.00 & 42.52 & 0.00 & 42.54 & 0.00 & 42.57 & 0.00 & 42.56 \\
\hline 52 & 0.00 & 43.40 & 0.00 & 43.35 & 0.00 & 43.38 & 0.00 & 43.41 & 0.00 & 43.40 \\
\hline 53 & 0.00 & 44.24 & 0.00 & 44.18 & 0.00 & 44.21 & 0.00 & 44.24 & 0.00 & 44.23 \\
\hline 54 & 0.00 & 45.07 & 0.00 & 45.02 & 0.00 & 45.05 & 0.00 & 45.07 & 0.00 & 45.06 \\
\hline 55 & 0.00 & 45.90 & 0.00 & 45.85 & 0.00 & 45.88 & 0.00 & 45.91 & 0.00 & 45.90 \\
\hline 56 & 0.00 & 46.74 & 0.00 & 46.68 & 0.00 & 46.71 & 0.00 & 46.74 & 0.00 & 46.73 \\
\hline 57 & 0.00 & 47.57 & 0.00 & 47.52 & 0.00 & 47.55 & 0.00 & 47.58 & 0.00 & 47.57 \\
\hline 58 & 0.00 & 48.41 & 0.00 & 48.35 & 0.00 & 48.38 & 0.00 & 48.41 & 0.00 & 48.40 \\
\hline 59 & 0.00 & 49.24 & 0.00 & 49.19 & 0.00 & 49.22 & 0.00 & 49.25 & 0.00 & 49.24 \\
\hline 60 & 0.00 & 50.08 & 0.00 & 50.02 & 0.00 & 50.05 & 0.00 & 50.08 & 0.00 & 50.07 \\
\hline 61 & 0.00 & 50.91 & 0.00 & 50.85 & 0.00 & 50.88 & 0.00 & 50.92 & 0.00 & 50.91 \\
\hline 62 & 0.00 & 51.75 & 0.00 & 51.69 & 0.00 & 51.72 & 0.00 & 51.75 & 0.00 & 51.74 \\
\hline 63 & 0.00 & 52.58 & 0.00 & 52.52 & 0.00 & 52.55 & 0.00 & 52.59 & 0.00 & 52.57 \\
\hline 64 & 0.00 & 53.42 & 0.00 & 53.35 & 0.00 & 53.39 & 0.00 & 53.42 & 0.00 & 53.41 \\
\hline 65 & 0.00 & 54.25 & 0.00 & 54.19 & 0.00 & 54.22 & 0.00 & 54.26 & 0.00 & 54.24 \\
\hline
\end{tabular}




\begin{tabular}{|c|c|c|c|c|c|c|c|c|c|c|}
\hline 66 & 0.00 & 55.09 & 0.00 & 55.02 & 0.00 & 55.06 & 0.00 & 55.09 & 0.00 & 55.08 \\
\hline 67 & 0.00 & 55.92 & 0.00 & 55.85 & 0.00 & 55.89 & 0.00 & 55.93 & 0.00 & 55.91 \\
\hline 68 & 0.00 & 56.75 & 0.00 & 56.69 & 0.00 & 56.72 & 0.00 & 56.76 & 0.00 & 56.75 \\
\hline 69 & 0.00 & 57.59 & 0.00 & 57.52 & 0.00 & 57.56 & 0.00 & 57.60 & 0.00 & 57.58 \\
\hline 70 & 0.00 & 58.42 & 0.00 & 58.36 & 0.00 & 58.39 & 0.00 & 58.43 & 0.00 & 58.42 \\
\hline 71 & 0.00 & 59.26 & 0.00 & 59.19 & 0.00 & 59.23 & 0.00 & 59.26 & 0.00 & 59.25 \\
\hline 72 & 0.00 & 60.09 & 0.00 & 60.02 & 0.00 & 60.06 & 0.00 & 60.10 & 0.00 & 60.09 \\
\hline 73 & 0.00 & 60.93 & 0.00 & 60.86 & 0.00 & 60.89 & 0.00 & 60.93 & 0.00 & 60.92 \\
\hline 74 & 0.00 & 61.76 & 0.00 & 61.69 & 0.00 & 61.73 & 0.00 & 61.77 & 0.00 & 61.75 \\
\hline 75 & 0.00 & 62.60 & 0.00 & 62.52 & 0.00 & 62.56 & 0.00 & 62.60 & 0.00 & 62.59 \\
\hline 76 & 0.00 & 63.43 & 0.00 & 63.36 & 0.00 & 63.40 & 0.00 & 63.44 & 0.00 & 63.42 \\
\hline 77 & 0.00 & 64.27 & 0.00 & 64.19 & 0.00 & 64.23 & 0.00 & 64.27 & 0.00 & 64.26 \\
\hline 78 & 0.00 & 65.10 & 0.00 & 65.02 & 0.00 & 65.07 & 0.00 & 65.11 & 0.00 & 65.09 \\
\hline 79 & 0.00 & 65.94 & 0.00 & 65.86 & 0.00 & 65.90 & 0.00 & 65.94 & 0.00 & 65.93 \\
\hline 80 & 0.00 & 66.77 & 0.00 & 66.69 & 0.00 & 66.73 & 0.00 & 66.78 & 0.00 & 66.76 \\
\hline 81 & 0.00 & 67.60 & 0.00 & 67.53 & 0.00 & 67.57 & 0.00 & 67.61 & 0.00 & 67.60 \\
\hline 82 & 0.00 & 68.44 & 0.00 & 68.36 & 0.00 & 68.40 & 0.00 & 68.45 & 0.00 & 68.43 \\
\hline 83 & 0.00 & 69.27 & 0.00 & 69.19 & 0.00 & 69.24 & 0.00 & 69.28 & 0.00 & 69.26 \\
\hline 84 & 0.00 & 70.11 & 0.00 & 70.03 & 0.00 & 70.07 & 0.00 & 70.12 & 0.00 & 70.10 \\
\hline 85 & 0.00 & 70.94 & 0.00 & 70.86 & 0.00 & 70.90 & 0.00 & 70.95 & 0.00 & 70.93 \\
\hline 86 & 0.00 & 71.78 & 0.00 & 71.69 & 0.00 & 71.74 & 0.00 & 71.79 & 0.00 & 71.77 \\
\hline 87 & 0.00 & 72.61 & 0.00 & 72.53 & 0.00 & 72.57 & 0.00 & 72.62 & 0.00 & 72.60 \\
\hline 88 & 0.00 & 73.45 & 0.00 & 73.36 & 0.00 & 73.41 & 0.00 & 73.45 & 0.00 & 73.44 \\
\hline 89 & 0.00 & 74.28 & 0.00 & 74.19 & 0.00 & 74.24 & 0.00 & 74.29 & 0.00 & 74.27 \\
\hline 90 & 0.00 & 75.12 & 0.00 & 75.03 & 0.00 & 75.08 & 0.00 & 75.12 & 0.00 & 75.11 \\
\hline 91 & 0.00 & 75.95 & 0.00 & 75.86 & 0.00 & 75.91 & 0.00 & 75.96 & 0.00 & 75.94 \\
\hline 92 & 0.00 & 76.79 & 0.00 & 76.70 & 0.00 & 76.74 & 0.00 & 76.79 & 0.00 & 76.78 \\
\hline 93 & 0.00 & 77.62 & 0.00 & 77.53 & 0.00 & 77.58 & 0.00 & 77.63 & 0.00 & 77.61 \\
\hline 94 & 0.01 & 78.45 & 0.01 & 78.36 & 0.01 & 78.41 & 0.01 & 78.46 & 0.01 & 78.44 \\
\hline 95 & 0.01 & 79.29 & 0.01 & 79.20 & 0.01 & 79.25 & 0.01 & 79.30 & 0.01 & 79.28 \\
\hline 96 & 0.01 & 80.12 & 0.01 & 80.03 & 0.01 & 80.08 & 0.01 & 80.13 & 0.01 & 80.11 \\
\hline 97 & 0.01 & 80.96 & 0.01 & 80.86 & 0.01 & 80.91 & 0.01 & 80.97 & 0.01 & 80.95 \\
\hline 98 & 0.01 & 81.79 & 0.01 & 81.70 & 0.01 & 81.75 & 0.01 & 81.80 & 0.01 & 81.78 \\
\hline 99 & 0.01 & 82.63 & 0.01 & 82.53 & 0.01 & 82.58 & 0.01 & 82.64 & 0.01 & 82.62 \\
\hline 100 & 0.01 & 83.46 & 0.01 & 83.36 & 0.01 & 83.42 & 0.01 & 83.47 & 0.01 & 83.45 \\
\hline 101 & 0.01 & 84.30 & 0.01 & 84.20 & 0.01 & 84.25 & 0.01 & 84.31 & 0.01 & 84.29 \\
\hline 102 & 0.02 & 85.13 & 0.02 & 85.03 & 0.02 & 85.08 & 0.02 & 85.14 & 0.02 & 85.12 \\
\hline 103 & 0.02 & 85.97 & 0.02 & 85.87 & 0.02 & 85.92 & 0.02 & 85.98 & 0.02 & 85.95 \\
\hline 104 & 0.02 & 86.80 & 0.02 & 86.70 & 0.02 & 86.75 & 0.02 & 86.81 & 0.02 & 86.79 \\
\hline 105 & 0.02 & 87.64 & 0.02 & 87.53 & 0.02 & 87.59 & 0.02 & 87.64 & 0.02 & 87.62 \\
\hline 106 & 0.03 & 88.47 & 0.03 & 88.37 & 0.03 & 88.42 & 0.03 & 88.48 & 0.03 & 88.46 \\
\hline 107 & 0.03 & 89.30 & 0.03 & 89.20 & 0.03 & 89.26 & 0.03 & 89.31 & 0.03 & 89.29 \\
\hline 108 & 0.04 & 90.14 & 0.03 & 90.03 & 0.03 & 90.09 & 0.03 & 90.15 & 0.03 & 90.13 \\
\hline 109 & 0.04 & 90.97 & 0.03 & 90.87 & 0.03 & 90.92 & 0.03 & 90.98 & 0.03 & 90.96 \\
\hline 110 & 0.04 & 91.81 & 0.04 & 91.70 & 0.04 & 91.76 & 0.04 & 91.82 & 0.04 & 91.80 \\
\hline 111 & 0.05 & 92.64 & 0.04 & 92.53 & 0.04 & 92.59 & 0.04 & 92.65 & 0.04 & 92.63 \\
\hline 112 & 0.06 & 93.48 & 0.05 & 93.37 & 0.05 & 93.43 & 0.05 & 93.49 & 0.05 & 93.47 \\
\hline 113 & 0.06 & 94.31 & 0.05 & 94.20 & 0.05 & 94.26 & 0.05 & 94.32 & 0.05 & 94.30 \\
\hline 114 & 0.07 & 95.15 & 0.06 & 95.03 & 0.06 & 95.09 & 0.06 & 95.16 & 0.06 & 95.13 \\
\hline 115 & 0.07 & 95.98 & 0.06 & 95.87 & 0.06 & 95.93 & 0.06 & 95.99 & 0.06 & 95.97 \\
\hline 116 & 0.08 & 96.82 & 0.08 & 96.70 & 0.07 & 96.76 & 0.08 & 96.83 & 0.08 & 96.80 \\
\hline 117 & 0.08 & 97.65 & 0.08 & 97.54 & 0.07 & 97.60 & 0.08 & 97.66 & 0.08 & 97.64 \\
\hline 118 & 0.10 & 98.48 & 0.09 & 98.37 & 0.09 & 98.43 & 0.09 & 98.50 & 0.10 & 98.47 \\
\hline 119 & 0.10 & 99.32 & 0.09 & 99.20 & 0.09 & 99.27 & 0.09 & 99.33 & 0.10 & 99.31 \\
\hline 120 & 0.12 & 100.15 & 0.11 & 100.04 & 0.11 & 100.10 & 0.11 & 100.16 & 0.12 & 100.14 \\
\hline
\end{tabular}




\section{Effect of Temperature on Mixing}

\begin{tabular}{|c|c|c|c|c|c|c|c|c|}
\hline \multicolumn{9}{|c|}{ Peripheral Placement of Nitrogen } \\
\hline \multirow{2}{*}{$\begin{array}{l}\text { Time } \\
\text { (days) }\end{array}$} & \multicolumn{2}{|c|}{ Temperature $-90^{\circ} \mathrm{F}$} & \multicolumn{2}{|c|}{ Temperature $-100^{\circ} \mathrm{F}$} & \multicolumn{2}{|c|}{ Temperature $-125^{\circ} \mathrm{F}$} & \multicolumn{2}{|c|}{ Temperature $-150^{\circ} \mathrm{F}$} \\
\hline & $\begin{array}{c}\% N_{2} \text { in } \\
\text { withdrawn gas }\end{array}$ & $\begin{array}{c}\% \text { W.G } \\
\text { withdrawn } \\
\text { (volume) }\end{array}$ & $\begin{array}{c}\% N_{2} \text { in } \\
\text { withdrawn gas }\end{array}$ & $\begin{array}{c}\% \text { W.G } \\
\text { withdrawn } \\
\text { (volume) }\end{array}$ & $\begin{array}{c}\% N_{2} \text { in } \\
\text { withdrawn gas }\end{array}$ & $\begin{array}{c}\% \text { W.G } \\
\text { withdrawn } \\
\text { (volume) }\end{array}$ & $\begin{array}{l}\quad \% \mathrm{~N}_{2} \text { in } \\
\text { withdrawn gas }\end{array}$ & $\begin{array}{c}\% \text { W.G } \\
\text { withdrawn } \\
\text { (volume) }\end{array}$ \\
\hline 1 & 0.00 & 0.84 & 0.00 & 0.84 & 0.00 & 0.84 & 0.00 & 0.84 \\
\hline 2 & 0.00 & 1.67 & 0.00 & 1.67 & 0.00 & 1.67 & 0.00 & 1.67 \\
\hline 3 & 0.00 & 2.51 & 0.00 & 2.51 & 0.00 & 2.51 & 0.00 & 2.51 \\
\hline 4 & 0.00 & 3.35 & 0.00 & 3.34 & 0.00 & 3.34 & 0.00 & 3.34 \\
\hline 5 & 0.00 & 4.19 & 0.00 & 4.18 & 0.00 & 4.18 & 0.00 & 4.18 \\
\hline 6 & 0.00 & 5.02 & 0.00 & 5.01 & 0.00 & 5.01 & 0.00 & 5.01 \\
\hline 7 & 0.00 & 5.86 & 0.00 & 5.85 & 0.00 & 5.85 & 0.00 & 5.85 \\
\hline 8 & 0.00 & 6.70 & 0.00 & 6.69 & 0.00 & 6.68 & 0.00 & 6.68 \\
\hline 9 & 0.00 & 7.54 & 0.00 & 7.52 & 0.00 & 7.52 & 0.00 & 7.52 \\
\hline 10 & 0.00 & 8.37 & 0.00 & 8.36 & 0.00 & 8.35 & 0.00 & 8.36 \\
\hline 11 & 0.00 & 9.21 & 0.00 & 9.19 & 0.00 & 9.19 & 0.00 & 9.19 \\
\hline 12 & 0.00 & 10.05 & 0.00 & 10.03 & 0.00 & 10.02 & 0.00 & 10.03 \\
\hline 13 & 0.00 & 10.88 & 0.00 & 10.86 & 0.00 & 10.86 & 0.00 & 10.86 \\
\hline 14 & 0.00 & 11.72 & 0.00 & 11.70 & 0.00 & 11.70 & 0.00 & 11.70 \\
\hline 15 & 0.00 & 12.56 & 0.00 & 12.54 & 0.00 & 12.53 & 0.00 & 12.53 \\
\hline 16 & 0.00 & 13.40 & 0.00 & 13.37 & 0.00 & 13.37 & 0.00 & 13.37 \\
\hline 17 & 0.00 & 14.23 & 0.00 & 14.21 & 0.00 & 14.20 & 0.00 & 14.20 \\
\hline 18 & 0.00 & 15.07 & 0.00 & 15.04 & 0.00 & 15.04 & 0.00 & 15.04 \\
\hline 19 & 0.00 & 15.91 & 0.00 & 15.88 & 0.00 & 15.87 & 0.00 & 15.88 \\
\hline 20 & 0.00 & 16.74 & 0.00 & 16.71 & 0.00 & 16.71 & 0.00 & 16.71 \\
\hline 21 & 0.00 & 17.58 & 0.00 & 17.55 & 0.00 & 17.54 & 0.00 & 17.55 \\
\hline 22 & 0.00 & 18.42 & 0.00 & 18.39 & 0.00 & 18.38 & 0.00 & 18.38 \\
\hline 23 & 0.00 & 19.26 & 0.00 & 19.22 & 0.00 & 19.21 & 0.00 & 19.22 \\
\hline 24 & 0.00 & 20.09 & 0.00 & 20.06 & 0.00 & 20.05 & 0.00 & 20.05 \\
\hline 25 & 0.00 & 20.93 & 0.00 & 20.89 & 0.00 & 20.88 & 0.00 & 20.89 \\
\hline 26 & 0.00 & 21.77 & 0.00 & 21.73 & 0.00 & 21.72 & 0.00 & 21.73 \\
\hline 27 & 0.00 & 22.61 & 0.00 & 22.56 & 0.00 & 22.56 & 0.00 & 22.56 \\
\hline 28 & 0.00 & 23.44 & 0.00 & 23.40 & 0.00 & 23.39 & 0.00 & 23.40 \\
\hline 29 & 0.00 & 24.28 & 0.00 & 24.24 & 0.00 & 24.23 & 0.00 & 24.23 \\
\hline 30 & 0.00 & 25.12 & 0.00 & 25.07 & 0.00 & 25.06 & 0.00 & 25.07 \\
\hline 31 & 0.00 & 25.95 & 0.00 & 25.91 & 0.00 & 25.90 & 0.00 & 25.90 \\
\hline 32 & 0.00 & 26.79 & 0.00 & 26.74 & 0.00 & 26.73 & 0.00 & 26.74 \\
\hline 33 & 0.00 & 27.63 & 0.00 & 27.58 & 0.00 & 27.57 & 0.00 & 27.57 \\
\hline 34 & 0.00 & 28.47 & 0.00 & 28.41 & 0.00 & 28.40 & 0.00 & 28.41 \\
\hline 35 & 0.00 & 29.30 & 0.00 & 29.25 & 0.00 & 29.24 & 0.00 & 29.25 \\
\hline 36 & 0.00 & 30.14 & 0.00 & 30.09 & 0.00 & 30.07 & 0.00 & 30.08 \\
\hline 37 & 0.00 & 30.98 & 0.00 & 30.92 & 0.00 & 30.91 & 0.00 & 30.92 \\
\hline 38 & 0.00 & 31.82 & 0.00 & 31.76 & 0.00 & 31.74 & 0.00 & 31.75 \\
\hline 39 & 0.00 & 32.65 & 0.00 & 32.59 & 0.00 & 32.58 & 0.00 & 32.59 \\
\hline 40 & 0.00 & 33.49 & 0.00 & 33.43 & 0.00 & 33.42 & 0.00 & 33.42 \\
\hline 41 & 0.00 & 34.33 & 0.00 & 34.27 & 0.00 & 34.25 & 0.00 & 34.26 \\
\hline 42 & 0.00 & 35.16 & 0.00 & 35.10 & 0.00 & 35.09 & 0.00 & 35.09 \\
\hline 43 & 0.00 & 36.00 & 0.00 & 35.94 & 0.00 & 35.92 & 0.00 & 35.93 \\
\hline 44 & 0.00 & 36.84 & 0.00 & 36.77 & 0.00 & 36.76 & 0.00 & 36.77 \\
\hline 45 & 0.00 & 37.68 & 0.00 & 37.61 & 0.00 & 37.59 & 0.00 & 37.60 \\
\hline 46 & 0.00 & 38.51 & 0.00 & 38.44 & 0.00 & 38.43 & 0.00 & 38.44 \\
\hline 47 & 0.00 & 39.35 & 0.00 & 39.28 & 0.00 & 39.26 & 0.00 & 39.27 \\
\hline 48 & 0.00 & 40.19 & 0.00 & 40.12 & 0.00 & 40.10 & 0.00 & 40.11 \\
\hline 49 & 0.00 & 41.02 & 0.00 & 40.95 & 0.00 & 40.93 & 0.00 & 40.94 \\
\hline 50 & 0.00 & 41.86 & 0.00 & 41.79 & 0.00 & 41.77 & 0.00 & 41.78 \\
\hline 51 & 0.00 & 42.70 & 0.00 & 42.62 & 0.00 & 42.60 & 0.00 & 42.61 \\
\hline 52 & 0.00 & 43.54 & 0.00 & 43.46 & 0.00 & 43.44 & 0.00 & 43.45 \\
\hline 53 & 0.00 & 44.37 & 0.00 & 44.29 & 0.00 & 44.28 & 0.00 & 44.29 \\
\hline 54 & 0.00 & 45.21 & 0.00 & 45.13 & 0.00 & 45.11 & 0.00 & 45.12 \\
\hline 55 & 0.00 & 46.05 & 0.00 & 45.97 & 0.00 & 45.95 & 0.00 & 45.96 \\
\hline 56 & 0.00 & 46.89 & 0.00 & 46.80 & 0.00 & 46.78 & 0.00 & 46.79 \\
\hline 57 & 0.00 & 47.72 & 0.00 & 47.64 & 0.00 & 47.62 & 0.00 & 47.63 \\
\hline 58 & 0.00 & 48.56 & 0.00 & 48.47 & 0.00 & 48.45 & 0.00 & 48.46 \\
\hline 59 & 0.00 & 49.40 & 0.00 & 49.31 & 0.00 & 49.29 & 0.00 & 49.30 \\
\hline 60 & 0.00 & 50.23 & 0.00 & 50.14 & 0.00 & 50.12 & 0.00 & 50.13 \\
\hline 61 & 0.00 & 51.07 & 0.00 & 50.98 & 0.00 & 50.96 & 0.00 & 50.97 \\
\hline 62 & 0.00 & 51.91 & 0.00 & 51.82 & 0.00 & 51.79 & 0.00 & 51.81 \\
\hline 63 & 0.00 & 52.75 & 0.00 & 52.65 & 0.00 & 52.63 & 0.00 & 52.64 \\
\hline 64 & 0.00 & 53.58 & 0.00 & 53.49 & 0.00 & 53.46 & 0.00 & 53.48 \\
\hline 65 & 0.00 & 54.42 & 0.00 & 54.32 & 0.00 & 54.30 & 0.00 & 54.31 \\
\hline 66 & 0.00 & 55.26 & 0.00 & 55.16 & 0.00 & 55.14 & 0.00 & 55.15 \\
\hline 67 & 0.00 & 56.09 & 0.00 & 55.99 & 0.00 & 55.97 & 0.00 & 55.98 \\
\hline 68 & 0.00 & 56.93 & 0.00 & 56.83 & 0.00 & 56.81 & 0.00 & 56.82 \\
\hline
\end{tabular}




\begin{tabular}{|c|c|c|c|c|c|c|c|c|}
\hline 69 & 0.00 & 57.77 & 0.00 & 57.67 & 0.00 & 57.64 & 0.00 & 57.65 \\
\hline 70 & 0.00 & 58.61 & 0.00 & 58.50 & 0.00 & 58.48 & 0.00 & 58.49 \\
\hline 71 & 0.00 & 59.44 & 0.00 & 59.34 & 0.00 & 59.31 & 0.00 & 59.33 \\
\hline 72 & 0.00 & 60.28 & 0.00 & 60.17 & 0.00 & 60.15 & 0.00 & 60.16 \\
\hline 73 & 0.00 & 61.12 & 0.00 & 61.01 & 0.00 & 60.98 & 0.00 & 61.00 \\
\hline 74 & 0.00 & 61.96 & 0.00 & 61.84 & 0.00 & 61.82 & 0.00 & 61.83 \\
\hline 75 & 0.00 & 62.79 & 0.00 & 62.68 & 0.00 & 62.65 & 0.00 & 62.67 \\
\hline 76 & 0.00 & 63.63 & 0.00 & 63.52 & 0.00 & 63.49 & 0.00 & 63.50 \\
\hline 77 & 0.00 & 64.47 & 0.00 & 64.35 & 0.00 & 64.32 & 0.00 & 64.34 \\
\hline 78 & 0.00 & 65.30 & 0.00 & 65.19 & 0.00 & 65.16 & 0.00 & 65.17 \\
\hline 79 & 0.00 & 66.14 & 0.00 & 66.02 & 0.00 & 66.00 & 0.00 & 66.01 \\
\hline 80 & 0.00 & 66.98 & 0.00 & 66.86 & 0.00 & 66.83 & 0.00 & 66.85 \\
\hline 81 & 0.00 & 67.82 & 0.00 & 67.69 & 0.00 & 67.67 & 0.00 & 67.68 \\
\hline 82 & 0.00 & 68.65 & 0.00 & 68.53 & 0.00 & 68.50 & 0.00 & 68.52 \\
\hline 83 & 0.00 & 69.49 & 0.00 & 69.37 & 0.00 & 69.34 & 0.00 & 69.35 \\
\hline 84 & 0.00 & 70.33 & 0.00 & 70.20 & 0.00 & 70.17 & 0.00 & 70.19 \\
\hline 85 & 0.00 & 71.16 & 0.00 & 71.04 & 0.00 & 71.01 & 0.00 & 71.02 \\
\hline 86 & 0.00 & 72.00 & 0.00 & 71.87 & 0.00 & 71.84 & 0.00 & 71.86 \\
\hline 87 & 0.00 & 72.84 & 0.00 & 72.71 & 0.00 & 72.68 & 0.00 & 72.69 \\
\hline 88 & 0.00 & 73.68 & 0.00 & 73.54 & 0.00 & 73.51 & 0.00 & 73.53 \\
\hline 89 & 0.00 & 74.51 & 0.00 & 74.38 & 0.00 & 74.35 & 0.00 & 74.37 \\
\hline 90 & 0.00 & 75.35 & 0.00 & 75.22 & 0.00 & 75.18 & 0.00 & 75.20 \\
\hline 91 & 0.00 & 76.19 & 0.00 & 76.05 & 0.00 & 76.02 & 0.00 & 76.04 \\
\hline 92 & 0.00 & 77.03 & 0.00 & 76.89 & 0.00 & 76.86 & 0.00 & 76.87 \\
\hline 93 & 0.00 & 77.86 & 0.00 & 77.72 & 0.00 & 77.69 & 0.01 & 77.71 \\
\hline 94 & 0.01 & 78.70 & 0.01 & 78.56 & 0.01 & 78.53 & 0.01 & 78.54 \\
\hline 95 & 0.01 & 79.54 & 0.01 & 79.39 & 0.01 & 79.36 & 0.01 & 79.38 \\
\hline 96 & 0.01 & 80.37 & 0.01 & 80.23 & 0.01 & 80.20 & 0.01 & 80.21 \\
\hline 97 & 0.01 & 81.21 & 0.01 & 81.07 & 0.01 & 81.03 & 0.01 & 81.05 \\
\hline 98 & 0.01 & 82.05 & 0.01 & 81.90 & 0.01 & 81.87 & 0.01 & 81.89 \\
\hline 99 & 0.01 & 82.89 & 0.01 & 82.74 & 0.01 & 82.70 & 0.01 & 82.72 \\
\hline 100 & 0.01 & 83.72 & 0.01 & 83.57 & 0.01 & 83.54 & 0.01 & 83.56 \\
\hline 101 & 0.01 & 84.56 & 0.01 & 84.41 & 0.01 & 84.37 & 0.01 & 84.39 \\
\hline 102 & 0.02 & 85.40 & 0.02 & 85.24 & 0.02 & 85.21 & 0.02 & 85.23 \\
\hline 103 & 0.02 & 86.24 & 0.02 & 86.08 & 0.02 & 86.04 & 0.02 & 86.06 \\
\hline 104 & 0.02 & 87.07 & 0.02 & 86.92 & 0.02 & 86.88 & 0.02 & 86.90 \\
\hline 105 & 0.02 & 87.91 & 0.02 & 87.75 & 0.02 & 87.72 & 0.02 & 87.73 \\
\hline 106 & 0.03 & 88.75 & 0.03 & 88.59 & 0.03 & 88.55 & 0.03 & 88.57 \\
\hline 107 & 0.03 & 89.58 & 0.03 & 89.42 & 0.03 & 89.39 & 0.03 & 89.41 \\
\hline 108 & 0.04 & 90.42 & 0.04 & 90.26 & 0.04 & 90.22 & 0.04 & 90.24 \\
\hline 109 & 0.04 & 91.26 & 0.04 & 91.09 & 0.04 & 91.06 & 0.04 & 91.08 \\
\hline 110 & 0.04 & 92.10 & 0.04 & 91.93 & 0.05 & 91.89 & 0.05 & 91.91 \\
\hline 111 & 0.05 & 92.93 & 0.04 & 92.77 & 0.05 & 92.73 & 0.05 & 92.75 \\
\hline 112 & 0.06 & 93.77 & 0.05 & 93.60 & 0.06 & 93.56 & 0.06 & 93.58 \\
\hline 113 & 0.06 & 94.61 & 0.06 & 94.44 & 0.06 & 94.40 & 0.06 & 94.42 \\
\hline 114 & 0.07 & 95.44 & 0.07 & 95.27 & 0.07 & 95.23 & 0.07 & 95.25 \\
\hline 115 & 0.07 & 96.28 & 0.07 & 96.11 & 0.07 & 96.07 & 0.07 & 96.09 \\
\hline 116 & 0.08 & 97.12 & 0.08 & 96.94 & 0.09 & 96.90 & 0.09 & 96.93 \\
\hline 117 & 0.08 & 97.96 & 0.08 & 97.78 & 0.09 & 97.74 & 0.09 & 97.76 \\
\hline 118 & 0.10 & 98.79 & 0.10 & 98.61 & 0.10 & 98.57 & 0.11 & 98.60 \\
\hline 119 & 0.10 & 99.63 & 0.10 & 99.45 & 0.11 & 99.41 & 0.11 & 99.43 \\
\hline 120 & 0.12 & 100.47 & 0.12 & 100.29 & 0.13 & 100.25 & 0.13 & 100.27 \\
\hline
\end{tabular}




\section{Effect of Permeability on Mixing}

Permeability Values - 10 md, 20 md, 50 md, 100 md

\begin{tabular}{|c|c|c|c|c|c|c|c|c|}
\hline \multicolumn{9}{|c|}{ Peripheral Placement of Nitrogen } \\
\hline \multirow{2}{*}{$\begin{array}{l}\text { Time } \\
\text { (days) }\end{array}$} & \multicolumn{2}{|c|}{ Permeability - 10 md } & \multicolumn{2}{|c|}{ Permeability - 20 md } & \multicolumn{2}{|c|}{ Permeability - $50 \mathrm{md}$} & \multicolumn{2}{|c|}{ Permeability - 100 md } \\
\hline & $\begin{array}{c}\% \mathrm{~N}_{2} \text { in } \\
\text { withdrawn } \\
\text { gas }\end{array}$ & $\begin{array}{c}\text { \% W.G } \\
\text { withdrawn } \\
\text { (volume) }\end{array}$ & $\begin{array}{c}\% \mathrm{~N}_{2} \text { in } \\
\text { withdrawn } \\
\text { gas }\end{array}$ & $\begin{array}{c}\text { \% W.G } \\
\text { withdrawn } \\
\text { (volume) }\end{array}$ & $\begin{array}{c}\% \mathrm{~N}_{2} \text { in } \\
\text { withdrawn } \\
\text { gas }\end{array}$ & $\begin{array}{c}\text { \% W.G } \\
\text { withdrawn } \\
\text { (volume) }\end{array}$ & $\begin{array}{c}\% \mathrm{~N}_{2} \text { in } \\
\text { withdrawn } \\
\text { gas }\end{array}$ & $\begin{array}{c}\% \text { W.G } \\
\text { withdrawn } \\
\text { (volume) }\end{array}$ \\
\hline 1 & 0.00 & 0.84 & 0.00 & 0.84 & 0.00 & 0.84 & 0.00 & 0.84 \\
\hline 2 & 0.00 & 1.67 & 0.00 & 1.67 & 0.00 & 1.67 & 0.00 & 1.67 \\
\hline 3 & 0.00 & 2.51 & 0.00 & 2.51 & 0.00 & 2.51 & 0.00 & 2.51 \\
\hline 4 & 0.00 & 3.34 & 0.00 & 3.34 & 0.00 & 3.34 & 0.00 & 3.34 \\
\hline 5 & 0.00 & 4.18 & 0.00 & 4.18 & 0.00 & 4.18 & 0.00 & 4.18 \\
\hline 6 & 0.00 & 5.01 & 0.00 & 5.01 & 0.00 & 5.01 & 0.00 & 5.01 \\
\hline 7 & 0.00 & 5.85 & 0.00 & 5.85 & 0.00 & 5.85 & 0.00 & 5.85 \\
\hline 8 & 0.00 & 6.68 & 0.00 & 6.69 & 0.00 & 6.69 & 0.00 & 6.69 \\
\hline 9 & 0.00 & 7.52 & 0.00 & 7.52 & 0.00 & 7.52 & 0.00 & 7.52 \\
\hline 10 & 0.00 & 8.36 & 0.00 & 8.36 & 0.00 & 8.36 & 0.00 & 8.36 \\
\hline 11 & 0.00 & 9.19 & 0.00 & 9.19 & 0.00 & 9.19 & 0.00 & 9.19 \\
\hline 12 & 0.00 & 10.03 & 0.00 & 10.03 & 0.00 & 10.03 & 0.00 & 10.03 \\
\hline 13 & 0.00 & 10.86 & 0.00 & 10.86 & 0.00 & 10.86 & 0.00 & 10.86 \\
\hline 14 & 0.00 & 11.70 & 0.00 & 11.70 & 0.00 & 11.70 & 0.00 & 11.70 \\
\hline 15 & 0.00 & 12.53 & 0.00 & 12.53 & 0.00 & 12.53 & 0.00 & 12.53 \\
\hline 16 & 0.00 & 13.37 & 0.00 & 13.37 & 0.00 & 13.37 & 0.00 & 13.37 \\
\hline 17 & 0.00 & 14.21 & 0.00 & 14.21 & 0.00 & 14.21 & 0.00 & 14.21 \\
\hline 18 & 0.00 & 15.04 & 0.00 & 15.04 & 0.00 & 15.04 & 0.00 & 15.04 \\
\hline 19 & 0.00 & 15.88 & 0.00 & 15.88 & 0.00 & 15.88 & 0.00 & 15.88 \\
\hline 20 & 0.00 & 16.71 & 0.00 & 16.71 & 0.00 & 16.71 & 0.00 & 16.71 \\
\hline 21 & 0.00 & 17.55 & 0.00 & 17.55 & 0.00 & 17.55 & 0.00 & 17.55 \\
\hline 22 & 0.00 & 18.38 & 0.00 & 18.38 & 0.00 & 18.38 & 0.00 & 18.38 \\
\hline 23 & 0.00 & 19.22 & 0.00 & 19.22 & 0.00 & 19.22 & 0.00 & 19.22 \\
\hline 24 & 0.00 & 20.05 & 0.00 & 20.06 & 0.00 & 20.06 & 0.00 & 20.06 \\
\hline 25 & 0.00 & 20.89 & 0.00 & 20.89 & 0.00 & 20.89 & 0.00 & 20.89 \\
\hline 26 & 0.00 & 21.73 & 0.00 & 21.73 & 0.00 & 21.73 & 0.00 & 21.73 \\
\hline 27 & 0.00 & 22.56 & 0.00 & 22.56 & 0.00 & 22.56 & 0.00 & 22.56 \\
\hline 28 & 0.00 & 23.40 & 0.00 & 23.40 & 0.00 & 23.40 & 0.00 & 23.40 \\
\hline 29 & 0.00 & 24.23 & 0.00 & 24.23 & 0.00 & 24.23 & 0.00 & 24.23 \\
\hline 30 & 0.00 & 25.07 & 0.00 & 25.07 & 0.00 & 25.07 & 0.00 & 25.07 \\
\hline 31 & 0.00 & 25.90 & 0.00 & 25.91 & 0.00 & 25.91 & 0.00 & 25.91 \\
\hline 32 & 0.00 & 26.74 & 0.00 & 26.74 & 0.00 & 26.74 & 0.00 & 26.74 \\
\hline 33 & 0.00 & 27.58 & 0.00 & 27.58 & 0.00 & 27.58 & 0.00 & 27.58 \\
\hline 34 & 0.00 & 28.41 & 0.00 & 28.41 & 0.00 & 28.41 & 0.00 & 28.41 \\
\hline 35 & 0.00 & 29.25 & 0.00 & 29.25 & 0.00 & 29.25 & 0.00 & 29.25 \\
\hline 36 & 0.00 & 30.08 & 0.00 & 30.08 & 0.00 & 30.08 & 0.00 & 30.08 \\
\hline 37 & 0.00 & 30.92 & 0.00 & 30.92 & 0.00 & 30.92 & 0.00 & 30.92 \\
\hline 38 & 0.00 & 31.75 & 0.00 & 31.75 & 0.00 & 31.75 & 0.00 & 31.75 \\
\hline 39 & 0.00 & 32.59 & 0.00 & 32.59 & 0.00 & 32.59 & 0.00 & 32.59 \\
\hline 40 & 0.00 & 33.42 & 0.00 & 33.43 & 0.00 & 33.43 & 0.00 & 33.43 \\
\hline 41 & 0.00 & 34.26 & 0.00 & 34.26 & 0.00 & 34.26 & 0.00 & 34.26 \\
\hline 42 & 0.00 & 35.10 & 0.00 & 35.10 & 0.00 & 35.10 & 0.00 & 35.10 \\
\hline 43 & 0.00 & 35.93 & 0.00 & 35.93 & 0.00 & 35.93 & 0.00 & 35.93 \\
\hline 44 & 0.00 & 36.77 & 0.00 & 36.77 & 0.00 & 36.77 & 0.00 & 36.77 \\
\hline 45 & 0.00 & 37.60 & 0.00 & 37.60 & 0.00 & 37.60 & 0.00 & 37.60 \\
\hline 46 & 0.00 & 38.44 & 0.00 & 38.44 & 0.00 & 38.44 & 0.00 & 38.44 \\
\hline 47 & 0.00 & 39.27 & 0.00 & 39.28 & 0.00 & 39.28 & 0.00 & 39.28 \\
\hline 48 & 0.00 & 40.11 & 0.00 & 40.11 & 0.00 & 40.11 & 0.00 & 40.11 \\
\hline 49 & 0.00 & 40.95 & 0.00 & 40.95 & 0.00 & 40.95 & 0.00 & 40.95 \\
\hline 50 & 0.00 & 41.78 & 0.00 & 41.78 & 0.00 & 41.78 & 0.00 & 41.78 \\
\hline 51 & 0.00 & 42.62 & 0.00 & 42.62 & 0.00 & 42.62 & 0.00 & 42.62 \\
\hline 52 & 0.00 & 43.45 & 0.00 & 43.45 & 0.00 & 43.45 & 0.00 & 43.45 \\
\hline 53 & 0.00 & 44.29 & 0.00 & 44.29 & 0.00 & 44.29 & 0.00 & 44.29 \\
\hline 54 & 0.00 & 45.12 & 0.00 & 45.12 & 0.00 & 45.13 & 0.00 & 45.13 \\
\hline 55 & 0.00 & 45.96 & 0.00 & 45.96 & 0.00 & 45.96 & 0.00 & 45.96 \\
\hline 56 & 0.00 & 46.79 & 0.00 & 46.80 & 0.00 & 46.80 & 0.00 & 46.80 \\
\hline 57 & 0.00 & 47.63 & 0.00 & 47.63 & 0.00 & 47.63 & 0.00 & 47.63 \\
\hline 58 & 0.00 & 48.47 & 0.00 & 48.47 & 0.00 & 48.47 & 0.00 & 48.47 \\
\hline 59 & 0.00 & 49.30 & 0.00 & 49.30 & 0.00 & 49.30 & 0.00 & 49.30 \\
\hline 60 & 0.00 & 50.14 & 0.00 & 50.14 & 0.00 & 50.14 & 0.00 & 50.14 \\
\hline 61 & 0.00 & 50.97 & 0.00 & 50.97 & 0.00 & 50.97 & 0.00 & 50.97 \\
\hline 62 & 0.00 & 51.81 & 0.00 & 51.81 & 0.00 & 51.81 & 0.00 & 51.81 \\
\hline 63 & 0.00 & 52.64 & 0.00 & 52.65 & 0.00 & 52.65 & 0.00 & 52.65 \\
\hline 64 & 0.00 & 53.48 & 0.00 & 53.48 & 0.00 & 53.48 & 0.00 & 53.48 \\
\hline 65 & 0.00 & 54.31 & 0.00 & 54.32 & 0.00 & 54.32 & 0.00 & 54.32 \\
\hline
\end{tabular}




\begin{tabular}{|c|c|c|c|c|c|c|c|c|}
\hline 66 & 0.00 & 55.15 & 0.00 & 55.15 & 0.00 & 55.15 & 0.00 & 55.15 \\
\hline 67 & 0.00 & 55.99 & 0.00 & 55.99 & 0.00 & 55.99 & 0.00 & 55.99 \\
\hline 68 & 0.00 & 56.82 & 0.00 & 56.82 & 0.00 & 56.82 & 0.00 & 56.82 \\
\hline 69 & 0.00 & 57.66 & 0.00 & 57.66 & 0.00 & 57.66 & 0.00 & 57.66 \\
\hline 70 & 0.00 & 58.49 & 0.00 & 58.49 & 0.00 & 58.50 & 0.00 & 58.50 \\
\hline 71 & 0.00 & 59.33 & 0.00 & 59.33 & 0.00 & 59.33 & 0.00 & 59.33 \\
\hline 72 & 0.00 & 60.16 & 0.00 & 60.17 & 0.00 & 60.17 & 0.00 & 60.17 \\
\hline 73 & 0.00 & 61.00 & 0.00 & 61.00 & 0.00 & 61.00 & 0.00 & 61.00 \\
\hline 74 & 0.00 & 61.83 & 0.00 & 61.84 & 0.00 & 61.84 & 0.00 & 61.84 \\
\hline 75 & 0.00 & 62.67 & 0.00 & 62.67 & 0.00 & 62.67 & 0.00 & 62.67 \\
\hline 76 & 0.00 & 63.51 & 0.00 & 63.51 & 0.00 & 63.51 & 0.00 & 63.51 \\
\hline 77 & 0.00 & 64.34 & 0.00 & 64.34 & 0.00 & 64.34 & 0.00 & 64.34 \\
\hline 78 & 0.00 & 65.18 & 0.00 & 65.18 & 0.00 & 65.18 & 0.00 & 65.18 \\
\hline 79 & 0.00 & 66.01 & 0.00 & 66.02 & 0.00 & 66.02 & 0.00 & 66.02 \\
\hline 80 & 0.00 & 66.85 & 0.00 & 66.85 & 0.00 & 66.85 & 0.00 & 66.85 \\
\hline 81 & 0.00 & 67.68 & 0.00 & 67.69 & 0.00 & 67.69 & 0.00 & 67.69 \\
\hline 82 & 0.00 & 68.52 & 0.00 & 68.52 & 0.00 & 68.52 & 0.00 & 68.52 \\
\hline 83 & 0.00 & 69.35 & 0.00 & 69.36 & 0.00 & 69.36 & 0.00 & 69.36 \\
\hline 84 & 0.00 & 70.19 & 0.00 & 70.19 & 0.00 & 70.19 & 0.00 & 70.19 \\
\hline 85 & 0.00 & 71.03 & 0.00 & 71.03 & 0.00 & 71.03 & 0.00 & 71.03 \\
\hline 86 & 0.00 & 71.86 & 0.00 & 71.86 & 0.00 & 71.87 & 0.00 & 71.87 \\
\hline 87 & 0.00 & 72.70 & 0.00 & 72.70 & 0.00 & 72.70 & 0.00 & 72.70 \\
\hline 88 & 0.00 & 73.53 & 0.00 & 73.54 & 0.00 & 73.54 & 0.00 & 73.54 \\
\hline 89 & 0.00 & 74.37 & 0.00 & 74.37 & 0.00 & 74.37 & 0.00 & 74.37 \\
\hline 90 & 0.00 & 75.20 & 0.00 & 75.21 & 0.00 & 75.21 & 0.00 & 75.21 \\
\hline 91 & 0.00 & 76.02 & 0.01 & 76.04 & 0.01 & 76.04 & 0.00 & 76.04 \\
\hline 92 & 0.00 & 76.83 & 0.00 & 76.88 & 0.00 & 76.88 & 0.00 & 76.88 \\
\hline 93 & 0.00 & 77.63 & 0.00 & 77.71 & 0.00 & 77.72 & 0.00 & 77.72 \\
\hline 94 & 0.01 & 78.42 & 0.01 & 78.55 & 0.01 & 78.55 & 0.01 & 78.55 \\
\hline 95 & 0.01 & 79.20 & 0.01 & 79.39 & 0.01 & 79.39 & 0.01 & 79.39 \\
\hline 96 & 0.01 & 79.96 & 0.01 & 80.22 & 0.01 & 80.22 & 0.01 & 80.22 \\
\hline 97 & 0.01 & 80.72 & 0.01 & 81.06 & 0.01 & 81.06 & 0.01 & 81.06 \\
\hline 98 & 0.01 & 81.47 & 0.01 & 81.89 & 0.01 & 81.89 & 0.01 & 81.89 \\
\hline 99 & 0.01 & 82.22 & 0.01 & 82.73 & 0.01 & 82.73 & 0.01 & 82.73 \\
\hline 100 & 0.01 & 82.95 & 0.01 & 83.56 & 0.01 & 83.56 & 0.01 & 83.56 \\
\hline 101 & 0.01 & 83.68 & 0.01 & 84.40 & 0.01 & 84.40 & 0.01 & 84.40 \\
\hline 102 & 0.01 & 84.39 & 0.02 & 85.23 & 0.02 & 85.24 & 0.02 & 85.24 \\
\hline 103 & 0.02 & 85.10 & 0.02 & 86.07 & 0.02 & 86.07 & 0.02 & 86.07 \\
\hline 104 & 0.02 & 85.80 & 0.02 & 86.90 & 0.02 & 86.91 & 0.02 & 86.91 \\
\hline 105 & 0.02 & 86.49 & 0.02 & 87.74 & 0.02 & 87.74 & 0.02 & 87.74 \\
\hline 106 & 0.02 & 87.17 & 0.03 & 88.58 & 0.03 & 88.58 & 0.03 & 88.58 \\
\hline 107 & 0.02 & 87.85 & 0.03 & 89.41 & 0.03 & 89.41 & 0.03 & 89.41 \\
\hline 108 & 0.03 & 88.52 & 0.04 & 90.25 & 0.04 & 90.25 & 0.04 & 90.25 \\
\hline 109 & 0.03 & 89.18 & 0.04 & 91.08 & 0.04 & 91.08 & 0.04 & 91.09 \\
\hline 110 & 0.03 & 89.83 & 0.04 & 91.92 & 0.04 & 91.92 & 0.05 & 91.92 \\
\hline 111 & 0.03 & 90.48 & 0.04 & 92.75 & 0.05 & 92.76 & 0.05 & 92.76 \\
\hline 112 & 0.04 & 91.12 & 0.05 & 93.59 & 0.06 & 93.59 & 0.06 & 93.59 \\
\hline 113 & 0.04 & 91.75 & 0.06 & 94.42 & 0.06 & 94.43 & 0.06 & 94.43 \\
\hline 114 & 0.05 & 92.37 & 0.07 & 95.26 & 0.07 & 95.26 & 0.07 & 95.26 \\
\hline 115 & 0.05 & 92.99 & 0.07 & 96.10 & 0.07 & 96.10 & 0.07 & 96.10 \\
\hline 116 & 0.06 & 93.60 & 0.08 & 96.93 & 0.08 & 96.93 & 0.08 & 96.93 \\
\hline 117 & 0.06 & 94.21 & 0.08 & 97.77 & 0.09 & 97.77 & 0.09 & 97.77 \\
\hline 118 & 0.06 & 94.80 & 0.10 & 98.60 & 0.10 & 98.61 & 0.10 & 98.61 \\
\hline 119 & 0.07 & 95.40 & 0.10 & 99.44 & 0.10 & 99.44 & 0.10 & 99.44 \\
\hline 120 & 0.07 & 95.98 & 0.12 & 100.27 & 0.12 & 100.28 & 0.13 & 100.28 \\
\hline
\end{tabular}

Permeability Values - 200 md, 300 md, 500 md, 1000 md

\begin{tabular}{|c|c|c|c|c|c|c|c|c|}
\hline \multicolumn{9}{|c|}{ Peripheral Placement of Nitrogen } \\
\hline \multirow{2}{*}{$\begin{array}{l}\text { Time } \\
\text { (days) }\end{array}$} & \multicolumn{2}{|c|}{ Permeability - 200 md } & \multicolumn{2}{|c|}{ Permeability - $\mathbf{3 0 0} \mathrm{md}$} & \multicolumn{2}{|c|}{ Permeability - 500 md } & \multicolumn{2}{|c|}{ Permeability - 1000 md } \\
\hline & $\begin{array}{c}\% \mathrm{~N}_{2} \text { in } \\
\text { withdrawn } \\
\text { gas }\end{array}$ & $\begin{array}{c}\% \text { W.G } \\
\text { withdrawn } \\
\text { (volume) }\end{array}$ & $\begin{array}{c}\% \mathrm{~N}_{2} \text { in } \\
\text { withdrawn } \\
\text { gas }\end{array}$ & $\begin{array}{c}\% \text { W.G } \\
\text { withdrawn } \\
\text { (volume) }\end{array}$ & $\begin{array}{c}\% \mathrm{~N}_{2} \text { in } \\
\text { withdrawn } \\
\text { gas }\end{array}$ & $\begin{array}{c}\% \text { W.G } \\
\text { withdrawn } \\
\text { (volume) }\end{array}$ & $\begin{array}{c}\% \mathrm{~N}_{2} \text { in } \\
\text { withdrawn } \\
\text { gas }\end{array}$ & $\begin{array}{c}\% \text { W.G } \\
\text { withdrawn } \\
\text { (volume) }\end{array}$ \\
\hline 1 & 0.00 & 0.84 & 0.00 & 0.84 & 0.00 & 0.84 & 0.00 & 0.84 \\
\hline 2 & 0.00 & 1.67 & 0.00 & 1.67 & 0.00 & 1.67 & 0.00 & 1.67 \\
\hline 3 & 0.00 & 2.51 & 0.00 & 2.51 & 0.00 & 2.51 & 0.00 & 2.51 \\
\hline 4 & 0.00 & 3.34 & 0.00 & 3.34 & 0.00 & 3.34 & 0.00 & 3.34 \\
\hline 5 & 0.00 & 4.18 & 0.00 & 4.18 & 0.00 & 4.18 & 0.00 & 4.18 \\
\hline 6 & 0.00 & 5.01 & 0.00 & 5.01 & 0.00 & 5.01 & 0.00 & 5.01 \\
\hline 7 & 0.00 & 5.85 & 0.00 & 5.85 & 0.00 & 5.85 & 0.00 & 5.85 \\
\hline 8 & 0.00 & 6.69 & 0.00 & 6.69 & 0.00 & 6.69 & 0.00 & 6.69 \\
\hline 9 & 0.00 & 7.52 & 0.00 & 7.52 & 0.00 & 7.52 & 0.00 & 7.52 \\
\hline 10 & 0.00 & 8.36 & 0.00 & 8.36 & 0.00 & 8.36 & 0.00 & 8.36 \\
\hline 11 & 0.00 & 9.19 & 0.00 & 9.19 & 0.00 & 9.19 & 0.00 & 9.19 \\
\hline 12 & 0.00 & 10.03 & 0.00 & 10.03 & 0.00 & 10.03 & 0.00 & 10.03 \\
\hline
\end{tabular}




\begin{tabular}{|c|c|c|c|c|c|c|c|c|}
\hline 13 & 0.00 & 10.86 & 0.00 & 10.86 & 0.00 & 10.86 & 0.00 & 10.86 \\
\hline 14 & 0.00 & 11.70 & 0.00 & 11.70 & 0.00 & 11.70 & 0.00 & 11.70 \\
\hline 15 & 0.00 & 12.53 & 0.00 & 12.53 & 0.00 & 12.53 & 0.00 & 12.53 \\
\hline 16 & 0.00 & 13.37 & 0.00 & 13.37 & 0.00 & 13.37 & 0.00 & 13.37 \\
\hline 17 & 0.00 & 14.21 & 0.00 & 14.21 & 0.00 & 14.21 & 0.00 & 14.21 \\
\hline 18 & 0.00 & 15.04 & 0.00 & 15.04 & 0.00 & 15.04 & 0.00 & 15.04 \\
\hline 19 & 0.00 & 15.88 & 0.00 & 15.88 & 0.00 & 15.88 & 0.00 & 15.88 \\
\hline 20 & 0.00 & 16.71 & 0.00 & 16.71 & 0.00 & 16.71 & 0.00 & 16.71 \\
\hline 21 & 0.00 & 17.55 & 0.00 & 17.55 & 0.00 & 17.55 & 0.00 & 17.55 \\
\hline 22 & 0.00 & 18.38 & 0.00 & 18.38 & 0.00 & 18.38 & 0.00 & 18.38 \\
\hline 23 & 0.00 & 19.22 & 0.00 & 19.22 & 0.00 & 19.22 & 0.00 & 19.22 \\
\hline 24 & 0.00 & 20.06 & 0.00 & 20.06 & 0.00 & 20.06 & 0.00 & 20.06 \\
\hline 25 & 0.00 & 20.89 & 0.00 & 20.89 & 0.00 & 20.89 & 0.00 & 20.89 \\
\hline 26 & 0.00 & 21.73 & 0.00 & 21.73 & 0.00 & 21.73 & 0.00 & 21.73 \\
\hline 27 & 0.00 & 22.56 & 0.00 & 22.56 & 0.00 & 22.56 & 0.00 & 22.56 \\
\hline 28 & 0.00 & 23.40 & 0.00 & 23.40 & 0.00 & 23.40 & 0.00 & 23.40 \\
\hline 29 & 0.00 & 24.23 & 0.00 & 24.23 & 0.00 & 24.23 & 0.00 & 24.23 \\
\hline 30 & 0.00 & 25.07 & 0.00 & 25.07 & 0.00 & 25.07 & 0.00 & 25.07 \\
\hline 31 & 0.00 & 25.91 & 0.00 & 25.91 & 0.00 & 25.91 & 0.00 & 25.91 \\
\hline 32 & 0.00 & 26.74 & 0.00 & 26.74 & 0.00 & 26.74 & 0.00 & 26.74 \\
\hline 33 & 0.00 & 27.58 & 0.00 & 27.58 & 0.00 & 27.58 & 0.00 & 27.58 \\
\hline 34 & 0.00 & 28.41 & 0.00 & 28.41 & 0.00 & 28.41 & 0.00 & 28.41 \\
\hline 35 & 0.00 & 29.25 & 0.00 & 29.25 & 0.00 & 29.25 & 0.00 & 29.25 \\
\hline 36 & 0.00 & 30.08 & 0.00 & 30.08 & 0.00 & 30.08 & 0.00 & 30.08 \\
\hline 37 & 0.00 & 30.92 & 0.00 & 30.92 & 0.00 & 30.92 & 0.00 & 30.92 \\
\hline 38 & 0.00 & 31.75 & 0.00 & 31.75 & 0.00 & 31.75 & 0.00 & 31.75 \\
\hline 39 & 0.00 & 32.59 & 0.00 & 32.59 & 0.00 & 32.59 & 0.00 & 32.59 \\
\hline 40 & 0.00 & 33.43 & 0.00 & 33.43 & 0.00 & 33.43 & 0.00 & 33.43 \\
\hline 41 & 0.00 & 34.26 & 0.00 & 34.26 & 0.00 & 34.26 & 0.00 & 34.26 \\
\hline 42 & 0.00 & 35.10 & 0.00 & 35.10 & 0.00 & 35.10 & 0.00 & 35.10 \\
\hline 43 & 0.00 & 35.93 & 0.00 & 35.93 & 0.00 & 35.93 & 0.00 & 35.93 \\
\hline 44 & 0.00 & 36.77 & 0.00 & 36.77 & 0.00 & 36.77 & 0.00 & 36.77 \\
\hline 45 & 0.00 & 37.60 & 0.00 & 37.60 & 0.00 & 37.60 & 0.00 & 37.60 \\
\hline 46 & 0.00 & 38.44 & 0.00 & 38.44 & 0.00 & 38.44 & 0.00 & 38.44 \\
\hline 47 & 0.00 & 39.28 & 0.00 & 39.28 & 0.00 & 39.28 & 0.00 & 39.28 \\
\hline 48 & 0.00 & 40.11 & 0.00 & 40.11 & 0.00 & 40.11 & 0.00 & 40.11 \\
\hline 49 & 0.00 & 40.95 & 0.00 & 40.95 & 0.00 & 40.95 & 0.00 & 40.95 \\
\hline 50 & 0.00 & 41.78 & 0.00 & 41.78 & 0.00 & 41.78 & 0.00 & 41.78 \\
\hline 51 & 0.00 & 42.62 & 0.00 & 42.62 & 0.00 & 42.62 & 0.00 & 42.62 \\
\hline 52 & 0.00 & 43.45 & 0.00 & 43.45 & 0.00 & 43.45 & 0.00 & 43.45 \\
\hline 53 & 0.00 & 44.29 & 0.00 & 44.29 & 0.00 & 44.29 & 0.00 & 44.29 \\
\hline 54 & 0.00 & 45.13 & 0.00 & 45.13 & 0.00 & 45.13 & 0.00 & 45.13 \\
\hline 55 & 0.00 & 45.96 & 0.00 & 45.96 & 0.00 & 45.96 & 0.00 & 45.96 \\
\hline 56 & 0.00 & 46.80 & 0.00 & 46.80 & 0.00 & 46.80 & 0.00 & 46.80 \\
\hline 57 & 0.00 & 47.63 & 0.00 & 47.63 & 0.00 & 47.63 & 0.00 & 47.63 \\
\hline 58 & 0.00 & 48.47 & 0.00 & 48.47 & 0.00 & 48.47 & 0.00 & 48.47 \\
\hline 59 & 0.00 & 49.30 & 0.00 & 49.30 & 0.00 & 49.30 & 0.00 & 49.30 \\
\hline 60 & 0.00 & 50.14 & 0.00 & 50.14 & 0.00 & 50.14 & 0.00 & 50.14 \\
\hline 61 & 0.00 & 50.97 & 0.00 & 50.97 & 0.00 & 50.97 & 0.00 & 50.97 \\
\hline 62 & 0.00 & 51.81 & 0.00 & 51.81 & 0.00 & 51.81 & 0.00 & 51.81 \\
\hline 63 & 0.00 & 52.65 & 0.00 & 52.65 & 0.00 & 52.65 & 0.00 & 52.65 \\
\hline 64 & 0.00 & 53.48 & 0.00 & 53.48 & 0.00 & 53.48 & 0.00 & 53.48 \\
\hline 65 & 0.00 & 54.32 & 0.00 & 54.32 & 0.00 & 54.32 & 0.00 & 54.32 \\
\hline 66 & 0.00 & 55.15 & 0.00 & 55.15 & 0.00 & 55.15 & 0.00 & 55.15 \\
\hline 67 & 0.00 & 55.99 & 0.00 & 55.99 & 0.00 & 55.99 & 0.00 & 55.99 \\
\hline 68 & 0.00 & 56.82 & 0.00 & 56.82 & 0.00 & 56.82 & 0.00 & 56.82 \\
\hline 69 & 0.00 & 57.66 & 0.00 & 57.66 & 0.00 & 57.66 & 0.00 & 57.66 \\
\hline 70 & 0.00 & 58.50 & 0.00 & 58.50 & 0.00 & 58.50 & 0.00 & 58.50 \\
\hline 71 & 0.00 & 59.33 & 0.00 & 59.33 & 0.00 & 59.33 & 0.00 & 59.33 \\
\hline 72 & 0.00 & 60.17 & 0.00 & 60.17 & 0.00 & 60.17 & 0.00 & 60.17 \\
\hline 73 & 0.00 & 61.00 & 0.00 & 61.00 & 0.00 & 61.00 & 0.00 & 61.00 \\
\hline 74 & 0.00 & 61.84 & 0.00 & 61.84 & 0.00 & 61.84 & 0.00 & 61.84 \\
\hline 75 & 0.00 & 62.67 & 0.00 & 62.67 & 0.00 & 62.67 & 0.00 & 62.67 \\
\hline 76 & 0.00 & 63.51 & 0.00 & 63.51 & 0.00 & 63.51 & 0.00 & 63.51 \\
\hline 77 & 0.00 & 64.35 & 0.00 & 64.35 & 0.00 & 64.35 & 0.00 & 64.35 \\
\hline 78 & 0.00 & 65.18 & 0.00 & 65.18 & 0.00 & 65.18 & 0.00 & 65.18 \\
\hline 79 & 0.00 & 66.02 & 0.00 & 66.02 & 0.00 & 66.02 & 0.00 & 66.02 \\
\hline 80 & 0.00 & 66.85 & 0.00 & 66.85 & 0.00 & 66.85 & 0.00 & 66.85 \\
\hline 81 & 0.00 & 67.69 & 0.00 & 67.69 & 0.00 & 67.69 & 0.00 & 67.69 \\
\hline 82 & 0.00 & 68.52 & 0.00 & 68.52 & 0.00 & 68.52 & 0.00 & 68.52 \\
\hline 83 & 0.00 & 69.36 & 0.00 & 69.36 & 0.00 & 69.36 & 0.00 & 69.36 \\
\hline 84 & 0.00 & 70.19 & 0.00 & 70.19 & 0.00 & 70.19 & 0.00 & 70.19 \\
\hline 85 & 0.00 & 71.03 & 0.00 & 71.03 & 0.00 & 71.03 & 0.00 & 71.03 \\
\hline 86 & 0.00 & 71.87 & 0.00 & 71.87 & 0.00 & 71.87 & 0.00 & 71.87 \\
\hline 87 & 0.00 & 72.70 & 0.00 & 72.70 & 0.00 & 72.70 & 0.00 & 72.70 \\
\hline 88 & 0.00 & 73.54 & 0.00 & 73.54 & 0.00 & 73.54 & 0.00 & 73.54 \\
\hline 89 & 0.00 & 74.37 & 0.00 & 74.37 & 0.00 & 74.37 & 0.00 & 74.37 \\
\hline 90 & 0.00 & 75.21 & 0.00 & 75.21 & 0.00 & 75.21 & 0.00 & 75.21 \\
\hline
\end{tabular}




\begin{tabular}{|c|c|c|c|c|c|c|c|c|}
\hline 91 & 0.00 & 76.04 & 0.00 & 76.04 & 0.00 & 76.04 & 0.00 & 76.04 \\
\hline 92 & 0.00 & 76.88 & 0.00 & 76.88 & 0.00 & 76.88 & 0.00 & 76.88 \\
\hline 93 & 0.00 & 77.72 & 0.00 & 77.72 & 0.00 & 77.72 & 0.00 & 77.72 \\
\hline 94 & 0.01 & 78.55 & 0.01 & 78.55 & 0.01 & 78.55 & 0.01 & 78.55 \\
\hline 95 & 0.01 & 79.39 & 0.01 & 79.39 & 0.01 & 79.39 & 0.01 & 79.39 \\
\hline 96 & 0.01 & 80.22 & 0.01 & 80.22 & 0.01 & 80.22 & 0.01 & 80.22 \\
\hline 97 & 0.01 & 81.06 & 0.01 & 81.06 & 0.01 & 81.06 & 0.01 & 81.06 \\
\hline 98 & 0.01 & 81.89 & 0.01 & 81.89 & 0.01 & 81.89 & 0.01 & 81.89 \\
\hline 99 & 0.01 & 82.73 & 0.01 & 82.73 & 0.01 & 82.73 & 0.01 & 82.73 \\
\hline 100 & 0.01 & 83.56 & 0.01 & 83.56 & 0.01 & 83.56 & 0.01 & 83.56 \\
\hline 101 & 0.01 & 84.40 & 0.01 & 84.40 & 0.01 & 84.40 & 0.01 & 84.40 \\
\hline 102 & 0.02 & 85.24 & 0.02 & 85.24 & 0.02 & 85.24 & 0.02 & 85.24 \\
\hline 103 & 0.02 & 86.07 & 0.02 & 86.07 & 0.02 & 86.07 & 0.02 & 86.07 \\
\hline 104 & 0.02 & 86.91 & 0.02 & 86.91 & 0.02 & 86.91 & 0.02 & 86.91 \\
\hline 105 & 0.02 & 87.74 & 0.02 & 87.74 & 0.02 & 87.74 & 0.02 & 87.74 \\
\hline 106 & 0.03 & 88.58 & 0.03 & 88.58 & 0.03 & 88.58 & 0.03 & 88.58 \\
\hline 107 & 0.03 & 89.41 & 0.03 & 89.41 & 0.03 & 89.41 & 0.03 & 89.41 \\
\hline 108 & 0.04 & 90.25 & 0.04 & 90.25 & 0.04 & 90.25 & 0.04 & 90.25 \\
\hline 109 & 0.04 & 91.09 & 0.04 & 91.09 & 0.04 & 91.09 & 0.04 & 91.09 \\
\hline 110 & 0.05 & 91.92 & 0.05 & 91.92 & 0.05 & 91.92 & 0.05 & 91.92 \\
\hline 111 & 0.05 & 92.76 & 0.05 & 92.76 & 0.05 & 92.76 & 0.05 & 92.76 \\
\hline 112 & 0.06 & 93.59 & 0.06 & 93.59 & 0.06 & 93.59 & 0.06 & 93.59 \\
\hline 113 & 0.06 & 94.43 & 0.06 & 94.43 & 0.06 & 94.43 & 0.06 & 94.43 \\
\hline 114 & 0.07 & 95.26 & 0.07 & 95.26 & 0.07 & 95.26 & 0.07 & 95.26 \\
\hline 115 & 0.07 & 96.10 & 0.07 & 96.10 & 0.07 & 96.10 & 0.07 & 96.10 \\
\hline 116 & 0.08 & 96.93 & 0.08 & 96.93 & 0.08 & 96.93 & 0.08 & 96.93 \\
\hline 117 & 0.09 & 97.77 & 0.09 & 97.77 & 0.09 & 97.77 & 0.09 & 97.77 \\
\hline 118 & 0.10 & 98.61 & 0.10 & 98.61 & 0.10 & 98.61 & 0.10 & 98.61 \\
\hline 119 & 0.10 & 99.44 & 0.10 & 99.44 & 0.10 & 99.44 & 0.10 & 99.44 \\
\hline 120 & 0.13 & 100.28 & 0.13 & 100.28 & 0.13 & 100.28 & 0.13 & 100.28 \\
\hline
\end{tabular}

\section{Effect of Porosity on Mixing}

\begin{tabular}{|c|c|c|c|c|c|c|c|c|}
\hline \multicolumn{9}{|c|}{ Peripheral Placement of Nitrogen } \\
\hline \multirow{2}{*}{$\begin{array}{l}\text { Time } \\
\text { (days) }\end{array}$} & \multicolumn{2}{|c|}{ Porosity - 10\% } & \multicolumn{2}{|c|}{ Porosity - 15\% } & \multicolumn{2}{|c|}{ Porosity - 20\% } & \multicolumn{2}{|c|}{ Porosity - 25\% } \\
\hline & $\begin{array}{l}\% N_{2} \text { in } \\
\text { withdrawn gas }\end{array}$ & $\begin{array}{c}\% \text { W.G } \\
\text { withdrawn } \\
\text { (volume) }\end{array}$ & $\begin{array}{c}\% \mathrm{~N}_{2} \text { in } \\
\text { withdrawn gas }\end{array}$ & $\begin{array}{c}\text { \% W.G } \\
\text { withdrawn } \\
\text { (volume) }\end{array}$ & $\begin{array}{c}\% N_{2} \text { in } \\
\text { withdrawn gas }\end{array}$ & $\begin{array}{c}\text { \% W.G } \\
\text { withdrawn } \\
\text { (volume) }\end{array}$ & $\begin{array}{l}\% N_{2} \text { in } \\
\text { withdrawn gas }\end{array}$ & $\begin{array}{c}\% \text { W.G } \\
\text { withdrawn } \\
\text { (volume) }\end{array}$ \\
\hline 1 & 0.00 & 0.83 & 0.00 & 0.84 & 0.00 & 0.84 & 0.00 & 0.91 \\
\hline 2 & 0.00 & 1.67 & 0.00 & 1.67 & 0.00 & 1.67 & 0.00 & 1.83 \\
\hline 3 & 0.00 & 2.50 & 0.00 & 2.51 & 0.00 & 2.51 & 0.00 & 2.74 \\
\hline 4 & 0.00 & 3.34 & 0.00 & 3.34 & 0.00 & 3.34 & 0.00 & 3.65 \\
\hline 5 & 0.00 & 4.17 & 0.00 & 4.18 & 0.00 & 4.18 & 0.00 & 4.57 \\
\hline 6 & 0.00 & 5.01 & 0.00 & 5.01 & 0.00 & 5.01 & 0.00 & 5.48 \\
\hline 7 & 0.00 & 5.84 & 0.00 & 5.85 & 0.00 & 5.85 & 0.00 & 6.39 \\
\hline 8 & 0.00 & 6.68 & 0.00 & 6.69 & 0.00 & 6.69 & 0.00 & 7.31 \\
\hline 9 & 0.00 & 7.51 & 0.00 & 7.52 & 0.00 & 7.52 & 0.00 & 8.22 \\
\hline 10 & 0.00 & 8.35 & 0.00 & 8.36 & 0.00 & 8.36 & 0.00 & 9.13 \\
\hline 11 & 0.00 & 9.18 & 0.00 & 9.19 & 0.00 & 9.19 & 0.00 & 10.05 \\
\hline 12 & 0.00 & 10.02 & 0.00 & 10.03 & 0.00 & 10.03 & 0.00 & 10.96 \\
\hline 13 & 0.00 & 10.85 & 0.00 & 10.86 & 0.00 & 10.86 & 0.00 & 11.87 \\
\hline 14 & 0.00 & 11.68 & 0.00 & 11.70 & 0.00 & 11.70 & 0.00 & 12.79 \\
\hline 15 & 0.00 & 12.52 & 0.00 & 12.53 & 0.00 & 12.53 & 0.00 & 13.70 \\
\hline 16 & 0.00 & 13.35 & 0.00 & 13.37 & 0.00 & 13.37 & 0.00 & 14.61 \\
\hline 17 & 0.00 & 14.19 & 0.00 & 14.21 & 0.00 & 14.21 & 0.00 & 15.53 \\
\hline 18 & 0.00 & 15.02 & 0.00 & 15.04 & 0.00 & 15.04 & 0.00 & 16.44 \\
\hline 19 & 0.00 & 15.86 & 0.00 & 15.88 & 0.00 & 15.88 & 0.00 & 17.35 \\
\hline 20 & 0.00 & 16.69 & 0.00 & 16.71 & 0.00 & 16.71 & 0.00 & 18.26 \\
\hline 21 & 0.00 & 17.53 & 0.00 & 17.55 & 0.00 & 17.55 & 0.00 & 19.18 \\
\hline 22 & 0.00 & 18.36 & 0.00 & 18.38 & 0.00 & 18.38 & 0.00 & 20.09 \\
\hline 23 & 0.00 & 19.20 & 0.00 & 19.22 & 0.00 & 19.22 & 0.00 & 21.00 \\
\hline 24 & 0.00 & 20.03 & 0.00 & 20.06 & 0.00 & 20.06 & 0.00 & 21.92 \\
\hline 25 & 0.00 & 20.87 & 0.00 & 20.89 & 0.00 & 20.89 & 0.00 & 22.83 \\
\hline 26 & 0.00 & 21.70 & 0.00 & 21.73 & 0.00 & 21.73 & 0.00 & 23.74 \\
\hline 27 & 0.00 & 22.54 & 0.00 & 22.56 & 0.00 & 22.56 & 0.00 & 24.66 \\
\hline 28 & 0.00 & 23.37 & 0.00 & 23.40 & 0.00 & 23.40 & 0.00 & 25.57 \\
\hline 29 & 0.00 & 24.20 & 0.00 & 24.23 & 0.00 & 24.23 & 0.00 & 26.48 \\
\hline 30 & 0.00 & 25.04 & 0.00 & 25.07 & 0.00 & 25.07 & 0.00 & 27.40 \\
\hline
\end{tabular}




\begin{tabular}{|c|c|c|c|c|c|c|c|c|}
\hline 31 & 0.00 & 25.87 & 0.00 & 25.90 & 0.00 & 25.91 & 0.00 & 28.31 \\
\hline 32 & 0.00 & 26.71 & 0.00 & 26.74 & 0.00 & 26.74 & 0.00 & 29.22 \\
\hline 33 & 0.00 & 27.54 & 0.00 & 27.58 & 0.00 & 27.58 & 0.00 & 30.14 \\
\hline 34 & 0.00 & 28.38 & 0.00 & 28.41 & 0.00 & 28.41 & 0.00 & 31.05 \\
\hline 35 & 0.00 & 29.21 & 0.00 & 29.25 & 0.00 & 29.25 & 0.00 & 31.96 \\
\hline 36 & 0.00 & 30.05 & 0.00 & 30.08 & 0.00 & 30.08 & 0.00 & 32.88 \\
\hline 37 & 0.00 & 30.88 & 0.00 & 30.92 & 0.00 & 30.92 & 0.00 & 33.79 \\
\hline 38 & 0.00 & 31.72 & 0.00 & 31.75 & 0.00 & 31.75 & 0.00 & 34.70 \\
\hline 39 & 0.00 & 32.55 & 0.00 & 32.59 & 0.00 & 32.59 & 0.00 & 35.62 \\
\hline 40 & 0.00 & 33.39 & 0.00 & 33.43 & 0.00 & 33.43 & 0.00 & 36.53 \\
\hline 41 & 0.00 & 34.22 & 0.00 & 34.26 & 0.00 & 34.26 & 0.00 & 37.44 \\
\hline 42 & 0.00 & 35.05 & 0.00 & 35.10 & 0.00 & 35.10 & 0.00 & 38.36 \\
\hline 43 & 0.00 & 35.89 & 0.00 & 35.93 & 0.00 & 35.93 & 0.00 & 39.27 \\
\hline 44 & 0.00 & 36.72 & 0.00 & 36.77 & 0.00 & 36.77 & 0.00 & 40.18 \\
\hline 45 & 0.00 & 37.56 & 0.00 & 37.60 & 0.00 & 37.60 & 0.00 & 41.10 \\
\hline 46 & 0.00 & 38.39 & 0.00 & 38.44 & 0.00 & 38.44 & 0.00 & 42.01 \\
\hline 47 & 0.00 & 39.23 & 0.00 & 39.27 & 0.00 & 39.28 & 0.00 & 42.92 \\
\hline 48 & 0.00 & 40.06 & 0.00 & 40.11 & 0.00 & 40.11 & 0.00 & 43.84 \\
\hline 49 & 0.00 & 40.90 & 0.00 & 40.95 & 0.00 & 40.95 & 0.00 & 44.75 \\
\hline 50 & 0.00 & 41.73 & 0.00 & 41.78 & 0.00 & 41.78 & 0.00 & 45.66 \\
\hline 51 & 0.00 & 42.57 & 0.00 & 42.62 & 0.00 & 42.62 & 0.00 & 46.58 \\
\hline 52 & 0.00 & 43.40 & 0.00 & 43.45 & 0.00 & 43.45 & 0.00 & 47.49 \\
\hline 53 & 0.00 & 44.24 & 0.00 & 44.29 & 0.00 & 44.29 & 0.00 & 48.40 \\
\hline 54 & 0.00 & 45.07 & 0.00 & 45.12 & 0.00 & 45.13 & 0.00 & 49.32 \\
\hline 55 & 0.00 & 45.90 & 0.00 & 45.96 & 0.00 & 45.96 & 0.00 & 50.23 \\
\hline 56 & 0.00 & 46.74 & 0.00 & 46.80 & 0.00 & 46.80 & 0.00 & 51.14 \\
\hline 57 & 0.00 & 47.57 & 0.00 & 47.63 & 0.00 & 47.63 & 0.00 & 52.05 \\
\hline 58 & 0.00 & 48.41 & 0.00 & 48.47 & 0.00 & 48.47 & 0.00 & 52.97 \\
\hline 59 & 0.00 & 49.24 & 0.00 & 49.30 & 0.00 & 49.30 & 0.00 & 53.88 \\
\hline 60 & 0.00 & 50.08 & 0.00 & 50.14 & 0.00 & 50.14 & 0.00 & 54.79 \\
\hline 61 & 0.00 & 50.91 & 0.00 & 50.97 & 0.00 & 50.97 & 0.00 & 55.71 \\
\hline 62 & 0.00 & 51.75 & 0.00 & 51.81 & 0.00 & 51.81 & 0.00 & 56.62 \\
\hline 63 & 0.00 & 52.58 & 0.00 & 52.64 & 0.00 & 52.65 & 0.00 & 57.53 \\
\hline 64 & 0.00 & 53.42 & 0.00 & 53.48 & 0.00 & 53.48 & 0.00 & 58.45 \\
\hline 65 & 0.00 & 54.25 & 0.00 & 54.32 & 0.00 & 54.32 & 0.00 & 59.36 \\
\hline 66 & 0.00 & 55.09 & 0.00 & 55.15 & 0.00 & 55.15 & 0.00 & 60.27 \\
\hline 67 & 0.00 & 55.92 & 0.00 & 55.99 & 0.00 & 55.99 & 0.00 & 61.19 \\
\hline 68 & 0.00 & 56.75 & 0.00 & 56.82 & 0.00 & 56.82 & 0.00 & 62.10 \\
\hline 69 & 0.00 & 57.59 & 0.00 & 57.66 & 0.00 & 57.66 & 0.00 & 63.01 \\
\hline 70 & 0.00 & 58.42 & 0.00 & 58.49 & 0.00 & 58.50 & 0.00 & 63.93 \\
\hline 71 & 0.00 & 59.26 & 0.00 & 59.33 & 0.00 & 59.33 & 0.00 & 64.84 \\
\hline 72 & 0.00 & 60.09 & 0.00 & 60.17 & 0.00 & 60.17 & 0.00 & 65.75 \\
\hline 73 & 0.00 & 60.93 & 0.00 & 61.00 & 0.00 & 61.00 & 0.00 & 66.67 \\
\hline 74 & 0.00 & 61.76 & 0.00 & 61.84 & 0.00 & 61.84 & 0.00 & 67.58 \\
\hline 75 & 0.00 & 62.60 & 0.00 & 62.67 & 0.00 & 62.67 & 0.00 & 68.49 \\
\hline 76 & 0.00 & 63.43 & 0.00 & 63.51 & 0.00 & 63.51 & 0.00 & 69.41 \\
\hline 77 & 0.00 & 64.27 & 0.00 & 64.34 & 0.00 & 64.34 & 0.00 & 70.32 \\
\hline 78 & 0.00 & 65.10 & 0.00 & 65.18 & 0.00 & 65.18 & 0.00 & 71.23 \\
\hline 79 & 0.00 & 65.94 & 0.00 & 66.01 & 0.00 & 66.02 & 0.00 & 72.15 \\
\hline 80 & 0.00 & 66.77 & 0.00 & 66.85 & 0.00 & 66.85 & 0.00 & 73.06 \\
\hline 81 & 0.00 & 67.60 & 0.00 & 67.69 & 0.00 & 67.69 & 0.00 & 73.97 \\
\hline 82 & 0.00 & 68.44 & 0.00 & 68.52 & 0.00 & 68.52 & 0.00 & 74.89 \\
\hline 83 & 0.00 & 69.27 & 0.00 & 69.36 & 0.00 & 69.36 & 0.00 & 75.80 \\
\hline 84 & 0.00 & 70.11 & 0.00 & 70.19 & 0.00 & 70.19 & 0.00 & 76.71 \\
\hline 85 & 0.00 & 70.94 & 0.00 & 71.03 & 0.00 & 71.03 & 0.01 & 77.62 \\
\hline 86 & 0.00 & 71.78 & 0.00 & 71.86 & 0.00 & 71.87 & 0.00 & 78.54 \\
\hline 87 & 0.00 & 72.61 & 0.00 & 72.70 & 0.00 & 72.70 & 0.00 & 79.45 \\
\hline 88 & 0.00 & 73.45 & 0.00 & 73.54 & 0.00 & 73.54 & 0.01 & 80.36 \\
\hline 89 & 0.00 & 74.28 & 0.00 & 74.37 & 0.00 & 74.37 & 0.01 & 81.28 \\
\hline 90 & 0.00 & 75.12 & 0.00 & 75.21 & 0.00 & 75.21 & 0.01 & 82.19 \\
\hline 91 & 0.00 & 75.95 & 0.00 & 76.04 & 0.00 & 76.04 & 0.01 & 83.10 \\
\hline 92 & 0.00 & 76.79 & 0.00 & 76.88 & 0.00 & 76.88 & 0.01 & 84.02 \\
\hline 93 & 0.00 & 77.62 & 0.00 & 77.71 & 0.00 & 77.72 & 0.01 & 84.93 \\
\hline 94 & 0.01 & 78.45 & 0.01 & 78.55 & 0.01 & 78.55 & 0.02 & 85.84 \\
\hline 95 & 0.01 & 79.29 & 0.01 & 79.38 & 0.01 & 79.39 & 0.02 & 86.76 \\
\hline 96 & 0.01 & 80.12 & 0.01 & 80.22 & 0.01 & 80.22 & 0.02 & 87.67 \\
\hline 97 & 0.01 & 80.96 & 0.01 & 81.06 & 0.01 & 81.06 & 0.02 & 88.58 \\
\hline 98 & 0.01 & 81.79 & 0.01 & 81.89 & 0.01 & 81.89 & 0.03 & 89.50 \\
\hline 99 & 0.01 & 82.63 & 0.01 & 82.73 & 0.01 & 82.73 & 0.03 & 90.41 \\
\hline 100 & 0.01 & 83.46 & 0.01 & 83.56 & 0.01 & 83.56 & 0.04 & 91.32 \\
\hline 101 & 0.01 & 84.30 & 0.01 & 84.40 & 0.01 & 84.40 & 0.04 & 92.24 \\
\hline 102 & 0.02 & 85.13 & 0.02 & 85.23 & 0.02 & 85.24 & 0.05 & 93.15 \\
\hline 103 & 0.02 & 85.97 & 0.02 & 86.07 & 0.02 & 86.07 & 0.05 & 94.06 \\
\hline 104 & 0.02 & 86.80 & 0.02 & 86.91 & 0.02 & 86.91 & 0.06 & 94.98 \\
\hline
\end{tabular}




\begin{tabular}{|c|c|c|c|c|c|c|c|c|}
\hline 105 & 0.02 & 87.64 & 0.02 & 87.74 & 0.02 & 87.74 & 0.07 & 95.89 \\
\hline 106 & 0.03 & 88.47 & 0.03 & 88.58 & 0.03 & 88.58 & 0.08 & 96.80 \\
\hline 107 & 0.03 & 89.30 & 0.03 & 89.41 & 0.03 & 89.41 & 0.08 & 97.72 \\
\hline 108 & 0.04 & 90.14 & 0.04 & 90.25 & 0.04 & 90.25 & 0.10 & 98.63 \\
\hline 109 & 0.04 & 90.97 & 0.04 & 91.08 & 0.04 & 91.09 & 0.10 & 99.54 \\
\hline 110 & 0.04 & 91.81 & 0.05 & 91.92 & 0.05 & 91.92 & 0.12 & 100.45 \\
\hline 111 & 0.05 & 92.64 & 0.05 & 92.75 & 0.05 & 92.76 & 0.13 & 101.37 \\
\hline 112 & 0.06 & 93.48 & 0.06 & 93.59 & 0.06 & 93.59 & 0.15 & 102.28 \\
\hline 113 & 0.06 & 94.31 & 0.06 & 94.43 & 0.06 & 94.43 & 0.15 & 103.19 \\
\hline 114 & 0.07 & 95.15 & 0.07 & 95.26 & 0.07 & 95.26 & 0.19 & 104.11 \\
\hline 115 & 0.07 & 95.98 & 0.07 & 96.10 & 0.07 & 96.10 & 0.19 & 105.02 \\
\hline 116 & 0.08 & 96.82 & 0.08 & 96.93 & 0.08 & 96.93 & 0.23 & 105.93 \\
\hline 117 & 0.08 & 97.65 & 0.09 & 97.77 & 0.09 & 97.77 & 0.23 & 106.85 \\
\hline 118 & 0.10 & 98.49 & 0.10 & 98.60 & 0.10 & 98.61 & 0.27 & 107.76 \\
\hline 119 & 0.10 & 99.32 & 0.10 & 99.44 & 0.10 & 99.44 & 0.28 & 108.67 \\
\hline 120 & 0.12 & 100.15 & 0.13 & 100.27 & 0.13 & 100.28 & 0.33 & 109.59 \\
\hline
\end{tabular}

\section{Effect on Mixing due to Variation in Percentage of Nitrogen Cushion in Reservoir}

\begin{tabular}{|c|c|c|c|c|c|c|c|c|}
\hline \multicolumn{9}{|c|}{ Peripheral Placement of Nitrogen } \\
\hline \multirow{2}{*}{$\begin{array}{l}\text { Time } \\
\text { (days) }\end{array}$} & \multicolumn{2}{|c|}{ Base Gas - $5 \%$ Nitrogen } & \multicolumn{2}{|c|}{ Base Gas - $10 \%$ Nitrogen } & \multicolumn{2}{|c|}{ Base Gas - $15 \%$ Nitrogen } & \multicolumn{2}{|c|}{ Base Gas - $20 \%$ Nitrogen } \\
\hline & $\begin{array}{c}\% \mathrm{~N}_{2} \text { in } \\
\text { withdrawn } \\
\text { gas }\end{array}$ & $\begin{array}{c}\text { \% W.G } \\
\text { withdrawn } \\
\text { (volume) }\end{array}$ & $\begin{array}{c}\% N_{2} \text { in } \\
\text { withdrawn } \\
\text { gas }\end{array}$ & $\begin{array}{c}\% \text { W.G } \\
\text { withdrawn } \\
\text { (volume) }\end{array}$ & $\begin{array}{c}\% \mathrm{~N}_{2} \text { in } \\
\text { withdrawn } \\
\text { gas }\end{array}$ & $\begin{array}{c}\% \text { W.G } \\
\text { withdrawn } \\
\text { (volume) }\end{array}$ & $\begin{array}{c}\% \mathrm{~N}_{2} \text { in } \\
\text { withdrawn } \\
\text { gas }\end{array}$ & $\begin{array}{c}\text { \% W.G } \\
\text { withdrawn } \\
\text { (volume) }\end{array}$ \\
\hline 1 & 0.00 & 0.01 & 0.00 & 0.01 & 0.00 & 0.01 & 0.00 & 0.01 \\
\hline 2 & 0.00 & 0.03 & 0.00 & 0.03 & 0.00 & 0.03 & 0.00 & 0.03 \\
\hline 3 & 0.00 & 0.07 & 0.00 & 0.07 & 0.00 & 0.07 & 0.00 & 0.08 \\
\hline 4 & 0.00 & 0.21 & 0.00 & 0.21 & 0.00 & 0.21 & 0.00 & 0.24 \\
\hline 5 & 0.00 & 0.64 & 0.00 & 0.64 & 0.00 & 0.64 & 0.00 & 0.72 \\
\hline 6 & 0.00 & 0.75 & 0.00 & 0.75 & 0.00 & 0.75 & 0.00 & 0.85 \\
\hline 7 & 0.00 & 1.50 & 0.00 & 1.51 & 0.00 & 1.51 & 0.00 & 1.70 \\
\hline 8 & 0.00 & 2.25 & 0.00 & 2.26 & 0.00 & 2.26 & 0.00 & 2.55 \\
\hline 9 & 0.00 & 3.00 & 0.00 & 3.01 & 0.00 & 3.01 & 0.00 & 3.40 \\
\hline 10 & 0.00 & 3.75 & 0.00 & 3.77 & 0.00 & 3.77 & 0.00 & 4.25 \\
\hline 11 & 0.00 & 4.50 & 0.00 & 4.52 & 0.00 & 4.52 & 0.00 & 5.10 \\
\hline 12 & 0.00 & 5.25 & 0.00 & 5.27 & 0.00 & 5.27 & 0.00 & 5.95 \\
\hline 13 & 0.00 & 6.00 & 0.00 & 6.03 & 0.00 & 6.03 & 0.00 & 6.80 \\
\hline 14 & 0.00 & 6.75 & 0.00 & 6.78 & 0.00 & 6.78 & 0.00 & 7.65 \\
\hline 15 & 0.00 & 7.50 & 0.00 & 7.53 & 0.00 & 7.53 & 0.00 & 8.50 \\
\hline 16 & 0.00 & 8.24 & 0.00 & 8.29 & 0.00 & 8.29 & 0.00 & 9.35 \\
\hline 17 & 0.00 & 8.99 & 0.00 & 9.04 & 0.00 & 9.04 & 0.00 & 10.20 \\
\hline 18 & 0.00 & 9.74 & 0.00 & 9.79 & 0.00 & 9.79 & 0.00 & 11.05 \\
\hline 19 & 0.00 & 10.49 & 0.00 & 10.55 & 0.00 & 10.55 & 0.00 & 11.91 \\
\hline 20 & 0.00 & 11.24 & 0.00 & 11.30 & 0.00 & 11.30 & 0.00 & 12.76 \\
\hline 21 & 0.00 & 11.99 & 0.00 & 12.05 & 0.00 & 12.05 & 0.00 & 13.61 \\
\hline 22 & 0.00 & 12.74 & 0.00 & 12.81 & 0.00 & 12.81 & 0.00 & 14.46 \\
\hline 23 & 0.00 & 13.49 & 0.00 & 13.56 & 0.00 & 13.56 & 0.00 & 15.31 \\
\hline 24 & 0.00 & 14.24 & 0.00 & 14.32 & 0.00 & 14.32 & 0.00 & 16.16 \\
\hline 25 & 0.00 & 14.99 & 0.00 & 15.07 & 0.00 & 15.07 & 0.00 & 17.01 \\
\hline 26 & 0.00 & 15.74 & 0.00 & 15.82 & 0.00 & 15.82 & 0.00 & 17.86 \\
\hline 27 & 0.00 & 16.49 & 0.00 & 16.58 & 0.00 & 16.58 & 0.00 & 18.71 \\
\hline 28 & 0.00 & 17.24 & 0.00 & 17.33 & 0.00 & 17.33 & 0.00 & 19.56 \\
\hline 29 & 0.00 & 17.99 & 0.00 & 18.08 & 0.00 & 18.08 & 0.00 & 20.41 \\
\hline 30 & 0.00 & 18.74 & 0.00 & 18.84 & 0.00 & 18.84 & 0.00 & 21.26 \\
\hline 31 & 0.00 & 19.49 & 0.00 & 19.59 & 0.00 & 19.59 & 0.00 & 22.11 \\
\hline 32 & 0.00 & 20.24 & 0.00 & 20.34 & 0.00 & 20.34 & 0.00 & 22.96 \\
\hline 33 & 0.00 & 20.99 & 0.00 & 21.10 & 0.00 & 21.10 & 0.00 & 23.81 \\
\hline 34 & 0.00 & 21.74 & 0.00 & 21.85 & 0.00 & 21.85 & 0.00 & 24.66 \\
\hline 35 & 0.00 & 22.49 & 0.00 & 22.60 & 0.00 & 22.60 & 0.00 & 25.51 \\
\hline 36 & 0.00 & 23.24 & 0.00 & 23.36 & 0.00 & 23.36 & 0.00 & 26.36 \\
\hline 37 & 0.00 & 23.98 & 0.00 & 24.11 & 0.00 & 24.11 & 0.00 & 27.21 \\
\hline 38 & 0.00 & 24.73 & 0.00 & 24.86 & 0.00 & 24.86 & 0.00 & 28.06 \\
\hline 39 & 0.00 & 25.48 & 0.00 & 25.62 & 0.00 & 25.62 & 0.00 & 28.91 \\
\hline 40 & 0.00 & 26.23 & 0.00 & 26.37 & 0.00 & 26.37 & 0.00 & 29.76 \\
\hline 41 & 0.00 & 26.98 & 0.00 & 27.12 & 0.00 & 27.12 & 0.00 & 30.61 \\
\hline 42 & 0.00 & 27.73 & 0.00 & 27.88 & 0.00 & 27.88 & 0.00 & 31.46 \\
\hline 43 & 0.00 & 28.48 & 0.00 & 28.63 & 0.00 & 28.63 & 0.01 & 32.31 \\
\hline 44 & 0.00 & 29.23 & 0.00 & 29.38 & 0.00 & 29.38 & 0.01 & 33.16 \\
\hline 45 & 0.00 & 29.98 & 0.00 & 30.14 & 0.00 & 30.14 & 0.01 & 34.01 \\
\hline 46 & 0.00 & 30.73 & 0.00 & 30.89 & 0.00 & 30.89 & 0.01 & 34.87 \\
\hline
\end{tabular}




\begin{tabular}{|c|c|c|c|c|c|c|c|c|}
\hline 47 & 0.00 & 31.48 & 0.00 & 31.64 & 0.00 & 31.64 & 0.01 & 35.72 \\
\hline 48 & 0.00 & 32.23 & 0.00 & 32.40 & 0.00 & 32.40 & 0.01 & 36.57 \\
\hline 49 & 0.00 & 32.98 & 0.00 & 33.15 & 0.00 & 33.15 & 0.02 & 37.42 \\
\hline 50 & 0.00 & 33.73 & 0.00 & 33.90 & 0.00 & 33.90 & 0.02 & 38.27 \\
\hline 51 & 0.00 & 34.48 & 0.00 & 34.66 & 0.00 & 34.66 & 0.02 & 39.12 \\
\hline 52 & 0.00 & 35.23 & 0.00 & 35.41 & 0.00 & 35.41 & 0.03 & 39.97 \\
\hline 53 & 0.00 & 35.98 & 0.00 & 36.16 & 0.00 & 36.16 & 0.03 & 40.82 \\
\hline 54 & 0.00 & 36.73 & 0.00 & 36.92 & 0.00 & 36.92 & 0.04 & 41.67 \\
\hline 55 & 0.00 & 37.48 & 0.00 & 37.67 & 0.00 & 37.67 & 0.04 & 42.52 \\
\hline 56 & 0.00 & 38.23 & 0.00 & 38.42 & 0.00 & 38.43 & 0.05 & 43.37 \\
\hline 57 & 0.00 & 38.97 & 0.00 & 39.18 & 0.00 & 39.18 & 0.06 & 44.22 \\
\hline 58 & 0.00 & 39.72 & 0.00 & 39.93 & 0.00 & 39.93 & 0.06 & 45.07 \\
\hline 59 & 0.00 & 40.47 & 0.00 & 40.69 & 0.00 & 40.69 & 0.08 & 45.92 \\
\hline 60 & 0.00 & 41.22 & 0.00 & 41.44 & 0.00 & 41.44 & 0.08 & 46.77 \\
\hline 61 & 0.00 & 41.97 & 0.00 & 42.19 & 0.00 & 42.19 & 0.10 & 47.62 \\
\hline 62 & 0.00 & 42.72 & 0.00 & 42.95 & 0.00 & 42.95 & 0.10 & 48.47 \\
\hline 63 & 0.00 & 43.47 & 0.00 & 43.70 & 0.00 & 43.70 & 0.12 & 49.32 \\
\hline 64 & 0.00 & 44.22 & 0.00 & 44.45 & 0.00 & 44.45 & 0.13 & 50.17 \\
\hline 65 & 0.00 & 44.97 & 0.00 & 45.21 & 0.00 & 45.21 & 0.15 & 51.02 \\
\hline 66 & 0.00 & 45.72 & 0.00 & 45.96 & 0.00 & 45.96 & 0.16 & 51.87 \\
\hline 67 & 0.00 & 46.47 & 0.00 & 46.71 & 0.00 & 46.71 & 0.19 & 52.72 \\
\hline 68 & 0.00 & 47.22 & 0.00 & 47.47 & 0.00 & 47.47 & 0.19 & 53.57 \\
\hline 69 & 0.00 & 47.97 & 0.00 & 48.22 & 0.00 & 48.22 & 0.23 & 54.42 \\
\hline 70 & 0.00 & 48.72 & 0.00 & 48.97 & 0.00 & 48.97 & 0.24 & 55.27 \\
\hline 71 & 0.00 & 49.47 & 0.00 & 49.73 & 0.00 & 49.73 & 0.27 & 56.12 \\
\hline 72 & 0.00 & 50.22 & 0.00 & 50.48 & 0.00 & 50.48 & 0.28 & 56.97 \\
\hline 73 & 0.00 & 50.97 & 0.00 & 51.23 & 0.00 & 51.23 & 0.33 & 57.82 \\
\hline 74 & 0.00 & 51.72 & 0.00 & 51.99 & 0.00 & 51.99 & 0.34 & 58.68 \\
\hline 75 & 0.00 & 52.47 & 0.00 & 52.74 & 0.00 & 52.74 & 0.39 & 59.53 \\
\hline 76 & 0.00 & 53.22 & 0.00 & 53.49 & 0.00 & 53.49 & 0.41 & 60.38 \\
\hline 77 & 0.00 & 53.97 & 0.00 & 54.25 & 0.00 & 54.25 & 0.47 & 61.23 \\
\hline 78 & 0.00 & 54.71 & 0.00 & 55.00 & 0.00 & 55.00 & 0.48 & 62.08 \\
\hline 79 & 0.00 & 55.46 & 0.00 & 55.75 & 0.00 & 55.75 & 0.55 & 62.93 \\
\hline 80 & 0.00 & 56.21 & 0.00 & 56.51 & 0.00 & 56.51 & 0.57 & 63.78 \\
\hline 81 & 0.00 & 56.96 & 0.00 & 57.26 & 0.00 & 57.26 & 0.65 & 64.63 \\
\hline 82 & 0.00 & 57.71 & 0.00 & 58.01 & 0.00 & 58.01 & 0.67 & 65.48 \\
\hline 83 & 0.00 & 58.46 & 0.00 & 58.77 & 0.00 & 58.77 & 0.75 & 66.33 \\
\hline 84 & 0.00 & 59.21 & 0.00 & 59.52 & 0.00 & 59.52 & 0.77 & 67.18 \\
\hline 85 & 0.00 & 59.96 & 0.00 & 60.27 & 0.00 & 60.27 & 0.87 & 68.03 \\
\hline 86 & 0.00 & 60.71 & 0.00 & 61.03 & 0.00 & 61.03 & 0.90 & 68.88 \\
\hline 87 & 0.00 & 61.46 & 0.00 & 61.78 & 0.00 & 61.78 & 1.01 & 69.73 \\
\hline 88 & 0.00 & 62.21 & 0.00 & 62.53 & 0.00 & 62.53 & 1.03 & 70.58 \\
\hline 89 & 0.00 & 62.96 & 0.00 & 63.29 & 0.01 & 63.29 & 1.16 & 71.43 \\
\hline 90 & 0.00 & 63.71 & 0.00 & 64.04 & 0.01 & 64.04 & 1.18 & 72.28 \\
\hline 91 & 0.00 & 64.46 & 0.00 & 64.79 & 0.01 & 64.80 & 1.32 & 73.13 \\
\hline 92 & 0.00 & 65.21 & 0.00 & 65.55 & 0.01 & 65.55 & 1.35 & 73.98 \\
\hline 93 & 0.00 & 65.96 & 0.00 & 66.30 & 0.01 & 66.30 & 1.50 & 74.83 \\
\hline 94 & 0.00 & 66.71 & 0.00 & 67.05 & 0.01 & 67.06 & 1.54 & 75.68 \\
\hline 95 & 0.00 & 67.46 & 0.00 & 67.81 & 0.01 & 67.81 & 1.70 & 76.53 \\
\hline 96 & 0.00 & 68.21 & 0.00 & 68.56 & 0.01 & 68.56 & 1.74 & 77.38 \\
\hline 97 & 0.00 & 68.96 & 0.00 & 69.32 & 0.01 & 69.32 & 1.92 & 78.23 \\
\hline 98 & 0.00 & 69.70 & 0.00 & 70.07 & 0.01 & 70.07 & 1.96 & 79.08 \\
\hline 99 & 0.00 & 70.45 & 0.00 & 70.82 & 0.02 & 70.82 & 2.16 & 79.93 \\
\hline 100 & 0.00 & 71.20 & 0.00 & 71.58 & 0.02 & 71.58 & 2.21 & 80.78 \\
\hline 101 & 0.00 & 71.95 & 0.00 & 72.33 & 0.02 & 72.33 & 2.43 & 81.63 \\
\hline 102 & 0.00 & 72.70 & 0.00 & 73.08 & 0.02 & 73.08 & 2.47 & 82.48 \\
\hline 103 & 0.00 & 73.45 & 0.00 & 73.84 & 0.02 & 73.84 & 2.71 & 83.33 \\
\hline 104 & 0.00 & 74.20 & 0.00 & 74.59 & 0.02 & 74.59 & 2.76 & 84.18 \\
\hline 105 & 0.00 & 74.95 & 0.00 & 75.34 & 0.03 & 75.34 & 3.03 & 85.04 \\
\hline 106 & 0.00 & 75.70 & 0.00 & 76.10 & 0.03 & 76.10 & 3.08 & 85.89 \\
\hline 107 & 0.00 & 76.45 & 0.00 & 76.85 & 0.03 & 76.85 & 3.36 & 86.74 \\
\hline 108 & 0.00 & 77.20 & 0.00 & 77.60 & 0.03 & 77.60 & 3.42 & 87.59 \\
\hline 109 & 0.00 & 77.95 & 0.01 & 78.36 & 0.04 & 78.36 & 3.73 & 88.44 \\
\hline 110 & 0.00 & 78.70 & 0.01 & 79.11 & 0.04 & 79.11 & 3.79 & 89.29 \\
\hline 111 & 0.00 & 79.45 & 0.01 & 79.86 & 0.04 & 79.86 & 4.12 & 90.14 \\
\hline 112 & 0.00 & 80.20 & 0.01 & 80.62 & 0.04 & 80.62 & 4.18 & 90.99 \\
\hline 113 & 0.00 & 80.95 & 0.01 & 81.37 & 0.05 & 81.37 & 4.54 & 91.84 \\
\hline 114 & 0.00 & 81.70 & 0.01 & 82.12 & 0.05 & 82.12 & 4.61 & 92.69 \\
\hline 115 & 0.00 & 82.45 & 0.01 & 82.88 & 0.06 & 82.88 & 5.00 & 93.54 \\
\hline 116 & 0.00 & 83.20 & 0.01 & 83.63 & 0.06 & 83.63 & 5.07 & 94.39 \\
\hline 117 & 0.00 & 83.95 & 0.02 & 84.38 & 0.07 & 84.38 & 5.49 & 95.24 \\
\hline 118 & 0.00 & 84.69 & 0.02 & 85.14 & 0.07 & 85.14 & 5.56 & 96.09 \\
\hline 119 & 0.00 & 85.44 & 0.02 & 85.89 & 0.08 & 85.89 & 6.01 & 96.94 \\
\hline 120 & 0.00 & 86.19 & 0.02 & 86.64 & 0.08 & 86.64 & 6.09 & 97.79 \\
\hline
\end{tabular}




\section{Effect on Mixing with Constant Pressure Withdrawal}

\section{Permeability - 100 md}

\begin{tabular}{|c|c|c|c|c|c|c|c|c|c|c|}
\hline \multicolumn{11}{|c|}{ Peripheral Placement of Nitrogen } \\
\hline \multirow{3}{*}{$\begin{array}{l}\text { TIME } \\
\text { (days) }\end{array}$} & \multirow{2}{*}{\multicolumn{2}{|c|}{$\begin{array}{c}\text { Withdrawal Pressure } \\
100 \mathrm{psia} \\
\end{array}$}} & \multirow{2}{*}{\multicolumn{2}{|c|}{$\begin{array}{c}\text { Withdrawal Pressure } \\
150 \text { psia }\end{array}$}} & \multirow{2}{*}{\multicolumn{2}{|c|}{$\begin{array}{c}\text { Withdrawal Pressure } \\
200 \text { psia }\end{array}$}} & \multirow{2}{*}{\multicolumn{2}{|c|}{$\begin{array}{c}\text { Withdrawal Pressure } \\
250 \text { psia }\end{array}$}} & \multirow{2}{*}{\multicolumn{2}{|c|}{$\begin{array}{c}\text { Withdrawal Pressure } \\
300 \mathrm{psia} \\
\end{array}$}} \\
\hline & & & & & & & & & & \\
\hline & $\begin{array}{c}\% N_{2} \text { in } \\
\text { withdrawn } \\
\text { gas }\end{array}$ & $\begin{array}{c}\text { \% W.G } \\
\text { withdrawn } \\
\text { (volume) }\end{array}$ & $\begin{array}{c}\% \mathrm{~N}_{2} \text { in } \\
\text { withdrawn } \\
\text { gas }\end{array}$ & $\begin{array}{c}\text { \% W.G } \\
\text { withdrawn } \\
\text { (volume) }\end{array}$ & $\begin{array}{c}\% \mathrm{~N}_{2} \text { in } \\
\text { withdrawn } \\
\text { gas }\end{array}$ & $\begin{array}{c}\text { \% W.G } \\
\text { withdrawn } \\
\text { (volume) }\end{array}$ & $\begin{array}{c}\% \mathrm{~N}_{2} \text { in } \\
\text { withdrawn } \\
\text { gas }\end{array}$ & $\begin{array}{c}\text { \% W.G } \\
\text { withdrawn } \\
\text { (volume) }\end{array}$ & $\begin{array}{c}\% \mathrm{~N}_{2} \text { in } \\
\text { withdrawn } \\
\text { gas }\end{array}$ & $\begin{array}{c}\text { \% W.G } \\
\text { withdrawn } \\
\text { (volume) }\end{array}$ \\
\hline 0.01 & 0.00 & 12.73 & 0.00 & 0.19 & 0.00 & 0.18 & 0.00 & 0.17 & 0.00 & 0.16 \\
\hline 0.04 & 0.00 & 22.96 & 0.00 & 0.59 & 0.00 & 0.56 & 0.00 & 0.54 & 0.00 & 0.51 \\
\hline 0.1 & 0.00 & 31.82 & 0.00 & 1.49 & 0.00 & 1.42 & 0.00 & 1.36 & 0.00 & 1.28 \\
\hline 0.29 & 0.00 & 39.54 & 0.00 & 3.95 & 0.00 & 3.78 & 0.00 & 3.60 & 0.00 & 3.42 \\
\hline 0.85 & 0.00 & 46.31 & 0.00 & 10.54 & 0.00 & 10.11 & 0.00 & 9.65 & 0.00 & 9.17 \\
\hline 1 & 0.00 & 52.28 & 0.00 & 12.25 & 0.00 & 11.74 & 0.00 & 11.22 & 0.00 & 10.66 \\
\hline 2 & 0.00 & 57.60 & 0.00 & 22.12 & 0.00 & 21.24 & 0.00 & 20.31 & 0.00 & 19.33 \\
\hline 3 & 0.00 & 62.34 & 0.00 & 30.69 & 0.00 & 29.49 & 0.00 & 28.23 & 0.00 & 26.89 \\
\hline 4 & 0.00 & 66.61 & 0.00 & 38.16 & 0.00 & 36.70 & 0.00 & 35.15 & 0.00 & 33.52 \\
\hline 5 & 0.00 & 70.46 & 0.00 & 44.73 & 0.00 & 43.05 & 0.00 & 41.26 & 0.00 & 39.36 \\
\hline 6 & 0.00 & 73.94 & 0.00 & 50.54 & 0.00 & 48.67 & 0.00 & 46.68 & 0.00 & 44.55 \\
\hline 7 & 0.00 & 77.12 & 0.00 & 55.70 & 0.00 & 53.67 & 0.00 & 51.50 & 0.00 & 49.18 \\
\hline 8 & 0.00 & 80.02 & 0.00 & 60.33 & 0.00 & 58.15 & 0.00 & 55.82 & 0.00 & 53.33 \\
\hline 9 & 0.00 & 82.68 & 0.00 & 64.48 & 0.00 & 62.19 & 0.00 & 59.72 & 0.00 & 57.07 \\
\hline 10 & 0.00 & 85.12 & 0.00 & 68.23 & 0.00 & 65.83 & 0.00 & 63.23 & 0.00 & 60.44 \\
\hline 11 & 0.35 & 87.35 & 0.00 & 71.64 & 0.00 & 69.13 & 0.00 & 66.42 & 0.00 & 63.50 \\
\hline 12 & 0.36 & 89.43 & 0.00 & 74.74 & 0.00 & 72.14 & 0.00 & 69.33 & 0.00 & 66.29 \\
\hline 13 & 0.85 & 91.33 & 0.00 & 77.57 & 0.00 & 74.89 & 0.00 & 71.98 & 0.00 & 68.83 \\
\hline 14 & 0.86 & 93.13 & 0.00 & 80.16 & 0.00 & 77.41 & 0.00 & 74.41 & 0.00 & 71.17 \\
\hline 15 & 2.44 & 94.76 & 0.00 & 82.55 & 0.00 & 79.73 & 0.00 & 76.65 & 0.00 & 73.31 \\
\hline 16 & 2.46 & 96.32 & 0.16 & 84.73 & 0.06 & 81.85 & 0.02 & 78.69 & 0.01 & 75.26 \\
\hline 17 & 5.95 & 97.73 & 0.16 & 86.77 & 0.07 & 83.82 & 0.03 & 80.60 & 0.01 & 77.08 \\
\hline 18 & 6.00 & 99.08 & 0.48 & 88.63 & 0.28 & 85.64 & 0.11 & 82.35 & 0.05 & 78.75 \\
\hline 19 & 10.19 & 100.32 & 0.48 & 90.38 & 0.28 & 87.34 & 0.11 & 83.98 & 0.05 & 80.31 \\
\hline 20 & 10.27 & 101.50 & 1.07 & 92.00 & 0.57 & 88.90 & 0.28 & 85.49 & 0.12 & 81.74 \\
\hline 21 & 11.12 & 102.62 & 1.08 & 93.51 & 0.58 & 90.37 & 0.29 & 86.90 & 0.13 & 83.08 \\
\hline 22 & 11.14 & 103.69 & 2.37 & 94.91 & 1.02 & 91.74 & 0.65 & 88.20 & 0.24 & 84.32 \\
\hline 23 & 11.88 & 104.69 & 2.39 & 96.24 & 1.03 & 93.02 & 0.66 & 89.43 & 0.24 & 85.49 \\
\hline 24 & 11.90 & 105.66 & 4.17 & 97.46 & 1.65 & 94.21 & 0.83 & 90.57 & 0.39 & 86.57 \\
\hline 25 & 12.92 & 106.56 & 4.21 & 98.63 & 1.66 & 95.34 & 0.83 & 91.65 & 0.40 & 87.58 \\
\hline 26 & 12.95 & 107.43 & 6.12 & 99.71 & 2.33 & 96.39 & 0.91 & 92.66 & 0.56 & 88.53 \\
\hline 27 & 13.23 & 108.26 & 6.16 & 100.74 & 2.35 & 97.38 & 0.91 & 93.60 & 0.57 & 89.42 \\
\hline 28 & 13.23 & 109.05 & 8.05 & 101.70 & 2.91 & 98.32 & 1.12 & 94.49 & 0.75 & 90.25 \\
\hline 29 & 13.42 & 109.81 & 8.10 & 102.62 & 2.93 & 99.20 & 1.14 & 95.33 & 0.76 & 91.03 \\
\hline 30 & 13.41 & 110.53 & 6.88 & 103.50 & 3.38 & 100.03 & 2.06 & 96.12 & 0.94 & 91.76 \\
\hline 31 & 6.49 & 110.91 & 11.31 & 103.63 & 3.40 & 100.82 & 2.11 & 96.86 & 0.95 & 92.46 \\
\hline 32 & 10.43 & 111.17 & 8.52 & 103.77 & 3.37 & 101.57 & 2.19 & 97.56 & 1.15 & 93.10 \\
\hline 33 & 10.91 & 111.25 & 5.20 & 104.17 & 3.37 & 102.28 & 2.21 & 98.22 & 1.16 & 93.72 \\
\hline 34 & 8.58 & 111.58 & 4.55 & 104.35 & 2.70 & 102.95 & 2.35 & 98.85 & 1.36 & 94.30 \\
\hline 35 & 7.95 & 111.93 & 4.26 & 105.14 & 2.67 & 103.59 & 2.34 & 99.45 & 1.37 & 94.84 \\
\hline
\end{tabular}




\begin{tabular}{|c|c|c|c|c|c|c|c|c|c|c|}
\hline 36 & 7.98 & 112.56 & 4.24 & 105.90 & 7.37 & 104.19 & 2.80 & 100.01 & 1.58 & 95.36 \\
\hline 37 & 7.98 & 113.17 & 5.28 & 106.61 & 7.56 & 104.76 & 2.85 & 100.54 & 1.59 & 95.84 \\
\hline 38 & 8.15 & 113.75 & 5.30 & 107.29 & 7.39 & 104.91 & 3.11 & 101.05 & 1.78 & 96.30 \\
\hline 39 & 8.16 & 114.31 & 6.39 & 107.46 & 6.62 & 105.16 & 3.13 & 101.53 & 1.80 & 96.74 \\
\hline 40 & 12.06 & 114.83 & 6.43 & 107.79 & 6.14 & 105.32 & 3.42 & 101.99 & 1.99 & 97.15 \\
\hline 41 & 12.19 & 115.34 & 6.32 & 107.95 & 5.12 & 105.84 & 3.45 & 102.42 & 2.00 & 97.54 \\
\hline 42 & 14.44 & 115.47 & 5.94 & 108.56 & 5.07 & 106.34 & 3.63 & 102.84 & 2.18 & 97.91 \\
\hline 43 & 16.59 & 115.58 & 5.92 & 109.15 & 5.08 & 106.82 & 3.64 & 103.23 & 2.20 & 98.27 \\
\hline 44 & 11.85 & 115.84 & 6.63 & 109.71 & 5.04 & 107.27 & 3.95 & 103.60 & 2.36 & 98.60 \\
\hline 45 & 10.97 & 116.12 & 6.65 & 110.25 & 5.86 & 107.70 & 3.98 & 103.96 & 2.38 & 98.92 \\
\hline 46 & 10.92 & 116.31 & 7.49 & 110.76 & 5.94 & 108.12 & 4.21 & 104.30 & 2.54 & 99.22 \\
\hline 47 & 11.15 & 116.76 & 7.45 & 111.25 & 6.07 & 108.51 & 4.23 & 104.63 & 2.56 & 99.50 \\
\hline 48 & 11.16 & 117.20 & 8.68 & 111.72 & 6.03 & 108.90 & 4.50 & 104.94 & 2.71 & 99.77 \\
\hline 49 & 11.63 & 117.62 & 8.73 & 112.16 & 6.67 & 109.26 & 4.52 & 105.24 & 2.72 & 100.03 \\
\hline 50 & 11.66 & 118.02 & 9.33 & 112.39 & 6.70 & 109.61 & 4.76 & 105.52 & 2.86 & 100.28 \\
\hline 51 & 12.74 & 118.41 & 8.87 & 112.60 & 6.94 & 109.94 & 4.77 & 105.79 & 2.88 & 100.51 \\
\hline 52 & 12.76 & 118.78 & 8.85 & 112.94 & 6.90 & 110.26 & 5.01 & 106.05 & 3.01 & 100.73 \\
\hline 53 & 13.43 & 119.14 & 8.86 & 113.01 & 7.22 & 110.57 & 5.03 & 106.30 & 3.02 & 100.95 \\
\hline 54 & 13.46 & 119.49 & 8.98 & 113.41 & 7.21 & 110.86 & 5.24 & 106.53 & 3.15 & 101.15 \\
\hline 55 & 13.62 & 119.82 & 9.00 & 113.79 & 7.89 & 111.14 & 5.27 & 106.76 & 3.16 & 101.34 \\
\hline 56 & 13.62 & 120.15 & 9.69 & 114.16 & 7.97 & 111.42 & 5.47 & 106.98 & 3.27 & 101.52 \\
\hline 57 & 14.07 & 120.46 & 9.74 & 114.51 & 8.03 & 111.68 & 5.49 & 107.19 & 3.29 & 101.70 \\
\hline 58 & 15.90 & 120.61 & 10.29 & 114.85 & 8.02 & 111.93 & 5.68 & 107.39 & 3.40 & 101.87 \\
\hline 59 & 18.62 & 120.73 & 10.33 & 115.18 & 8.49 & 112.17 & 5.70 & 107.58 & 3.41 & 102.02 \\
\hline 60 & 18.32 & 120.76 & 10.76 & 115.49 & 8.54 & 112.40 & 5.89 & 107.76 & 3.51 & 102.18 \\
\hline 61 & 16.07 & 120.91 & 10.78 & 115.79 & 8.77 & 112.63 & 5.90 & 107.94 & 3.53 & 102.32 \\
\hline 62 & 15.75 & 121.05 & 11.34 & 116.08 & 8.80 & 112.84 & 6.07 & 108.11 & 3.61 & 102.46 \\
\hline 63 & 15.90 & 121.33 & 11.40 & 116.37 & 9.11 & 113.05 & 6.09 & 108.27 & 3.63 & 102.59 \\
\hline 64 & 15.92 & 121.61 & 11.81 & 116.64 & 9.16 & 113.25 & 6.24 & 108.42 & 3.71 & 102.72 \\
\hline 65 & 16.29 & 121.87 & 11.82 & 116.90 & 9.39 & 113.44 & 6.26 & 108.57 & 3.73 & 102.84 \\
\hline 66 & 16.30 & 122.13 & 12.33 & 117.15 & 9.43 & 113.63 & 6.42 & 108.72 & 3.80 & 102.95 \\
\hline 67 & 17.41 & 122.38 & 12.37 & 117.40 & 9.70 & 113.81 & 6.43 & 108.85 & 3.81 & 103.06 \\
\hline 68 & 17.48 & 122.62 & 12.76 & 117.63 & 9.72 & 113.98 & 6.57 & 108.99 & 3.87 & 103.17 \\
\hline 69 & 17.60 & 122.86 & 12.81 & 117.86 & 9.96 & 114.15 & 6.59 & 109.11 & 3.91 & 103.27 \\
\hline 70 & 17.60 & 123.08 & 13.23 & 118.08 & 9.98 & 114.31 & 6.71 & 109.24 & 3.95 & 103.36 \\
\hline 71 & 18.36 & 123.30 & 13.28 & 118.30 & 10.21 & 114.47 & 6.73 & 109.35 & 3.98 & 103.45 \\
\hline 72 & 18.41 & 123.52 & 13.65 & 118.51 & 10.26 & 114.62 & 6.85 & 109.47 & 4.03 & 103.54 \\
\hline 73 & 18.95 & 123.73 & 13.70 & 118.71 & 10.47 & 114.76 & 6.87 & 109.58 & 4.04 & 103.62 \\
\hline 74 & 18.95 & 123.93 & 14.09 & 118.90 & 10.47 & 114.90 & 6.97 & 109.68 & 4.10 & 103.70 \\
\hline 75 & 19.47 & 124.13 & 14.13 & 119.09 & 10.70 & 115.04 & 7.01 & 109.78 & 4.11 & 103.78 \\
\hline 76 & 19.46 & 124.32 & 14.48 & 119.27 & 10.73 & 115.17 & 7.08 & 109.88 & 4.16 & 103.85 \\
\hline 77 & 20.02 & 124.51 & 14.50 & 119.45 & 10.92 & 115.30 & 7.12 & 109.97 & 4.19 & 103.92 \\
\hline 78 & 20.07 & 124.69 & 14.89 & 119.62 & 10.95 & 115.42 & 7.23 & 110.06 & 4.21 & 103.99 \\
\hline 79 & 20.51 & 124.87 & 14.88 & 119.79 & 11.13 & 115.54 & 7.21 & 110.15 & 4.23 & 104.05 \\
\hline 80 & 20.54 & 125.04 & 15.26 & 119.95 & 11.15 & 115.65 & 7.34 & 110.23 & 4.26 & 104.12 \\
\hline 81 & 21.03 & 125.21 & 15.25 & 120.11 & 11.33 & 115.76 & 7.34 & 110.31 & 4.26 & 104.17 \\
\hline 82 & 21.06 & 125.37 & 15.60 & 120.26 & 11.38 & 115.87 & 7.40 & 110.39 & 4.31 & 104.23 \\
\hline 83 & 21.56 & 125.53 & 15.65 & 120.41 & 11.53 & 115.98 & 7.46 & 110.46 & 4.32 & 104.28 \\
\hline 84 & 21.56 & 125.68 & 15.95 & 120.55 & 11.53 & 116.08 & 7.50 & 110.53 & 4.36 & 104.34 \\
\hline 85 & 21.98 & 125.84 & 15.95 & 120.69 & 11.71 & 116.17 & 7.54 & 110.60 & 4.39 & 104.38 \\
\hline 86 & 22.01 & 125.98 & 16.25 & 120.83 & 11.73 & 116.27 & 7.59 & 110.67 & 4.39 & 104.43 \\
\hline
\end{tabular}




\begin{tabular}{|c|c|c|c|c|c|c|c|c|c|c|}
\hline 87 & 22.48 & 126.13 & 16.32 & 120.96 & 11.86 & 116.36 & 7.62 & 110.73 & 4.44 & 104.48 \\
\hline 88 & 22.49 & 126.27 & 16.60 & 121.09 & 11.91 & 116.45 & 7.69 & 110.79 & 4.44 & 104.52 \\
\hline 89 & 22.91 & 126.41 & 16.61 & 121.22 & 12.03 & 116.54 & 7.70 & 110.85 & 4.44 & 104.56 \\
\hline 90 & 22.96 & 126.54 & 16.87 & 121.34 & 12.05 & 116.62 & 7.75 & 110.91 & 4.49 & 104.60 \\
\hline 91 & 23.31 & 126.67 & 16.95 & 121.46 & 12.17 & 116.70 & 7.77 & 110.96 & 4.48 & 104.64 \\
\hline 92 & 23.39 & 126.80 & 17.18 & 121.57 & 12.22 & 116.78 & 7.79 & 111.02 & 4.50 & 104.67 \\
\hline 93 & 23.74 & 126.93 & 17.20 & 121.68 & 12.35 & 116.85 & 7.89 & 111.07 & 4.54 & 104.71 \\
\hline 94 & 23.80 & 127.05 & 17.45 & 121.79 & 12.37 & 116.93 & 7.87 & 111.12 & 4.54 & 104.74 \\
\hline 95 & 24.20 & 127.17 & 17.49 & 121.90 & 12.46 & 117.00 & 7.89 & 111.16 & 4.55 & 104.77 \\
\hline 96 & 24.20 & 127.28 & 17.72 & 122.00 & 12.50 & 117.07 & 7.94 & 111.21 & 4.57 & 104.81 \\
\hline 97 & 24.56 & 127.40 & 17.78 & 122.10 & 12.62 & 117.14 & 7.99 & 111.25 & 4.55 & 104.83 \\
\hline 98 & 24.56 & 127.51 & 17.98 & 122.20 & 12.62 & 117.20 & 8.00 & 111.30 & 4.63 & 104.86 \\
\hline 99 & 24.97 & 127.62 & 18.00 & 122.30 & 12.69 & 117.26 & 8.07 & 111.34 & 4.57 & 104.89 \\
\hline 100 & 24.98 & 127.73 & 18.28 & 122.39 & 12.79 & 117.33 & 8.10 & 111.38 & 4.60 & 104.92 \\
\hline 101 & 25.27 & 127.83 & 18.27 & 122.48 & 12.87 & 117.38 & 8.05 & 111.42 & 4.62 & 104.94 \\
\hline 102 & 25.42 & 127.93 & 18.44 & 122.57 & 12.86 & 117.44 & 8.16 & 111.45 & 4.70 & 104.96 \\
\hline 103 & 25.61 & 128.03 & 18.51 & 122.66 & 12.96 & 117.50 & 8.13 & 111.49 & 4.64 & 104.99 \\
\hline 104 & 25.78 & 128.13 & 18.70 & 122.74 & 12.95 & 117.55 & 8.20 & 111.52 & 4.68 & 105.01 \\
\hline 105 & 26.01 & 128.23 & 18.73 & 122.82 & 13.08 & 117.61 & 8.18 & 111.56 & 4.63 & 105.03 \\
\hline 106 & 26.04 & 128.32 & 18.94 & 122.90 & 13.10 & 117.66 & 8.19 & 111.59 & 4.68 & 105.05 \\
\hline 107 & 26.39 & 128.41 & 18.99 & 122.98 & 13.17 & 117.71 & 8.27 & 111.62 & 4.65 & 105.07 \\
\hline 108 & 26.40 & 128.50 & 19.06 & 123.06 & 13.20 & 117.76 & 8.21 & 111.65 & 4.71 & 105.09 \\
\hline 109 & 26.69 & 128.59 & 19.22 & 123.13 & 13.29 & 117.80 & 8.31 & 111.68 & 4.71 & 105.10 \\
\hline 110 & 26.74 & 128.68 & 19.31 & 123.20 & 13.26 & 117.85 & 8.26 & 111.71 & 4.71 & 105.12 \\
\hline 111 & 27.03 & 128.76 & 19.41 & 123.28 & 13.37 & 117.89 & 8.30 & 111.73 & 4.70 & 105.14 \\
\hline 112 & 27.00 & 128.85 & 19.51 & 123.34 & 13.35 & 117.94 & 8.35 & 111.76 & 4.82 & 105.15 \\
\hline 113 & 27.34 & 128.93 & 19.55 & 123.41 & 13.47 & 117.98 & 8.44 & 111.78 & 4.74 & 105.17 \\
\hline 114 & 27.32 & 129.01 & 19.76 & 123.48 & 13.49 & 118.02 & 8.28 & 111.81 & 4.65 & 105.18 \\
\hline 115 & 27.65 & 129.09 & 19.72 & 123.54 & 13.52 & 118.06 & 8.37 & 111.83 & 4.81 & 105.19 \\
\hline 116 & 11.94 & 117.52 & 19.85 & 123.61 & 13.43 & 118.10 & 8.49 & 111.85 & 4.74 & 105.21 \\
\hline 117 & 11.94 & 117.62 & 19.94 & 123.67 & 13.61 & 118.13 & 8.35 & 111.87 & 4.79 & 105.22 \\
\hline 118 & 11.97 & 117.72 & 20.09 & 123.73 & 13.66 & 118.17 & 8.47 & 111.89 & 4.74 & 105.23 \\
\hline 119 & 11.98 & 117.82 & 20.08 & 123.79 & 13.74 & 118.20 & 8.50 & 111.91 & 4.68 & 105.24 \\
\hline 120 & 12.01 & 117.91 & 20.26 & 123.84 & 13.69 & 118.24 & 8.36 & 111.93 & 4.79 & 105.25 \\
\hline
\end{tabular}

\section{Permeability - 200 md}

\begin{tabular}{|c|c|c|c|c|c|c|c|c|c|c|}
\hline \multicolumn{11}{|c|}{ Peripheral Placement of Nitrogen } \\
\hline \multirow{3}{*}{$\begin{array}{l}\text { TIME } \\
\text { (days) }\end{array}$} & \multirow{2}{*}{\multicolumn{2}{|c|}{$\begin{array}{c}\text { Withdrawal Pressure } \\
100 \text { psia } \\
\end{array}$}} & \multirow{2}{*}{\multicolumn{2}{|c|}{$\begin{array}{c}\text { Withdrawal Pressure } \\
150 \text { psia }\end{array}$}} & \multirow{2}{*}{\multicolumn{2}{|c|}{$\begin{array}{c}\text { Withdrawal Pressure } \\
200 \text { psia } \\
\end{array}$}} & \multirow{2}{*}{\multicolumn{2}{|c|}{$\begin{array}{c}\text { Withdrawal Pressure } \\
250 \text { psia } \\
\end{array}$}} & \multirow{2}{*}{\multicolumn{2}{|c|}{$\begin{array}{c}\text { Withdrawal Pressure } \\
300 \text { psia } \\
\end{array}$}} \\
\hline & & & & & & & & & & \\
\hline & $\begin{array}{c}\% \mathrm{~N}_{2} \text { in } \\
\text { withdrawn } \\
\text { gas }\end{array}$ & $\begin{array}{c}\text { \% W.G } \\
\text { withdrawn } \\
\text { (volume) }\end{array}$ & $\begin{array}{c}\% \mathrm{~N}_{2} \text { in } \\
\text { withdrawn } \\
\text { gas }\end{array}$ & $\begin{array}{c}\text { \% W.G } \\
\text { withdrawn } \\
\text { (volume) }\end{array}$ & $\begin{array}{c}\% \mathrm{~N}_{2} \text { in } \\
\text { withdrawn } \\
\text { gas }\end{array}$ & $\begin{array}{l}\text { \% W.G } \\
\text { withdrawn } \\
\text { (volume) }\end{array}$ & $\begin{array}{c}\% \mathrm{~N}_{2} \text { in } \\
\text { withdrawn } \\
\text { gas }\end{array}$ & $\begin{array}{c}\text { \% W.G } \\
\text { withdrawn } \\
\text { (volume) }\end{array}$ & $\begin{array}{c}\% \mathrm{~N}_{2} \text { in } \\
\text { withdrawn } \\
\text { gas }\end{array}$ & $\begin{array}{c}\% \text { W.G } \\
\text { withdrawn } \\
\text { (volume) }\end{array}$ \\
\hline 0.01 & 0.00 & 0.16 & 0.00 & 0.15 & 0.00 & 0.14 & 0.00 & 0.13 & 0.00 & 0.13 \\
\hline 0.04 & 0.00 & 0.52 & 0.00 & 0.50 & 0.00 & 0.47 & 0.00 & 0.45 & 0.00 & 0.42 \\
\hline 0.1 & 1.52 & 1.35 & 1.43 & 1.32 & 1.32 & 1.26 & 1.20 & 1.18 & 1.09 & 1.13 \\
\hline 0.29 & 4.08 & 2.79 & 3.98 & 2.71 & 3.84 & 2.59 & 3.69 & 2.42 & 3.54 & 2.37 \\
\hline 0.85 & 5.67 & 6.89 & 5.62 & 6.64 & 5.56 & 6.37 & 5.49 & 5.86 & 5.41 & 5.87 \\
\hline 1 & 6.18 & 12.30 & 6.15 & 11.77 & 6.11 & 11.23 & 6.07 & 10.14 & 6.03 & 10.12 \\
\hline 2 & 6.52 & 22.76 & 6.49 & 21.79 & 6.47 & 20.81 & 6.44 & 18.69 & 6.41 & 18.80 \\
\hline 3 & 6.51 & 32.24 & 6.49 & 30.90 & 6.47 & 29.53 & 6.44 & 26.48 & 6.41 & 26.72 \\
\hline
\end{tabular}




\begin{tabular}{|c|c|c|c|c|c|c|c|c|c|c|}
\hline 4 & 6.53 & 40.76 & 6.52 & 39.10 & 6.52 & 37.41 & 6.51 & 33.53 & 6.50 & 33.90 \\
\hline 5 & 6.58 & 48.53 & 6.57 & 46.59 & 6.56 & 44.60 & 6.55 & 39.97 & 6.54 & 40.48 \\
\hline 6 & 6.90 & 55.57 & 6.87 & 53.38 & 6.82 & 51.14 & 6.78 & 45.81 & 6.74 & 46.48 \\
\hline 7 & 6.97 & 62.01 & 6.93 & 59.61 & 6.81 & 57.15 & 6.78 & 51.20 & 6.75 & 52.00 \\
\hline 8 & 7.09 & 67.90 & 7.04 & 65.31 & 7.08 & 62.65 & 7.02 & 56.12 & 6.96 & 57.07 \\
\hline 9 & 7.14 & 73.32 & 7.10 & 70.57 & 7.13 & 67.73 & 7.08 & 60.66 & 7.02 & 61.77 \\
\hline 10 & 7.38 & 78.31 & 7.31 & 75.41 & 7.18 & 72.41 & 7.10 & 64.85 & 7.04 & 66.10 \\
\hline 11 & 7.37 & 82.93 & 7.30 & 79.90 & 7.09 & 76.76 & 6.94 & 68.76 & 6.92 & 70.14 \\
\hline 12 & 7.69 & 87.20 & 7.59 & 84.05 & 7.62 & 80.78 & 7.63 & 72.35 & 7.49 & 73.87 \\
\hline 13 & 7.67 & 91.17 & 7.59 & 87.91 & 7.59 & 84.53 & 7.53 & 75.70 & 7.46 & 77.36 \\
\hline 14 & 7.81 & 94.86 & 7.71 & 91.51 & 7.56 & 88.02 & 7.45 & 78.82 & 7.35 & 80.61 \\
\hline 15 & 7.62 & 98.32 & 7.59 & 94.88 & 7.39 & 91.29 & 7.24 & 81.76 & 7.18 & 83.66 \\
\hline 16 & 8.22 & 101.53 & 8.07 & 98.01 & 8.05 & 94.33 & 8.01 & 84.47 & 7.87 & 86.50 \\
\hline 17 & 8.20 & 104.55 & 8.06 & 100.95 & 8.02 & 97.20 & 7.95 & 87.02 & 7.86 & 89.17 \\
\hline 18 & 8.07 & 107.38 & 7.99 & 103.72 & 7.85 & 99.88 & 7.71 & 89.42 & 7.60 & 91.68 \\
\hline 19 & 7.91 & 110.05 & 7.89 & 106.32 & 7.72 & 102.42 & 7.56 & 91.69 & 7.46 & 94.05 \\
\hline 20 & 8.63 & 112.54 & 8.43 & 108.77 & 8.34 & 104.80 & 8.26 & 93.81 & 8.11 & 96.28 \\
\hline 21 & 8.58 & 114.91 & 8.42 & 111.07 & 8.34 & 107.04 & 8.25 & 95.81 & 8.13 & 98.38 \\
\hline 22 & 8.41 & 117.14 & 8.30 & 113.25 & 8.14 & 109.17 & 7.99 & 97.70 & 7.86 & 100.36 \\
\hline 23 & 8.31 & 119.25 & 8.22 & 115.32 & 8.05 & 111.18 & 7.87 & 99.50 & 7.75 & 102.25 \\
\hline 24 & 8.88 & 121.24 & 8.70 & 117.27 & 8.57 & 113.08 & 8.45 & 101.19 & 8.28 & 104.03 \\
\hline 25 & 8.87 & 123.14 & 8.70 & 119.13 & 8.59 & 114.89 & 8.47 & 102.79 & 8.32 & 105.71 \\
\hline 26 & 8.73 & 124.93 & 8.59 & 120.89 & 8.42 & 116.60 & 8.25 & 104.31 & 8.11 & 107.32 \\
\hline 27 & 8.66 & 126.65 & 8.53 & 122.56 & 8.36 & 118.23 & 8.17 & 105.77 & 8.04 & 108.84 \\
\hline 28 & 9.11 & 128.27 & 8.92 & 124.15 & 8.76 & 119.78 & 8.61 & 107.14 & 8.42 & 110.29 \\
\hline 29 & 9.12 & 129.82 & 8.94 & 125.67 & 8.78 & 121.26 & 8.64 & 108.45 & 8.45 & 111.67 \\
\hline 30 & 9.03 & 131.30 & 8.86 & 127.12 & 8.68 & 122.67 & 8.50 & 109.70 & 8.34 & 112.98 \\
\hline 31 & 8.99 & 132.71 & 8.83 & 128.50 & 8.64 & 124.02 & 8.45 & 110.89 & 8.30 & 114.23 \\
\hline 32 & 9.33 & 134.05 & 9.12 & 129.82 & 8.93 & 125.30 & 8.75 & 112.02 & 8.55 & 115.43 \\
\hline 33 & 9.34 & 135.34 & 9.13 & 131.08 & 8.95 & 126.53 & 8.77 & 113.11 & 8.57 & 116.57 \\
\hline 34 & 9.30 & 136.58 & 9.11 & 132.29 & 8.91 & 127.70 & 8.72 & 114.15 & 8.54 & 117.66 \\
\hline 35 & 9.27 & 137.76 & 9.09 & 133.44 & 8.89 & 128.83 & 8.69 & 115.14 & 8.52 & 118.71 \\
\hline 36 & 9.53 & 138.89 & 9.31 & 134.55 & 9.10 & 129.91 & 8.89 & 116.09 & 8.67 & 119.71 \\
\hline 37 & 9.54 & 139.98 & 9.31 & 135.62 & 9.10 & 130.94 & 8.90 & 117.00 & 8.68 & 120.67 \\
\hline 38 & 9.55 & 141.02 & 9.34 & 136.64 & 9.12 & 131.94 & 8.91 & 117.87 & 8.70 & 121.59 \\
\hline 39 & 9.54 & 142.03 & 9.32 & 137.62 & 9.11 & 132.89 & 8.89 & 118.71 & 8.70 & 122.47 \\
\hline 40 & 9.72 & 142.99 & 9.48 & 138.56 & 9.25 & 133.81 & 9.02 & 119.51 & 8.79 & 123.31 \\
\hline 41 & 9.72 & 143.92 & 9.48 & 139.47 & 9.25 & 134.69 & 9.02 & 120.29 & 8.80 & 124.12 \\
\hline 42 & 9.77 & 144.82 & 9.54 & 140.35 & 9.30 & 135.54 & 9.07 & 121.03 & 8.85 & 124.90 \\
\hline 43 & 9.76 & 145.68 & 9.53 & 141.19 & 9.29 & 136.35 & 9.06 & 121.74 & 8.84 & 125.65 \\
\hline 44 & 9.90 & 146.51 & 9.65 & 142.00 & 9.39 & 137.14 & 9.15 & 122.43 & 8.91 & 126.37 \\
\hline 45 & 9.91 & 147.31 & 9.65 & 142.78 & 9.40 & 137.90 & 9.15 & 123.09 & 8.91 & 127.07 \\
\hline 46 & 9.97 & 148.08 & 9.71 & 143.54 & 9.46 & 138.63 & 9.21 & 123.73 & 8.97 & 127.73 \\
\hline 47 & 9.97 & 148.83 & 9.71 & 144.27 & 9.45 & 139.34 & 9.21 & 124.35 & 8.96 & 128.38 \\
\hline 48 & 10.08 & 149.55 & 9.81 & 144.97 & 9.54 & 140.02 & 9.27 & 124.94 & 9.01 & 129.00 \\
\hline 49 & 10.07 & 150.25 & 9.80 & 145.66 & 9.53 & 140.68 & 9.28 & 125.51 & 9.02 & 129.59 \\
\hline 50 & 10.15 & 150.93 & 9.87 & 146.31 & 9.60 & 141.31 & 9.32 & 126.06 & 9.07 & 130.17 \\
\hline 51 & 10.16 & 151.58 & 9.87 & 146.95 & 9.60 & 141.93 & 9.33 & 126.59 & 9.07 & 130.73 \\
\hline 52 & 10.24 & 152.22 & 9.95 & 147.57 & 9.66 & 142.52 & 9.38 & 127.11 & 9.11 & 131.26 \\
\hline 53 & 10.24 & 152.83 & 9.95 & 148.16 & 9.67 & 143.10 & 9.38 & 127.61 & 9.11 & 131.78 \\
\hline 54 & 10.32 & 153.42 & 10.02 & 148.74 & 9.72 & 143.65 & 9.44 & 128.09 & 9.16 & 132.28 \\
\hline
\end{tabular}




\begin{tabular}{|c|c|c|c|c|c|c|c|c|c|c|}
\hline 55 & 10.32 & 154.00 & 10.02 & 149.30 & 9.72 & 144.19 & 9.43 & 128.55 & 9.16 & 132.76 \\
\hline 56 & 10.40 & 154.56 & 10.09 & 149.85 & 9.78 & 144.72 & 9.49 & 129.00 & 9.20 & 133.23 \\
\hline 57 & 10.40 & 155.10 & 10.09 & 150.37 & 9.78 & 145.22 & 9.49 & 129.44 & 9.21 & 133.68 \\
\hline 58 & 10.48 & 155.63 & 10.15 & 150.89 & 9.84 & 145.71 & 9.54 & 129.86 & 9.24 & 134.12 \\
\hline 59 & 10.47 & 156.14 & 10.15 & 151.38 & 9.84 & 146.19 & 9.53 & 130.26 & 9.25 & 134.54 \\
\hline 60 & 10.55 & 156.64 & 10.22 & 151.86 & 9.89 & 146.65 & 9.58 & 130.66 & 9.28 & 134.95 \\
\hline 61 & 10.54 & 157.12 & 10.22 & 152.33 & 9.89 & 147.10 & 9.58 & 131.04 & 9.28 & 135.34 \\
\hline 62 & 10.62 & 157.59 & 10.28 & 152.79 & 9.94 & 147.53 & 9.63 & 131.41 & 9.32 & 135.73 \\
\hline 63 & 10.62 & 158.05 & 10.28 & 153.23 & 9.96 & 147.96 & 9.63 & 131.77 & 9.32 & 136.10 \\
\hline 64 & 10.69 & 158.49 & 10.34 & 153.66 & 9.99 & 148.37 & 9.67 & 132.12 & 9.35 & 136.46 \\
\hline 65 & 10.69 & 158.92 & 10.34 & 154.08 & 9.99 & 148.77 & 9.66 & 132.46 & 9.36 & 136.81 \\
\hline 66 & 10.75 & 159.35 & 10.39 & 154.49 & 10.04 & 149.15 & 9.71 & 132.79 & 9.38 & 137.14 \\
\hline 67 & 10.76 & 159.76 & 10.39 & 154.88 & 10.05 & 149.53 & 9.71 & 133.11 & 9.39 & 137.47 \\
\hline 68 & 10.82 & 160.16 & 10.44 & 155.27 & 10.09 & 149.90 & 9.75 & 133.42 & 9.41 & 137.79 \\
\hline 69 & 10.82 & 160.55 & 10.46 & 155.64 & 10.08 & 150.25 & 9.74 & 133.72 & 9.43 & 138.09 \\
\hline 70 & 10.88 & 160.93 & 10.50 & 156.01 & 10.14 & 150.60 & 9.78 & 134.01 & 9.44 & 138.39 \\
\hline 71 & 10.89 & 161.30 & 10.50 & 156.36 & 10.13 & 150.94 & 9.79 & 134.30 & 9.46 & 138.68 \\
\hline 72 & 10.94 & 161.66 & 10.55 & 156.71 & 10.17 & 151.27 & 9.81 & 134.57 & 9.46 & 138.96 \\
\hline 73 & 10.94 & 162.01 & 10.55 & 157.05 & 10.18 & 151.59 & 9.82 & 134.84 & 9.48 & 139.24 \\
\hline 74 & 11.01 & 162.35 & 10.60 & 157.38 & 10.22 & 151.90 & 9.85 & 135.10 & 9.51 & 139.50 \\
\hline 75 & 11.00 & 162.69 & 10.61 & 157.70 & 10.22 & 152.20 & 9.85 & 135.36 & 9.50 & 139.76 \\
\hline 76 & 11.05 & 163.02 & 10.65 & 158.02 & 10.25 & 152.50 & 9.88 & 135.60 & 9.53 & 140.01 \\
\hline 77 & 11.06 & 163.34 & 10.66 & 158.32 & 10.27 & 152.79 & 9.87 & 135.84 & 9.53 & 140.25 \\
\hline 78 & 11.12 & 163.65 & 10.69 & 158.62 & 10.30 & 153.07 & 9.93 & 136.08 & 9.56 & 140.48 \\
\hline 79 & 11.11 & 163.95 & 10.70 & 158.91 & 10.29 & 153.34 & 9.92 & 136.31 & 9.55 & 140.71 \\
\hline 80 & 11.18 & 164.25 & 10.74 & 159.20 & 10.33 & 153.61 & 9.94 & 136.53 & 9.59 & 140.94 \\
\hline 81 & 11.17 & 164.54 & 10.74 & 159.48 & 10.35 & 153.87 & 9.94 & 136.74 & 9.57 & 141.15 \\
\hline 82 & 11.22 & 164.83 & 10.78 & 159.75 & 10.36 & 154.12 & 9.97 & 136.95 & 9.62 & 141.36 \\
\hline 83 & 11.21 & 165.11 & 10.78 & 160.01 & 10.36 & 154.37 & 9.98 & 137.16 & 9.60 & 141.57 \\
\hline 84 & 11.28 & 165.38 & 10.82 & 160.27 & 10.41 & 154.61 & 9.99 & 137.36 & 9.61 & 141.77 \\
\hline 85 & 11.28 & 165.65 & 10.84 & 160.53 & 10.40 & 154.85 & 10.00 & 137.55 & 9.63 & 141.96 \\
\hline 86 & 11.33 & 165.91 & 10.87 & 160.78 & 10.43 & 155.08 & 10.02 & 137.74 & 9.64 & 142.15 \\
\hline 87 & 11.31 & 166.17 & 10.87 & 161.02 & 10.42 & 155.31 & 10.04 & 137.92 & 9.63 & 142.33 \\
\hline 88 & 11.38 & 166.42 & 10.90 & 161.26 & 10.47 & 155.53 & 10.04 & 138.10 & 9.66 & 142.51 \\
\hline 89 & 11.38 & 166.66 & 10.91 & 161.49 & 10.46 & 155.74 & 10.04 & 138.28 & 9.67 & 142.68 \\
\hline 90 & 11.42 & 166.90 & 10.94 & 161.72 & 10.49 & 155.95 & 10.08 & 138.45 & 9.67 & 142.85 \\
\hline 91 & 11.42 & 167.14 & 10.95 & 161.94 & 10.50 & 156.16 & 10.09 & 138.62 & 9.69 & 143.01 \\
\hline 92 & 11.47 & 167.37 & 10.98 & 162.16 & 10.53 & 156.36 & 10.08 & 138.78 & 9.69 & 143.17 \\
\hline 93 & 11.47 & 167.59 & 10.98 & 162.37 & 10.52 & 156.55 & 10.12 & 138.94 & 9.70 & 143.33 \\
\hline 94 & 11.52 & 167.81 & 11.02 & 162.58 & 10.55 & 156.74 & 10.11 & 139.09 & 9.72 & 143.48 \\
\hline 95 & 11.52 & 168.03 & 11.02 & 162.78 & 10.55 & 156.93 & 10.12 & 139.24 & 9.70 & 143.63 \\
\hline 96 & 11.54 & 168.24 & 11.04 & 162.98 & 10.59 & 157.11 & 10.12 & 139.39 & 9.73 & 143.77 \\
\hline 97 & 11.56 & 168.45 & 11.07 & 163.18 & 10.59 & 157.29 & 10.15 & 139.54 & 9.75 & 143.91 \\
\hline 98 & 11.61 & 168.66 & 11.08 & 163.37 & 10.58 & 157.47 & 10.14 & 139.68 & 9.72 & 144.05 \\
\hline 99 & 11.60 & 168.86 & 11.09 & 163.56 & 10.62 & 157.64 & 10.16 & 139.81 & 9.74 & 144.18 \\
\hline 100 & 11.62 & 169.05 & 11.13 & 163.74 & 10.64 & 157.81 & 10.19 & 139.95 & 9.78 & 144.31 \\
\hline 101 & 11.65 & 169.25 & 11.10 & 163.92 & 10.63 & 157.97 & 10.17 & 140.08 & 9.75 & 144.44 \\
\hline 102 & 11.68 & 169.43 & 11.16 & 164.10 & 10.65 & 158.13 & 10.20 & 140.21 & 9.77 & 144.56 \\
\hline 103 & 11.69 & 169.62 & 11.15 & 164.27 & 10.66 & 158.29 & 10.21 & 140.33 & 9.76 & 144.68 \\
\hline 104 & 11.70 & 169.80 & 11.18 & 164.44 & 10.66 & 158.44 & 10.21 & 140.45 & 9.81 & 144.80 \\
\hline 105 & 11.74 & 169.98 & 11.18 & 164.61 & 10.69 & 158.60 & 10.22 & 140.57 & 9.80 & 144.91 \\
\hline
\end{tabular}




\begin{tabular}{|c|c|c|c|c|c|c|c|c|c|c|}
\hline 106 & 11.75 & 170.16 & 11.22 & 164.77 & 10.71 & 158.74 & 10.24 & 140.69 & 9.79 & 145.02 \\
\hline 107 & 11.78 & 170.33 & 11.21 & 164.93 & 10.72 & 158.89 & 10.22 & 140.80 & 9.81 & 145.13 \\
\hline 108 & 11.80 & 170.50 & 11.25 & 165.09 & 10.69 & 159.03 & 10.25 & 140.91 & 9.80 & 145.23 \\
\hline 109 & 11.79 & 170.67 & 11.23 & 165.24 & 10.75 & 159.17 & 10.25 & 141.02 & 9.82 & 145.34 \\
\hline 110 & 11.86 & 170.83 & 11.27 & 165.39 & 10.74 & 159.30 & 10.25 & 141.13 & 9.80 & 145.44 \\
\hline 111 & 11.83 & 170.99 & 11.28 & 165.54 & 10.75 & 159.44 & 10.28 & 141.23 & 9.85 & 145.53 \\
\hline 112 & 11.86 & 171.15 & 11.30 & 165.69 & 10.76 & 159.57 & 10.27 & 141.33 & 9.84 & 145.63 \\
\hline 113 & 11.87 & 171.30 & 11.29 & 165.83 & 10.77 & 159.69 & 10.28 & 141.43 & 9.83 & 145.72 \\
\hline 114 & 11.90 & 171.46 & 11.32 & 165.97 & 10.81 & 159.82 & 10.28 & 141.53 & 9.85 & 145.81 \\
\hline 115 & 11.93 & 171.61 & 11.34 & 166.11 & 10.77 & 159.94 & 10.30 & 141.62 & 9.83 & 145.90 \\
\hline 116 & 11.94 & 171.75 & 11.36 & 166.24 & 10.80 & 160.06 & 10.33 & 141.72 & 9.87 & 145.99 \\
\hline 117 & 11.94 & 171.90 & 11.36 & 166.38 & 10.81 & 160.18 & 10.27 & 141.81 & 9.85 & 146.07 \\
\hline 118 & 11.97 & 172.04 & 11.37 & 166.51 & 10.85 & 160.29 & 10.33 & 141.89 & 9.89 & 146.15 \\
\hline 119 & 11.98 & 172.18 & 11.37 & 166.64 & 10.80 & 160.41 & 10.36 & 141.98 & 2.91 & 146.23 \\
\hline 120 & 12.01 & 172.32 & 11.41 & 166.76 & 10.84 & 160.52 & 10.32 & 142.07 & 2.91 & 146.31 \\
\hline
\end{tabular}

\section{Permeability - 300 md}

\begin{tabular}{|c|c|c|c|c|c|c|c|c|c|c|}
\hline \multicolumn{11}{|c|}{ Peripheral Placement of Nitrogen } \\
\hline \multirow{3}{*}{$\begin{array}{l}\text { TIME } \\
\text { (days) }\end{array}$} & \multirow{2}{*}{\multicolumn{2}{|c|}{$\begin{array}{c}\text { Withdrawal Pressure } \\
100 \text { psia } \\
\end{array}$}} & \multirow{2}{*}{\multicolumn{2}{|c|}{$\begin{array}{c}\text { Withdrawal Pressure } \\
150 \text { psia } \\
\end{array}$}} & \multirow{2}{*}{\multicolumn{2}{|c|}{$\begin{array}{c}\text { Withdrawal Pressure } \\
200 \text { psia } \\
\end{array}$}} & \multirow{2}{*}{\multicolumn{2}{|c|}{$\begin{array}{c}\text { Withdrawal Pressure } \\
250 \text { psia } \\
\end{array}$}} & \multirow{2}{*}{\multicolumn{2}{|c|}{$\begin{array}{c}\text { Withdrawal Pressure } \\
300 \text { psia } \\
\end{array}$}} \\
\hline & & & & & & & & & & \\
\hline & $\begin{array}{c}\% \mathrm{~N}_{2} \text { in } \\
\text { withdrawn } \\
\text { gas }\end{array}$ & $\begin{array}{c}\text { \% W.G } \\
\text { withdrawn } \\
\text { (volume) }\end{array}$ & $\begin{array}{c}\% \mathrm{~N}_{2} \text { in } \\
\text { withdrawn } \\
\text { gas }\end{array}$ & $\begin{array}{c}\text { \% W.G } \\
\text { withdrawn } \\
\text { (volume) }\end{array}$ & $\begin{array}{c}\% \mathrm{~N}_{2} \text { in } \\
\text { withdrawn } \\
\text { gas }\end{array}$ & $\begin{array}{c}\text { \% W.G } \\
\text { withdrawn } \\
\text { (volume) }\end{array}$ & $\begin{array}{c}\% \mathrm{~N}_{2} \text { in } \\
\text { withdrawn } \\
\text { gas }\end{array}$ & $\begin{array}{c}\text { \% W.G } \\
\text { withdrawn } \\
\text { (volume) }\end{array}$ & $\begin{array}{c}\% \mathrm{~N}_{2} \text { in } \\
\text { withdrawn } \\
\text { gas }\end{array}$ & $\begin{array}{c}\text { \% W.G } \\
\text { withdrawn } \\
\text { (volume) }\end{array}$ \\
\hline 0.01 & 0.00 & 0.54 & 0.00 & 0.52 & 0.00 & 0.49 & 0.00 & 0.47 & 0.00 & 0.44 \\
\hline 0.04 & 0.00 & 1.65 & 0.00 & 1.60 & 0.00 & 1.53 & 0.00 & 1.45 & 0.00 & 1.38 \\
\hline 0.1 & 0.00 & 4.17 & 0.00 & 4.05 & 0.00 & 3.88 & 0.00 & 3.70 & 0.00 & 3.51 \\
\hline 0.29 & 0.00 & 9.85 & 0.00 & 9.60 & 0.00 & 10.20 & 0.00 & 9.73 & 0.00 & 9.25 \\
\hline 0.85 & 0.00 & 21.95 & 0.00 & 21.41 & 0.00 & 23.30 & 0.00 & 22.28 & 0.00 & 21.20 \\
\hline 1 & 0.00 & 31.72 & 0.00 & 30.59 & 0.00 & 29.37 & 0.00 & 28.10 & 0.00 & 26.77 \\
\hline 2 & 0.00 & 49.00 & 0.00 & 47.89 & 0.00 & 46.90 & 0.00 & 45.59 & 0.00 & 43.47 \\
\hline 3 & 0.00 & 51.60 & 0.00 & 49.76 & 0.00 & 47.72 & 0.00 & 58.29 & 0.00 & 55.63 \\
\hline 4 & 0.00 & 65.48 & 0.00 & 63.27 & 0.00 & 60.84 & 0.00 & 67.81 & 0.00 & 64.75 \\
\hline 5 & 0.00 & 75.88 & 0.00 & 73.41 & 0.00 & 70.70 & 0.00 & 75.14 & 0.00 & 71.77 \\
\hline 6 & 0.00 & 83.89 & 0.00 & 81.23 & 0.00 & 78.30 & 0.00 & 80.92 & 0.00 & 77.29 \\
\hline 7 & 0.00 & 90.21 & 0.00 & 87.41 & 0.00 & 84.30 & 0.00 & 85.57 & 0.00 & 81.72 \\
\hline 8 & 0.00 & 95.32 & 0.00 & 92.39 & 0.00 & 89.13 & 0.00 & 89.36 & 0.00 & 85.31 \\
\hline 9 & 0.00 & 99.51 & 0.00 & 96.48 & 0.00 & 93.09 & 0.00 & 92.50 & 0.00 & 88.26 \\
\hline 10 & 0.00 & 103.01 & 0.00 & 99.89 & 0.00 & 96.38 & 0.00 & 95.12 & 0.00 & 90.72 \\
\hline 11 & 0.00 & 105.96 & 0.00 & 102.76 & 0.00 & 99.14 & 0.00 & 97.33 & 0.00 & 92.77 \\
\hline 12 & 0.00 & 107.30 & 0.00 & 105.21 & 0.00 & 101.48 & 0.00 & 99.20 & 0.00 & 94.50 \\
\hline 13 & 0.00 & 107.73 & 0.00 & 106.32 & 0.00 & 103.48 & 0.00 & 100.81 & 0.00 & 95.97 \\
\hline 14 & 0.00 & 108.13 & 1.49 & 106.66 & 0.58 & 104.39 & 0.00 & 102.19 & 0.00 & 97.22 \\
\hline 15 & 18.66 & 108.37 & 18.77 & 106.88 & 9.96 & 105.15 & 37.33 & 103.20 & 5.90 & 98.26 \\
\hline 16 & 18.77 & 108.49 & 15.86 & 107.20 & 10.13 & 105.19 & 5.52 & 104.36 & 1.88 & 99.19 \\
\hline 17 & 17.01 & 108.81 & 15.10 & 107.29 & 9.07 & 105.71 & 4.85 & 105.31 & 1.78 & 99.99 \\
\hline 18 & 10.98 & 109.74 & 11.09 & 108.21 & 4.76 & 106.09 & 12.30 & 106.11 & 2.09 & 100.68 \\
\hline 19 & 7.08 & 110.58 & 4.75 & 108.86 & 3.49 & 106.69 & 12.52 & 106.82 & 2.28 & 101.28 \\
\hline 20 & 6.94 & 112.38 & 3.32 & 109.08 & 4.10 & 107.65 & 5.85 & 107.48 & 2.17 & 101.80 \\
\hline 21 & 6.93 & 113.99 & 5.00 & 110.50 & 4.41 & 107.99 & 5.61 & 108.06 & 1.98 & 102.25 \\
\hline 22 & 7.16 & 115.41 & 5.05 & 110.63 & 5.28 & 109.10 & 5.76 & 108.58 & 2.90 & 102.65 \\
\hline
\end{tabular}




\begin{tabular}{|c|c|c|c|c|c|c|c|c|c|c|}
\hline 23 & 7.16 & 115.59 & 6.23 & 111.98 & 5.30 & 110.09 & 5.77 & 109.03 & 3.16 & 102.99 \\
\hline 24 & 21.66 & 115.71 & 6.25 & 113.19 & 6.15 & 110.96 & 5.21 & 109.44 & 2.88 & 103.30 \\
\hline 25 & 27.21 & 115.88 & 21.25 & 113.32 & 6.26 & 111.74 & 4.96 & 109.80 & 2.74 & 103.56 \\
\hline 26 & 21.38 & 116.13 & 21.93 & 113.40 & 10.84 & 112.42 & 6.38 & 110.12 & 3.28 & 103.80 \\
\hline 27 & 14.92 & 116.55 & 13.97 & 113.59 & 13.06 & 112.51 & 6.62 & 110.41 & 3.41 & 104.00 \\
\hline 28 & 14.22 & 116.66 & 10.27 & 114.09 & 13.75 & 112.59 & 6.77 & 110.67 & 3.41 & 104.18 \\
\hline 29 & 12.16 & 117.77 & 9.75 & 114.27 & 10.58 & 112.83 & 6.80 & 110.90 & 3.40 & 104.34 \\
\hline 30 & 12.12 & 118.79 & 10.26 & 115.21 & 9.95 & 113.06 & 6.97 & 111.10 & 3.57 & 104.48 \\
\hline 31 & 23.61 & 119.66 & 10.26 & 116.06 & 9.78 & 113.61 & 6.98 & 111.29 & 3.60 & 104.61 \\
\hline 32 & 23.82 & 119.74 & 11.93 & 116.83 & 9.77 & 114.12 & 7.31 & 111.45 & 3.70 & 104.72 \\
\hline 33 & 17.43 & 119.83 & 15.57 & 117.00 & 9.57 & 114.57 & 7.38 & 111.60 & 3.72 & 104.81 \\
\hline 34 & 13.22 & 119.97 & 12.82 & 117.17 & 9.55 & 114.98 & 7.52 & 111.74 & 3.78 & 104.90 \\
\hline 35 & 17.10 & 120.20 & 12.30 & 117.36 & 12.92 & 115.35 & 7.55 & 111.86 & 3.80 & 104.97 \\
\hline 36 & 18.62 & 120.52 & 12.59 & 117.54 & 13.10 & 115.68 & 7.71 & 111.97 & 3.88 & 105.04 \\
\hline 37 & 18.42 & 121.12 & 13.45 & 118.07 & 11.66 & 115.85 & 7.74 & 112.06 & 3.88 & 105.10 \\
\hline 38 & 18.29 & 121.27 & 13.51 & 118.17 & 11.86 & 116.00 & 7.84 & 112.15 & 3.92 & 105.15 \\
\hline 39 & 18.37 & 121.96 & 14.00 & 118.74 & 11.89 & 116.22 & 7.89 & 112.23 & 3.92 & 105.20 \\
\hline 40 & 18.37 & 122.60 & 14.02 & 119.27 & 11.84 & 116.28 & 8.00 & 112.30 & 3.96 & 105.24 \\
\hline 41 & 19.08 & 123.19 & 16.79 & 119.74 & 12.01 & 116.54 & 8.01 & 112.37 & 3.98 & 105.27 \\
\hline 42 & 19.07 & 123.33 & 16.87 & 119.97 & 12.02 & 116.77 & 8.09 & 112.43 & 4.00 & 105.30 \\
\hline 43 & 24.39 & 123.47 & 15.25 & 120.12 & 12.56 & 116.98 & 8.11 & 112.48 & 4.03 & 105.33 \\
\hline 44 & 22.90 & 123.67 & 15.63 & 120.19 & 12.61 & 117.18 & 8.14 & 112.53 & 4.02 & 105.36 \\
\hline 45 & 22.61 & 123.73 & 16.50 & 120.48 & 13.02 & 117.35 & 8.22 & 112.57 & 4.07 & 105.38 \\
\hline 46 & 21.53 & 124.23 & 16.66 & 120.59 & 13.05 & 117.52 & 8.23 & 112.61 & 4.05 & 105.40 \\
\hline 47 & 21.50 & 124.69 & 17.22 & 120.96 & 13.36 & 117.67 & 8.27 & 112.64 & 4.10 & 105.41 \\
\hline 48 & 25.98 & 124.81 & 17.24 & 121.30 & 13.37 & 117.80 & 8.28 & 112.68 & 4.04 & 105.43 \\
\hline 49 & 24.63 & 124.95 & 18.33 & 121.62 & 13.63 & 117.93 & 8.34 & 112.71 & 4.14 & 105.44 \\
\hline 50 & 24.11 & 125.13 & 18.45 & 121.91 & 13.73 & 118.04 & 8.28 & 112.73 & 4.09 & 105.46 \\
\hline 51 & 24.39 & 125.53 & 19.10 & 122.18 & 13.92 & 118.15 & 8.42 & 112.75 & 4.10 & 105.47 \\
\hline 52 & 24.40 & 125.90 & 19.06 & 122.43 & 13.94 & 118.25 & 8.27 & 112.78 & 4.02 & 105.48 \\
\hline 53 & 24.89 & 126.25 & 19.62 & 122.67 & 14.12 & 118.34 & 8.48 & 112.79 & 4.16 & 105.48 \\
\hline 54 & 24.93 & 126.58 & 19.55 & 122.88 & 14.17 & 118.42 & 8.31 & 112.81 & 4.21 & 105.49 \\
\hline 55 & 29.33 & 126.73 & 20.63 & 123.09 & 14.35 & 118.50 & 8.57 & 112.83 & 4.13 & 105.50 \\
\hline 56 & 27.23 & 126.88 & 20.84 & 123.27 & 14.33 & 118.57 & 8.36 & 112.84 & 4.09 & 105.50 \\
\hline 57 & 26.96 & 127.04 & 20.86 & 123.45 & 14.48 & 118.63 & 8.42 & 112.85 & 4.10 & 105.51 \\
\hline 58 & 27.18 & 127.18 & 20.81 & 123.61 & 14.58 & 118.69 & 8.55 & 112.87 & 4.19 & 105.51 \\
\hline 59 & 27.79 & 127.44 & 21.61 & 123.77 & 14.57 & 118.75 & 8.55 & 112.88 & 4.04 & 105.52 \\
\hline 60 & 27.85 & 127.70 & 21.64 & 123.91 & 14.67 & 118.80 & 8.32 & 112.89 & 3.90 & 105.52 \\
\hline 61 & 28.51 & 127.94 & 21.97 & 124.05 & 14.73 & 118.84 & 8.50 & 112.89 & 4.21 & 105.52 \\
\hline 62 & 28.58 & 128.17 & 21.95 & 124.17 & 14.82 & 118.89 & 8.74 & 112.90 & 4.20 & 105.53 \\
\hline 63 & 30.15 & 128.38 & 22.37 & 124.29 & 14.79 & 118.93 & 8.34 & 112.91 & 4.24 & 105.53 \\
\hline 64 & 30.31 & 128.58 & 22.48 & 124.40 & 14.95 & 118.96 & 8.40 & 112.92 & 4.40 & 105.53 \\
\hline 65 & 30.96 & 128.77 & 22.73 & 124.50 & 14.96 & 119.00 & 8.52 & 112.92 & 4.40 & 105.53 \\
\hline 66 & 30.96 & 128.96 & 22.78 & 124.60 & 14.87 & 119.03 & 8.85 & 112.93 & 4.40 & 105.53 \\
\hline 67 & 31.71 & 129.13 & 23.05 & 124.69 & 15.03 & 119.06 & 8.58 & 112.93 & 4.40 & 105.54 \\
\hline 68 & 31.70 & 129.29 & 23.02 & 124.78 & 15.10 & 119.09 & 8.47 & 112.94 & 4.40 & 105.54 \\
\hline 69 & 29.01 & 129.37 & 23.36 & 124.86 & 15.10 & 119.11 & 8.33 & 112.94 & 4.40 & 105.54 \\
\hline 70 & 31.25 & 129.45 & 23.37 & 124.93 & 14.92 & 119.13 & 8.34 & 112.94 & 4.40 & 105.54 \\
\hline 71 & 32.27 & 129.54 & 23.57 & 125.00 & 15.28 & 119.15 & 8.35 & 112.95 & 4.40 & 105.54 \\
\hline 72 & 32.76 & 129.60 & 23.63 & 125.07 & 15.01 & 119.17 & 8.84 & 112.95 & 4.40 & 105.54 \\
\hline 73 & 32.77 & 129.74 & 23.86 & 125.13 & 15.36 & 119.19 & 9.56 & 112.95 & 4.40 & 105.54 \\
\hline
\end{tabular}




\begin{tabular}{|c|c|c|c|c|c|c|c|c|c|c|}
\hline 74 & 32.88 & 129.87 & 23.82 & 125.19 & 15.22 & 119.21 & 9.56 & 112.95 & 4.40 & 105.54 \\
\hline 75 & 33.28 & 130.00 & 24.05 & 125.25 & 15.16 & 119.22 & 9.56 & 112.96 & 4.40 & 105.54 \\
\hline 76 & 33.35 & 130.12 & 24.00 & 125.30 & 15.18 & 119.24 & 9.56 & 112.96 & 4.40 & 105.54 \\
\hline 77 & 33.92 & 130.24 & 24.25 & 125.35 & 15.25 & 119.25 & 9.56 & 112.96 & 4.40 & 105.54 \\
\hline 78 & 33.93 & 130.35 & 24.19 & 125.40 & 15.05 & 119.26 & 9.56 & 112.96 & 4.40 & 105.54 \\
\hline 79 & 34.35 & 130.45 & 24.41 & 125.44 & 15.33 & 119.27 & 9.56 & 112.96 & 4.40 & 105.55 \\
\hline 80 & 34.37 & 130.55 & 24.28 & 125.48 & 15.72 & 119.28 & 9.56 & 112.96 & 4.40 & 105.55 \\
\hline 81 & 34.86 & 130.65 & 24.46 & 125.52 & 15.25 & 119.29 & 9.56 & 112.97 & 4.40 & 105.55 \\
\hline 82 & 34.98 & 130.74 & 24.68 & 125.56 & 15.29 & 119.30 & 9.56 & 112.97 & 4.40 & 105.55 \\
\hline 83 & 35.20 & 130.83 & 24.56 & 125.59 & 15.49 & 119.31 & 9.56 & 112.97 & 4.40 & 105.55 \\
\hline 84 & 35.31 & 130.91 & 24.71 & 125.63 & 15.11 & 119.32 & 9.56 & 112.97 & 4.40 & 105.55 \\
\hline 85 & 35.64 & 130.99 & 24.68 & 125.66 & 15.49 & 119.33 & 9.56 & 112.97 & 4.40 & 105.55 \\
\hline 86 & 35.74 & 131.07 & 24.71 & 125.69 & 15.17 & 119.33 & 9.56 & 112.97 & 4.40 & 105.55 \\
\hline 87 & 35.97 & 131.14 & 24.83 & 125.71 & 15.03 & 119.34 & 9.56 & 112.97 & 4.40 & 105.55 \\
\hline 88 & 36.05 & 131.21 & 24.98 & 125.74 & 15.71 & 119.34 & 9.56 & 112.97 & 4.40 & 105.55 \\
\hline 89 & 36.44 & 131.28 & 24.92 & 125.76 & 15.64 & 119.35 & 9.56 & 112.97 & 4.40 & 105.55 \\
\hline 90 & 36.40 & 131.35 & 24.91 & 125.79 & 14.70 & 119.35 & 9.56 & 112.97 & 4.40 & 105.55 \\
\hline 91 & 36.68 & 131.41 & 24.95 & 125.81 & 15.77 & 119.36 & 9.56 & 112.97 & 4.40 & 105.55 \\
\hline 92 & 36.78 & 131.47 & 25.05 & 125.83 & 16.11 & 119.36 & 9.56 & 112.97 & 4.40 & 105.55 \\
\hline 93 & 36.96 & 131.53 & 24.82 & 125.85 & 15.04 & 119.37 & 9.56 & 112.97 & 4.40 & 105.55 \\
\hline 94 & 36.90 & 131.58 & 25.05 & 125.87 & 15.41 & 119.37 & 9.56 & 112.97 & 4.40 & 105.55 \\
\hline 95 & 37.42 & 131.63 & 25.42 & 125.88 & 15.88 & 119.37 & 9.56 & 112.97 & 4.40 & 105.55 \\
\hline 96 & 37.22 & 131.68 & 25.33 & 125.90 & 14.89 & 119.38 & 9.56 & 112.97 & 4.40 & 105.55 \\
\hline 97 & 37.37 & 131.73 & 24.81 & 125.92 & 15.66 & 119.38 & 9.56 & 112.97 & 4.40 & 105.55 \\
\hline 98 & 37.50 & 131.78 & 25.37 & 125.93 & 14.63 & 119.38 & 9.56 & 112.97 & 4.40 & 105.55 \\
\hline 99 & 37.77 & 131.82 & 25.52 & 125.94 & 15.61 & 119.38 & 9.56 & 112.97 & 4.40 & 105.55 \\
\hline 100 & 37.64 & 131.87 & 25.06 & 125.96 & 17.08 & 119.39 & 9.56 & 112.97 & 4.40 & 105.55 \\
\hline 101 & 38.05 & 131.91 & 25.33 & 125.97 & 13.67 & 119.39 & 9.56 & 112.97 & 4.40 & 105.55 \\
\hline 102 & 38.02 & 131.95 & 24.94 & 125.98 & 14.97 & 119.39 & 9.56 & 112.97 & 4.40 & 105.55 \\
\hline 103 & 38.14 & 131.99 & 25.35 & 125.99 & 15.40 & 119.39 & 9.56 & 112.98 & 4.40 & 105.55 \\
\hline 104 & 37.94 & 132.02 & 25.85 & 126.00 & 15.79 & 119.39 & 9.56 & 112.98 & 4.40 & 105.55 \\
\hline 105 & 38.49 & 132.06 & 25.65 & 126.01 & 16.98 & 119.39 & 9.56 & 112.98 & 4.40 & 105.55 \\
\hline 106 & 38.28 & 132.09 & 24.61 & 126.02 & 17.58 & 119.40 & 9.56 & 112.98 & 4.40 & 105.55 \\
\hline 107 & 38.63 & 132.12 & 26.30 & 126.03 & 17.58 & 119.40 & 9.56 & 112.98 & 4.40 & 105.55 \\
\hline 108 & 38.48 & 132.16 & 25.26 & 126.04 & 15.49 & 119.40 & 9.56 & 112.98 & 4.40 & 105.55 \\
\hline 109 & 38.44 & 132.19 & 25.22 & 126.05 & 14.53 & 119.40 & 9.56 & 112.98 & 4.40 & 105.55 \\
\hline 110 & 38.91 & 132.22 & 25.21 & 126.05 & 19.03 & 119.40 & 9.56 & 112.98 & 4.40 & 105.55 \\
\hline 111 & 38.44 & 132.24 & 25.34 & 126.06 & 18.03 & 119.40 & 9.56 & 112.98 & 4.40 & 105.55 \\
\hline 112 & 38.95 & 132.27 & 25.48 & 126.07 & 11.76 & 119.40 & 9.56 & 112.98 & 4.40 & 105.55 \\
\hline 113 & 39.09 & 132.30 & 25.73 & 126.07 & 15.97 & 119.40 & 9.56 & 112.98 & 4.40 & 105.55 \\
\hline 114 & 38.72 & 132.32 & 26.09 & 126.08 & 14.53 & 119.40 & 9.56 & 112.98 & 4.40 & 105.55 \\
\hline 115 & 39.48 & 132.35 & 24.99 & 126.08 & 24.24 & 119.40 & 9.56 & 112.98 & 4.40 & 105.55 \\
\hline 116 & 38.55 & 132.37 & 25.51 & 126.09 & 13.04 & 119.41 & 9.56 & 112.98 & 4.40 & 105.55 \\
\hline 117 & 39.35 & 132.39 & 26.03 & 126.09 & 12.28 & 119.41 & 9.56 & 112.98 & 4.40 & 105.55 \\
\hline 118 & 39.12 & 132.41 & 25.02 & 126.10 & 20.00 & 119.41 & 9.56 & 112.98 & 4.40 & 105.55 \\
\hline 119 & 39.49 & 132.43 & 25.76 & 126.10 & 18.70 & 119.41 & 9.56 & 112.98 & 4.40 & 105.55 \\
\hline 120 & 39.24 & 132.45 & 24.70 & 126.11 & 18.03 & 119.41 & 9.56 & 112.98 & 4.40 & 105.55 \\
\hline
\end{tabular}

